\title{
WestVirginiaUniversity
}

THE RESEARCH REPOSITORY @ WVU

Graduate Theses, Dissertations, and Problem Reports

2020

\section{Essays in Development Economics}

\author{
Zachary Rodriguez \\ West Virginia University, zr0009@mix.wvu.edu
}

Follow this and additional works at: https://researchrepository.wvu.edu/etd

Part of the Growth and Development Commons

\section{Recommended Citation}

Rodriguez, Zachary, "Essays in Development Economics" (2020). Graduate Theses, Dissertations, and Problem Reports. 7755.

https://researchrepository.wvu.edu/etd/7755

This Dissertation is protected by copyright and/or related rights. It has been brought to you by the The Research Repository @ WVU with permission from the rights-holder(s). You are free to use this Dissertation in any way that is permitted by the copyright and related rights legislation that applies to your use. For other uses you must obtain permission from the rights-holder(s) directly, unless additional rights are indicated by a Creative Commons license in the record and/ or on the work itself. This Dissertation has been accepted for inclusion in WVU Graduate Theses, Dissertations, and Problem Reports collection by an authorized administrator of The Research Repository @ WVU.

For more information, please contact researchrepository@mail.wvu.edu. 


\title{
Essays in Development Economics
}

\author{
Zachary Rodriguez
}

Dissertation submitted to the Chambers College of Business and Economics at West Virginia University in partial fulfillment of the requirements for the degree of Doctor of Philosophy in Economics

\author{
Bryan McCannon, Ph.D., Chair \\ Daniel Grossman, Ph.D. \\ Javier Reyes, Ph.D. \\ Mark Wilson, Ph.D.
}

Department of Economics

Morgantown, West Virginia

2020

Keywords: development, growth, microfinance, poverty, empowerment

Copyright 2020 Zachary Rodriguez 


\section{Abstract \\ Essays in Development Economics}

\section{Zachary Rodriguez}

My dissertation focuses on several fields of study within economics. The common lens through which I ask all my questions is development economics. I employ health and public economics to aide in the interpretation and discussion of my analyses. Separately, my chapters explore issues related positive spillovers from overcompetition in contests, demand for financial services among low-income households, and the empowerment of women through access to guaranteed employment. Collectively, my dissertation offers evidence and insight regarding how we analyze and improve development initiatives that aim to change the lives of people who are poor or ill. 


\section{Acknowledgements}

My dissertation was finished through the hard work and insights of many people. I am grateful for the time, direction, and advice of my dissertation chair, Dr. Bryan McCannon, as well as, the helpful insights

from my dissertation committee, Dr. Dan Grossman, Dr. Javier Reyes, and Dr. Mark Wilson. I would also like my Mom and Dad for their constant support and Dr. Josh Hall and Dr. Scott Schuh for their time and effort spent on furthering my career as an economist. Finally, I am grateful for the many conversations with Alex Cardazzi, Erika Davies, Eduardo Minuci, and the WVU Brown Bag Seminar participants. 


\section{Contents}

1 Acknowledgements iii

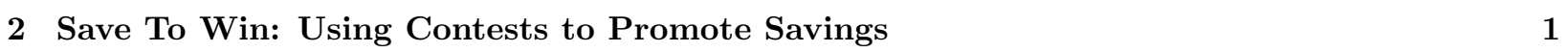

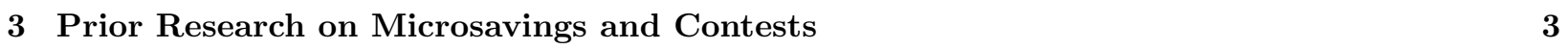

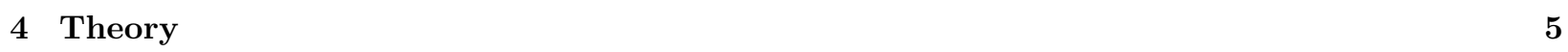

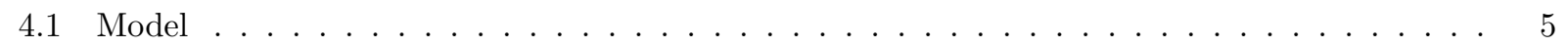

4.2 Save to Win . . . . . . . . . . . . . . . . . . . . . 7

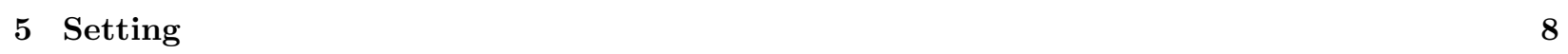

\begin{tabular}{llr}
\hline 6 & Method & 9
\end{tabular}

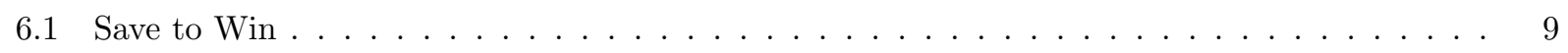

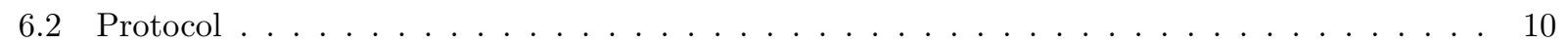

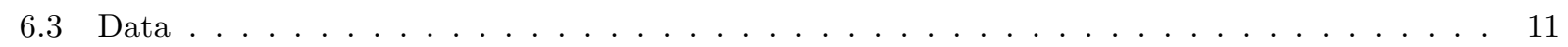

\begin{tabular}{lll}
\hline & Results & 12
\end{tabular}

7.1 Outlier Test . . . . . . . . . . . . . . . . . . . . . . . . . . . . . . . 13

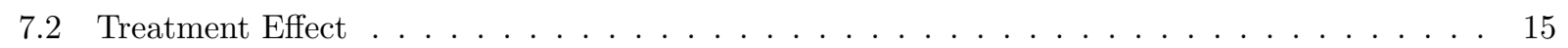

7.3 Heterogeneous Treatment Effect. . . . . . . . . . . . . . . . . . . . . 21

$7.3 .1 \quad$ Risk Preference . . . . . . . . . . . . . . . . . . . . . . . . . . . 21

7.3 .2 Time Preference . . . . . . . . . . . . . . . . . . . . . . 24

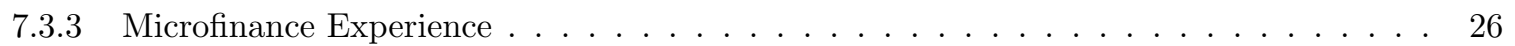

7.3 .4 Gambling . . . . . . . . . . . . . . . . . . . . . . 28

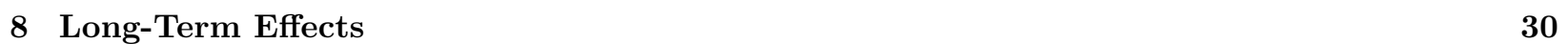

8.1 Wealth Accumulation $\ldots \ldots \ldots \ldots \ldots \ldots \ldots \ldots \ldots$

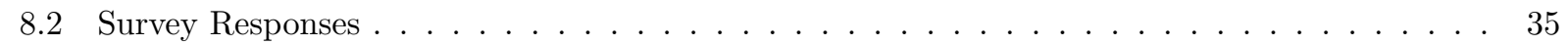

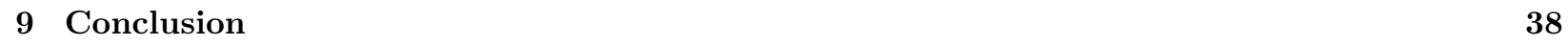

\begin{tabular}{lr}
\hline 10 References & 39
\end{tabular}

\begin{tabular}{ll}
\hline 1 Appendix & 43
\end{tabular}

11.1 Proofs from the Theoretical Model $\ldots \ldots \ldots \ldots$. . . . . . . . . . . . . . . 45

12 The Demand For Microfinance: Effects of India's Employment Guarantee on Credit and $\begin{array}{ll}\text { Savings } & 47\end{array}$

\begin{tabular}{|cr}
\hline 13 Literature Review & 48
\end{tabular}

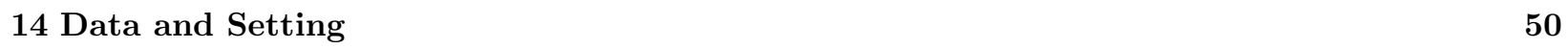

14.1 NABARD and the Self-Help Group Model . . . . . . . . . . . . . . . . . . . . 50

14.2 The Mahatma Gandhi National Rural Employment Guarantee Act 2005 . . . . . . . . . . 51

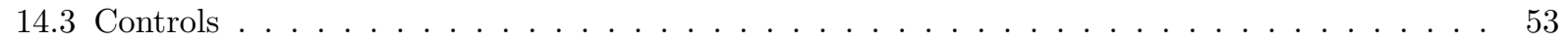


15 Empirical Strategy $\quad 53$

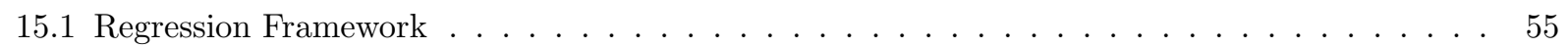

$\begin{array}{ll}16 \text { Results } & 55\end{array}$

16.1 Effects of MGNREGA Employment on Microcredit . . . . . . . . . . . . . . . . . 55

16.2 Effects of MGNREGA Employment on Savings Mobilization . . . . . . . . . . . . . . 58

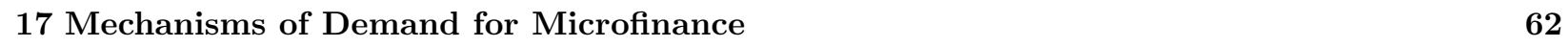

17.1 Microfinance As Poverty Alleviation $\ldots \ldots \ldots \ldots$. . . . . . . . . . . . . . . . . . . . . . . . . . 63

17.2 Microfinance as Entrepreneurship $\ldots \ldots \ldots \ldots \ldots$

17.3 Microfinance and Annual District Rainfall Analysis . . . . . . . . . . . . . . . . . . . 64

\begin{tabular}{ll}
\hline 18 Discussion & 68
\end{tabular}

\begin{tabular}{lr}
\hline 19 Conclusion & 69
\end{tabular}

\begin{tabular}{ll}
\hline 20 Appendix & $\mathbf{7 5}$
\end{tabular}

20.1 Parallel Trends . . . . . . . . . . . . . . . . . . . . . . . . . . . . . 75

20.2 Histograms of Microfinance Use $\ldots \ldots \ldots \ldots \ldots \ldots$

20.3 Pre and Post Period Comparison of Microfinance Outcomes . . . . . . . . . . . . . . . 81

20.4 Mechanism of Demand - Extended Treated-on-Treatment Rainfall Analysis . . . . . . . . . 83

21 The Power of Employment: Effects of India's Employment Guarantee on Women Em$\begin{array}{lr}\text { powerment } & 85\end{array}$

\begin{tabular}{|lr}
\hline 22 Literature Review & 86
\end{tabular}

22.1 Women Empowerment and Microfinance . . . . . . . . . . . . . . . . . . . . . 87

22.2 Women Empowerment and Primary Education $\ldots \ldots \ldots$. . . . . . . . . . . . 88

22.3 Women Empowerment and Violence Against Women $\ldots \ldots \ldots$. . . . . . . . . . . . 88

23 Data and Setting $\quad 89$

23.1 The Mahatma Gandhi National Rural Employment Guarantee Act 2005 . . . . . . . . . . . . 89

23.2 NABARD and the Self-Help Group Model $\ldots \ldots \ldots \ldots$. . . . . . . . . . . 91

23.3 District Information System for Education $\ldots \ldots \ldots \ldots$. . . . . . . . . . . . . . . 92

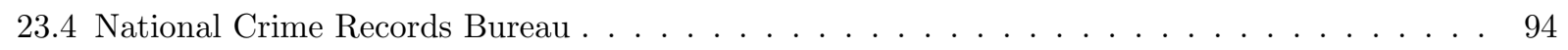

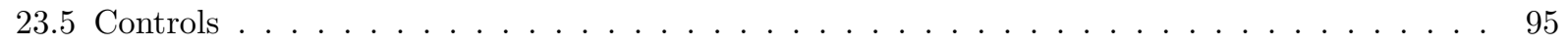

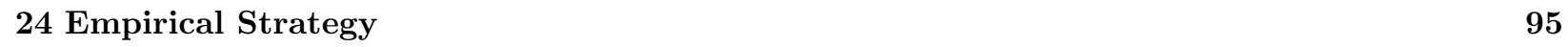

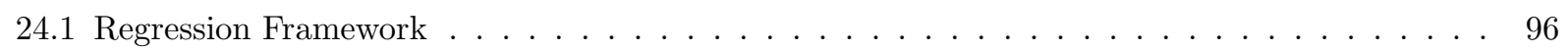

$\begin{array}{ll}25 \text { Results } & 97\end{array}$

25.1 Women Empowerment and Microfinance . . . . . . . . . . . . . . . . . . . . 97

25.2 Women Empowerment and Primary School Enrollment. . . . . . . . . . . . . . . . . . . 101

25.2 .1 Primary School Enrollment . . . . . . . . . . . . . . . . . . . 102

25.2 .2 Government School Enrollment . . . . . . . . . . . . . . . . . . . . . . . . . . . . . 103

25.3 Women Empowerment and Violence Against Women $\ldots \ldots \ldots$. . . . . . . . . . . 106 
\begin{tabular}{ll}
\hline 26 Conclusion & 107
\end{tabular}

\begin{tabular}{ll}
\hline 27 Appendix & 112
\end{tabular}

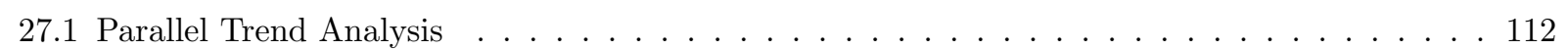

27.2 Women Empowerment and Microfinance - Self-help Groups Membership . . . . . . . . . . . 121

27.3 Private School Enrollment . . . . . . . . . . . . . . . . . . . . . . 121

27.4 Violence Against Women - Sexual Assault . . . . . . . . . . . . . . . . . . . . . 123 


\section{Save To Win: Using Contests to Promote Savings}

In developing countries, the poor face numerous uncertainties and must develop costly coping strategies to deal with them (Morduch, 1995). Governmental agencies, non-governmental organizations, and academic researchers have devised numerous interventions to help the poor. A central component to these interventions is a focus on financial markets. Financial markets provide the opportunity to self-insure through savings, smooth consumption via borrowing, and obtain the capital necessary for entrepreneurship. Since the popularization by Mohammed Yunus and his Grameen Bank (Pitt and Khandker, 1998; Yunus, 1999), microfinance activities, particularly microcredit, has been a useful tool to cope with the uncertainties of economic life in poor communities.

What has received considerably less attention is interventions designed to promote savings amongst the poor. As emphasized by Besley, Coate, and Loury (1998), this is an important omission. While income constrained, the poor do have the ability to save. Demand for durable goods and a desire to smooth adverse income shocks are high. As has been well documented, credit instruments come at extremely high interest rates (Morduch, 2000). Thus, savings, even at negative real interest rates, should be of considerable value. Early microfinance initiatives did not offer savings products, as many institutions targeted entrepreneurs, offering them microcredit. As institutions begin to incorporate more formal savings products into their services, we see a shift in the focus of microfinance from entrepreneurship to risk-coping mechanisms for households (Churchill, 2002).

The practical question becomes how to design financial institutions, mechanisms, and products to promote savings by the poor. Financial sustainability (Louis, Sere, and Baesens, 2013) is a problem faced by many microfinance institutions. Lack of subsidies (D'Espallier, Hudon, and Szafarz, 2013) and poor governance (Servin, Lensink, and van den Berg, 2012) make it difficult for these institutions to operate efficiently within communities. The addition of savings products provides institutions with the means to address sustainability, but questions arise regarding how to structure savings products that meet the demands of households. Time preferences, such as time inconsistency and impatience (Ashraf, Karlan, and Yin, 2006), are hindrances. Financial literacy (Lusardi and Tufano, 2009) can be expected to be minimal. Further, salience in appreciating the future benefits to the savings, relative to the more-salient, immediate opportunity costs of forgone consumption, can be expected to be a barrier.

We design a novel mechanism which we believe can promote savings. We call it "Save to Win" accounts. Our intuition comes from the extensive behavioral and experimental economics literature on contests. Building off Tullock's (1980) seminal theoretical contribution, contests ask participants to make non-refundable expenditures to obtain a prize. The prize is assigned probabilistically to one contestant, and the probability of winning is driven by a participant's relative share of total expenditures made. Extensive literatures have applied this framework to rent-seeking, R\&D expenditures, election spending, and employee effort just to name a few. Central to our intuition, laboratory experiments have documented consistently an over-spending where subjects compete excessively, relative to Nash equilibrium predictions, which are themselves excessive relative to social optimums (Dechenaux, Sheremeta, and Kovenock, 2015). Numerous explanations have been investigated including, prominently, a joy of winning preference (Sheremeta, 2010) and impulsivity (Sheremeta, 2018).

Typically, these contests are viewed through the lens of destructive competition. The excessive competition is socially wasteful. For example, consider rent seeking. If a government agency is to award a procurement contract to one supplier, for example, firms in that market are incentivized to promote their bids, which can include lobbying expenditures, perks to the decision makers, and even corrupt activities such 
as bribes (Tullock, 1967). Our innovation is to ask whether the excessive competitiveness contests generate can be harnessed for the good. Rather, can linking contests to savings activities produce the positive spillover effect of building up wealth in a poverty stricken community not currently utilizing savings opportunities?

To answer this question, we partner with a small, nonprofit organization operating in rural, southern Uganda. The organization had previously made microloans in the community as part of its development strategy. It had just expanded by constructing a microfinance bank that now also accepts deposits. Seeing little uptake, we created contest-linked savings accounts and made them available in two six-month phases. Participation eligibility for our control and treatment mechanisms was done randomly to establish our interventions' causal effects.

In our Save to Win accounts, subjects are assigned to a treatment. In it, we provide the necessary opening account balance (2500 Ugandan Schilling) and provide the funds to cover the interest on the deposits $(2 \%$ per month). In the control group, subjects are free to make deposits into the account. The high interest rate compensates them for the illiquidity, as the money could not be withdrawn until the end of the sixmonth trial phase. In our treatments, a fixed proportion of a subject's deposit each month is entered into a contest. The remaining is deposited into their savings account. Subjects are put into five person groups and a prize winner is determined probabalistically, as in Tullock Contests. The prize is deposited into the winner's account. Treatments differ in the proportion of the deposit that goes towards the contest and by the determination of the size of the prize. Those in the control are given the high interest rate and beginning account balance as well, but do not have the opportunity to engage in the contests.

In the first phase, two treatments were implemented where $40 \%$ and $20 \%$ of the deposit, respectively, went into the contest (leaving $60 \%$ and $80 \%$, respectively, for the savings account). For both, the prize was set equal to the total expenditure of the five group members. Hence, our Save to Win intervention was zero sum. In the second phase, the treatment maintained the 20/80 distribution, but introduced a guaranteed minimum prize.

By comparing depositing behavior of those in the treatments to those in the control, we can assess the causal impact of contests on savings. By comparing subject savings choices to their own choices prior to the intervention and to those not in the study, we can evaluate the overall impact of our intervention on savings and wealth. Finally, by tracking the account balances in the year after the intervention, when their accounts become liquid and the high monthly interest rate is gone, we can appreciate the longer term impact on wealth.

We document a number of important findings. First, during our intervention those in our study deposit substantially more than they did prior to our intervention and by others in the community not currently participating in the study. Average account balances in the month prior to our intervention were 3757 Ugandan Schillings (hereafter, UGX) per subject. By the end of our intervention it is 21,027 UGX. Savings grew by a factor of 5.6. Thus, we promoted savings.

Second, the Save to Win treatments had higher deposits than the control group, with the effect greatest in our treatment with the lower proportion going into the contest and the guaranteed minimum prize. Here, average monthly deposits are almost 2000 UGX greater than the control group, and the probability of making any deposit in a month is almost 8 percentage points higher. Therefore, properly constructed, introducing contests into savings account, can promote savings.

Third, we administer decision-making assessments and collect background information on our subjects. We document important heterogeneous treatment effects. For one, we show that our Save to Win intervention is valued primarily by those who are recorded (in an incentivized, price-menu instrument) as not being risk 
averse. This is reasonable since the intervention introduces uncertainty. We also show that the increased deposits are concentrated in those who self report as being a patient person. Hence, we find evidence that both risk and time preferences matter for the intervention's success. Additionally, surveying our subjects' past experiences with financial markets, we find evidence that those who have previously received microloans do not utilize the Save to Win accounts. This effect is sensitive to the inclusion of other background characteristics though. Finally, we document a relationship between self-reported participation in gambling on sports. Gamblers "gamble" more when their savings is linked to contests. In fact, the effect is enhanced when there is not a minimum guarantee on the prize. Thus, we have suggestive evidence that participation in our Save to Win program correlates with other, related personal finance activities.

Fourth, we track the account balances of our subjects after the intervention. We document, contrary to our initial worries, that subjects do not liquidate after their account balances roll over into standard accounts without withdrawal restrictions or interest payments. While $88 \%$ of our subjects did not have an account prior to the intervention, only two closed their accounts within six months of the end of our trial (1.4\%). For most subjects, balances remain relatively stable and for some treatment cohorts, average balances actually grow! Even at twelve months after the Save to Win accounts ended, the average savings account balance is 28,076 UGX for our subjects (regardless of treatment) when it was 4020 UGX prior 1 This is almost a doubling of the average account balance (x 1.8) since the end of our intervention.

We are obviously concerned about where the funds came from and what consumption opportunities were given up to make the deposits we observe. Tracking use of informal savings and borrowing mechanisms (such as family loans) and correctly identifying forgone consumption is notoriously difficult. Even more problematic is identifying the normative implications of our intervention. To that end, we survey subjects twelve months (six months) after our intervention ended for participants in the first (second) phase. We find that the majority of our subjects report that they would have saved their money at home absent our intervention. Thus, we mitigate risk. Approximately one-third of our subjects say that they gave up consumption. Regarding anticipated future behavior, only $10 \%$ expect to close their account in the future, while $60 \%$ plan to further increase their balance.

In Section 2 we briefly survey the literature on microsavings efforts as part of poverty mitigation, outlining how our mechanism compares to others attempted. It also samples the behavioral literature on contests. In Section 3 we provide a straightforward theoretical model, which generates testable hypotheses. We describe our intervention's setting in Section 4. In Section 5, the methods and protocols employed are outlined. We analyze the data in Section 6 establishing both the average and heterogeneous treatment effects. Section 7 presents the post-intervention quantitative and qualitative results. In Section 8 we provide our concluding discussion.

\section{Prior Research on Microsavings and Contests}

Prior research on microfinance is vast and focuses primarily on microcredit. Mostly due to the influence of Muhammad Yunus and the Grameen Bank, microcredit was quickly adopted by many governments and nonprofit organizations as part of large-scale economic development strategies that target poverty alleviation among low-income households (Morduch, 1999). Results from these studies identify two channels through which microfinance functions, as entrepreneurship or consumption smoothing.

\footnotetext{
${ }^{1}$ As will be described in the methods section, these last two figures are based on the subjects who participated in the first phase of the invention, so that they have a full twelve months after the invention.
} 
Many of the first microcredit initiatives targeted small scale entrepreneurs as their clientele. Evaluations of profits and incomes (Banerjee et al., 2015), employment (Augsburg et al., 2015), investment (Crépon et al., 2015), return on capital (de Mel, McKenzie, and Woodruff, 2008) offer compelling evidence with regards to microfinance and local economic growth and institutional efficiency. Studies that assess the effects on social welfare characterize microfinance as used as a consumption smoothing mechanism. Studies of food consumption (Pitt and Khandkar, 1998; Attanasio et al., 2015), health outcomes (Hamad, Fernald, and Karlan, 2011), and subjective well-being (Karlan and Zinman, 2011) provide evidence for important effects of microfinance on low-income households.

Given the identified benefits of microfinance to households, a large portion of the academic literature focuses on the various structures of microcredit and evaluate its delivery and use by individuals and groups. The institutions studied aim to address possible shortcomings of traditional credit-lending mechanism and design financial products to meet the environment and demand of local communities. Attempts to experiment with repayment frequency (Field and Pande, 2008) and grace periods (Field et al., 2013) provides information to institutions that help determine the most effective menu of financial products, with regards to both financial sustainability and customer retention (Tedeschi, 2006). Moral hazard and adverse selection make it difficult for microfinance institutions to operate effectively in rural communities. Group lending has traditionally been a way for these institutions to mitigate the monitoring costs associated with credit. Other studies have looked at dynamics of group-lending like the regularity of group meetings (Feigenberg, Field, and Pande, 2013; Feigenberg et al., 2014), group size (Abbink, Irlenbusch, and Renner, 2006), and incumbent lending (McIntosh, De Janvry, and Sadoulet, 2005).

Ultimately, the economic impact is mixed and the general consensus is that the positive effects of microcredit is limited and temporary (Banerjee, Karlan, and Zinman, 2015) $2^{2}$ This has led researchers to evaluate alternative financial market interventions.

Some have considered conditional cash transfers (Baird, McIntosh, and Ozler, 2011) and microinsurance (Banerjee, Dufalo, and Horbeck, 2014). A few, like us, have explored ways to promote savings among those in poverty. Savings products were not offered by many early microfinance initiatives, as many assumed low-income households were too poor to save (Morduch, 2000). Yet, empirical evidence on savings finds the opposite to be the case. Positive effects to savings mobilization like increased account balances and savings activity (Asharf, Karlan, and Yin, 2008; Dupas, Keat, and Robinson, 2018), as well as investments in household public goods (Schaner, 2016), suggests significant welfare effects for low-income households. Increased empowerment of women (Anderson and Baland, 2002; Duflo, 2012), lower education expenditures (Karlan and Linden, 2014), and reduced risky sexual behavior (Witte, et al., 2015) represent more important benefits of savings to communities, at large.

Like the research on microcredit, microfinance institutions work to design different products to encourage savings among low-income households. Studies explore the effects of no-fee savings accounts (Dupas and Robinson, 2013), fixed-deposit savings, and bank-insured savings groups (El-Gamle et al., 2014) on households' willingness to save. Each study provides insight into the demand for savings, and we add to this literature by introducing contests as a mechanism to promote savings activity.

The design of our savings mechanism most closely resembles a prize-linked savings account. Kearney et al. (2010) provides a survey of the literature on prize-linked savings products and their prevalence in banking institutions around the world. A large portion of these products target medium to low-income

\footnotetext{
${ }^{2}$ The reader is encouraged to consult the special issue in American Economic Journal: Applied Economics which provides a special issue bringing together numerous papers attempting to measure microfinance's impact.
} 
households, given the high demand for gambling and lotteries among these groups. These accounts pool the interest accrued on the deposits of account holders and uses it as the prize in a monthly lottery. The probability of winning the lottery becomes a function of how frequently you make deposits, thus encouraging savings among account holders. Experimental evidence shows that this deposit behavior can be driven by the expected value of winning or a joy of winning behavior, where individuals gain utility from participating in risky environments, even more so than the expected value of a prize. Contests represent an environment where the joy from winning is particularly prevalent. Sheremeta (2013) provides an extensive survey of the experimental economics literature on the overbidding, which raises concerns about the the utility gained from the joy of winning in contests. Wasteful spending is destructive to communities in any context, but especially so for medium and low-income households. Banking institutions that understand this overbidding behavior can offer a savings product to reduce its consequences and harness potentially destructive behavior for a positive spillover for an individual.

We contribute to the literature on field experiments and savings mobilization in rural communities by designing and implementing a contest-linked savings product that promotes savings behavior in southern Uganda. Our experiment is the first to combine a contest and savings mechanism in the real world, where deposits directly affect your probability of winning a prize. The effects of prize-linked savings accounts have been studied in laboratory settings, where studies explore preferences for prize-linked product design (Dizon and Lybbert, 2019) and how accounts affect wealth generation (Filiz-Ozbay et al., 2015). Two other field experiments have designed and implemented prize-linked savings accounts, but each design constrains the competitive environment, as a participant's probability of winning is based on either a monthly savings balance (Linardi and Tanaka, (2013) or a fixed deposit amount (Cole, Iverson, and Tufano, 2016; Gertler et al., 2018)). Our contest environment allows participants to choose their monthly 'effort' level to win the prize, and conforms closely with the behavioral literature on contests which lead to excessive competition. Finding important treatment effects in our field experiment, our results are also the first to indicate positive, long-term effects of contest-linked savings accounts. Our results align with experimental literature regarding competitive behavior in contests and provide a novel contribution to the field of development economics and a broad literature on the positive effects of savings mobilization in growing, rural communities.

\section{Theory}

To create our hypothesis regarding the intervention's effects, we build a straightforward theoretical environment. We consider an individual making the decision between current consumption and future consumption in a two-period model. Savings allows for both consumption smoothing and participation in a contest, which is enjoyable. Parameterizing a joy of winning, risk preference, and the contest treatment, we derive testable predictions.

\subsection{Model}

An individual plans consumption over two time periods, labeled 1 and 2. As is standard, one can think of $t=1$ as "today" and $t=2$ as the "future". Let $c_{t}$ and $w_{t}$ denote the amount consumed and earned in period $t$. Income is exogenous. Along with choosing how much to consume, the individual has the opportunity to save, with the amount denoted by $s$. We consider an environment where the individual can save but not borrow; i.e., $s \geq 0$. This, we believe, accurately represents the typical opportunities for an individual in 
a developing part of the world. Informal savings mechanisms are available, such as at-home savings, but poverty is correlated with inaccessible financial markets.

Let the instantaneous utility from consumption be denoted $u\left(c_{t}\right)$ and let time be discounted at the rate $\delta \in(0,1)$. The parameter $\theta$ captures the subject's risk preference. Larger values of $\theta$ correspond to a more risk averse individual ${ }^{3}$ Thus, the individual benefits from the discounted utility from consumption in the two time periods. Assume the utility function is continuously differentiable, strictly increasing, and strictly concave to ensure the full exhaustion of resources.

Also, research in behavioral economics has provided evidence that a "joy of winning" exists. Subjects tend to enjoy winning, above and beyond the additional expected consumption that can arise with the prize. We use the term joy of winning loosely so as to represent any motivation that leads to the excessive competitiveness observed in the laboratory. To keep the analysis general, we let $J(\rho, \Pi ; \theta)$ denote the expected joy experienced from the contest. This benefit term can be thought of as a function of the probability of winning the contest and a function of the size of the prize.

Thus, the expected, discounted utility function to be maximized is,

$$
U\left(c_{1}, c_{2}, s\right)=u\left(c_{1} ; \theta\right)+\delta u\left(c_{2} ; \theta\right)+J(\rho(s, \bar{s}), \Pi(s, ; \theta),
$$

where $\bar{s}$ is the (total) amount saved by the others in the contest.

The contest we implement organizes individuals into cohorts (in the field, we set the cohort size to 5). Each subject is assigned a treatment and the cohort $\mathrm{s} /$ he is grouped into includes individuals of the same treatment (where both the treatment and cohort are random assignments). We parameterize the treatment by $\tau \in[0,1]$. If the individual chooses to save $s$, then $\tau s$ is deposited into his/her savings account and $(1-\tau) s$ is entered into a contest. Following a traditional Tullock Contest framework (Tullock, 1975; 1980; Dechenaux, Sheremeta, and Kovenock, 2015), the probability the individual wins the pot of size $\Pi$ is $\rho=\frac{(1-\tau) s}{(1-\tau) \Sigma s_{j}}$ where $\Sigma s_{j}$ is the total amount saved by all subjects in the contest. If the individual wins the contest, the prize is deposited into his/her savings account and, therefore, is subject to interest accumulation. Along with varying the treatments, we will differentiate the determination of the prize.

In the field, we consider three values of $\tau$. In the "Low" treatment for every 500 UGX deposited, 300 UGX goes into the savings account and $200 \mathrm{UGX}$ are entered into the contest. Thus, $\tau_{L}=0.6$. In the "High" treatment less is entered into the contest and more is deposited into the savings account. In it, for every 500 UGX deposited, 400 UGX are saved and 100 UGX are entered into the contest. Hence, $\tau_{H}=0.8$. In the "Control" all money deposited goes into the savings account. Nothing is entered into the contest. Thus, $\tau_{C}=1$.

A budget constraint exists for each time period. The constraints on the individual's utility maximization problem are $c_{1}+s \leq w_{1}$ for $t=1$ and $c_{2} \leq w_{2}+\tau(1+i) s+(1+i) E$ for $t=2$ where $E$ is the expected gain from the prize 4 The term $i$ is the interest rate earned on the savings ${ }^{5}$

Finally, we consider two mechanisms to determine the size of the prize. In the first, the prize received by the contest winner is simply the sum of the expenditures made by the subjects in the cohort. This is done so

\footnotetext{
${ }^{3}$ We have in mind $\theta$ as the coefficient of relative risk aversion that would arise in the CRRA utility function $u(c ; \theta)=\frac{1}{1-\theta} c^{1-\theta}$. We choose to not limit ourselves to a specific function form though.

${ }^{4}$ We are considering a very simple problem where the expected prize is used in the budget constraint. A fuller model would allow second period consumption to be a function of the realization of the contest. Our goal here is to present the simplest model possible to create testable hypotheses for our field experiment.

${ }^{5}$ While it is natural to presume $i$ is positive, it can be zero (as many bank accounts in the developing world do not provide non-zero (nominal) interest rates) or even negative (with inflation causing negative real interest rates). We only require $1+i>0$. In the field, we provide a $2 \%$ interest rate per month.
} 
that the intervention is zero-sum fostering savings in the community without external subsidization ${ }^{6}$ Hence, $\Pi^{z}=(1-\tau) \Sigma s_{j}$. In the second mechanism, we ensure a guaranteed minimum prize. That is, if the total expenditures on the contest falls below a set threshold, denoted $\Pi^{g}$, then the contest winner receives $\Pi^{g}$. If the total expenditures exceed this threshold, then $\Pi=(1-\tau) \Sigma s_{j}\left(=\pi^{z}\right)$, as before. Traditional contests in the lab utilize a fixed prize that does not vary with expenditures. Thus, our guaranteed minimum attempts to foster the over-competitiveness identified there.

\subsection{Save to Win}

The Lagrangian to be maximized is

$$
L=u\left(c_{1}\right)+\delta u\left(c_{2}\right)+J(\rho, \Pi)+\lambda_{1}\left(w_{1}-c_{1}-s\right)+\lambda_{2}\left(w_{2}+(1+i) \tau s+(1+i) E-c_{2}\right)
$$

First, it follows immediately that the joy of winning component is necessary for our intervention's success. If $J(\rho, \Pi)=0$ and $\Pi=\Pi^{z}$ (so that the second-period budget constraint is simply $w_{2}+(1+i) s \geq c_{2}$ ), then a standard utility maximization problem arises and our treatments do not have an effect on savings choices made.

Hypothesis 0: If subjects derive utility only from consumption, then: [1] the Save to Win program will not change the likelihood that they will save a non-zero amount, [2] the amount saved (if a non-zero amount is chosen) will not change if offered the Save to Win intervention, and [3] savings behavior will be the same across the treatments.

Hence, a joy of winning is needed if our intervention is to change behavior.

Our intervention is designed to leverage individual's willingness to "over-compete" in contests. To illustrate this, when a subject selects a non-zero level of saving it follows from complementary slackness that $\frac{d L}{d s}=0$. Rather,

$$
\frac{d L}{d s}=\frac{d J}{d s}-\lambda_{1}+\lambda_{2}\left[(1+i) \tau+(1+i) \frac{d E}{d s}\right]
$$

Consequently, the optimal level of saving for the individual will be driven in large part by the marginal benefit to the contest, $\frac{d J}{d s}$. We make the following assumption regarding the individual's joy of winning benefit:

Assumption: Assume (1) $\frac{d^{2} J}{d s^{2}}<0,(2) \frac{d^{2} J}{d s d \tau}>0$, and $(3) \frac{d^{3} J}{d s d \tau d \theta}>0$.

The implication of the first is that there is diminishing returns to the contest. That is, as more is saved and, hence, more is entered into the contest, the joy increases, but at a decreasing rate. This would arise, for example, if the joy to winning is modeled as a constant parameter multiplied by the expected utility from the contest and the individual is risk averse. The second assumption states that the marginal joy from entering the contest is greater if less is entered into the contest (higher values of $\tau$ ). Again, this can be thought of as assuming there is diminishing returns. When the treatment lets a smaller proportion of the individual's deposit to go into the contest, then the marginal benefit of depositing more is higher. The third relates to how the treatment's effect varies with the risk preference. As stated, a higher value of $\theta$ denotes a more risk averse individual. A more risk-averse individual has a "more-concave" payoff function. Hence,

\footnotetext{
${ }^{6}$ As will be discussed in the upcoming section, though, we do cover the interest earned, provide the minimum opening account balances, and provide a community meal as a "show-up" compensation.
} 
if more is entered into the contest (i.e., a lower value of $\tau$ ) then the marginal benefit for saving is less for a more risk averse individual.

Applying these assumptions, it is straightforward to verify the following result.

Hypothesis 1: If subjects experience a joy to winning and assumptions (1) and (2) hold, then there exists an intermediate value of $\tau$, denoted $\widehat{\tau}(\theta)$. For $\tau<\widehat{\tau}$, the amount saved is increasing in $\tau$. For $\tau>\widehat{\tau}$, the amount saved is decreasing in $\tau$. Hence, there is a "golden rule" intervention that maximizes savings.

Hypothesis 1 is our main result and motivation for conducting the field experiment. Fixing the enjoyment of contests and risk preferences, the Save to Win intervention is expected to increase the amount deposited, relative to the environment where all of the deposit goes directly into a savings account. Also, Hypothesis 1 suggests that too much can be entered into the contest. A risk averse individual, for example, dislikes the uncertainty created by the Save to Win product. If only a small share of each deposit is entered, the loss is not that great. If a lot of amount saved enters the contest, then the individual can be disincentivized. Hence, there is an intermediate treatment (i.e., a golden rule proportion entered into the contest) that maximizes savings.

This result, though, while building on them, takes the individual's risk preference as given. One would expect a heterogeneous impact of our intervention should be considered.

Hypothesis 2: If subjects experience a joy of winning and assumptions (1), (2), and (3) hold, then $\frac{d \widehat{\tau}}{d \theta}>0$. Hence, the golden rule treatment is at a greater value of $\tau$ so that savings is relatively greater without the contest $(\tau=1)$ for more risk averse subjects.

Hypothesis 2 provides a heterogeneous effect of the treatment. Introducing the contest increases savings, so long as the proportion that goes into the contest is not too great (Hypothesis 1). If an individual is quite risk averse it is more likely that the treatment selected will have too much entered into the contest. The Save to Win intervention should be more effect for the less risk averse individuals.

Finally, as stated, we consider two ways to determine the prize's size. From the individual's optimal saving perspective, the difference manifests itself by affecting the marginal benefit to saving. If others are not spending much on the contest, then with the zero-sum prize the marginal gain to saving for the individual is small - there is not much of a prize to win. The addition of the guaranteed minimum increases the marginal benefit to saving (by further relaxing the second period budget constraint $\left(\frac{d E}{d s}\right)$.

Hypothesis 3: If subjects experience a joy of winning and assumptions (1) and (2) hold, then saving is greater with the guaranteed minimum prize.

Notice that the comparative statics predictions are not conditioned on the behavior of the others in the cohort. The amount saved is driven by others' expenditures (through affecting $\rho$ and, hence, $J$ and $E$ ). Thus, Hypotheses 1, 2, and 3 also apply to the Nash equilibrium of the game as well.

\section{$5 \quad$ Setting}

Embrace It Africa is a 501(c)3 nonprofit organization operating in the town of Bethlehem in the Rakai district. The Rakai district is in southern Uganda bordering Tanzania. Embrace It Africa has been functioning in the 
region since 2008 providing access to education for orphans and microfinance to entrepreneurs.7 In January 2018 the organization opened a bank facility, named Mikwano, to provide savings opportunities to those in the community.

We partnered with the organization to design a savings product, which we describe in the next section. Our intervention occurred in two six-month phases. Phase 1 occurred between July and December 2018. Phase 2 occurred between January and June 2019.

We utilized the networks established by the nonprofit organization to recruit. Embrace It Africa provides funding for the school in town and has a long history of providing microloans. Community leaders and region-wide advertising were utilized to let individuals in the community know that a savings product will be made available at the beginning of each phase.

During the first week of July 2018, 103 adults showed up to participate in our intervention. These individuals were randomly assigned into one of three cohorts, again described in the next section. All members of the community were eligible to participate, including those who had previously opened savings accounts at the bank and those who had not. During the first week of January 2019, 43 additional individuals showed up to participated in our second phase. These 43 did not participate in Phase 1, and those who participates in Phase 1 were not eligible for Phase 2. Those in Phase 2 were randomly selected to be in one of two cohorts. The Phase 2 intervention ended in June 2019.

Mikwano started opening savings accounts and accepting deposits in January 2018. The accounts offered were standard for the country. To open an account, an individual is required to have a 2500 UGX minimum account balance. Deposits can be withdrawn at any time that the bank was open. No interest is paid on the balances. Having an account, though, does provide the opportunity to receive microloans in the future.

Over the first six months of the bank's existence, few in the community utilized the opportunity. Those who did open an account maintained only small balances. The upcoming section provides descriptive data on these accounts. Embrace It Africa had been making microloans in the community for over a decade, so it has a strong, positive image in the community and should not suffer from lack of institutional trust. Therefore, we worked with Embrace It Africa to promote the new savings opportunity they provide to the community.

\section{Method}

We first describe the Save to Win accounts provided. Then, we lay out the protocols used in the field. Finally, the data collected is described.

\subsection{Save to Win}

Subjects in the treatment can make any size deposit any time within the month. A proportion $\tau$ of the deposit went into the individual's savings account and $1-\tau$ goes into a contest. Subjects may make more than one deposit during the month, or may choose not to make a deposit.

On the last business day of the month, subjects within a cohort who made a non-zero deposit during the month were grouped randomly into five person cohorts. The amounts entered into the contest for the five are pooled together. One person is selected at random and wins the pooled amount. The probability of winning is equal to that person's share of the total expenditures for the five-subject group for the month.

\footnotetext{
${ }^{7}$ See McCannon and Rodriguez (2019a) for an analysis of Embrace It Africa's microfinance activities' spillover effect onto pro-sociality in the community and McCannon and Rodriguez (2019b) for the effect of orphanhood in the community.
} 
The winner's prize is publicly announced and deposited into that subject's account. Interest is then paid on each account at the nominal rate of $2 \%$ per month. This procedure is redone each month for six months. Thus, each subject has six observations - his/her monthly deposits for the six months of the trial.

In Phase 1, subjects are randomly assigned to one of three protocols. One is the control who may not enter the contest. For them, 100\% of each month's deposit goes into the savings account. In a second, which we call Treatment 4-1, four of every five Ugandan Schillings deposited go into the savings account. Thus, if a subject deposits 5000 UGX, then 4000 UGX go into savings and 1000 UGX are entered into a contest. In the third, which we call Treatment 3-2, three of every five UGX deposited go to savings. Thus, a person in this cohort who deposits 5000 UGX, for example, would have 3000 UGX added to savings and 2000 UGX entered into a contest. Phase 2 subjects were randomly assigned to one of two protocols. One is a replication of the control group from before. The other cohort engages in Treatment 4-1 again.

The difference between Phase 1 and Phase 2 is the size of the prize gained by those in Treatment 4-1. In Phase 1, as described, the prize is equal to the total expenditures of the five in the group. Rather, it is zero sum. Our motivation is that this design requires the least amount of subsidization. We do cover the interest payment, to reduce the burden of our intervention on the community's bank, and provide the opening account balances, as a "show-up" fee for our experimental subjects. After that, no additional funds are needed from the bank or the researchers to offer Save to Win accounts.

In Phase 2, we instituted a minimum prize guarantee. We ensured that if the total prize was less than 20,000 UGX, then we would make up the difference to give the winner 20,000 UGX. If total expenditures exceeds this lower bound, then the prize is equal to the full pot.

The minimum prize was set to be near, but exceed, the upper bound of the prize sizes from Phase 1. We did this to see if we can increase deposits from what we see in Phase 1. It was designed to further promote savings. Also, our intention was to consider a design that more closely resembles Tullock Contests, which typically involved pre-determined, fixed prizes. The five person group size was selected to promote anonymity, given our modest sample sizes. The group size is held constant across all treatments. Finally, we decided not to replicate Treatment 3-2 with a minimum prize guarantee in Phase 2. As will be shown in the upcoming section, this treatment did not have an effect on savings relative to the control. Fearing that it may be dis-incentivizing savings by putting too much into the contest, we discontinued it for the second phase.

\subsection{Protocol}

As described, our intervention was widely advertised throughout the community. On the opening day of our intervention, we provided food for a community meal, which is an expected cultural practice. Adults willing to participate came into Mikwano's bank building and completed the paperwork necessary to open the account.

During this process, subjects pulled a piece of colored paper out of a cup. Three colors were used in equal proportions. The colors corresponded to the three cohorts. Thus, each subject was equally likely to be assigned to the Control, Treatment 4-1, and Treatment 3-2.

A total of 103 individuals agreed to participate during the first week of July 2018. This makes up the Phase 1 subject pool. There were 34 selected for Treatment 3-2, 43 for Treatment 4-1, and 26 for Control.

Included in the application paperwork was a survey collecting basic background information. Subject reported their gender, age, marital status, number of children, education obtained, occupation, and experience with financial markets. 
Deposits were taken continuously over the month. On the last business day of the month the contests were scored. Subjects often attended the contest drawings, but this was not mandatory. The winner's prize was deposited into his/her account. The procedure for determining the winner was repeated each month for six months. The groupings were randomly determined and anonymous 8 Each group consisted only of those within the same treatment.

Individuals who did not open an account the first week of the study, were recruited to engage in Phase 2. This was introduced in January 2019, corresponding to the end of Phase 1. The same procedures were utilized. With equal likelihood subjects were assigned to Treatment 4-1 and Control. As before, the treatment stayed the same over the six month trial.

A total of 43 adults participated in Phase 2. Of them, 33 were assigned to Treatment 4-1 and 10 were assigned to Control. Thus, we have a total of 146 subjects engaged in our intervention monthly over six months spread out over two phases.

During the six months of the intervention, withdrawals from the Save to Win accounts were not allowed. Subjects were free to have standard savings accounts as well. A few subjects had opened accounts before the intervention. Subjects who had these standard accounts can deposit and withdraw from them freely. The standard accounts did not pay interest. To compensate individuals for the illiquidity of our intervention, we paid each subject a $2 \%$ monthly interest 9

At the end of the six month phase of our intervention, the account balances were rolled over into standard savings accounts. Thus, they were liquid and earned no interest.

\subsection{Data}

First, while we use a randomization device to assign subjects to treatments, it is appropriate to check the similarity of the partitions of the subject pool. Table 1 presents a balance table comparing the subsample averages on the background characteristics measured.

The asterisks in the table are the result of a difference-in-means t-test between that particular treatment and the control group. For the most part, the samples are indistinguishable - age, family size, education, and occupations look similar. Those in Treatment 4-1 are slightly more likely to be married and may have less access to electricity. The one anomaly is that they are more likely to have an elected position in the community. Overall, the subject pools are similar in these observables.

Regarding deposits made, participation varied. Only 18 had a savings account prior to the intervention (12\%). During the intervention, 98 made no additional deposits beyond what they contributed the first day of the trial (68\%). Thus, in the upcoming analysis, we will explore both the extensive and intensive margins to saving. For those deposits after the initial month of each phase, the average monthly deposit made was just less than 9000 UGX. In the next section, though, we evaluate differences in depositing behavior across the treatments. By the end of our intervention, total wealth in the accounts is 16,260,359 UGX was only 544,700 UGX prior - an increase by a factor of 30 !

Finally, consider the pot sizes won in the actual contests. The distribution of the pots is depicted in Figure 1. For Treatment 4-1, Phase 1 (darker gray) is separated from Phase 2 (lighter gray). We separate

\footnotetext{
${ }^{8}$ It was anonymous except for the identities of the winners, who were publicly announced. Also, it was common for the number of depositors in a treatment for a month to not be perfectly divisible by five. The remainders (randomly selected) were paired with depositors in the next month (of the same treatment) to determine the prize winner.

${ }^{9}$ Therefore, our (external) compensation to the participants consists of the community meals (before the start of Phase 1), the 2500 UGX opening balance for each of the 143 subjects, and the $2 \%$ monthly interest on deposits made.

${ }^{10}$ This figure includes (compounded) interest earned and the opening account balance, along with the deposits made and prizes won.
} 
Table 1: Balance Table

\begin{tabular}{llll}
\hline \hline & Control & Treatment 4-1 & Treatment 3-2 \\
\hline Age & 32.11 & 33.12 & 28.53 \\
Number of years of education & 7.60 & 7.30 & 7.18 \\
Number of children & 3.26 & 3.61 & 2.44 \\
Are you married? (Yes =1) & 0.514 & $0.697^{*}$ & 0.529 \\
Are you single? & 0.343 & $0.184^{*}$ & 0.412 \\
Are you divorced? & 0.057 & 0.053 & $\emptyset$ \\
Are you widowed? & 0.086 & 0.066 & 0.059 \\
Do you grow crops? & 0.829 & 0.933 & 0.824 \\
Do you own livestock? & 0.686 & 0.684 & 0.853 \\
Do you hold an elected position? & 0.114 & $0.408 * * *$ & 0.235 \\
Is your house made of mud? & 0.057 & 0.066 & 0.030 \\
Is the floor of your house concrete/solid? & 0.771 & 0.803 & 0.735 \\
Does your house have electricity? & 0.457 & $0.263 *$ & 0.324 \\
$N$ & & & \\
$N$ & 35 & 76 & 34 \\
\hline \hline
\end{tabular}

The individual-level data set is considered.

A difference-in-means t-test (allowing for unequal variances) compares the treatment's mean to the control group's mean; ${ }^{* * *}$ denotes $1 \%$ level of significance, while ${ }^{* *}$ and ${ }^{*}$ denote $5 \%$ and $10 \%$, respectively.

Data from both phases pooled.

the prizes received in Treatment 4-1 since it differs in the use of the guaranteed minimum. The distribution of prizes in Treatment 3-2 is provided in black.

As one can see, the pots are concentrated in the 5000 UGX to 15,000 UGX range in both phases. Overall, the average size of the pot is 11,339 for the five subject groupings (combining both treatments and both phases). Thus, the 20,000 UGX minimum guarantee represents a nontrivial increase in the expected prize's size. In fact, for those subjects in Phase 2, the minimum was a binding constraint for $85 \%$ of the cohorts. The distribution of pots in Treatment 3-2 sit to the left of those in Treatment 4-1. For them, the distribution shifts to the right for Phase 2, where the minimum prize guarantee was added. These two observations will be explored further in the upcoming section.

\section{$7 \quad$ Results}

Our analysis of the results is done in three steps. First, we conduct an outlier test. Due to the small, rural community as our targeted population, our sample sizes are modest. As a consequence, one can reasonably be concerned that extreme behavior out of one subject can have meaningful distortions on the sample averages. Second, we establish the treatment effects statistically. This provides our main result. In the final subsection, we evaluate heterogeneous treatment effects to assess which subject characteristics correspond to the success of the treatments. 
Figure 1: Distribution of Contest 'Pots'

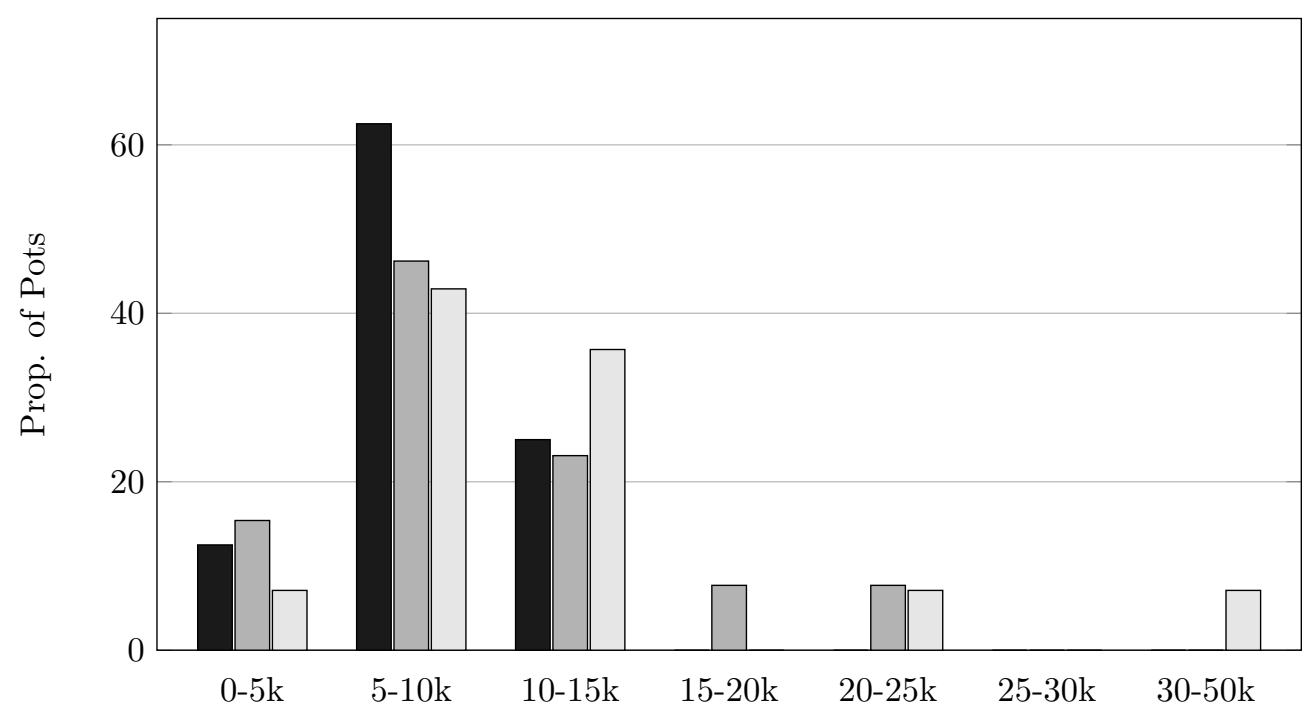

Each column depicts the proportion of scored contests that have a pot size within each specified range. The black bars are the distribution in Treatment 3-2. For Treatment 4-1, the dark gray depicts the distribution from Phase 1 and the light gray provides it for Phase 2.

\subsection{Outlier Test}

As with any individual-level data set with a modest number of observations, one should be concerned about an outlier observation affecting the estimated average treatment effect. We first depict the average per month deposit made by those subjects randomly selected to be in the control group. The subjects are ordered from the lowest mean value to the highest.

As one can see, one subject deposited substantially more than any other individual in the cohort. His/her deposits are almost 3.4 times as large as the second largest depositor. The savings behavior of this one subject sits far beyond the rest of the subjects in the pool.

Compare this to the distribution of deposits made by those selected to be in the Treatment 4-1, Guarantee subject pool. Figure 3 presents this cohort's average per month deposit.

Behavior is more consistent within this subject pool. The person with the highest average deposits has a per month value only $19.7 \%$ higher than the second highest depositor and is 24.3 times as great as the median individual, as compared to 133.7 times as great for the outlier in the control cohort.

Figure 4 presents the distribution of deposits in the Treatment 4-1, No Guarantee treatment. Again, modest between-subject variation exists 11 The control subject pool has one outlier individual who engaged in substantially more savings than others in the experiment. The concern, then, is that the presence of this one individual with extreme behavior can sufficiently distort the average treatment effects.

Therefore, in the upcoming analysis, we exclude this individual from the analysis. Also, Figure 10 in the appendix depicts the primary result - our average treatment effect which will be derived in Section 6.2 - re-estimated by systematically dropping each of the other subjects in the control. It illustrates that there is little change in the estimated average treatment effect when any other subject is eliminated from

\footnotetext{
${ }^{11}$ In Treatment 4-1 without the guarantee, the person with the highest average deposit is only $16.8 \%$ higher than the second highest depositor. The amount is 46.3 times as great as the median.
} 
Figure 2: Average Monthly Deposit for Control Subjects

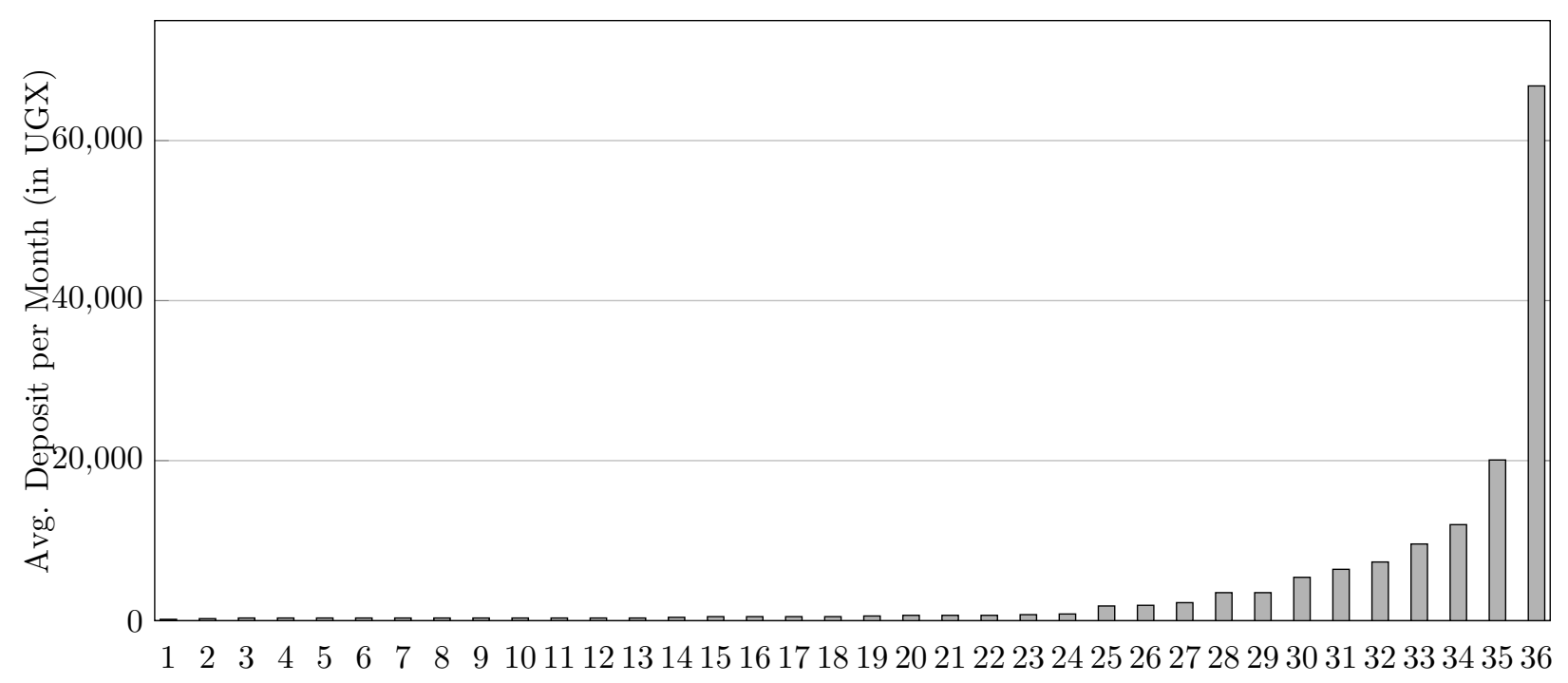

Figure 3: Average Monthly Deposit for Treatment 4-1, Guarantee Subjects

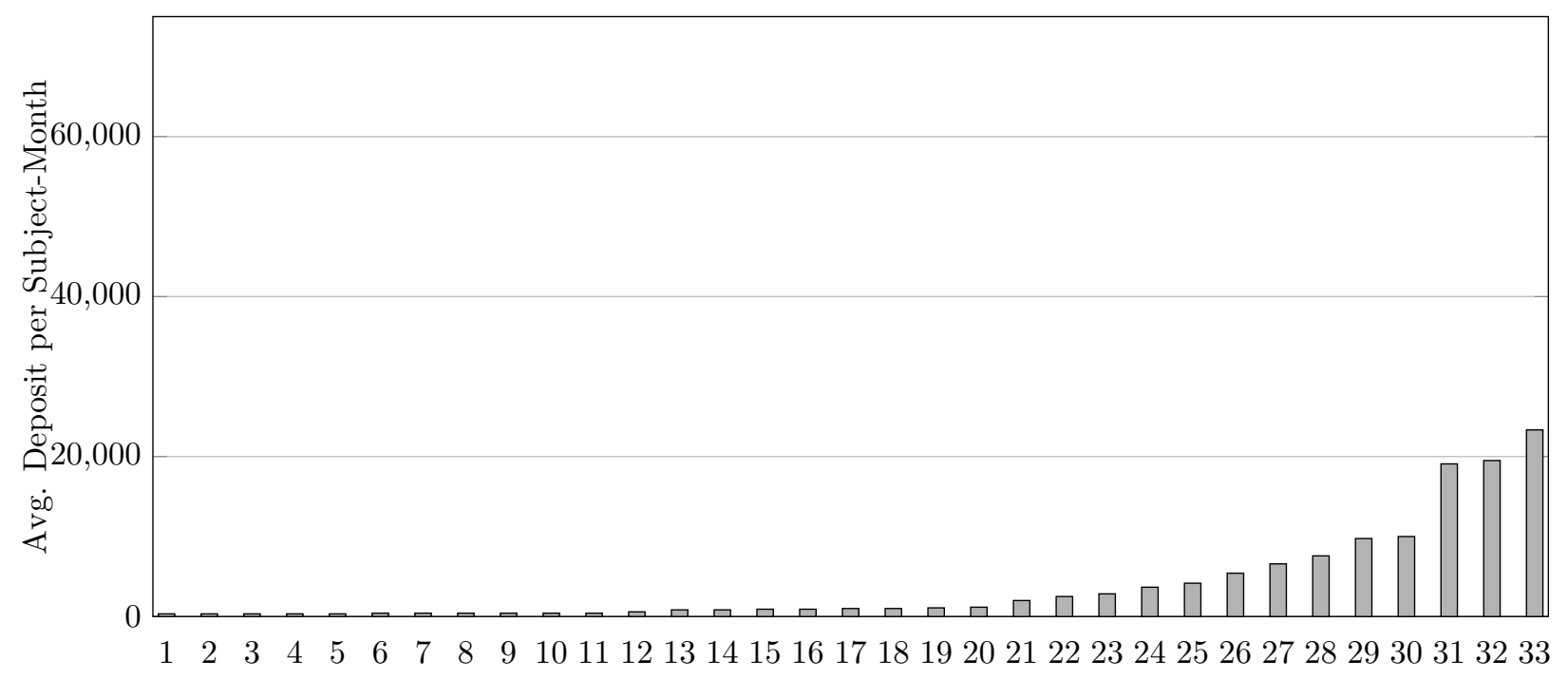


Figure 4: Average Monthly Deposit for Treatment 4-1, No Guarantee Subjects

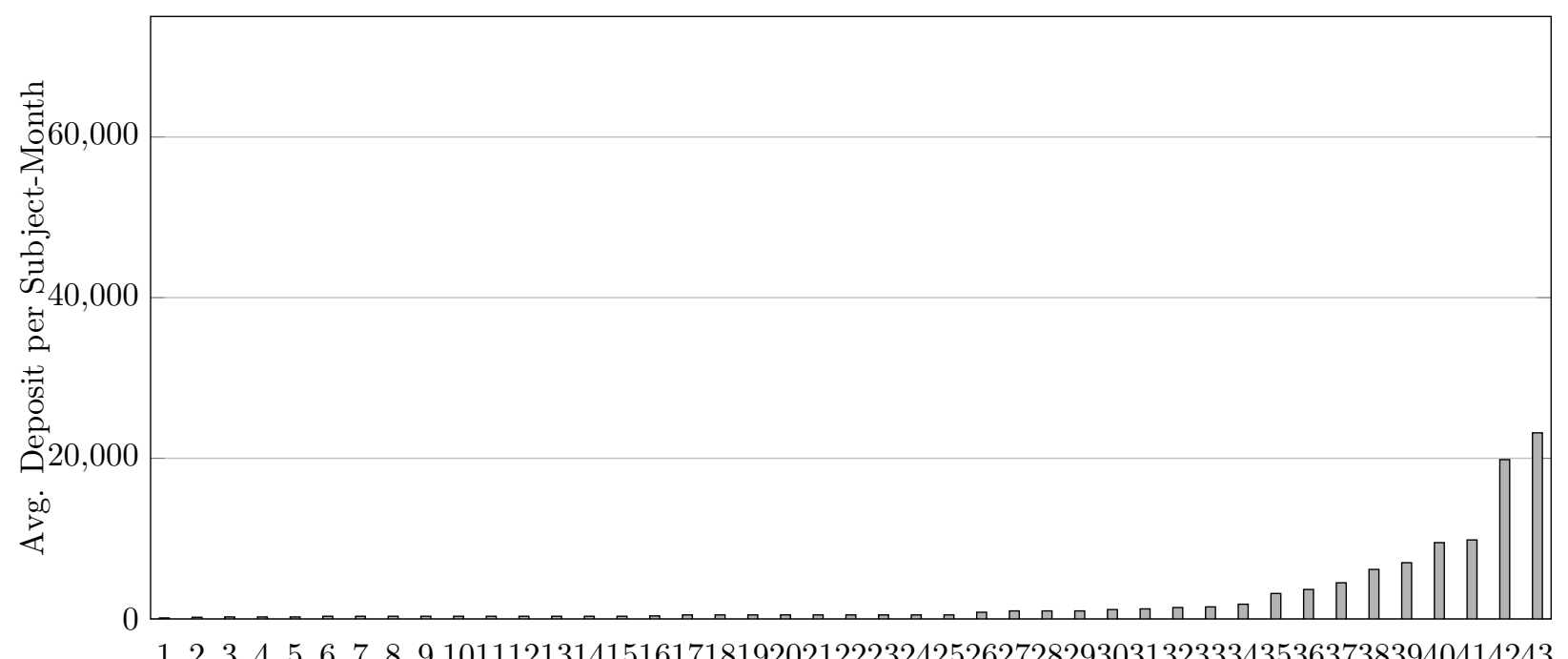

12345678910111213141516171819202122232425262728293031323334353637383940414243

consideration. Thus, are results are not sensitive to the subjects selected in our control sample, except the single outlier shown in Figure 2.

\subsection{Treatment Effect}

We now turn to the primary question - whether the Save to Win intervention promoted savings. We evaluate it using two metrics. First, is the savings level observed (statistically) greater than zero? Since our subject pool is made up of those who do not engage in savings (for the most part), any savings is a victory. Prior to the beginning of the two phases, only $11.6 \%$ of the subjects had a savings account at the community bank. Our intervention consists of two parts - an enhanced monthly interest rate well above market rates and a contest. Therefore, the second, higher hurdle to leap over is to establish that the Save to Win accounts outperform the control group's savings behavior. As stated, our control group gains from the high interest rates, but does not have the contest.

Figure 5 first compares the cohort average per month deposit sizes. We chose to separate those who engaged in Treatment 4-1 into those with the guarantee, labeled "T4-1+G", and those who did not, labeled "T4-1+NG". We include average per month per subject deposits of those assigned to Treatment 3-2, labeled "T3-2", and the Control.

As one can see, all cohorts experience savings behavior far exceeding zero levels. Thus, the intervention leads to more (formal) savings. In addition, the average per month deposit into traditional savings accounts prior to the intervention is less than 500 UGX. Each confidence interval lies above this amount. Hence, deposits during our intervention are all substantially greater than what is observed using traditional savings accounts. The difference is highly statistically significant. Thus, we achieved our first goal.

Result 1: The Save to Win intervention lead to more formal saving than traditional savings accounts.

Regarding the second hurdle, first note that the Treatment 3-2 has a substantially lower average deposit 
Figure 5: Treatment Effect: Deposit Size

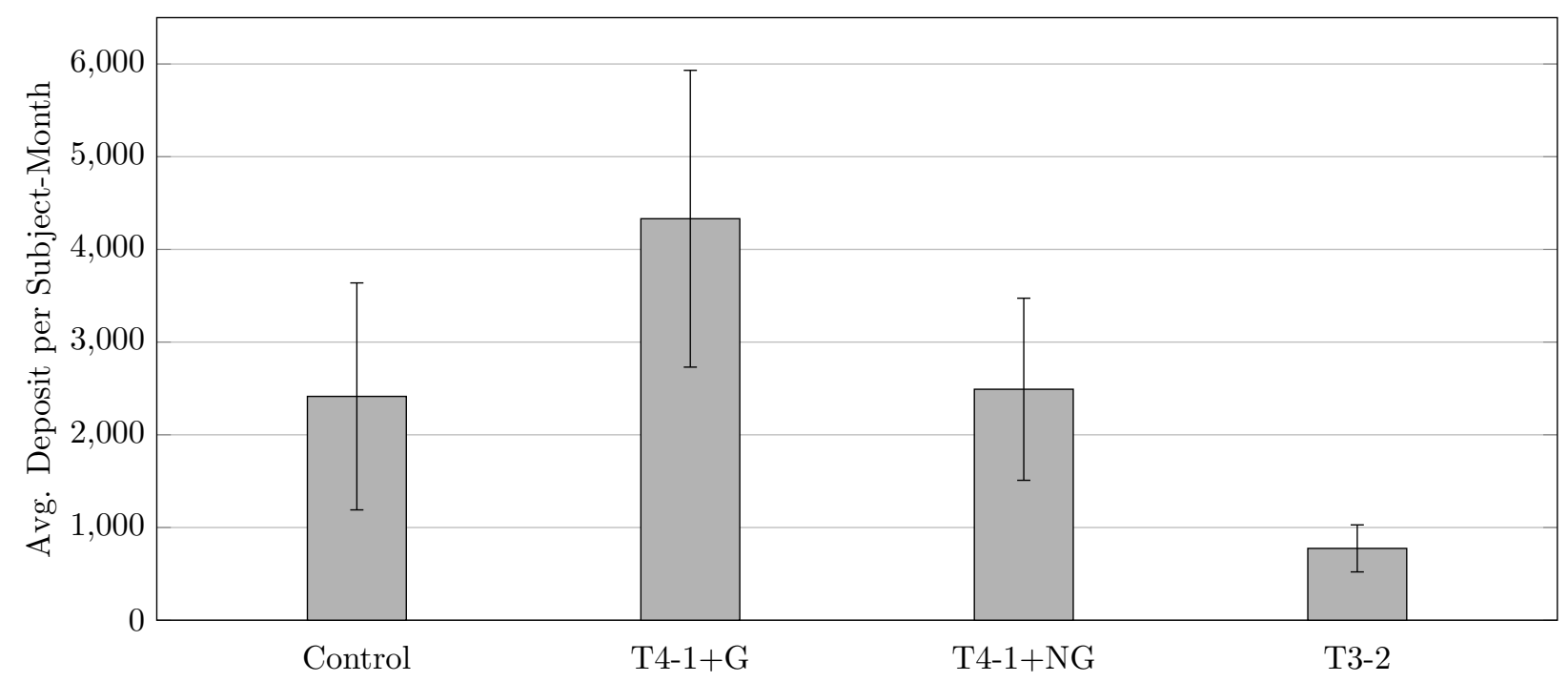

Comparing only the Control to the Treatment 4-1, Guarantee group (labeled "T4-1+G" in the figure), a two-tailed, difference-in-means t-test (allowing for unequal variances) has $t=1.88(p=0.062)$. A Wilcoxon Ranksum test has $z=2.07(p=0.038)$.

than any other cohort including, importantly, the control group. Thus, it seems that too much of the amount deposited went to the contest. Presumably, subjects were uninterested (for the most part) in participating.

Treatment 4-1, without the guarantee, sees greater depositing than Treatment 3-2 (which also does not have the guarantee), but is statistically indistinguishable from the control group's savings behavior.

The noticeable treatment effect arises when the guaranteed minimum prize is introduced. The average, per month deposit is $79.4 \%$ greater than in the control. Using a Wilcoxon Ranksum test, the difference in the distributions is statistically significant $(z=2.07 ; p=0.038)$. Therefore, a treatment effect exists.

Another way to assess our intervention and the difference between the treatments is to consider the time series of account balances. Figure 6 presents the average account balance for our subjects in each month separating the individuals into the four cohorts. Hence, Phase 1 and Phase 2 are pooled together. Time is re-centered around the beginning of the treatment. That is, rather than consider the calendar months, we consider Time $=0$ as the first month of the intervention. Thus, the Save to Win contest occurred in Time $\in[0,5]$. We also report in Figure 6 data from account balances prior to the intervention. Since the microfinance bank had been open for six months prior to our intervention for participants in Phase 1, we include Time $\in[-6,-1]$ as well.

As one can see, average account balances were quite modest prior to our intervention. Regardless of which cohort a subject is assigned to, a substantial improvement in savings occurs. Our Treatment 4-1, where $80 \%$ of one's deposit goes into the savings account, especially with the prize guarantee, sees the largest response.

Figure 7 also considers the prevalence of making a deposit. Specifically, it considers the proportion of subjects in a month who make at least one deposit, regardless of its size. In other words, it investigates saving's extensive margin.

Similar findings arise. Treatment 3-2 has relatively less savings activity. Treatment 4-1 without the guarantee is, again, statistically indistinguishable from the control. Treatment 4-1 with the guarantee records 
Figure 6: Account Balances Centered on the Treatment

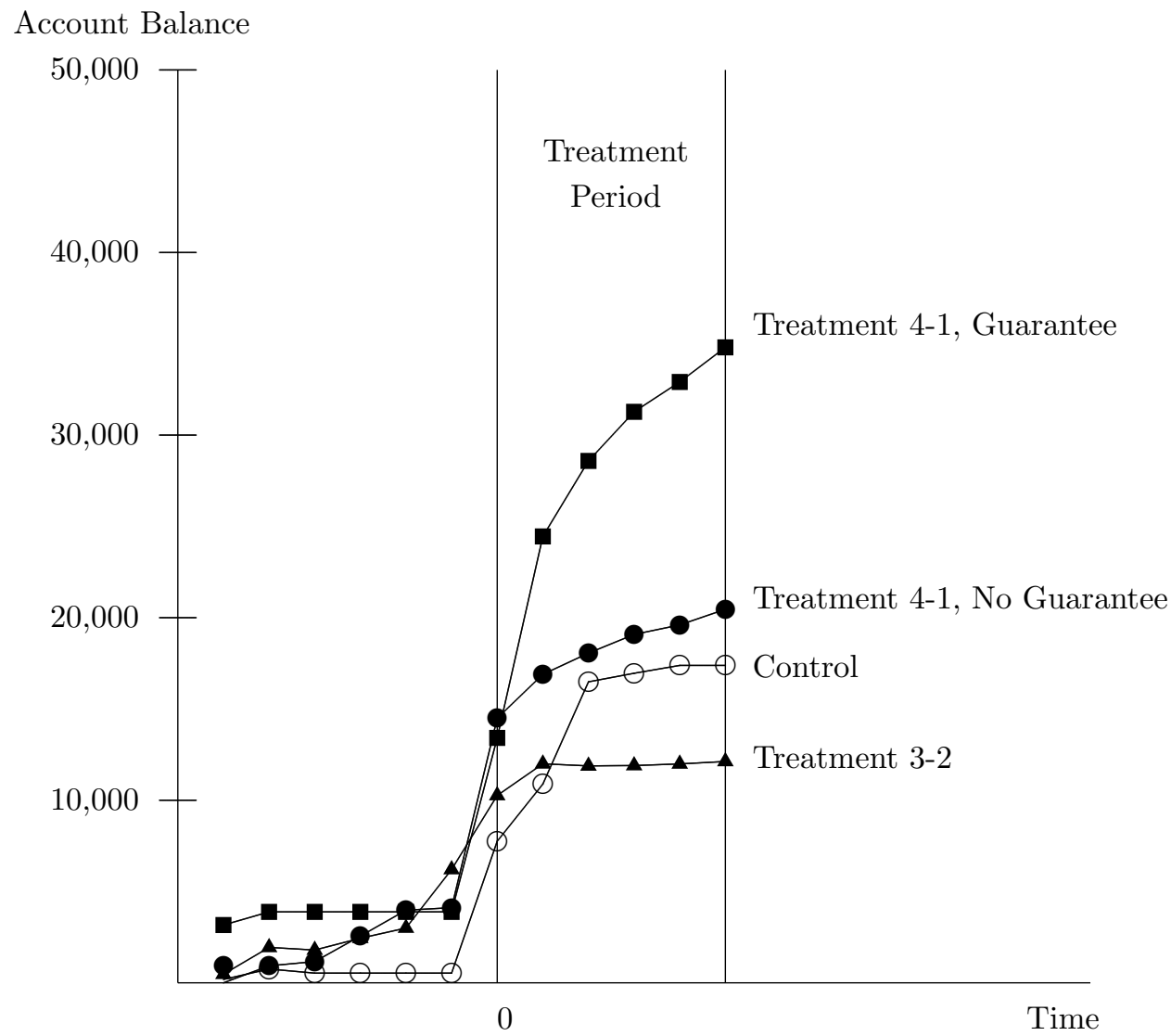

Data is centered on the beginning of the treatment.

Open circles denote the average account balance of those within the Control group. Closed circles denote the average account balance of those within the Treatment 4-1, No Guarantee group. The squares denote the average account balance of those within the Treatment 4-1, Guarantee group. The triangles denote the average account balance of those within the Treatment 3-2 group.

The y-axis measures the average (per subject) account balance for those within each cohort each month. 
Figure 7: Treatment Effect: Activity

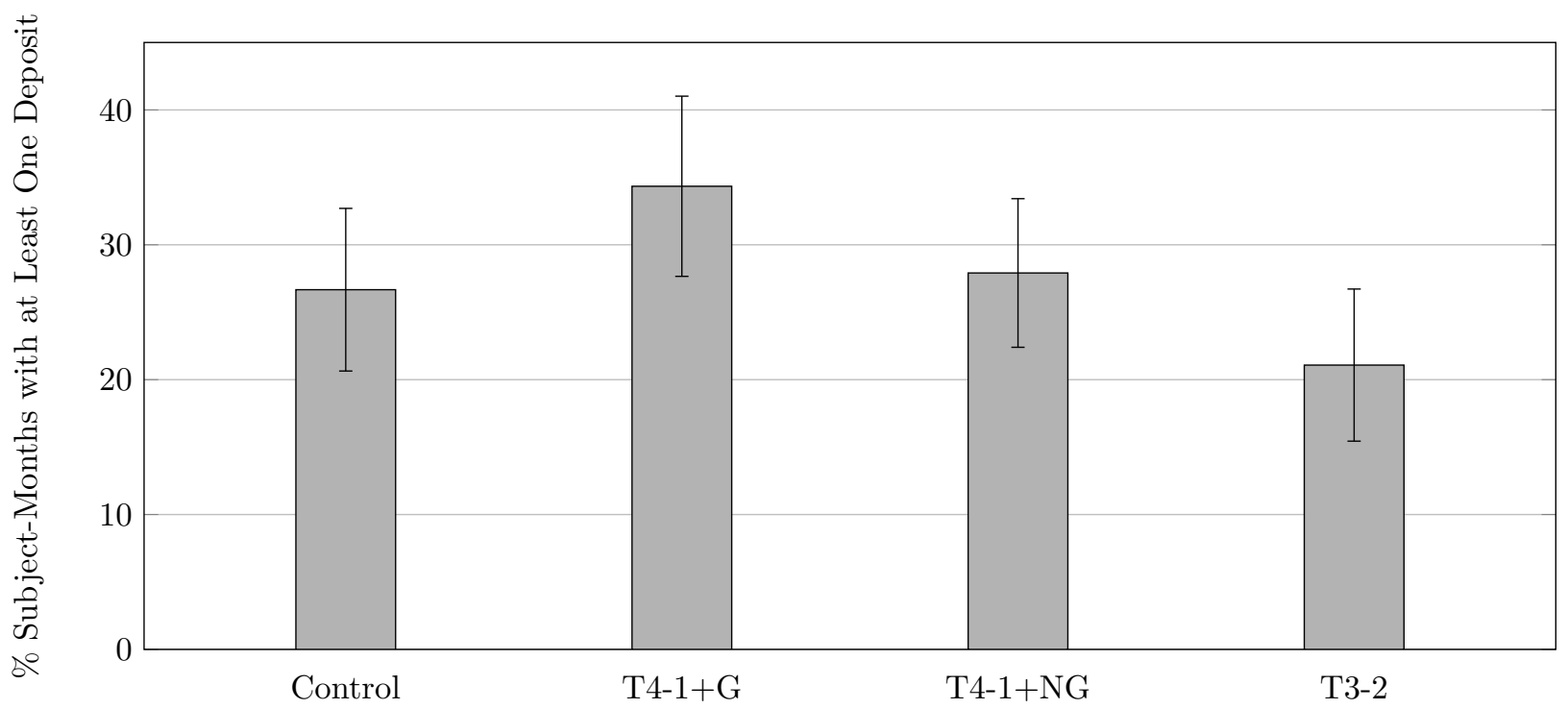

Comparing only the Control to the Treatment 4-1, Guarantee group (labeled "T4-1+G" in the figure), a two-tailed, difference-in-means t-test (allowing for unequal variances) has $t=1.68(p=0.093)$. A Wilcoxon Ranksum test has $z=1.68(p=0.092)$.

a noticeably higher proportion of the subjects who make a deposit in a given month than the Control.

While Figures 5, 6, and 7 provide our main result, they do not account for differences in the background characteristics and experiences of the individuals who make up each cohort. The balance table previously presented shows some slight differences in the subject pools. Thus, it is appropriate to establish that the cohort differences identified are not sensitive to controlling for differences in the subject pools. Table 2 presents the results.

As suggested in Figure 5. Treatment 3-2 coincides with lower average monthly deposits. Treatment 4-1 has larger deposits than the control, but the difference is statistically indistinguishable from zero, column (1). When this treatment is separated into those who had the guarantee and those who did not, the effect is identified, column (2).

The average treatment effect is robust to the inclusion of subject specific controls, column (3). Also, we estimate a Tobit model recognizing the large number of zeroes that exist in the data ${ }^{12}$ The treatment effect persists in this alternative estimation, column (4).

While Table 2 establishes the volume of savings, Table 3 uses an indicator variable equal to one if a deposit of any size is made in a month by the subject as the dependent variable. This table tests the robustness of the observations made in Figure 7.

Again, the Treatment 4-1, especially with those within the cohort that were given the guarantee on the prize's size, respond by increasing the rate at which they participate in the savings program. Therefore, we establish our second result.

Result 2: The Save to Win intervention with contests for a guaranteed prize lead to more formal savings than the control group with only the high interest rate.

\footnotetext{
${ }^{12}$ Here, $72.0 \%$ of our subject-month observations are zero.
} 
Table 2: Treatment Effect: Deposit Size

\begin{tabular}{lllll}
\hline \hline Model: & OLS & OLS & OLS & Tobit \\
& $(1)$ & $(2)$ & $(3)$ & $(4)$ \\
\hline Treatment 3-2 & $-163.78^{* * *}$ & $-1639.78^{* *}$ & -930.81 & -5240.65 \\
& $(819.05)$ & $(816.94)$ & $(804.44)$ & $(2719.83)$ \\
& & & & \\
Treatment 4-1 & 875.74 & & & \\
& $(694.83)$ & & & \\
& & & & \\
Treatment 4-1, Guarantee & & $1916.52^{* *}$ & $1836.34 * *$ & $6299.18^{* * *}$ \\
& & $(823.19)$ & $(838.71)$ & $(2493.37)$ \\
& & & & \\
Treatment 4-1, No Guarantee & & 76.99 & 786.25 & 3703.05 \\
& & $(772.36)$ & $(773.61)$ & $(2453.81)$ \\
Background Controls & No & No & Yes & Yes \\
Treatment Month Controls & No & No & Yes & Yes \\
& & & & \\
$R^{2}$ & 0.015 & 0.021 & 0.158 & 0.062 \\
AIC & 18180 & 18177 & 17673 & 5423 \\
\hline \hline
\end{tabular}

The dependent variable is the size of the subject's total deposit for a month (in Ugandan Shillings); $\mu=2488.79$ UGX.

A constant is included in each specification, but not reported.

Standard errors are presented in parentheses; *** $1 \% ; * * 5 \% ; * 10 \%$ level of significance.

$N=870$ for (1) and (2). For (3) and (4), it is $N=852$. There is missing information from one subject on Age, one subject on Crops, and one subject on Mud.

In (4), there are 622 left-censored observations and 230 uncensored observations. 
Table 3: Treatment Effect: Activity

\begin{tabular}{llll}
\hline \hline & $(1)$ & $(2)$ & $(3)$ \\
\hline Treatment 3-2 & -0.0559 & -0.0559 & -0.0460 \\
& $(0.0438)$ & $(0.0438)$ & $(0.0290)$ \\
& & & \\
Treatment 4-1 & 0.0404 & & \\
& $(0.0371)$ & & \\
& & & \\
Treatment 4-1, Guarantee & & $0.0768 *$ & $0.0757^{* *}$ \\
& & $(0.0441)$ & $(0.0302)$ \\
Treatment 4-1, No Guarantee & & & \\
& & 0.0124 & $0.0484 *$ \\
& & $(0.0414)$ & $(0.0279)$ \\
Background Controls & No & No & Yes \\
Treatment Month Controls & No & No & Yes \\
& & & \\
$R^{2}$ & 0.008 & 0.010 & 0.626 \\
AIC & 1065 & 1064 & 239 \\
\hline \hline
\end{tabular}

The dependent variable is an indicator variable equal to one if the subject made at least one deposit; $\mu=0.2747$.

A constant is included in each specification, but not reported. Linear probability model estimated.

Standard errors are presented in parentheses; $* * * 1 \% ; * * 5 \% ; * 10 \%$ level of significance. $N=870$ for (1) and (2). For (3) and (4), it is $N=852$. 
Thus, Hypothesis 3 receives strong empirical support.

Finally, while not the focus on the analysis, we also identify an effect of winning a contest on subsequent deposits. Table 12 in the appendix provides the estimates. If a subject won the contest in the past month or had won a contest in any previous month, the size of the deposit made in the next month grows. The former grows the average deposit made by more than 8000 UGX, increasing the probability of making a deposit by $30 \%$, while the latter increases the average deposit by approximately 3000 UGX increasing the probability of making a deposit in the month by about $10 \%$. Thus, the act of winning a contest creates inertia.

\subsection{Heterogeneous Treatment Effect}

The previous subsection established that the Save to Win accounts, buttressed with a minimum prize guarantee, can promote savings by those who otherwise would not be saving. We next ask who it is who responds positively to the intervention. In this subsection, we will explore four dimensions to the background and characteristics of the subject pool.

First, we consider two important dimensions to preferences, namely risk aversion and patience. We had each subject complete an incentivized price menu, risk assessment. Similar to Eckel and Grossman (2002), subjects make a series of binary choices between a 50-50 lottery and a certain amount. The lottery resulted in either 0 or 1000 UGX. The decision problems differ by the size of the certain amount (ranging from 50 to 1000 UGX). A reproduction of the risk assessment is provided in Table 11 of the appendix.

We record a subject as being risk averse if the number of choices where $\mathrm{s} /$ he selected the certain outcome is more than what a risk neutral decision maker would select 13 In our sample, $79.3 \%$ of our subjects who completed the risk assessment are recorded as being risk averse.

In addition, in the background questionnaire a simple survey question asks subjects to rate on a one to five Likert scale how patient of a person s/he views him/herself. The mean value is 3.95 . In total, $34.2 \%$ score themselves as a ' 5 ' on the scale, while $36.8 \%$ report a ' 4 '. This leaves $29.0 \%$ of the subjects viewing themselves as having some degree of impatience. These two assessments allow us to evaluate two important dimensions to savings behavior: risk and time preferences.

Third, we will compare those subjects with differing financial market activities. In our questionnaire, we ask about experience with microfinance loans. This will potentially be important as the implementation of Save to Win accounts by others will likely be done through already established microfinance institutions. Overall, $44.1 \%$ of our subjects have received a microloan in the past.

Also, we compare those subjects who enjoy gambling to those who do not. Our Save to Win accounts introduce uncertainty which may be enjoyed by those who enjoy gambling. We record a subject as being a gambler if they report that they had placed a wager in the previous month; $5.6 \%$ of our subjects had.

\subsubsection{Risk Preference}

First, the Save to Win account's design was done to take advantage of subject's competitiveness and utility received from engaging in lotteries. Of course, not every subject will prefer to have uncertainty interjected into his/her savings decisions. Risk-averse individuals can be expected to be less interested in participating in the Save to Win program.

\footnotetext{
${ }^{13}$ In our assessment, ten of the twenty decision problems have the certain amount strictly greater than the expected value of the lottery. The eleventh has the two equal. Hence, a risk averse subject will select the certain at least ten times. In addition, due to incomplete participation in the assessments, data on risk preferences exist for 111 subjects ( $76.6 \%$ of the subject population). An indicator variable for missing information is created and included in the upcoming regression analysis. Thus, the risk aversion metric should be interpreted as being conditioned on the completion of the assessment.
} 
Figure 8: Difference Between Risk Averse and Non-Risk Averse Subjects

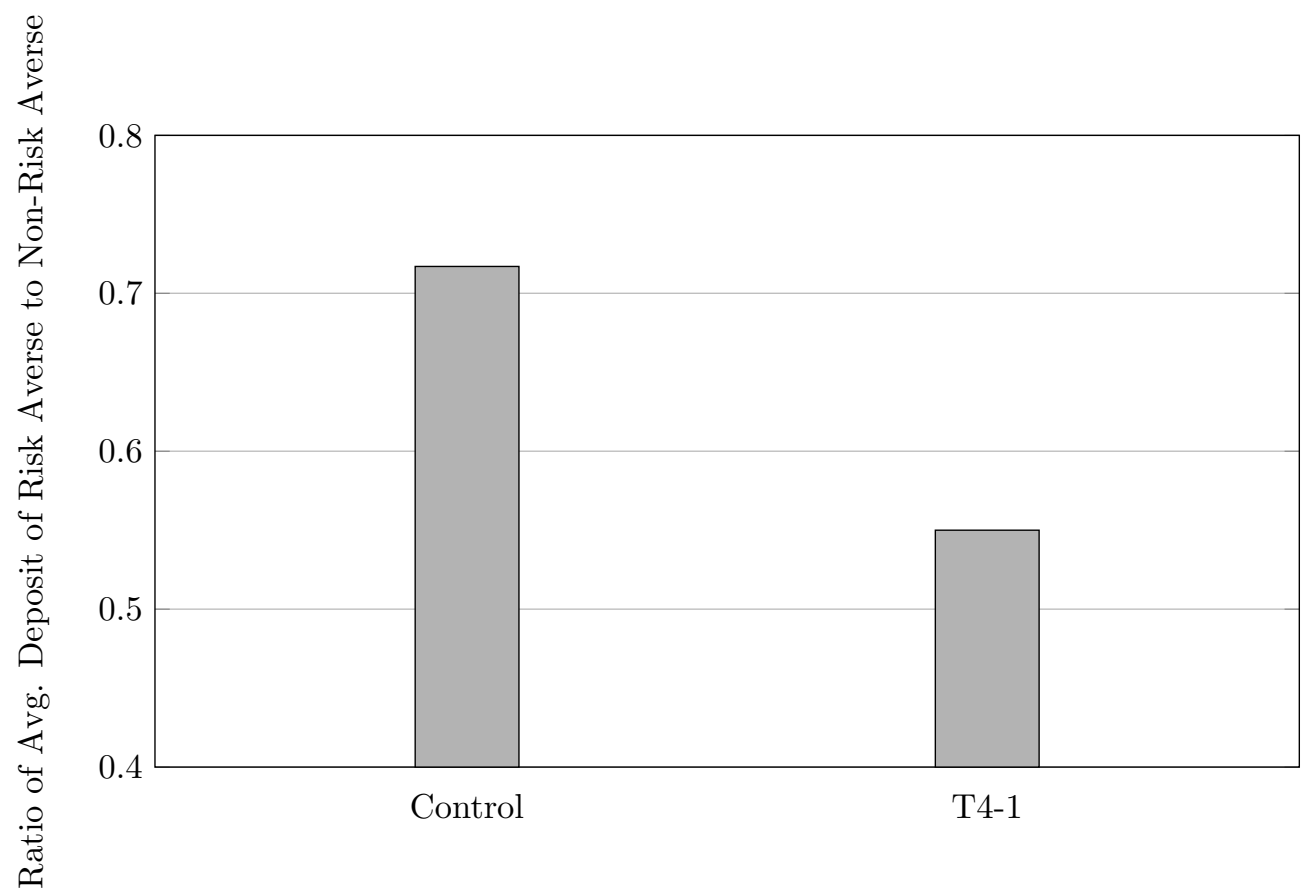

Each column depicts the average per subject deposit for those who are risk averse divided by the average per subject deposit for those who are not risk averse (for that cohort). Thus, values less than one indicate that the risk averse make smaller deposits than the non-risk averse.

Therefore, we use the risk assessment to identify those subjects who are risk averse. To first evaluate differences in behavior of risk-averse and non-risk-averse subjects, we consider the ratio of average deposit size (per month, per subject) for those who are identified as being risk averse, over the average deposit size for those who are not identified as being risk averse. If this ratio is less than 1.0, then the risk-averse subjects deposit relatively less, which is what we anticipate will happen. Lower values to this ratio, though, denote a stronger relative effect of risk aversion. Figure 8 presents this ratio for the those in the Control and those in Treatment 4-1.

For both cohorts, risk-averse individuals deposit less than non-risk-averse subjects. The difference is more pronounced for those in Treatment 4-1, which includes the lottery. The risk averse only deposit approximately $55 \%$ as much as others within the same treatment. Thus, Figure 8 provides suggestive evidence that risk preferences matter for the success of the Save to Win program.

To evaluate econometrically risk's heterogeneous treatment effect, we extend the previous tables to include the subjects' risk preference metric. We include this characteristic as an explanatory variable for the deposit sizes made by subjects in the treatments. We also interact it with the treatment indicators to evaluate heterogeneous treatment effects. Table 4 provides the results.

Within the control group, the deposits of risk-averse individuals are slightly smaller than the non-risk averse. This difference, though, is not statistically significant. This is reasonable since those randomly selected to be in the control group do not have the uncertainty created by the contest. Without this uncertainty, the difference in behavior is not pronounced. 
Table 4: Risk Preference \& Deposit Size

\begin{tabular}{lll}
\hline \hline Model: & $\begin{array}{l}\text { OLS } \\
(1)\end{array}$ & $\begin{array}{l}\text { Tobit } \\
(2)\end{array}$ \\
\hline Risk Averse & -891.28 & -1809.62 \\
& $(1508.46)$ & $(4172.56)$ \\
Treatment 4-1, Guarantee & $7847.22^{* * *}$ & $17296.38^{* * *}$ \\
& $(2171.04)$ & $(5981.10)$ \\
Treatment 4-1, No Guarantee & 77.99 & 5511.42 \\
& $(1659.98)$ & $(4465.09)$ \\
Risk Averse x Treatment 4-1, Guarantee & $-6697.80 * * *$ & $-11955.63 *$ \\
& $(2343.84)$ & $(6357.52)$ \\
Risk Averse x Treatment 4-1, No Guarantee & -168.65 & -2299.26 \\
& $(1876.88)$ & $(5140.14)$ \\
Background Controls & & \\
Treatment Month Controls & No & Yes \\
$R^{2}$ & No & Yes \\
AIC & & \\
\hline \hline
\end{tabular}

The dependent variable is the size of the subject's deposit for a month (in Ugandan Shillings); $\mu=2488.79$ UGX.

A constant is included in each specification, but not reported. Also, the Treatment 3-2 indicator, along with its interaction with risk aversion, are included as well.

Standard errors are presented in parentheses; ${ }^{* * *} 1 \% ; * * 5 \% ; * 10 \%$ level of significance.

$N=870$ for (1) and $N=852$ for (2).

In (2), there are 622 left-censored observations and 230 uncensored observations. 
Regarding those individuals selected randomly to be in the treatment, a noticeable difference arises. Relative to those in the control group (the omitted category), the non-risk averse increase their deposits when the contests are included in the intervention. Once again, this effect is pronounced for those who also have the minimum guaranteed amount on the prize. Using the coefficient estimate in column (1) of 7847.22, being in Treatment 4-1 with the guarantee for a non-risk-averse subject results in almost a full standard deviation increase in the amount deposited each month (0.94 standard deviations). For those in this treatment, the risk-averse subjects deposit significantly less than the non-risk-averse subjects. Using the estimated coefficient in column (1) of -6687.80 and the summary statistics for only those subjects assigned to Treatment 4-1, the risk averse deposit more than two-thirds of a standard deviation less than the nonrisk-averse subjects ${ }^{14}$ Hence, risk preferences are an important consideration in the implementation of Save to Win.

As before, column (2) adds the background control variables and treatment month fixed effects, and estimates a Tobit model acknowledging the clumping of the data at zero. The results identified in column (1) persist with these alterations.

The specifications presented in Table 4 include an indicator variable for being assigned to Treatment 3-2, along with an interaction between it and a subject being risk averse. They are added to maintain subjects in the control as the omitted, reference category. We do not present the results because, as already established, behavior by those in this treatment are not statistically different from the control and the differentiation between guaranteed and non-guaranteed prizes were not done ${ }^{15}$ Also, while not presented here, the risk averse are less likely to make a deposit and those within the treatment with the guarantee are less likely to make a deposit than those who are not risk averse. These differences are small and, for the most part, statistically insignificant. Thus, they are not presented separately here. The margin that adjusts is the size of the deposit, as illustrated in Table 4

\subsubsection{Time Preference}

A second dimension to individual's traits is time preferences. Here, we use the survey question asking subjects to rank, on a Likert scale, the degree to which they view themselves as a patient person 16 Table 5 explores the relationship between patience and savings.

Regarding those individuals selected randomly to be in the treatment, the more patient a subject is the greater the monthly deposit becomes. For example, comparing a self-identified 'somewhat patient' person to a 'very patient person' (i.e., comparing a "agree" to "strongly agree" response) is associated, using the estimate in column (1), with a increase in deposits per month of 4149.24 UGX. Again, using the distribution of deposits made by those assigned to Treatment 4-1, this corresponds to an increase of almost one-half of a standard deviation (0.43 standard deviations). Thus, within the group selected to participate in the Save to Win accounts, the effectiveness of the intervention in encouraging savings is stronger the more future orientated the person is.

Interestingly, this effect also exists for those assigned to Treatment 4-1 without the guaranteed minimum prize. Here, comparing a 'somewhat' to 'very' patient subject, deposits per month are 0.22 standard deviations greater. Thus, both Save to Win designs are effective for patient individuals.

\footnotetext{
${ }^{14}$ For the sample of those randomly assigned to Treatment 4-1, the standard deviation to the deposits is 9673.16 . Hence, $\frac{6697.80}{9673.16}=0.69$.

${ }^{9673.16}$ The results presented do not change when these subjects are instead omitted from the data set.

${ }^{16}$ The survey question simply states, "I consider myself a patient person." and provides a five-point Likert scale ranging from 'Strongly Disagree' (=1) to 'Strongly Agree' (=5).
} 
Table 5: Patience \& Deposit Size

\begin{tabular}{lll}
\hline \hline Model: & OLS & Tobit \\
& $(1)$ & $(2)$ \\
\hline Patient & $-3261.75^{* * *}$ & $-6271.80^{*}$ \\
& $(983.30)$ & $(3365.73)$ \\
Treatment 4-1, Guarantee & $-14167.22^{* * *}$ & -23400.87 \\
& $(4557.23)$ & $(16134.00)$ \\
Treatment 4-1, No Guarantee & $-13240.55^{* * *}$ & -21586.55 \\
& $(-13240.55)$ & $(18852.00)$ \\
Patient x Treatment 4-1, Guarantee & $4139.24 * * *$ & $8579.90 * *$ \\
& $(1190.43)$ & $(4191.71)$ \\
Patient x Treatment 4-1, No Guarantee & $2089.13 * *$ & 6194.51 \\
& $(1429.77)$ & $(4831.98)$ \\
Background Controls & & \\
Treatment Month Controls & No & Yes \\
$R^{2}$ & No & Yes \\
AIC & & 0.063 \\
\hline \hline
\end{tabular}

The dependent variable is the size of the subject's deposit for a month (in Ugandan Shillings); $\mu=2585.20$ UGX (for those observations without missing values).

A constant is included in each specification, but not reported. Also, the Treatment 3-2 indicator, along with its interaction with patience, are included as well.

Standard errors are presented in parentheses; ${ }^{* * *} 1 \% ; * * 5 \% ; * 10 \%$ level of significance.

$N=870$ for (1) and $N=852$ for (2).

In (2), there are 324 left-censored observations and 126 uncensored observations. 
As before, column (2) adds the background control variables and treatment month fixed effects, and estimates a Tobit model acknowledging the censoring of the data at zero. For the most part, the results identified in column (1) persist.

Again, while not presented, patient individuals in the treatment are more likely to make a deposit in a month than less patient individuals in the treatment. Hence, time preferences matter for both the intensive and extensive margin of savings with our Save to Win intervention.

Putting together the results from these last two tables, predictable relationships between individual preferences and savings behavior arises. The Save to Win program, which was shown to be effective on average, is especially effective amongst those subjects who are not risk averse and who are patient. It may not be a useful tool for risk averse and impatient individuals.

Result 3: The Save to Win intervention is more effective for those who are not risk averse and not impatient.

\subsubsection{Microfinance Experience}

Along with considering a subject's assessed preferences directly, we can also consider observable choices in financial markets that can reasonably correlate with savings behavior. This is relevant for application. Financial institutions promoting local development will be unlikely to directly measure preferences. Implementation through existing microfinance organizations is likely.

First, we correlate the relationship between experience in financial markets and savings behavior. Our subject pool is made primarily of those who for the most part do not use formal savings accounts. Many have experience with financial markets through microcredit (more than $40 \%$, see Table 4). We separate our subjects by those who have received a microfinance loan in the past from those who have not. In Figure 9 we consider the ratio of the average per month deposit of those who have received a microloan to those who have not, similar to Figure 8 is analysis of risk preferences.

The relative size of the deposit amounts of those with microfinance experience are substantially higher than those without the experience in the control group. Those who have received microloans in the past take advantage of the high monthly interest rate provided in the baseline intervention. This difference reverses for those subjects assigned to the Save to Win treatment. Those who have previously received microloans do not participate. This suggests that individuals with experience in financial markets respond poorly to the intervention, relative to those with less experience.

Next, we consider the econometric results controlling for differences in the subject population. Table 6 presents the results.

Again, within those assigned to the control group, past microloan recipients behave (statistically) similar to those without that experience. Within the treatment group, especially those with the guaranteed prize, microfinance recipients make smaller deposits. Using the estimated coefficient in column (1), this corresponds to 0.60 standard deviation decrease.

In column (2), though, the statistical significance of this effect is gone. Investigating this change further, if (2) is re-estimated using OLS, the coefficient on Microfinance x Treatment 4-1, Guarantee remains statistically insignificant. Significance is regained if either the wealth-related controls (i.e., composition of the floor and walls of a subject's house and the availability of electricity) or the occupation-related indicators (whether the subject owns livestock or farms crops) are excluded. Thus, microfinance experiences coincides with economic well-being of the subject. Relatively better off individuals tend to be the one's who receive microfinance loans in the past. It is this group that does not respond positively when the Save to Win 
Table 6: Microfinance Experience \& Deposit Size

\begin{tabular}{lll}
\hline \hline Model: & $\begin{array}{l}\text { OLS } \\
(1)\end{array}$ & $\begin{array}{l}\text { Tobit } \\
(2)\end{array}$ \\
\hline Microfinance & 997.79 & -5658.47 \\
& $(1227.80)$ & $(3784.03)$ \\
Treatment 4-1, Guarantee & $3863.59^{* * *}$ & $6992.64 * *$ \\
& $(1007.60)$ & $(3020.64)$ \\
Treatment 4-1, No Guarantee & & \\
& 771.99 & 3467.33 \\
Microfinance x Treatment 4-1, Guarantee & $(1051.42)$ & $(3373.61)$ \\
& & \\
Microfinance x Treatment 4-1, No Guarantee & $-5489.85 * * *$ & -4799.02 \\
& $(1731.05)$ & $(5430.48)$ \\
& $(1610.60)$ & $(4890.53)$ \\
Background Controls & & \\
Treatment Month Controls & No & Yes \\
$R^{2}$ & No & Yes \\
AIC & 0.037 & 0.065 \\
\hline \hline
\end{tabular}

The dependent variable is the size of the subject's deposit for a month (in Ugandan Shillings); $\mu=2488.79$ UGX.

A constant is included in each specification, but not reported. Also, the Treatment 3-2 indicator, along with its interaction with microfinance, are included as well.

Standard errors are presented in parentheses; ${ }^{* * *} 1 \% ;{ }^{* *} 5 \% ; * 10 \%$ level of significance. $N=870$ for (1) and $N=852$ for (2).

In (2), there are 622 left-censored observations and 230 uncensored observations. 
Figure 9: Difference Between Those Who Have Received Microloans and Those Who Have Not

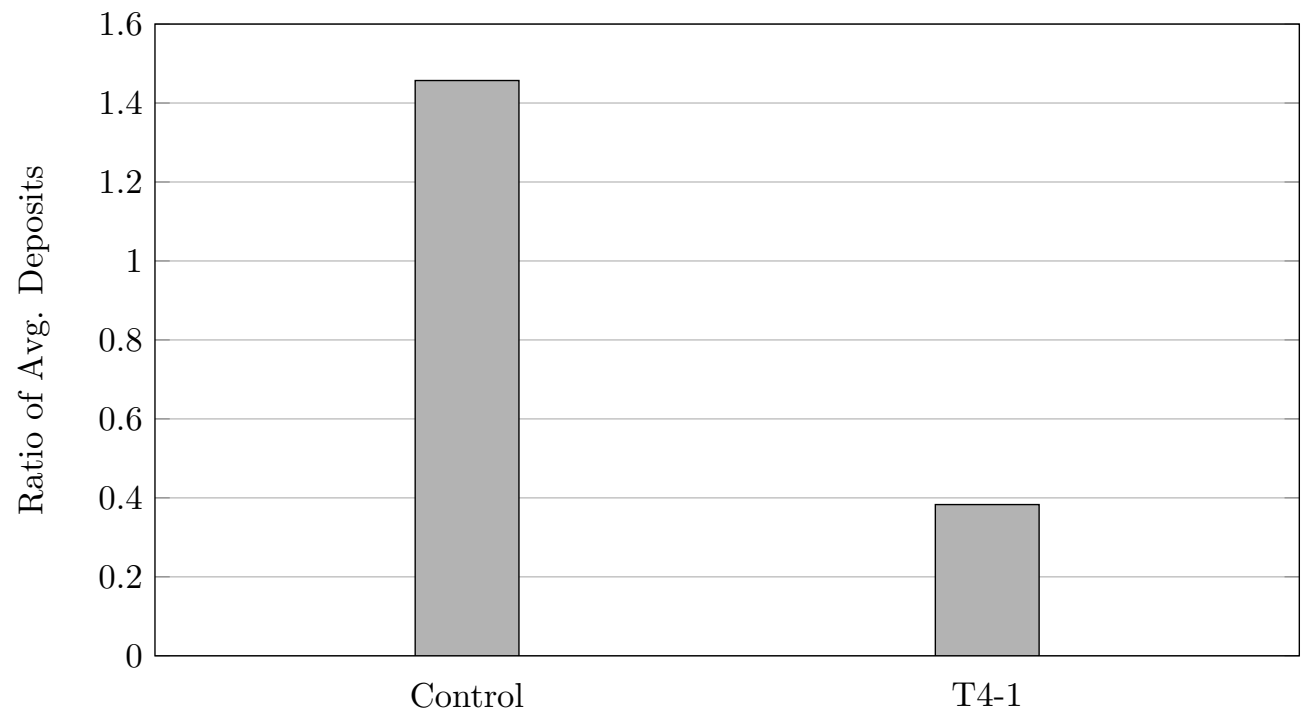

Each column depicts the average per subject deposit for those who who have received a microfinance loan divided by the average per subject deposit for those who have not. Thus, values less than one indicate that those who have received a microloan make smaller deposits than those who have not received a microloan.

intervention is offered.

Once again, while not presented here, similar findings arise if the extensive margin to savings is considered (rather, whether a deposit was made in a month). Taken together, those types of people who chose to seek out microloans are also the ones who save and prefer not to participate in the Save to Win program. Our intervention is effective for those without experience with financial markets.

\subsubsection{Gambling}

Finally, the Save to Win program introduces uncertainty into the savings decision by having contests. The winner of the contest is driven by "luck", akin to gambling. Therefore, we consider a subject's self-reported interaction in gambling markets and use of Save to Win in Table 7.

The increase in the average, per month deposit is concentrated in those who gamble leisurely. What is noteworthy about the findings in Table 7 is that this heterogeneous effect occurs in the Treatment 4-1 cohort who did not have the guarantee. This suggests that "gamblers" prefer not to have the protection of the minimum prize. They escalate their savings when risks exist. In the treatment with the guaranteed minimum, it is the non-gamblers who respond by depositing relatively more.

Result 4: Savings behavior of those in the Save to Win intervention is correlated with microfinance experience and gambling participation. 
Table 7: Gambling Participation \& Deposit Size

\begin{tabular}{lll}
\hline \hline Model: & OLS & Tobit \\
& $(1)$ & $(2)$ \\
\hline Gambler & $\begin{array}{l}-2142.16 \\
(3410.61)\end{array}$ & $\begin{array}{l}-7522.62 \\
(12529.66)\end{array}$ \\
& & \\
Treatment 4-1, Guarantee & $1964.61^{* *}$ & $6344.46^{* * *}$ \\
& $(827.93)$ & $(2465.41)$ \\
& & \\
Treatment 4-1, No Guarantee & -472.44 & 1816.84 \\
& $(779.72)$ & $(2477.77)$ \\
Gambler x Treatment 4-1, Guarantee & -1464.61 & -9497.94 \\
& $(4825.48)$ & $(17458.78)$ \\
Gambler x Treatment 4-1, No Guarantee & $12639.11 * * *$ & $29152.28 * *$ \\
& $(4190.20)$ & $(13820.38)$ \\
Background Controls & & \\
Treatment Month Controls & No & Yes \\
$R^{2}$ & No & Yes \\
AIC & & \\
\hline \hline
\end{tabular}

The dependent variable is the size of the subject's deposit for a month (in Ugandan Shillings); $\mu=2488.79$ UGX.

A constant is included in each specification, but not reported. Also, the Treatment 3-2 indicator, along with its interaction with gambling, are included as well.

Standard errors are presented in parentheses; ${ }^{* *} 1 \% ; * * 5 \% ; * 10 \%$ level of significance.

$N=870$ for (1) and $N=852$ for (2).

In (2), there are 622 left-censored observations and 230 uncensored observations. 


\section{Long-Term Effects}

While we have documented an effect of our treatment, it is prudent to ask whether we have a long-term impact. In this section, we evaluate two additional data. First, we track account balances over time after our intervention ended. Second, we survey subjects one year after Phase 1 ended (six months after Phase 2 ended) to gain insight into their post-intervention behavior.

\subsection{Wealth Accumulation}

A concern is that the wealth accumulation documented is transitory. As stated, the intervention provided both a higher monthly interest rate and a contest. After the six month intervention ended, all accounts automatically rolled over into a $0 \%$ interest savings account, but without withdrawal constraints. It is quite possible that a subject would rather not engage in the savings contest, prefers to not save when the interest rate is zero, but is willing to save and even take on the contest's uncertainty when the interest rate is $2 \%$ per month. Such a person would be expected to participate but liquidate his or her holdings at the end of the trial's phase. Consumption could have simply been delayed. Alternatively, if the wealth accumulated during the intervention promoted savings, and more importantly promoted saving behavior, then the account balances will stay above zero.

Therefore, we track the subjects after the intervention. Figure 10 depicts the average savings account balances of the Phase 1 subjects in each cohort. It includes data since the opening of the bank in the community, through our intervention, and for the twelve months after Phase 1 of the Save to Win mechanism ended. This means that we have twelve months of post-study balance information for those in Phase 1 and six months for those in Phase 2. It also means that we have six months of pre-study information for those in Phase 1 and twelve months for those in Phase 2. We do not include interest accumulation in these balances so that we isolate saving choices.

During Phase 1, the balances of the subjects in all cohorts grow rapidly. Clearly, there is an initial jump in the intervention's first month, which is to be expected given that a deposit must be made to be eligible to be a part of our intervention. Recall that if a subject came to the advertised meeting to be a part of the study, they received an account with a starting balance of 2500 UGX, which is the minimum account balance allowed by the bank. The per subject balance, though, is substantially higher than this minimum. For example, the per subject account balance for those in the control is 14.4 times as great after the first month of our intervention than the month prior. If subjects had only taken the opening account balances as charity, the per subject balance would have only increased by a factor of 6.2 .

Balances grow for subjects in all three cohorts over the intervention's time period, as established previously. Interestingly and importantly, the balances after the intervention do not zero out. As one can see in Figure 10, the balances of those in Treatment 3-2 and the control stay relatively stable afterwards. Over time they begin to grow. Those assigned to Treatment 4-1 experience an escalated post-intervention growth. There are periods of partial liquidation. A subset of this subject pool starts actively using their savings account building up their balances substantially. These observations suggest that the intervention promoting savings behavior.

To evaluate post-intervention behavior in Phase 2, we recenter the data around the timing of the treatment so that Time $=0$ is the first month of the intervention for both phases and the post intervention behavior is measured for Time $\geq 6$. Rather, we extend Figure 5. Data from subjects in the two controls are pooled. Figure 11 presents the average account balances for subjects in both phases. 
Figure 10: Account Balances for Phase 1 Participants

Account Balance

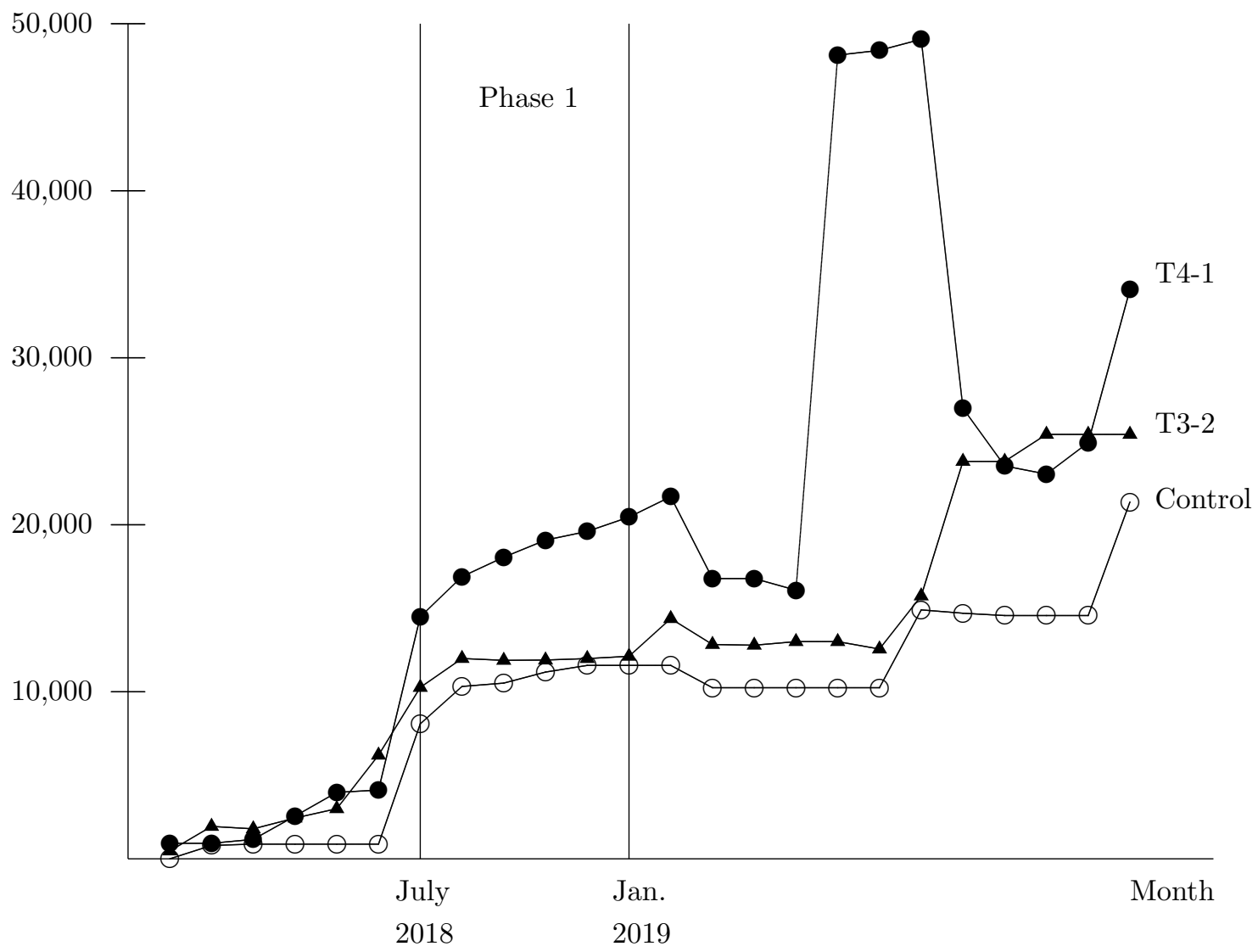

Open circles denote the average account balance of those within the Control group. Closed circles denote the average account balance of those within the Treatment $4-1$ group. The triangles denote the average account balance of those within the Treatment 3-2 group.

The y-axis measures the average (per subject) account balance for those within each cohort each month. 
Figure 11: Account Balances Centered on the Treatment

Account Balance

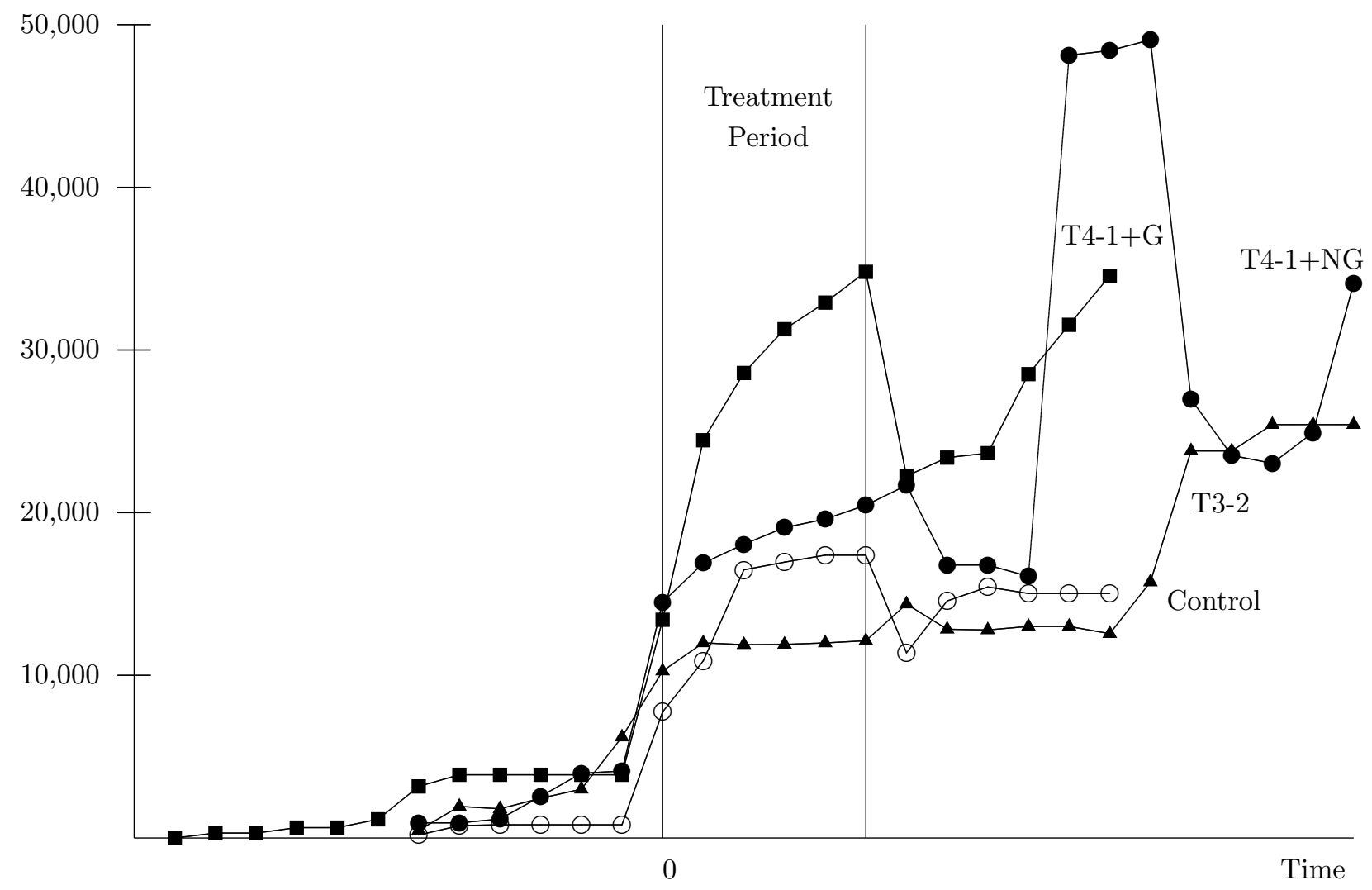

Data is centered on the beginning of the treatment.

Open circles denote the average account balance of those within the Control group. Closed circles denote the average account balance of those within the Treatment 4-1, No Guarantee group. The squares denote the average account balance of those within the Treatment 4-1, Guarantee group. The triangles denote the average account balance of those within the Treatment 3-2 group.

The y-axis measures the average (per subject) account balance for those within each cohort each month. 
Recall that since Phase 2 started at the conclusion of Phase 1, subjects in this phase had a twelve months to open savings accounts and save prior. Few in these cohorts did so. Therefore, it is fair to presume that Phase 2 considers individuals who would not be interacting in formal financial markets absent our intervention.

Once again, the treated subjects build up their savings both during and after the intervention (depicted by the "T4-1+G" line). Again, immediate liquidation after the conclusion of the mechanism does not occur. Balances continuously grow for those in Treatment 4-1 with the guarantee.

To confirm econometrically, we consider the pooled data set of account balances of the subjects from Time $=-12$ to Time $=1 \sqrt{17}$ and evaluate the time trend in wealth accumulation. We allow jumps in the time trend at the beginning and end of the intervention, and allow for the trend to adjust after each. Rather, we estimate

$$
\text { Balance }_{i t}=\alpha_{0}+\alpha_{1} \text { Study }_{i t}+\alpha_{2} \text { Post }_{i t}+\alpha_{3} \text { Time }_{i t}+\alpha_{4} \text { Time }_{i t} \times \text { Study }_{i t}+\alpha_{5} \text { Time }_{i t} \times \text { Post }_{i t}+\epsilon_{i t} .
$$

The indicator Study equals one for the months where the Save to Win accounts are active and the indicator Post equals one for the periods after. That is, Study $=1$ for Time $\in[0,5]$ and Post $=1$ for Time $\in[6,17]$. This equation is estimated for each treatment cohort. Immediate liquidation would result in $\alpha_{2}<0$. Instead, if we promoted continued savings behavior after our intervention, then $\alpha_{5}>0$. Table 8 presents the results.

Notice that the coefficient on Time $\times$ Post, $\alpha_{5}$, is positive and statistically significant for Treatment 4-1 with the guaranteed prize. Thus, not only did this treatment produce the most savings during the intervention (as acknowledged by the positive and statistically significant coefficients on the intervention indicator and its interaction with time), but it improved the average savings rate over time. We interpret this as savings behavior being promoted.

The effect is small and statistically indistinguishable from zero for that treatment without the guarantee. Instead, those subjects experience a large (but statistically insignificant) level increase after the intervention's end. Again, the results for those in Treatment 3-2 point to its ineffectiveness. The high interest rate provided to those in the control promotes both savings during, but sustained savings after.

The final dimension to our post-intervention analysis is the question of whose savings behavior changed. Our presumption is that the inducement to save during the intervention encouraged a subset of the subjects to continue to save afterwards. An alternative is that the uncertainty discouraged potential savers. After our intervention ended, this group begins to save. To evaluate this, we differentiate our subjects by the number of months they participated by making a deposit. Some subjects were active only in the first month and did not return to the bank and make a deposit in any of the remaining five months. Moderate participants come back one more month. We classify the users of the program as those who make additional deposits in at least two more months, thus participating in contests at least one-half of the time. Table 9 compares their average account balances at the end of the intervention to their balances six months after 18

First, as to be expected, the average account balance for those who made deposits in two or more months after the initial month have higher average balances 19

There is a monotonic relationship between the number of months participating in the intervention and the growth rate of the accounts. In fact, those who did not participate see a reduction in their balance.

\footnotetext{
${ }^{17}$ Time runs to a value of 17 since the study's intervention occurs for periods 0 through 5 of the re-centered data and the twelve months of post-intervention behavior occurs from period 6 to 17 .

${ }^{18}$ We choose six months because we have data on account balances for participants in both phases through six months.

${ }^{19}$ The account balance information provided does not include interest accumulation, but does include the prizes that were won in the contests.
} 
Table 8: Time Series

\begin{tabular}{|c|c|c|c|c|}
\hline & $\begin{array}{l}\text { Treatment } \\
4-1, \text { Guarantee }\end{array}$ & $\begin{array}{l}\text { Treatment } \\
4-1, \text { No Guarantee }\end{array}$ & $\begin{array}{l}\text { Treatment } \\
3-2\end{array}$ & Control \\
\hline Time & $\begin{array}{l}447.74 \\
(416.42)\end{array}$ & $\begin{array}{l}756.15 \\
(3270.07)\end{array}$ & $\begin{array}{l}928.57 \\
(1264.27)\end{array}$ & $\begin{array}{l}102.94 \\
(446.03)\end{array}$ \\
\hline Time x Study & $\begin{array}{l}3409.75^{* * *} \\
(1260.43)\end{array}$ & $\begin{array}{l}357.28 \\
(4624.57)\end{array}$ & $\begin{array}{l}-662.23 \\
(1787.95)\end{array}$ & $\begin{array}{l}1843.59 * \\
(1000.20)\end{array}$ \\
\hline Time x Post & $\begin{array}{l}2149.41 * \\
(1260.43)\end{array}$ & $\begin{array}{l}40.37 \\
(3464.39)\end{array}$ & $\begin{array}{l}513.56 \\
(1339.40)\end{array}$ & $\begin{array}{l}10142.36^{* *} \\
(4687.39)\end{array}$ \\
\hline constant & $\begin{array}{l}5045.27 \\
(3063.14)\end{array}$ & $\begin{array}{l}4925.58 \\
(12735.08)\end{array}$ & $\begin{array}{l}5892.16 \\
(4923.62)\end{array}$ & $\begin{array}{l}1041.98 \\
(2542.77)\end{array}$ \\
\hline Study & $\begin{array}{l}12884.74 * * * \\
(4728.42)\end{array}$ & $\begin{array}{l}10388.93 \\
(16130.86)\end{array}$ & $\begin{array}{l}5134.49 \\
(6236.49)\end{array}$ & $\begin{array}{l}8567.41 * * \\
(3716.50)\end{array}$ \\
\hline Post & $\begin{array}{l}197.70 \\
(10760.05)\end{array}$ & $\begin{array}{l}15034.60 \\
(3464.39)\end{array}$ & $\begin{array}{l}-4298.32 \\
(7241.67)\end{array}$ & $\begin{array}{l}10142.36 \text { ** } \\
(4687.39)\end{array}$ \\
\hline$R^{2}$ & 0.179 & 0.016 & 0.054 & 0.089 \\
\hline$N$ & 792 & 1032 & 816 & 840 \\
\hline
\end{tabular}

Dependent variable is the ending account balance for a subject for the month.

Each column presents the results for the subsample defined.

Standard errors presented in parentheses; *** $1 \%, * * 5 \%, * 10 \%$ level of significance.

Table 9: Account Balance Growth

\begin{tabular}{lllc}
\hline \hline $\begin{array}{l}\text { Number of months with a } \\
\text { deposit after the initial month }\end{array}$ & $\begin{array}{l}\text { Avg. account balance at } \\
\text { the end of the intervention }\end{array}$ & $\begin{array}{l}\text { Avg. account balance six } \\
\text { months after intervention }\end{array}$ & $\begin{array}{c}\% \text { change } \\
N\end{array}$ \\
\hline 0 & 7573.47 & 7231.63 & $-4.5 \%$ \\
1 & $21,609.09$ & $31,836.36$ & $+47.3 \%$ \\
2 or more & $83,940.38$ & $127,713.50$ & 22 \\
\hline \hline
\end{tabular}

Subjects are classified by the number of months, after the first month of the intervention (when everyone must make a deposit), where at least one deposit is made. 
These subjects presumably gained from the community meal and the opening account balance, but did not want to save. For those who frequently participated, they continued to grow and in fact escalated their average monthly deposits. This is especially noteworthy remembering that after the intervention, accounts did not pay any interest.

Overall, our Save to Win intervention had a meaningful impact on savings in the community even after our intervention ended.

Result 5: The Save to Win intervention has a longer-term improvement in wealth.

\subsection{Survey Responses}

In December 2019 Embrace It Africa engaged in a survey of those who had participated in our Save to Win program. They asked questions about the growing use of mobile money accounts, participation in ROSCAs, and use of other SACCOs. We added a few questions to their short survey 20 Specifically, we wanted to assess (i) what our intervention crowded out and (ii) what are their future plans with the account balances.

Survey data is notoriously unreliable. Subjects may not respond truthfully, instead providing answers that they feel the survey taker wants to hear. In addition, respondents may not be aware of their actual behavior at the margin. Nevertheless, we felt that the responses, while potentially imprecise, could be informative in providing a glimpse of our intervention's impact.

We feel that this is important in our context. We intervened in a poverty stricken community where income and wealth are insufficient. Educational attainment is low and health is poor - Rakai was the center of the HIV/AIDS pandemic in the 1980s and 1990s with high prevalence to this day. For one, saving at Mikwano requires that money to be taken away from another use. For another, we are introducing uncertainty into a world full of uncertainties with little formal or informal insurance.

The survey team was able to connect with 128 of our subjects (88\%). The month of the survey corresponds to twelve months since the completion of Phase 1 and six months since the end of Phase 2. To address (i), we asked them "If you had not deposited money into the Save to Win account, which of the following would you have done with the money?" and asked them to select one of multiple choices. Figure 12 depicts the results.

A slight majority would have saved the money at home. Thus, for these subjects, Mikwano was able to provide a safe place to save and our intervention encouraged it. Given that our subjects do not liquidate after the intervention, this risk mitigation seems to be a big part of our intervention's value. Also, about one-third of the subjects report forgone consumption ${ }^{21}$ Interestingly, for one-sixth of our subjects, we substituted away from using another bank. Since members of the Bethlehem community must travel a distance (without paved roads) to the nearest city to find another bank, our intervention presumably lowered the transaction cost to saving for these subjects.

We also asked our subjects in a multiple choice question what they plan to do with their balances in the future. Figure 13 depicts their responses.

Three-fifths of the respondents plan to further increase their balances, and only $10 \%$ plan to close their accounts. Given that approximately $88 \%$ did not have accounts prior to our intervention, we clearly brought financial inclusion to the community.

\footnotetext{
${ }^{20}$ We also covered the labor costs of the survey.

${ }^{21}$ These responses were split between buying something for one's self and buying something for friends and family.
} 
Figure 12: What would you have done with the money you deposited?

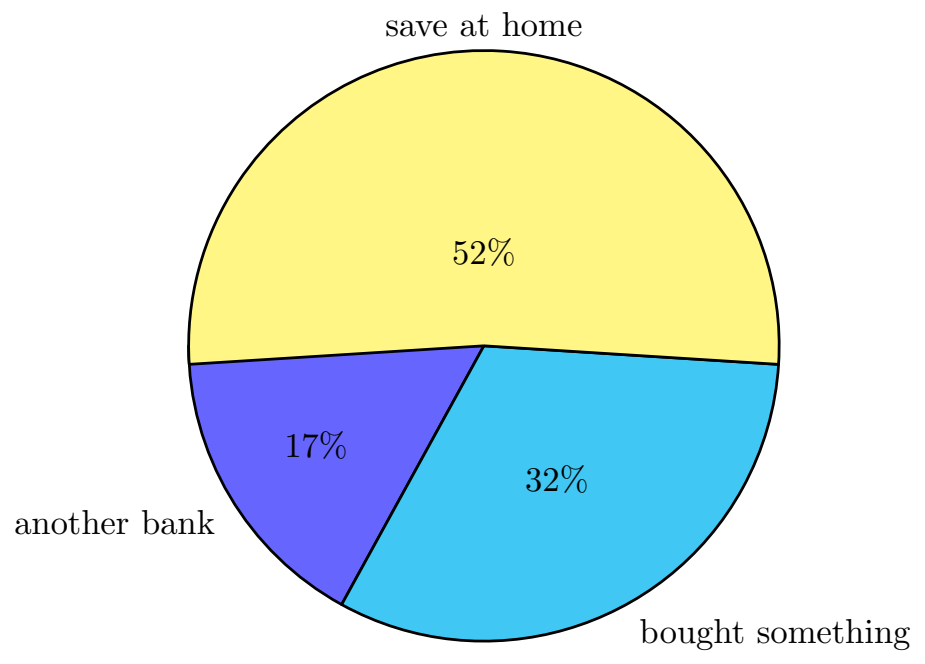

Figure 13: What will you do with your account balance?

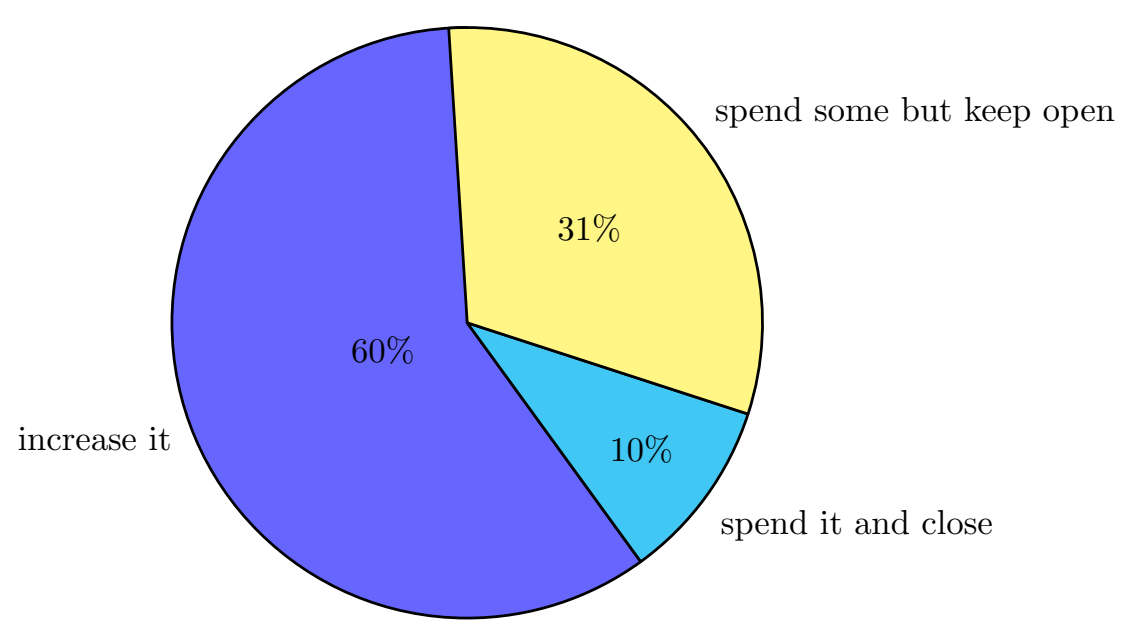


Figure 14: Would you like to participate in Save to Win in the Future?

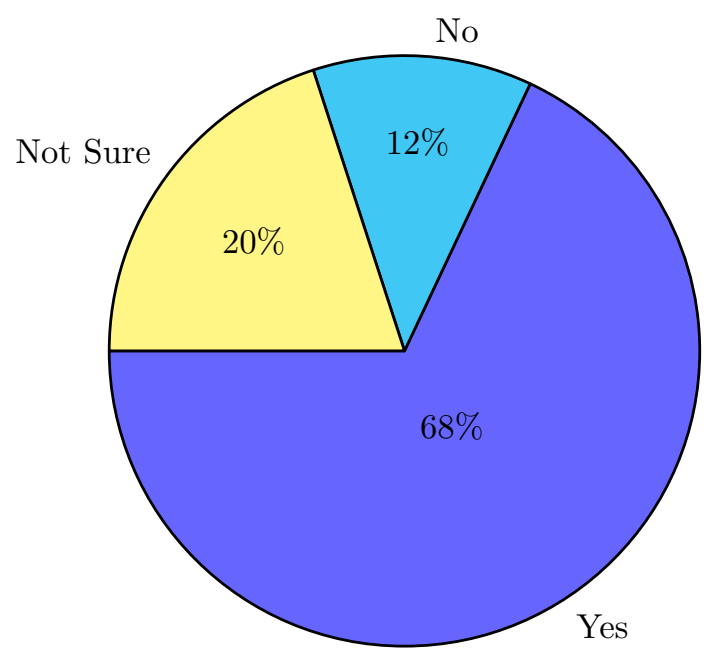

Finally, to gauge utility/satisfaction with the Save to Win program, we asked simple evaluative questions. First, we asked subjects whether they would like to participate in the future if Mikwano was to offer the accounts. Figure 14 depicts their responses.

Only $12 \%$ report that they would not. Therefore, we believe that for the vast majority of the community, our intervention was utility enhancing. Less encouraging, though, is the results from our follow up question asking which treatment they would have preferred to be in. Just over $70 \%$ of the subjects who said they would be willing to participate in the future report a preference for the control (accounts without the contest). No subject prefers the Treatment 3-2, which coincides with the lack of enthusiasm in our previously reported depositing behavior.

Digging further into these responses, interestingly, $75 \%$ of the subjects selected randomly to be in Treatment 3-2 report a preference for having been in the control. On the other hand, $70 \%$ of those chosen to be in the control would have preferred to have the contest included. The grass seems greener on the other side of the fence.

Of those who were selected randomly to be in Treatment 4-1, a noticeable difference in responses arises between those who had the guaranteed minimum prize and those who did not. The proportion who prefer to continue with the contest is $75 \%$ higher for those who had the guarantee than those who did not.

Taken together, this suggests that it is important to design the Save to Win accounts properly. Treatment 3-2 did not inspire savings behavior and generated a dis-satisfaction with the contest linked savings. The guaranteed minimum prize promoted an interest in including the contest, while those who did not get to participate wish they could have.

The divided opinions regarding the Save to Win program did not spill over and diminish participants' views on Mikwano. Figure 15 depicts their assessment of our partner organization.

The community was motivated by the savings product and respond eagerly to opportunities at the microfinance bank we partnered with. 
Figure 15: Future savings at Mikwano?

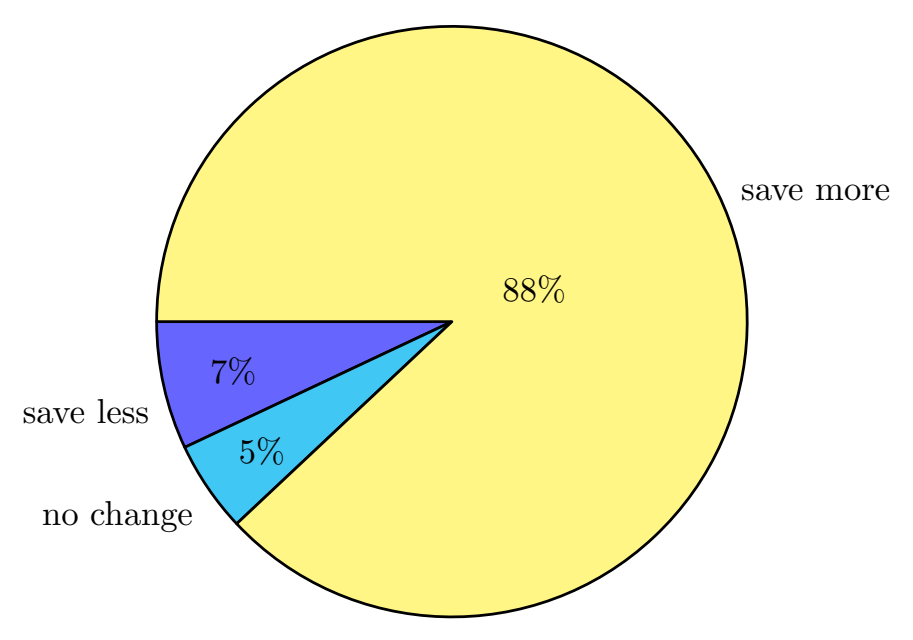

\section{Conclusion}

We develop an innovative mechanism to promote saving in a poverty stricken area of the world. Our insight builds upon the findings in behavioral and experimental economics on contests, which consistently documents an excessive amount of competition in these environments. We link contests to savings in our Save to Win accounts and randomize assignment to them varying the allocation of deposits and the determination of the prize's size. Our intuition is that the motivations that drive excessive competition in contests can be harnessed to promote savings.

Overall, we document an important increase in savings due to our intervention. In all cohorts, savings far exceeds that observed prior to the intervention and by those not currently in our treatments. Second, our control group benefits from the opening balance and high interest rate, but does not get to participate in the savings contest. Those in our treatments also have a portion of their deposits put into a contest. We show that our Save to Win account promotes saving, especially those treated with a guaranteed minimum prize. Third, we establish important and intuitive heterogeneous treatment effects. The introduction of contests promote savings of those who are not risk averse and who are patient. It is not used by those who have recently received microloans and are enjoyed by those who like to gamble. Fourth, we show that our intervention has long lasting effects on savings behavior as average balances actually grow over time.

Our objective was to implement a novel savings mechanism in the field, which was informed by research in behavioral and experimental economics, that can easily be implemented by existing microfinance institutions at a relatively low cost. We are constrained in both sample size and number of treatments by the population size of the community we worked with. Nevertheless, our positive results point the way to a potential valuable intervention for organizations striving to mitigate poverty.

Caution is prudent. Along with concerns about Save to Win's external validity in different communities with contrasting economic, social, legal, and cultural environments, the normative implications are unclear. Undeniably, our intervention built up savings account balances. What is uncertain is what was the opportunity cost of doing so. Given our savings results, we crowded out other forms of savings; especially informal, at-home saving. Thus, our benefit to most may have been mitigation of risk and lowered transaction cost to 
saving. Some report reduced consumption as well. It is unclear what disutilities were experienced so that subjects could engage in our intervention. Our sincere hope is that subjects expect more benefit from this savings than the costs incurred, and that negative spillovers were minimal. A second note of caution is that our treatment effect requires not too much is put into the contest and that a minimum prize is ensured. Thus, the value of Save to Win accounts is sensitive to its design. If our mechanism was to be rolled out and scaled up, further evaluation of the best design parameters and a fuller understanding of the tradeoffs present is necessary and appropriate.

\section{References}

Angelucci, Manuela, Dean Karlan, and Jonathan Zinman (2015), Microcredit Impacts: Evidence from a Randomized Microcredit Program Placement Experiment by Compartamos Banco, American Economic Journal: Applied Economics 7(1): 151-82.

Ashraf, Nava, Dean S. Karlan, and Wesley Yin (2006), Tying Odysseus to the Mast: Evidence from a Commitment Savings Product in the Philippines, Quarterly Journal of Economics 121(2): 635-672.

Atalay, Kadir, Fayzan Bakhtiar, Stephen Cheung, and Robert Slonim (2014), Savings and Prize-Linked Savings Accounts, Journal of Economic Behavior \& Organization 107(A): 86-106.

Attanasio, Orazio, Britta Augsburg, Ralph De Haas, Emla Fitzsimons, and Heike Harmgart (2015), The Impacts of Microfinance: Evidence from Joint-Liability Lending in Mongolia, American Economic Journal: Applied Economics 7(1): 90-122.

Augsburg, Britta, Ralph De Haas, Heike Harmgart, and Costas Meghir (2015), The Impacts of Microcredit: Evidence from Bosnia and Herzegovina, American Economic Journal: Applied Economics 7(1): 183-203.

Baird, Sarah and Craig McIntosh and Berk Ozler (2011), Cash or Condition? Evidence from a Cash Transfer Experiment, Quarterly Journal of Economics 126(4): 1709-1753.

Banerjee, Abhijit and Esther Duflo (2011), Poor Economics: A Radical Rethinking of the Way to Fight Global Poverty, New York: Public Affairs.

Banerjee, Abhijit, Esther Duflo, and Richard Hornbeck. (2014), Bundling Health Insurance and Microfinance in India: There Cannot Be Adverse Selection If There Is No Demand, American Economic Review 104(5): 291-97.

Banerjee, Abhijit, Esther Duflo, Rachel Glennerster, and Cynthia Kinnan (2015), The Miracle of Microfinance? Evidence from a Randomized Evaluation, American Economic Journal: Applied Economics 7(1): $22-53$.

Banerjee, Abhijit, Esther Duflo, and Richard Hornbeck (2014), Bundling Health Insurance and Microfinance in India: There Cannot be Adverse Selection If There Is No Demand, American Economic Review 104(5): 291-297. 
Banerjee, Abhijit, Dean Karlan, and Jonathan Zinman (2015), Six Randomized Evaluations of Microcredit: Introduction and Further Steps, American Economic Journal: Applied Economics 7(1): 1-21.

Besley, Timothy, Stephen Coate and Glenn Loury (1993), The Economics of Rotating Savings and Credit Associations, American Economic Review 83(4): 792-810.

Bryan, Gharad, Dean Karlan, and Jonathan Zinman (2015), Referrals: Peer Screening and Enforcement in a Consumer Credit Field Experiment, American Economic Journal: Microeconomics 7(3): 174-204.

Casini, Paolo (2015), Competitive Microcredit Markets: Differentiation and Ex Ante Incentives for Multiple Borrowing, Oxford Economic Papers 67(4): 1015-1033.

Churchill, Craig (2002), Trying to Understand the Demand for Microinsurance, Journal of International Development 14(3): 381-387.

Cole, Shawn Allen, Benjamin Charles Iverson, and Peter Tufano (2014), Can Gambling Increase Savings? Empirical Evidence on Prize-Linked Savings Accounts, Saïd Business School Working Paper Number 2014-10.

Crépon, Bruno, Florencia Devoto, Esther Duflo, and William Parienté (2015), Estimating the Impact of Microcredit on Those Who Take It Up: Evidence from a Randomized Experiment in Morocco, American Economic Journal: Applied Economics 7(1): 123-50.

D'Espallier, Marek Hudon, and Ariane Szafarz (2013), Unsubsidized Microfinance Institutions, Economics Letters 120(2): 174-176.

Dechenaux, Emmanuel, Roman Sheremeta, Dan Kovenock (2015), A Survey of Experimental Research on Contests, All-Pay Auctions and Tournaments, Experimental Economics 18(4): 609-669.

de Mel, Suresh, David McKenzie, and Christopher Woodruff (2008), Returns to Capital in Microenterprises: Evidence from a Field Experiment, Quarterly Journal of Economics 123(4): 1329-1372.

Dizon, Felipe and Travis J Lybbert (2019), Leveraging the Lottery for Financial Inclusion: Lotto-Linked Savings Accounts in Haiti, Economic Development and Cultural Change, forthcoming.

Dupas, Pascaline, Dean Karlan, Jonathan Robinson, and Diego Ubfal (2018), Banking the Unbanked? Evidence from Three Countries, American Economic Journal: Applied Economics 10(2): 257-297.

Dupas, Pascaline, Anthony Keats, and Jonathan Robinson (2018), The Effect of Savings Accounts on Interpersonal Financial Relationships: Evidence from a Field Experiment in Rural Kenya, Economic Journal 129(617): 273-310.

Dupas, Pascaline and Jonathan Robinson (2013), Why Don't the Poor Save More? Evidence from Health Savings Experiments, American Economic Review 103(4): 1138-1171.

Dupas, Pascaline and Jonathan Robinson (2013), Savings Constraints and Microenterprise Development: Evidence from a Field Experiment in Kenya, American Economic Journal: Applied Economics 5(1): 163192. 
Eckel, Catherine C. and Philip J. Grossman (2002), Sex Differences and Statistical Stereotyping in Attitudes Towards Financial Risk, Evolution and Human Behavior 23(4): 281-295.

Feigenberg, Benjamin, Erica Field, and Rohini Pande (2013), The Economic Returns to Social Interaction: Experimental Evidence from Microfinance, Review of Economic Studies 80(4): 1459-1483.

Feigenberg, Benjamin, Erica Field, Rohini Pande, Natalia Rigol, and Shayak Sarkar (2014), Do Group Dynamics Influence Social Capital Gains Among Microfinance Clients? Evidence from a Randomized Experiment in Urban India, Journal of Policy Analysis and Management 33(4): 932- 949.

Field, Erica and Rohini Pande (2008), Repayment Frequency and Default in Microfinance: Evidence from India, Journal of the European Economic Association 6(2-3): 501-509.

Field, Erica, Rohini Pande, John Papp, and Natalia Rigol (2013), Does the Classical Microfinance Model Discourage Entrepreneurship Among the Poor? Experimental Evidence from India, American Economic Review 103(6): 2196-2226.

Filiz-Ozbay, Emil, Jonathan Guryan, Kyle Hyndman, Melissa Kearney, and Erkut Y. Ozbay, (2015) Do Lottery Payments Induce Savings Behavior? Evidence from the Lab, Journal of Public Economics 126: $1-24$.

Gertler, Paul, Sean Higgins, Aisling Scott, and Enrique Seira (2018), The Long-Term Effects of Temporary Incentives to Save: Evidence from a Prize-Linked Savings Field Experiment, Working Paper.

Hamad, Rita, Lia C.H. Fernald, and Dean S. Karlan (2011), Health Education for Microcredit Clients in Peru: A Randomized Controlled Trial, BMC Public Health 11(1): 51-60.

Kearney, Melissa Schettini, Peter Tufano, Jonathan Guryan, and Erik Hurst (2010), Making Savers Winners: An Overview of Prize-Linked Savings Products, NBER Working Paper No. 16433.

Karlan, Dean and Jonathan Zinman (2011), Microcredit in Theory and Practice: Using Randomized Credit Scoring for Impact Evaluation, Science 332: 1278-1284.

Lusardi, Annamaria and Tufano, Peter (2015), Debt Literacy, Financial Experiences, and Overindebtedness, Journal of Pension Economics Finance 14(4): 332-368.

Linardi, Sera and Tomomi Tanaka (2013), Competition as a Savings Incentives: A Field Experiment at a Homeless Shelter, Journal of Economic Behavior \& Organization 95: 240-251.

McCannon, Bryan C. and Zachary Rodriguez (2019a), The Impact of Microfinance on Pro-Social Behaviors: Experimental Evidence of Public Goods Contributions in Uganda, Journal of Institutional and Theoretical Economics 175(2): 228-257.

McCannon, Bryan C. and Zachary Rodriguez (2019b), A Lasting Effect of the HIV/AIDs Pandemic in Africa: Orphans and Pro-Social Behaviors, Journal of International Development 31(6): 473-520. 
McIntosh, Craig and Bruce Wydick (2005), Competition and Microfinance, Journal of Development Economics 78(2): 271-298.

McIntosh, Craig, Alain de Janvry, and Elisabeth Sadoulet (2005), How Rising Competition Among Microfinance Institutions Affects Incumbent Lenders, Economic Journal 115(506): 987-1004.

Morduch, Jonathan (1995), Income Smoothing and Consumption Smoothing, Journal of Economic Perspectives 9(3): 103-114.

Morduch, Jonathan (2000), The Microfinance Schism, World Development 28(4): 617-629.

Pitt, Mark M. and Shahidur Khandker (1998), The Impact of Group-Based Credit Programs on Poor Households in Bangladesh: Does the Gender of Participants Matter?, Journal of Political Economy 106(5): 958-996.

Servin, Roselia, Robert Lensink, and Marritvan den Berg (2012), Ownership and Technical Efficiency of Microfinance Institutions: Empirical evidence from Latin America, Journal of Banking Finance 36(7): 136-2144.

Sheremeta, Roman M. (2010), Experimental Comparison of Multi-Stage and One-Stage Contests, Games and Economic Behavior 68: 731-747.

Sheremeta, Roman (2018), Impulsive Behavior in Competition: Testing Theories of Overbidding in RentSeeking Contests, Working Paper.

Tedeschi, Gwendolyn Alexander (2006), Here Today, Gone Tomorrow: Can Dynamic Incentives Make Microfinance More Flexible?, Journal of Development Economics 80(1): 84-105.

Tullock, Gordon. (1967), The Welfare Costs of Tariffs, Monopolies and Theft, Western Economic Journal 5: $224-232$.

Tullock, Gordon (1980). Efficient Rent Seeking, In James M. Buchanan, Robert D. Tollison, and Gordon Tullock (eds.), Toward a Theory of the Rent-Seeking Society, College Station, TX: Texas A\&M University Press, 97-112.

Witte, Susan S., Toivgoo Aira, Laura Cordisco Tsai, Marion Riedel, Reid Offringa, Mingway Chang, Nabila El-Bassel, and Fred Ssewamala (2015), Efficacy of a Savings-Led Microfinance Intervention to Reduce Sexual Risk for HIV among Women Engaged in Sex Work: a Randomized Clinical Trial, American Journal of Public Health 105(3):e95-e102.

Yunus, Muhammad (1999), Banker to the Poor: Micro-lending and the Battle against World Poverty, New York: Worth Publishers. 


\section{Appendix}

Table 10 presents a reproduction of the risk assessment used.

Table 10: Risk Assessment

\begin{tabular}{lll}
\hline \hline $\begin{array}{l}\text { Decision } \\
\text { number }\end{array}$ & $\begin{array}{l}\text { Option A } \\
\text { (certain amount) }\end{array}$ & $\begin{array}{l}\text { Option B } \\
(50-50 \text { lottery })\end{array}$ \\
\hline 1 & 1000 & $(1000,0)$ \\
2 & 950 & $(1000,0)$ \\
3 & 900 & $(1000,0)$ \\
4 & 850 & $(1000,0)$ \\
5 & 800 & $(1000,0)$ \\
6 & 750 & $(1000,0)$ \\
7 & 700 & $(1000,0)$ \\
8 & 650 & $(1000,0)$ \\
9 & 600 & $(1000,0)$ \\
10 & 550 & $(1000,0)$ \\
11 & 500 & $(1000,0)$ \\
12 & 450 & $(1000,0)$ \\
13 & 400 & $(1000,0)$ \\
14 & 350 & $(1000,0)$ \\
15 & 300 & $(1000,0)$ \\
16 & 250 & $(1000,0)$ \\
17 & 200 & $(1000,0)$ \\
18 & 150 & $(1000,0)$ \\
19 & 100 & $(1000,0)$ \\
20 & 50 & $(1000,0)$ \\
\hline \hline
\end{tabular}


Figure 16: Treatment Effect Dropping One Subject

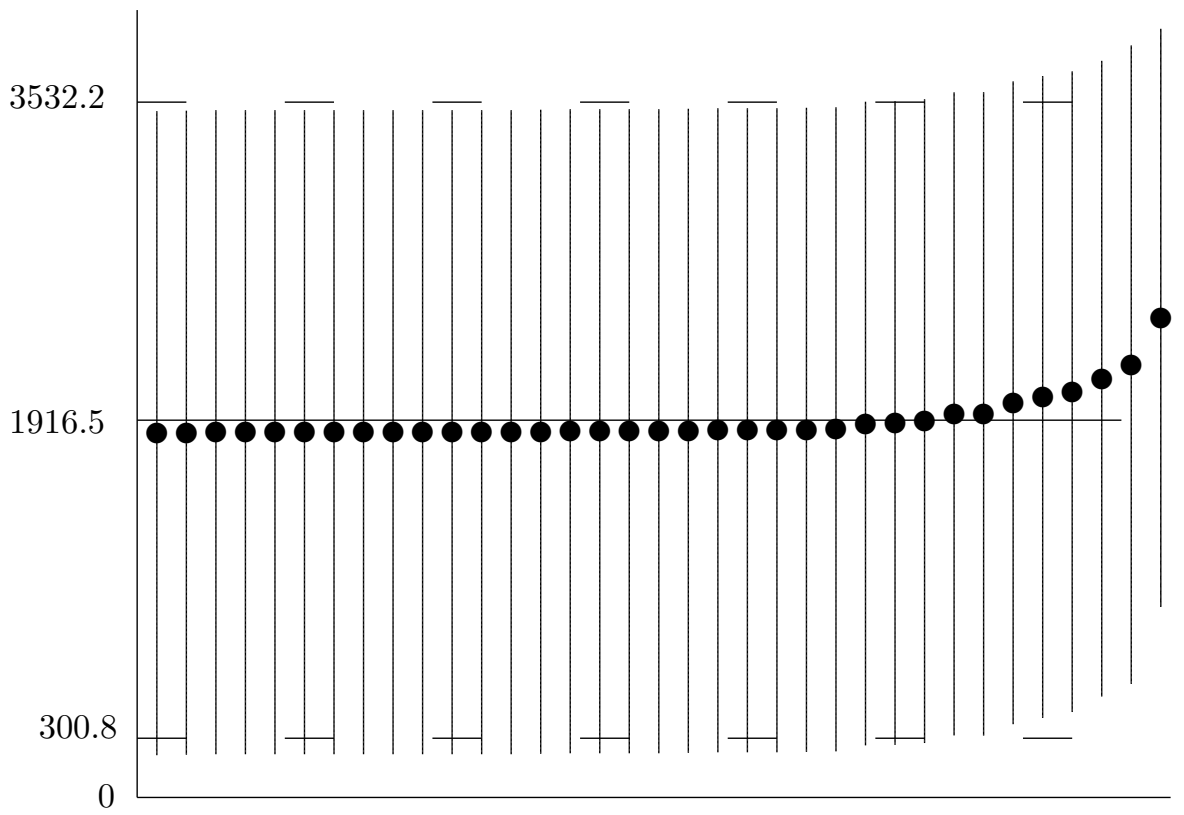

Each circle provides the estimated coefficient on Treatment 4-1, Guarantee from column 2 of Table 2, but dropping one subject from the Control.

The estimates are ordered from the lowest estimated coefficient to the greatest.

The vertical bars depict the $95 \%$ confidence intervals.

The solid line is the estimated coefficient without dropping any other subjects (the one presented in column 2 of Table 2). The dashed lines are the $95 \%$ confidence interval. 
Table 11: Effect of Past Victories

\begin{tabular}{|c|c|c|c|c|}
\hline Dep. Var.= Deposit & (1) & $(2)$ & (3) & (4) \\
\hline Won Last Month & $\begin{array}{l}8795.51 \text { ** } \\
(1710.56)\end{array}$ & $\begin{array}{l}8280.31 \text { *** } \\
(1712.86)\end{array}$ & & \\
\hline Won In the Past & & & $\begin{array}{l}3624.18^{* * *} \\
(993.71)\end{array}$ & $\begin{array}{l}2960.32 \text { *** } \\
(1026.92)\end{array}$ \\
\hline Treatment Indicators Included? & No & Yes & No & Yes \\
\hline$R^{2}$ & 0.030 & 0.047 & 0.015 & 0.030 \\
\hline $\mathrm{AIC}$ & 18165 & 18156 & 18178 & 18171 \\
\hline Dep. Var. $=$ Active & $(1)$ & $(2)$ & $(3)$ & $(4)$ \\
\hline Won Last Month & $\begin{array}{l}0.3174 \text { *** } \\
(0.0919)\end{array}$ & $\begin{array}{l}0.2965^{* * *} \\
(0.0924)\end{array}$ & & \\
\hline Won In the Past & & & $\begin{array}{l}0.1261 \text { ** } \\
(0.0158)\end{array}$ & $\begin{array}{l}0.0990 * \\
(0.0552)\end{array}$ \\
\hline Treatment Indicators Included? & No & Yes & No & Yes \\
\hline$R^{2}$ & 0.014 & 0.022 & 0.006 & 0.014 \\
\hline $\mathrm{AIC}$ & 1058 & 1056 & 1064 & 1063 \\
\hline
\end{tabular}

The variable Won Last Month equals one if the subject won a prize in the previous month. The variable Won In the Past is equal to one if the subject won a prize in any previous month.

Columns (1) and (3) only include the indicator variable and a constant in a linear regression. Columns (2) and (4) also include the three treatment variables (with the control as the omitted, reference group).

\subsection{Proofs from the Theoretical Model}

From complementary slackness, if $\widetilde{s}>0$, then $\frac{d L}{d s}=0$. Rather,

$$
\frac{d J}{d s}-\lambda_{1}+\lambda_{2}\left[(1+i) \tau+(1+i) \frac{d E}{d s}\right]=0
$$

Using the implicit function theorem

$$
\begin{array}{r}
d s\left[\frac{d^{2} J}{d s^{2}}-\frac{d \lambda_{1}}{d s}+\frac{d \lambda_{2}}{d s}\left[(1+i) \tau+(1+i) \frac{d E}{d s}\right]+\lambda_{2}(1+i) \frac{d^{2} E}{d s^{2}}\right]+ \\
d \tau\left[\frac{d^{2} J}{d s d \tau}-\frac{d \lambda_{1}}{d \tau}+\frac{d \lambda_{2}}{d \tau}\left[(1+i) \tau+(1+i) \frac{d E}{d s}\right]+\lambda_{2}\left[(1+i)+(1+i) \frac{d^{2} E}{d s d \tau}\right]=0\right.
\end{array}
$$

Since $\lambda_{1}$ and $\lambda_{2}$ are the equilibrium values, it follows that $\operatorname{fracd} \lambda_{1} d s=f r a c d \lambda_{2} d s=0$. Therefore,

$$
\frac{d s}{d \tau}=\frac{\frac{d^{2} J}{d s d \tau}-\frac{d \lambda_{1}}{d \tau}+\frac{d \lambda_{2}}{d \tau}\left[(1+i) \tau+(1+i) \frac{d E}{d s}\right]+\lambda_{2}\left[(1+i)+(1+i) \frac{d^{2} E}{d s d \tau}\right.}{-\frac{d^{2} J}{d s^{2}}-\lambda_{2}(1+i) \frac{d^{2} E}{d s^{2}}}
$$


It follows that $\frac{d^{2} E}{d s^{2}} \leq 0$ for the guaranteed minimum prize and equal to 0 for the zero-sum prize. Paired with assumption (1), the denominator of (9) is positive. Hence, the sign of $\frac{d s}{d \tau}$ is the sign of its numerator.

It is straightforward to show that $\frac{d^{2} E}{d s d \tau}<0$ for both determinations of the prize. Hence, assumption (2) ensures that for smaller values of $\tau$ the numerator is positive, while for larger values of $\tau$ the numerator is negative. This verifies Hypothesis 1.

Furthermore, assumption (3), then, ensures that the value of $\tau$ which makes the numerator zero is greater for individuals with a greater degree of risk aversion, $\theta$. This verifies Hypothesis 2. 


\section{The Demand For Microfinance: Effects of India's Employment Guarantee on Credit and Savings}

Moral hazard, adverse selection, and small transaction amounts limit the possibilities for traditional banks to operate profitably in poor communities. It is within this lack of services that microfinance operates. By targeting these under-banked communities and offering low-interest credit and savings mobilization, microfinance institutions act as mechanism to release the productive capacities of households dependent on self-employment (Morduch, 2017). In 2018, 139.9 million clients benefited from microfinance worldwide, with large portions of those beneficiaries being women and rural households (Microfinance Barometer, 2019).

At its outset, microfinance was synonymous with microcredit, which offers small loans with lower than market interest rates to individuals and groups. Muhammad Yunus pioneered this model of microfinance through his work with the Grameen Bank (Yunus, 1999). Working with groups of women in rural Bangladesh, Yunus used a "group-lending" model that provides access to financial markets by spreading the default risk and responsibility of repayment across group members. Organizations and governments quickly adopted the Grameen model and implemented these banks in rural communities around the world. Numerous empirical studies identify important benefits to microcredit. Access to credit can boost business performance (Banerjee et al., 2017), increase daily wages and household earnings (Banerjee, Karlan, and Zinman, 2015; Breza and Kinnan, 2018), and improve both health outcomes (Montalvao et al., 2013; Karlan et al., 2017) and subjective well-being (Karlan and Zinman, 2011).

Savings products were not offered by many early microfinance initiatives, as their initial target clientele were entrepreneurs. The addition of savings with microcredit changed the focus of microfinance from entrepreneurs to the financial services for households (Churchill, 2002). Empirical research documents positive effects from microfinance savings mobilization activities like increased income and investments in household public goods (Schaner, 2016), female empowerment in the household (Anderson and Baland, 2002; Duflo, 2012), lower education expenditures (Karlan and Linden, 2014), and reduced risky sexual behavior (Witte et al., 2015).

While empirical results support the benefits of microfinance products, demand for microfinance remains unclear. Many empirical studies of microfinance analyze its demand as if income and consumption remain constant in the household. Thus, these results analyze demand in terms of access to microfinance. Yet, we know that as incomes fluctuate, households change their savings and borrowing behavior (Baker, 2018). We would then expect the demand for microfinance to change as household incomes change. Income changes can affect households negatively, like unemployment, or positively, like increased wages through private rather than self-employment. As a contribution to the literature, I offer a novel approach to measuring the demand for microfinance by using data from both the Mahatma Gandhi National Rural Employment Guarantee Act (hereafter "MGNREGA") and the National Bank For Agriculture And Rural Development ("NABARD") to estimate the causal impact of changes to income on the use of microfinance in India.

I use an established identification strategy (Imbert and Papp, 2014) to causally estimate district-level demand for credit and savings, as tracked by NABARD, given increases to income through participation in the MGNREGA employment guarantee program. The quasi-experimental roll-out of the MGNREGA program allow for the use of a difference-in-differences panel fixed effect regression model to estimate the demand for microfinance. Results show that as uptake for the employment guarantee program increases, so also increases the number of credit-linked self-helps groups and the amount of credit disbursed to these groups. This suggests that households who use MGNGREA are more likely to engage in credit activity. Similar 
effects are found for savings activity, as uptake of the employment guarantee program causes an increase in the number of savings-linked self-helps groups, members in self-help groups, and the amount saved by these groups. A likely reason that credit and savings activity increase together is that, by design, NABARD savings self-help group must accumulate capital above a given savings threshold, in order to both open a savings account and disburse loans across groups members. Testing this effect given both access to MGNREGA employment (extensive margin) and uptake of MGNREGA employment (intensive margin) indicates that the effects occur given uptake of MGNREGA and are not simply driven by access to employment in a district. Measuring demand for financial services as household income increases through MGNREGA aligns with a large literature on the positive spillovers of employment on rural economies (Haggblade et al., 2010). A novel feature of my results is that I support numerous field experiments that measure the positive effects of microfinance on income and employment, but through the reversed channel, as my results indicate that the demand for microfinance increases given growth to household income through MGNREGA employment.

While I document how income growth causes demand for financial services, the mechanism of demand remain unclear. Possible mechanism identified in the literature on microfinance include households using financial services to smooth consumption, while another is that households use these services to take entrepreneurial risks and invest in the household. I investigate the mechanism of demand by analyzing annual district rainfall conditions. If we detect our main results in times of adverse weather, which we would identify in the tails (droughts and floods) of the distribution of annual rainfall across districts, then this would suggest that the character of demand is one of poverty alleviation. However, if our main effects concentrate in times of average rainfall, then the character of the demand for microfinance appears entrepreneurial, as households engage in credit and savings activities in times of relative household stability. Analysis of adverse weather shocks suggests that uptake of MGNREGA employment during droughts decreases the demand for microfinance, while average rainfall conditions and floods lead to an increase in both credit and savings activity. While increasing in both, demand for microfinance is highest during times of average rainfall, which suggests that households use microfinance during times of relative stability, and not as a "safety net" mechanism.

The paper begins by providing an overview of poverty alleviation initiatives in India in Section 2. Sections 3 and 4 explain the data and empirical strategy, respectively, and Section 5 offers the results of the analysis. Section 6 explores heterogeneous effects on the demand for microfinance and Section 7 concludes.

\section{Literature Review}

Informal banking mechanisms have always existed in communities, particularly communities that lack financial institutions. Collins et al. (2009) analyze household financial diaries from Bangladesh, India and South Africa, finding that households maintain high cash flows through a mixed use of informal financial instruments relative to their net income ${ }^{22}$ A concern among scholars is that microfinance crowds out these informal banking mechanism, often due to misperceptions about the informal lending market. While claims of high interest rates and ruthless moneylenders make a compelling story of microfinance, studies indicate that informal debt is often facilitated through neighbors and family members and it is not until households meet pressing consumption needs that they turn to moneylender loans (Cull et al., 2009).

Given the informal banking mechanisms available to households, microfinance does provide several benefits to households under sudden shocks to consumption. Studies have looked at the effects of negative income

\footnotetext{
${ }^{22}$ Shankar (2013) explains that the over 250 diaries analyzed indicate between 80 and 300 percent more cash turnover occurs through informal financial instruments relative to household net income.
} 
shocks on microfinance clients either caused by illness (Gertler et al., 2009), agricultural shocks (Kochar, 1999; Gaurav, 2015), or natural disaster (Becchetti and Castriota, 2009). In these situations, evidence suggests that microfinance is a useful mechanism to meet household needs in times of financial vulnerability. As these results indicate, access to savings and credit can smooth consumption (Samphantharak and Townsend, 2009), but this access remains largely limited to high income households. I contribute to this literature by documenting an increase in the demand for microfinance given growth to household income. Further, I identify entrepreneurship as a possible mechanism of demand, given that demand concentrates in times of average rainfall conditions, relative to droughts and floods.

How to make microfinance available and encourage its use within communities has been the subject of numerous empirical studies. Target populations of microfinance initiatives typically include rural farmers, women, and small-scale entrepreneurs. Individuals often engage with microfinance either for investments in the households (Karlan and Valdivia, 2011) or for insuring against possible risk (Barnett and Mahul, 2007). Investments from microfinance have shown to have positive effects on many aspects of the household. From increases in income, business revenue, and financial literacy rates to improved fertility rates, nutrition, and levels of education, microfinance provides opportunities to households that did not exist previously.

Much of the research on the demand for microfinance explores the demand for specific financial products. Products like interest-free loans (Kaleem and Ahmed, 2009), flexible repayment schedules (Meyer, 2002), fixed deposit savings (Ashraf et al., 2006), as well as bundled financial products with health insurance (Banerjee et al., 2014) and improved sanitation services (Davies et al., 2008) have been offered to measure the demand for microfinance within communities. Demand in these contexts refers to specific products, which introduces problems of replication (Hermes and Lensink, 2011) and limits the generality of results across communities.

I contribute to this literature by analyzing the demand for microfinance using data collected from the NABARD Self-Help Group - Bank Linkage Program that provides financial services to underserved households throughout India. The program represents a decentralised, cost effective microfinance initiative, successfully facilitating access to financial services for over 103 million households across India 23 The self-help groups monitored by NABARD represent about $55 \%$ of total self-help groups in the country, the rest remaining unlinked to a third-party financial institutions (A Handbook on SHG - Bank Linkage Program, 2017). For this study, I collect information on the savings an credit activity of self-help groups provided in the annual The Status of Microfinance report published by NABARD. Others have used this data collected from NABARD to analyze access to microfinance (Laha and Kuri, 2014), as well as financial inclusion and gender (Swamy, 2014).

How low-income households demand microfinance given positive changes to their income remains understudied. This not for want of trying, as it is difficult to find empirical environments where low-income households suddenly gain access to other sources of income. For this reason, several studies measure potential demand based on household characteristics (Khandker, 2005; Guangwen, 2008), and project how households may use microfinance, given their income, education, and landholding. As a novel contribution to the literature, my analysis measures the demand of microfinance, as determined by changes in income from uptake of the world's largest employment guarantee program, MGNREGA, in India.

India provides a unique context to study the demand for microfinance, as it has a long history of social welfare initiatives aimed at reducing poverty. Studies over the past 20 years have documented the positive effects of microfinance on poverty reduction in India (Imai et al., 2010). Other documented social welfare

232017-18 Status of Mircofinance 
improvements from microfinance in India include female empowerment (Rai and Ravi, 2013), increased entrepreneurship (Field et al., 2013), home improvement (McIntosh, Villaran, and Wydick, 2011), and decision-making agency (Holvoet, 2005). Given this evidence, studying the demand for microfinance in light of changes to income is appropriate in this context, as households have had at least exposure, if not access, to microfinance due to its proliferation around India.

\section{Data and Setting}

\subsection{NABARD and the Self-Help Group Model}

It was in Bangladesh that Muhammad Yunus pioneered the use of microcredit with the Grameen Bank (Yunus, 1999) in 1976. The influence of Grameen Bank encouraged India, and in particular, NABARD to develop and test models of financial services that could reach rural, unbanked populations. In 1992, NABARD started the Self-Help Group - Bank Linkage Program to provide financial services to underserved households throughout India. The NABARD linkage program is considered one of the largest microfinance efforts in terms of clientele and outreach in the world 24 Besides establishing links between banks and self-help groups, NABARD offers training seminars to officials of banks, non-profit organizations, and government agencies to enhance their efficacy in the microfinance sector. These seminars focus on teaching people on how to go into villages and form self-help groups. Encouraging practices like regular site visits, contract development, and financial literacy has made the program successful in reaching over 11 million households across India 25

The bank linkage program functions by connecting commercial, regional, and cooperative banks and nongovernment organizations with rural, poor groups of about 10-15 individuals. These groups are encouraged to meet frequently and pool their savings, so that they can open a savings account, as many people do not have enough savings to open an account on their own (Bansal, 2003). NABARD tracks the success and growth of self-help groups through its Status of Microfinance report, which has been published since 2000. As its focus was on microcredit at its creation, early NABARD reports focus only on credit activities at the state and district level across India. In 2006, NABARD started tracking savings-linked, self-help groups, which are separately tracked from credit-linked, self-help groups. Two institutions through which NABARD forms self-help groups are district cooperative banks and non-government organizations. Each of these entities work on a grassroots level to establish, develop, and connect self-help groups to banks. In their reporting, NABARD tracks the number of groups established annually through its various partner agencies: commercial banks, regional rural banks, cooperative banks, and non-profit organizations. Also, NABARD records the amount disbursed as credit, as well as, the amount saved by self-help groups per institution.

In this analysis, I focus on both credit and savings self-help groups linked to district cooperative banks and NGOs starting in 2002 and going until 2017, as NABARD collects information from these institutions annually. This level of detail allows for a comparison to MGNERGA, which also collects information at the district level ${ }^{26}$ The number of credit self-help groups and the loans disbursed to groups will be my credit outcome variables. For savings, NABARD collects information regarding self-help groups membership, number of groups, and annual group deposits. NABARD does not collect information regarding credit-linked self-help group membership, which is why I focus my analysis of credit at the group level. An important

\footnotetext{
${ }^{24}$ MicoCredit Innovations Department, NABARD

${ }^{25}$ Status of Microfinance 2017-18

${ }^{26}$ MGNREA reports annual program use at the national, state, district, and block levels.
} 
facet of the data is its missing observations. Throughout the 15 years of data starting in 2002 and going until 2017, a number of districts inconsistently report the number of self-help groups over time ${ }^{27}$ These missing observations present a limitation to the data provided by NABARD.

Table 12: Comparison of Microfinance Outcomes in Districts Across Phases

\begin{tabular}{llll}
\hline \hline & Phase1 $\mu$ & Phase2 $\mu$ & Phase3 $\mu$ \\
Credit-linked SHGs & $768^{* * *}$ & $853^{* * *}$ & 497 \\
Credit Disbursed to SHGs (in Rs. Lakh) & 303.49 & 390.21 & 369.49 \\
Savings-linked SHGs & & $4,233^{* * *}$ & 2,588 \\
Savings SHG Membership & & $41,688^{* * *}$ & 30,577 \\
Amount Saved by SHGs (in Rs. Lakh) & & $586.45^{* * *}$ & 270.99 \\
\hline
\end{tabular}

I use a paired t-test to separate our sample into two comparable samples: Phase 1 districts vs. Phase 3 districts and Phase 2 districts vs. Phase 3 districts. A paired t-test acknowledges that these observations are dependent on on another. We report the two-tailed p-value; ${ }^{* *} 1 \%, * * 5 \%, * 10 \%$ level of significance.

Early districts, i.e. Phases 1 and 2, appear to differ from late districts in their microcredit activity. Given the similar difference in uptake of MGNREGA, it is likely that early districts include higher populations of households who are targeted by anti-poverty programs (Imbert and Papp, 2016). Also, it is likely that early districts were selected based on variables that are correlated with the anti-poverty initiatives set out by NABARD. Thus, comparing the districts may not reveal the full impact of MGNRGEA on microfinance. To delve deeper into how households use of microfinance given the roll out of MGNREGA, I use a difference-indifferences framework to analyze the causal impact of MGNREGA on microfinance over time across districts.

Several studies analyze self-help groups, while focusing their scope of analysis to particular states or districts within states in India. Karuppannan (2012) provides a literature review of 53 such studies conducted from 2000-2012. The review identifies positive trends in poverty alleviation and economic well-being across Indian states. Many of these focused studies find self-help group membership has positive effects on female empowerment and community development (Swain and Wallentin, 2009; Desai and Joshi, 2013), healthcare seeking behavior (Raza, et al., 2016), and long-term consumption and asset accumulation (Deiniger and Liu, 2013). I contribute to this literature by providing a comprehensive evaluation of self-help group formation and activity across and within districts in India, given positive changes to household income.

\subsection{The Mahatma Gandhi National Rural Employment Guarantee Act 2005}

The Mahatma Gandhi National Rural Employment Guarantee Act ("MGNREGA") passed in September 2005. The act entitles any household in rural India up to 100 days of employment for members who are willing to do unskilled, manual labor (Imbert and Papp, 2014). If workers demand employment and they are not granted work within 15 days, then they are entitled to unemployment allowance. Funding for MGNREGA comes from both the central and state governments. The central government provides $100 \%$ of the wages and $75 \%$ of the material costs for MGNREGA projects undertaken by Indian states (Padma, 2015). State governments provide $25 \%$ of the material costs, and $100 \%$ of unemployment allowances, which is approximately $50 \%$ of an insured worker's daily average earnings. Over 52 million rural households were provided with 2.6 billion person-days of employment in FY 2018-2019 (MGNREGA At a Glance, 2018). These statistics make MGNREGA the largest workforce program in the world.

\footnotetext{
${ }^{27}$ This could occur, for example if there were no changes to microfinance activity in the district.
} 
To obtain employment, adult household members register with the gram panchayat, which is the village council within a district (MGNREGA Operational Guidelines, 2013). After submitting the necessary documents, the gram panchayat issues a job card to household members. Registered workers then submit applications for work to the gram panchayat. Employment is to be provided at a minimum of fourteen days of continuous work and within a radius of $5 \mathrm{~km}$ of the panchayat. Extra wages are given to employment that is beyond the $5 \mathrm{~km}$ radius. The Ministry of Rural Development collects detailed information regarding number of job cards, workers expenditure details, work details, and worker account details. We are able to analyze this information because the Ministry of Rural Development makes all employment information publicly available.

The roll-out of the program received global attention as the MGNREGA Planning Commission worked to balance the access to employment equally across India. The Commission identified and ranked districts across states according to their agricultural wages, proportions of scheduled castes and schedule tribes, and agricultural output per-worker. Districts in the highest need of employment according to this identification were placed in Phase 1, the next highest were placed in Phase 2, and the remaining districts in India were included in Phase 3. The Commission implemented MGNREGA for 200 Phase 1 districts in February 2006, then 130 more districts in April 2007, and finally all remaining districts in April 2008.

MGNREGA has made an impact outside of providing financial security for rural households. Studies have found that MGNREGA public sector hiring crowds out private sector work and increases private sector wages (Imbert and Papp, 2014; Berg et al., 2018), increased schooling for younger children and increased child labor for older children (Islam and Sivaskankaran, 2015), and decreases crime in district with higher levels of MGRNEGA uptake (Das and Mocan, 2016). Crasweel and De Deve (2014) identify other positive outcomes like increased rural wage levels, enhanced low-caste working bargaining power, and reduced dependence on high-caste employers. Kumar and Joshi (2013) further identify increased steadiness to household consumption and higher nutritional security.

Yet, several criticism have been levied against MGNREGA with regards to untimely payments for work and lack of available employment. Chopra (2015) and Das, Singh, and Mahanto (2012) analyze specific states, Rajasthan and West Bengal, respectively, and document how participation may be low in areas due to a lack of awareness in how MGNREGA operates. This lack of information contributes to administrative corruption, and ultimately, households not receiving MNGREGA benefits. Others studies, like Shah (2016), argue for broader consequences of MGNREGA and its effects on the agricultural industry, as farmers move away from their farms for the benefits of the employment guarantee, thus making agriculture less productive. With its criticisms, rural households continue to use MGNERGA, and therefore, its effects on rural households is both policy relevant and socially significant. The following section describes the data collected from both NABARD and MGNREGA in my analysis of the demand for microfinance in India.

Information regarding uptake of MGNREGA is tracked and made public by the Ministry of Rural Development. Uptake of MGNREGA is tracked in terms of the annual number of jobs per village, district, and state, in terms of worker-days generated, as the program works by offering 100 days of employment per rural household. Like Das and Mocan (2016), I calculate the intensity of the MGNREGA program by dividing the total number of worker days generated in each district by the number of rural households. Given the intention of the program, I exclude some districts from my analysis. Urban districts were not included in the roll-out of MGNREGA and so I omit these district from my analysis. Following Das and Mocan (2016), I exclude northeastern states except for Asaam, as these states benefit from other funding from the central government as part of other programs. I also exclude the Union Territories, as the governance follows a 
different structure to other states and Maharashtra because it has had its own rural employment guarantee scheme since 1977. Finally, I drop divided or newly established districts between 2002-2017. Thus, of the 624 districts in India, my sample includes 144 Phase 1 districts, 85 Phase 2 districts, and 162 Phase 3 districts, for a total of 391 districts.

Table 13: Comparison of MGNREGA Uptake by Rural Household Across Phases

\begin{tabular}{cl}
\hline \hline Job Days Per Rural Household & \\
Phase 1 & $17.12^{* * *}$ \\
Phase 2 & $12.05^{* * *}$ \\
Phase 3 & 11.13 \\
\hline
\end{tabular}

I use a paired t-test to separate our sample into two comparable samples: Phase 1 districts vs. Phase 3 districts and Phase 2 districts vs. Phase 3 districts. A paired t-test acknowledges that these observations are dependent on on another. We report the two-tailed p-value; *** $1 \%, * * 5 \%,{ }^{*} 10 \%$ level of significance.

\subsection{Controls}

The Ministry of Health and Family Welfare and the International Institute of Population Sciences conduct the district level household and facility survey to collect information regarding the health and well-being of all 611 districts in India. The survey has been carried out in four rounds, starting in 1998-99, 2002-04, 2007-08, and 2012-13. I also connect these survey questions to those collected as part of the USAID demographic and health survey collected in 2015-16. Questions regarding household living conditions, gender composition, tribe and caste composition, and literacy are comparable across surveys. As in Imbert and Papp (2015) and Das and Mocan (2016), I interpolate data across surveys and survey rounds to construct controls for my empirical analysis so as to capture demographic and social changes in districts over time. Table 14

Table 14: Comparison of Control Variables Across Phases

\begin{tabular}{llll}
\hline \hline & Phase1 $\mu$ & Phase2 $\mu$ & Phase3 $\mu$ \\
Rural households by population & $627.20^{* * *}$ & 612.52 & 598.59 \\
Population density $\left(\right.$ per km $\left.{ }^{2}\right)$ & 0.166 & $0.309^{* * *}$ & 0.171 \\
Percentage scheduled caste & 0.780 & 0.736 & 0.818 \\
Percentage scheduled tribe & $0.032^{* * *}$ & $0.104^{* * *}$ & 0.226 \\
Literacy rate & $43.89^{*}$ & $43.53^{*}$ & 45.95 \\
Average Rainfall (in mm) & $1,143^{* * *}$ & $1,217^{* * *}$ & 1,047 \\
\hline
\end{tabular}

We use a paired t-test to separate our sample into two comparable samples: Phase 1 districts vs. Phase 3 districts and Phase 2 districts vs. Phase 3 districts. A paired t-test acknowledges that these observations are dependent on on another. We report the two-tailed p-value; *** $1 \%,{ }^{*} 5 \%, * 10 \%$ level of significance.

\section{Empirical Strategy}

The empirical strategy for this study is possible through the efforts of the MGNREGA Planning Commission to balance the spread of employment across states. Access to MGREGA was implemented and made available to districts over three distinct phases from April 2006 to January 2008. Sukhtankar (2016) provides a literature review of the various empirical strategies used by researchers to measure the effects of 
MGNREGA. A difference-in-differences framework is most commonly used for analysis of MGNREGA, as the approach measures level differences between phases of the roll-out. An important assumption of this approach requires that the outcomes being tested follow similiar pre-trends before MGNREGA was accessible in a district, otherwise we cannot be sure that any effects found are due to the implementation of MGNREGA. I econometrically test trends in my microfinance outcomes to confirm the parallel trend assumption. Using a simple regression, my outcome variables show pre-trend differences across any MGRNEGA implementation phases. These results can be found in Table 32 of the Appendix. Another threat to identification could be that households migrate across districts to take advantage of the program. Das (2015) and Imbert and Papp (2016) identify reductions in short-term or seasonal labor migration to urban areas, thus addressing this concern.

MGNREGA and its effects on districts and households have been analyzed in terms of employment and wages (Imbert and Papp, 2014; Berg et al., 2018), schooling and child labor (Islam and Sivaskankaran, 2015), labor migration (Imbert and Papp, 2016) and crime (Das and Mocan, 2016) using this differencein-differences framework. Each study exploits the roll-out of MGNEGRA to compare its effects on various outcomes across districts. Like these studies, I exploit the gradual implementation of the roll-out to estimate of the causal impact of MGNREGA on microfinance outcomes.

Figure 31 highlights the differences in timing of MGNREGA across districts. The roll out of MGNREGA across districts appears to be balanced across phases and states in Figure 31 . Since the intention of the Planning Commission was to affect more impoverished districts with access to guaranteed employment, comparing our microfinance outcomes and controls across districts can provide cursory evidence of how MGNREGA affected households.

Figure 17: The National Rural Employment Guarantee Act 2005

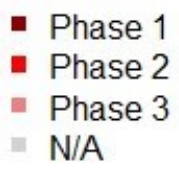

- Phase 1

- Phase 2

- N/A

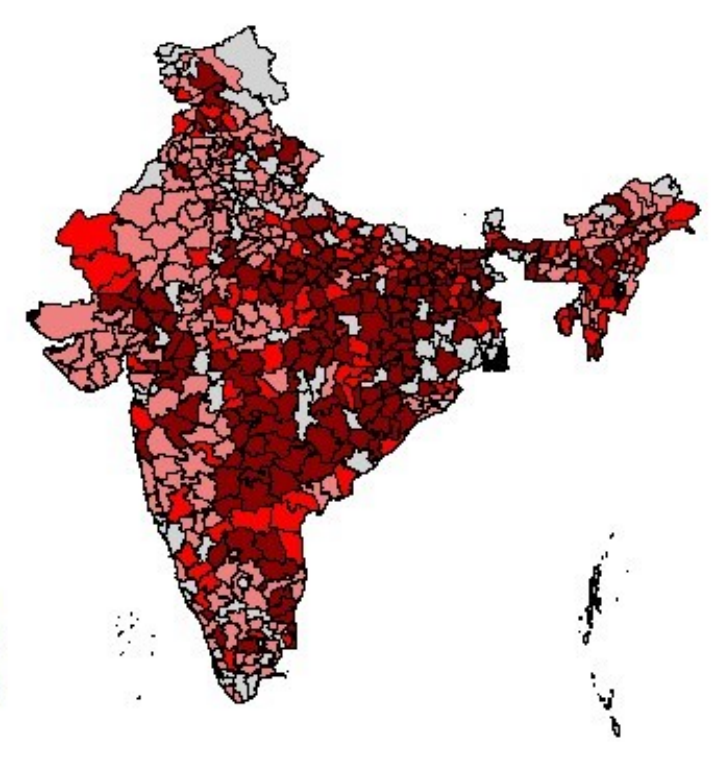




\subsection{Regression Framework}

Since I know both when the MGRNEGA is made available in a district and the use of microfinance across districts, I can perform both an intent-to-treat and treated-on-treatment difference-in-differences test on my microfinance outcomes variables. These levels of analysis provide insight into how both access and uptake of MGNREGA affects the use of microfinance. Estimates for the intent-to-treat effect on the demand for microfinance is based on the following equation:

$$
\text { microfinance }_{i d t}=\beta_{0}+\beta_{1} M G N R E G A_{i t}+\lambda X_{d t}+\sigma_{t}+\mu_{d}+\epsilon_{i d t} .
$$

I estimate the intent-to-treat effect using an indicator variable, $M G N R E G A_{d t}$, that indicates when a district gains access to the program. I include controls, $\lambda X_{i t}$, to capture differential changes across districts. These controls are caste composition, agricultural output per worker, levels of education, gender, and population density. I choose these controls based on what the MGNREGA Planning Commission preprogram measures (Imbert and Papp, 2015). $\sigma_{t}$ and $\mu_{d}$ represents time and district fixed effects, respectively. The district fixed effects account for any time-invariant factors that may affect microfinance activity at the district level and the time fixed effects account economic flutuations over time. $\epsilon_{i d t}$ is our error term. Estimates for the treatment effect of MGNREGA on the demand of credit-linked self-help groups is based on the following equations:

$$
\text { microfinance }_{i d t}=\beta_{0}+\beta_{1} M G N R E G A_{i t}+\beta_{2} M G N R E G A_{i t} \times J o b s_{i t}+\lambda X_{d t}+\sigma_{t}+\mu_{d}+\epsilon_{i d t} .
$$

Following Das and Mocan (2016), the main difference in the specification of equation 2 is the addition of $J o b s_{d t}$, which interacts the number of jobs days generated in a district with the indicator variable, $M G N R E G A_{d t}$, to estimate the effect on microfinance activity given the uptake of MGNREGA in a district. Equation 2 contains the same controls variables and fixed effects. The interaction of the uptake of jobs in

a district provides a treated-on-treatment estimate, which indicates the effect of increased income on the demand for microfinance in a district.

The following section describes my main results regarding the effect of increased income from MGNREGA uptake on microfinance. First I estimate the intent-to-treat effect or the effect that access to MGNREGA has on the use of microfinance. After this, I analyze the treatment-on-treated effect which is interaction of the intensity of job days in a district with the use of microfinance after MGNREGA is accessible in a district.

\section{Results}

The following section describes the results from my analysis of MGNREGA employment on microfinance. I present my main results in two subsections that explain the effects of MGNREGA on credit and savings separately. In the subsections on credit and savings, I provide estimations of both the intent-to-treat, and then my main results, the treatment-on-treated effects of MGNREGA on microfinance. I conclude each subsection with a quantile regression analysis of my main results to investigate confirm that the effect of MGNREGA on microfinance is consistent as the concentration of microfinance increases across districts.

\subsection{Effects of MGNREGA Employment on Microcredit}

First, I exploit the differences in when district households gain access to MGNREGA as a measurement of an intent-to-treat effect on the demand for microcredit. Effects at this level of analysis measure MGNREGA 
as a policy, and how households use microfinance when opportunity costs to other means of income decrease. Figure 18 considers the demand for microcredit after MGNREGA is implemented in a district. Since we do not know how many jobs are being generated in each district over time, we can think of Figure 18 as presentation the effects of MGNREGA on microcredit at the extensive margin. Looking at the effects across phases, demand for microcredit appears to increase after MGNREGA is made available in districts. The biggest increase occurs in Phase 1 districts as the average number of credit self-help groups jumps from 271 to 486 after MGNREGA is available, which suggest a meaningful change communities in Phase 1 districts. The changes after implementation of MGNREGA are strongest for Phases 1 and 2, which indicates that MGNREGA had an effect on the demand for microcredit, given that access to employment in these districts was sooner relative to Phase 3.

Figure 18: Pre and Post Comparison of Credit Self-help Groups across Phases

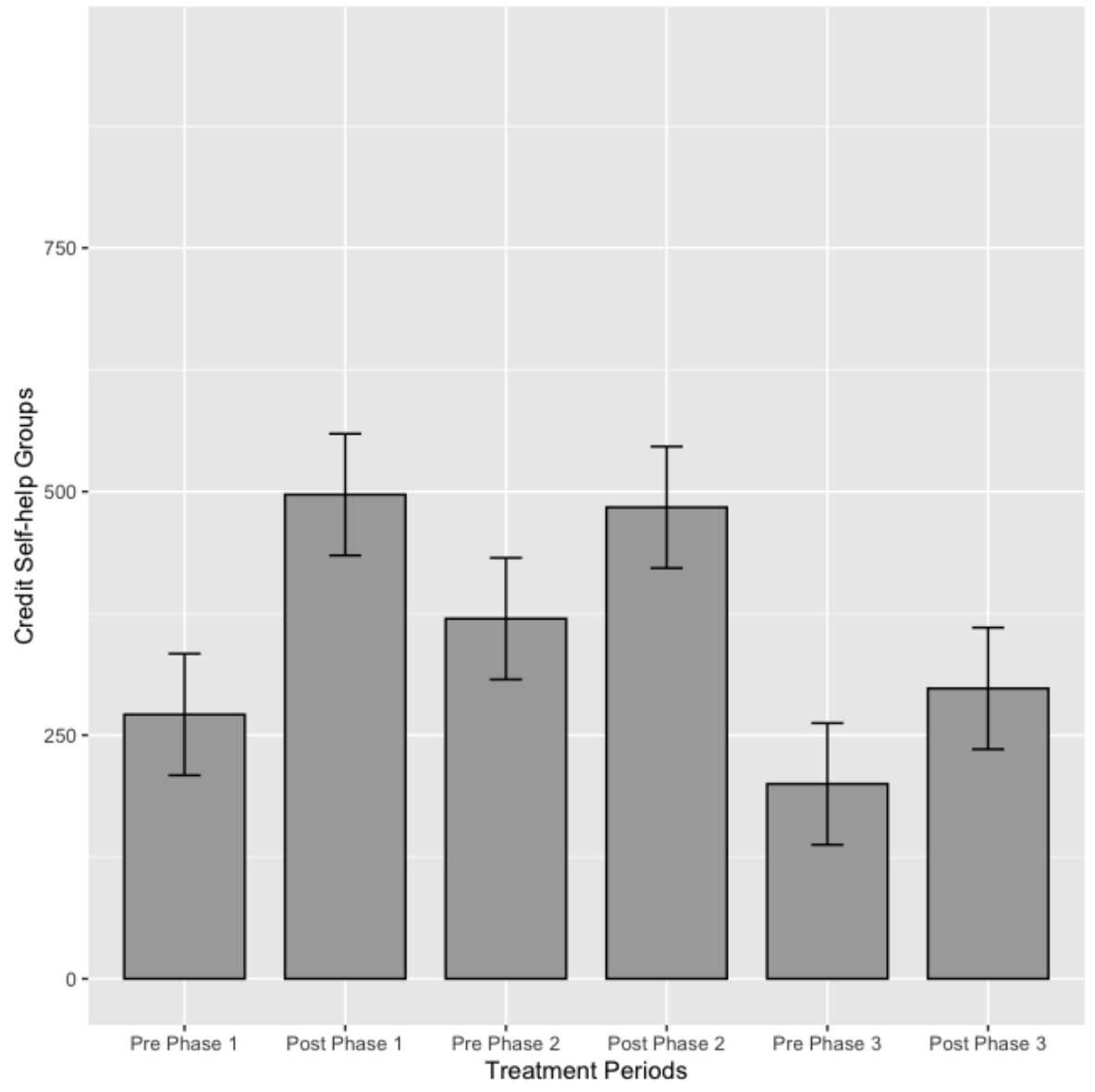

Table 15 presents results from my econometric analysis. In order to investigate the causal impact of MGNREGA on the demand for microfinance, I use an ordinary least squared difference-in-differences estimation strategy to measure the intent-to-treat effects in Columns (1) and (3). Access to MGNREGA employment appears to affect microcredit activity differently. Results show that access to MGNERGA employment increases the number of credit self-help groups in a district, but not the credit disbursed to groups. While weakly significant, the effect on the number of credit self-help groups persists in Column (2), which estimates the treated-on-treatment effect using MGNREGA uptake as measured by the number of job days generated per rural household in a district. Credit disbursed to self-help groups is not affected by MGN- 
ERGA employment becoming accessible in a district, but if we observe both Columns (2) and (4), then we see that the uptake of MGNREGA employment in a district significantly increases all microcredit activity in a district. Considering these results together, the demand for microcredit, interpretation of these results suggests that people organize themselves into credit self-help groups given access to MGNREGA, however, there appears to be no difference in the credit disbursed to these groups, which limits the impact of this effect since groups are not being give more credit to accommodate this increase in demand.

Table 15: Effect of MGNREGA Employment on Microcredit

\begin{tabular}{lcccc}
\hline \hline & \multicolumn{4}{c}{ Dependent variable: } \\
\cline { 2 - 5 } & \multicolumn{2}{c}{ Credit Self-help Groups } & \multicolumn{2}{c}{ Credit Disbursed } \\
& $(1)$ & $(2)$ & $(3)$ & $(4)$ \\
\hline MGNREGA & $0.131^{*}$ & 0.076 & 0.075 & -0.042 \\
& $(0.076)$ & $(0.083)$ & $(0.054)$ & $(0.060)$ \\
& & & & \\
MGNREGA $\times$ Job Days & & $0.004^{*}$ & & $0.008^{* * *}$ \\
& & $(0.002)$ & & $(0.002)$ \\
\hline Controls & $\checkmark$ & $\checkmark$ & $\checkmark$ & $\checkmark$ \\
District FE & $\checkmark$ & $\checkmark$ & $\checkmark$ & $\checkmark$ \\
Year FE & $\checkmark$ & $\checkmark$ & $\checkmark$ & $\checkmark$ \\
\hline \hline
\end{tabular}

Dependent variables are count variables for the annual number of credit self-help groups and the amount disbursed (in Lakh) to self-help groups, I transform these outcomes using inverse hyperbolic sine $\log$ transformation; Intensity of MGNREGA is measured by the annual number of Job Days generated by rural households in a district; I control for access to water, literacy rates, population density, scheduled caste and tribe, incidence of domestic violence, and area of agricultural land; Robust standard errors are clustered at the district level (391 clusters) and given in parentheses; ${ }^{*} \mathrm{p}<0.1 ;{ }^{* *} \mathrm{p}<0.05 ;{ }^{* * *} \mathrm{p}<0.01$

When considering this increased in demand for microcredit, we also want to know where these effects concentrate. For example, districts where microfinance is readily available may be disproportionately affected by the roll-out of MGNREGA. Thus, districts with low MGNREGA uptake may demand microfinance differently. However, estimating this effect across different quantiles of our dependent variable, credit-linked self-help groups, like in Figure 19 shows that the effect is always positive and consistent as the concentration of microcredit increases across districts. 
Figure 19: Effect of MGNREGA Uptake on Credit-linked Self-help Groups - By Quantile

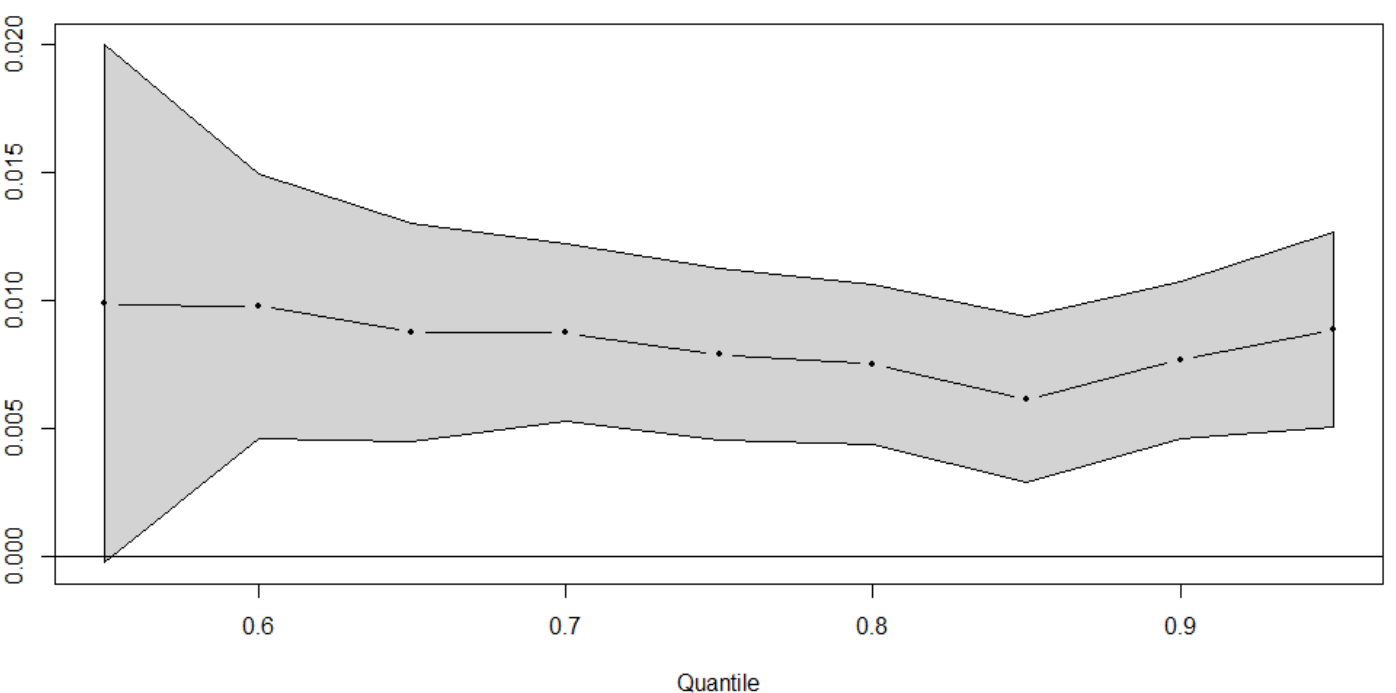

An important interpretation of these results, taken together, is that at whatever level of microcredit activity in a district, uptake of MGNREGA employment in a district increases the demand for microcredit. My results show that one more job day worked per household increases credit self-help groups and credit disbursed by $0.4 \%$ and $0.8 \%$ respectively. These results align with other empirical studies that investigate the reverse effect, where participation in microfinance leads to growth in household income. In this context, I find that income growth through employment causes an increase to microcredit activity. Having explored the effect of MGNREGA on microcredit, I turn my analysis to estimating the causal effect of job days generated through MGNREGA on savings activity.

\subsection{Effects of MGNREGA Employment on Savings Mobilization}

I take the same approach to study the effects of MGNREGA on savings mobilization across districts as I did in my previous analysis of microcredit. As stated previously, savings mobilization activities began in 2006, which prevents me from reasonably understanding the impact of MGRENGA on savings mobilization in Phase 1 districts. Figure 20 shows large increases in the number of savings savings help groups after MGNREGA is implemented in a district. Similar increases occur across my other savings outcomes, the members of savings groups per district and the amount saved by groups per district. I show these graphs in the Appendix. 
Figure 20: Pre and Post Comparison of Savings Self-help Groups across Phases

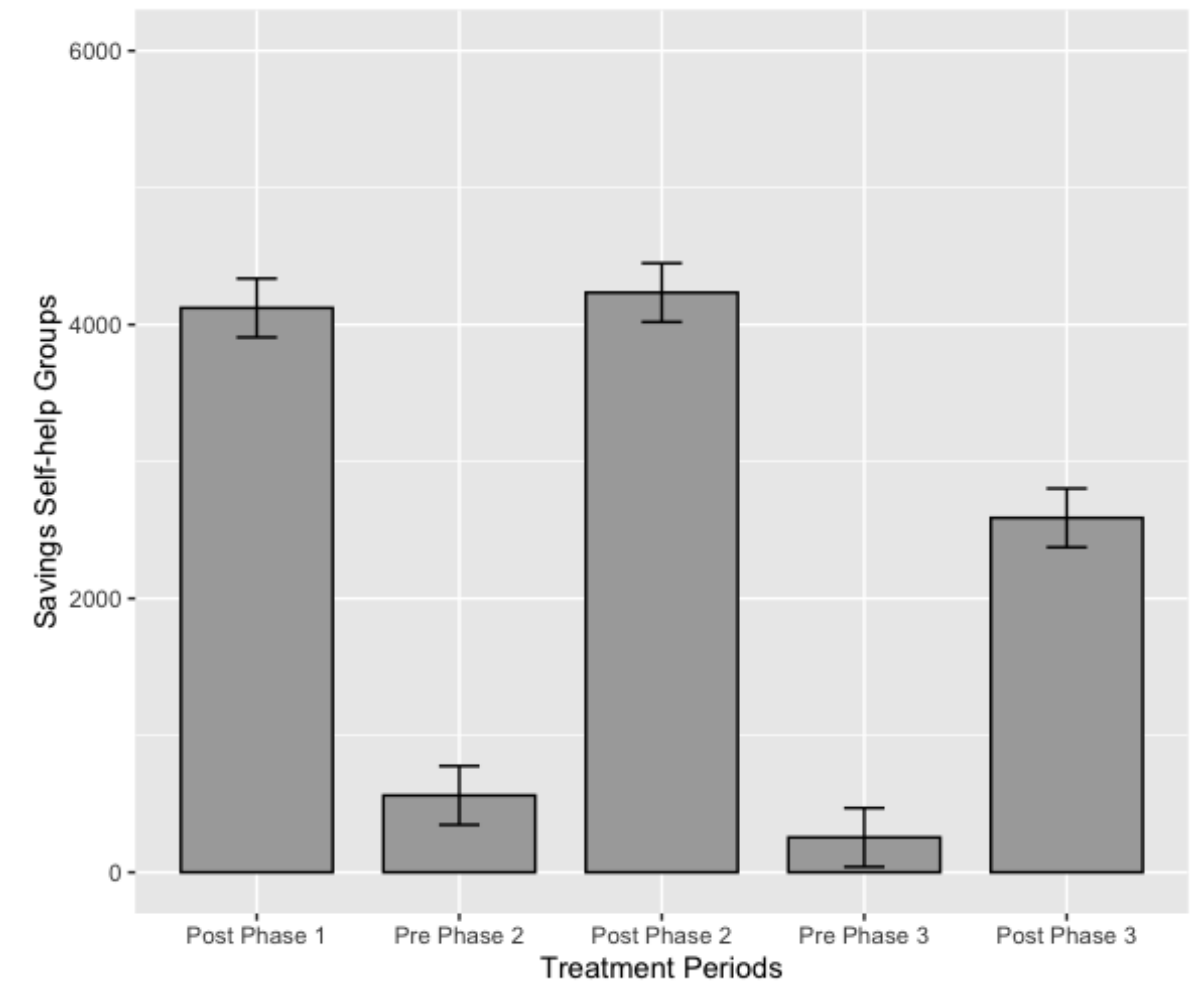

Identifying increased savings activity after the implementation of MGNREGA does suggest that growth in household income leads individuals to save more with self-help groups. Yet, given the relatively short pre-period for savings activity, further investigation is needed to see if this effect is statistically meaningful. Table 16 provides the main results with regards to my difference-in-difference estimations of the effect of MGNREGA uptake on savings activity. I present intent-to-treat effects in Columns (1), (3), and (5). We see that access to MGNREGA has no effect on the the number of savings-linked self-help groups and the amount deposited by groups, but a positive effect does exist for the number of members in self-help groups. This suggests that individuals are organizing themselves for savings activity after MGNREGA is implemented in a district, but no differences appear in savings activity. Finding few intent-to-treat effects can give us more confidence that any effects found given changes in income are independent of any general trends in savings activity across India.

Columns (2), (4), and (6) identify the causal effects of increased income on the demand for savings given uptake of MGNREGA employment across districts. These results indicate that with one more work day generated per rural household, savings self-help groups, membership, and amount saved increases by $0.1 \%$, $0.3 \%$, and $0.2 \%$, respectively. These effects are strongly significant, which is an indication that income growth causes individuals to save. These results are both economically and socially meaningful, as other empirical studies identify increased savings with important changes regarding household decision-making and human capital investments. 
Table 16: Effect of MGNREGA Employment on Savings Mobilization

\begin{tabular}{lcccccc}
\hline \hline & \multicolumn{5}{c}{ Dependent variable: } \\
\cline { 2 - 7 } & \multicolumn{2}{c}{ Savings Self-help Groups } & \multicolumn{2}{c}{ Savings Group Members } & \multicolumn{2}{c}{ Amount Saved } \\
& $(1)$ & $(2)$ & $(3)$ & $(4)$ & $(5)$ & $(6)$ \\
\hline MGNREGA & -0.058 & $-0.240^{*}$ & $0.381^{* *}$ & 0.073 & 0.013 & $-0.141^{*}$ \\
& $(0.123)$ & $(0.130)$ & $(0.188)$ & $(0.194)$ & $(0.077)$ & $(0.082)$ \\
& & & & & & \\
MGNREGA $\times$ Job Days & & $0.019^{* * *}$ & & $0.032^{* * *}$ & & $0.016^{* * *}$ \\
& & $(0.003)$ & & $(0.005)$ & & $(0.002)$ \\
\hline Controls & $\checkmark$ & $\checkmark$ & $\checkmark$ & $\checkmark$ & $\checkmark$ & $\checkmark$ \\
District FE & $\checkmark$ & $\checkmark$ & $\checkmark$ & $\checkmark$ & $\checkmark$ & $\checkmark$ \\
Year FE & $\checkmark$ & $\checkmark$ & $\checkmark$ & $\checkmark$ & $\checkmark$ & $\checkmark$ \\
\hline \hline
\end{tabular}

Dependent variables are count variables for the number of savings groups, members and amount (in Lakh) saved per group, I transform these outcomes using inverse hyperbolic sine log transformation; Tracking of savings activity began in 2006, thus the effects on savings behavior concerns Phase 2 vs. Phase 3 districts; Intensity of MGNREGA employment is measured by the annual number of Job Days generated by rural households in a district; I control for access to water, literacy rates, population density, scheduled caste and tribe, incidence of domestic violence, and area of agricultural land; Since we are now interacting our difference-in-difference interaction term with the intensity of job-days generated in a district, I include district and year fixed effects in all models; Robust standard errors are clustered at the district level and given in parentheses; ${ }^{*} \mathrm{p}<0.1{ }^{* *} \mathrm{p}<0.05 ;{ }^{* * *} \mathrm{p}<0.01$;

Like the results for microcredit activity, savings appears to only increase after households take up MGNREGA employment. We Investigating the effect given the concentration of savings activity, Figure ?? estimates the effect across various deciles of savings-linked self-help groups. Results, presented in the Appendix, show that the size of the effect is positive regardless of the level of savings activity in a district.

Results in Table 16 indicate that the effect of MGNREGA uptake on savings groups and amount saved depends on the number of jobs days generated, as the intent-to-treat effect is negative, while the treatment effect is positive. I plot these regressions in Figures 21 and 22 to see at what point the effect of MGNREGA has a positive effect on savings. Figure 21 shows that the effect on savings crosses the zero point when at least 8 job days are generated per rural household. When I add confidence intervals, the effect of MGNREGA uptake on savings occurs when at least 12 jobs are taken up in a district. Described in Table 13 , the average number of jobs per rural household is at least 12 in phases 1 and 2, while the average is 11 in phase 3 districts. 
Figure 21: Effect of MGNREGA Uptake on Savings-linked Self-help Groups

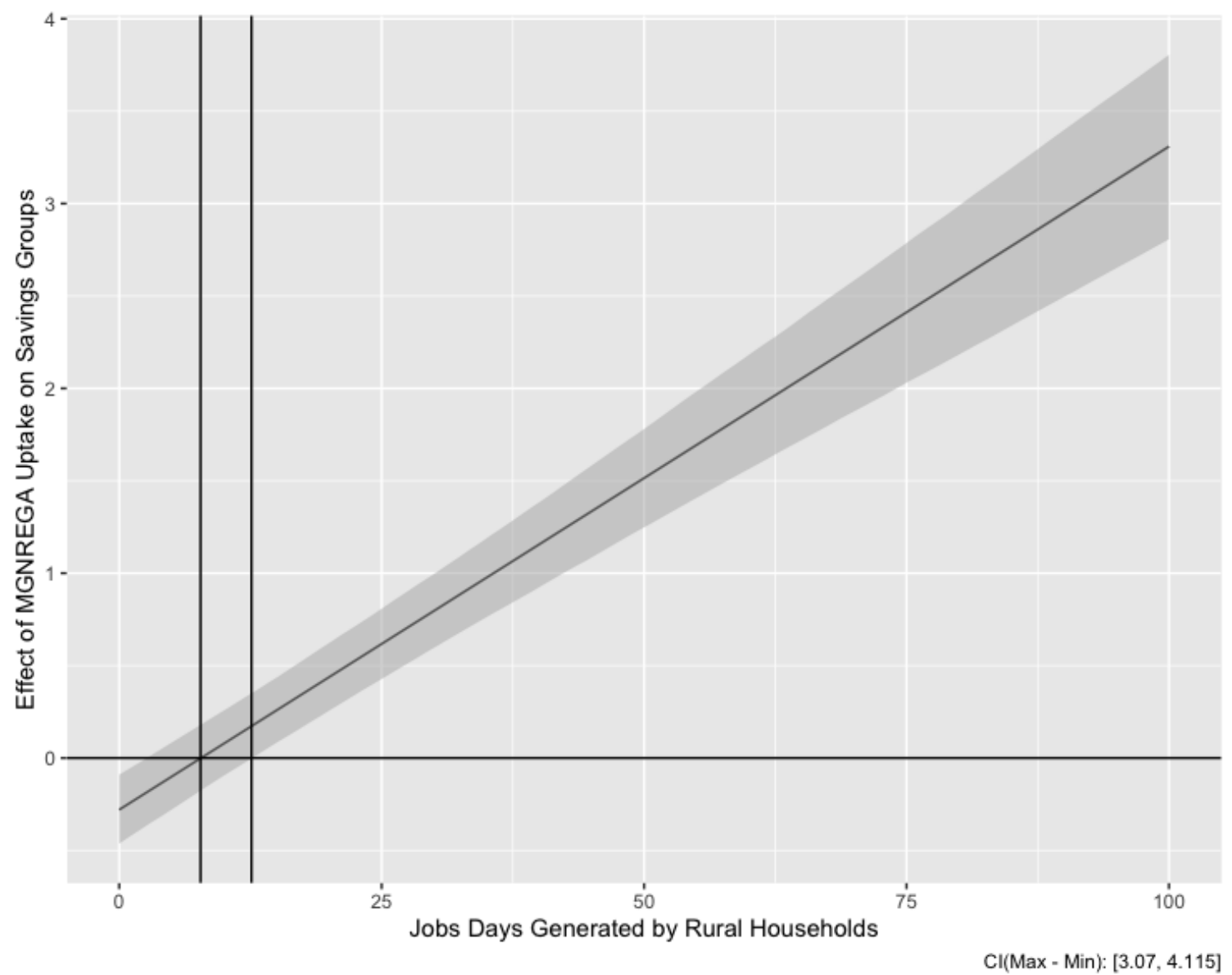

As in Figure 21. Figure 22 shows how the effect of MGNREGA uptake on the amount saved by selfhelp groups occurs across all districts, and that the effect of MGNREGA on savings occurs after districts generated more than nine jobs per rural household. Both Figures 21 and 22 indicate that the effect of MGNREGA on savings concentrates in districts where MGNREGA was implemented before 2008. As other studies have noted these earlier phase districts are associated with high levels of poverty, these results suggest that MGNREGA uptake is having a meaningful effect on households' savings behavior, which we know has many benefits for the household currently and in the future. 
Figure 22: Effect of MGNREGA Uptake on Amount Saved by Groups

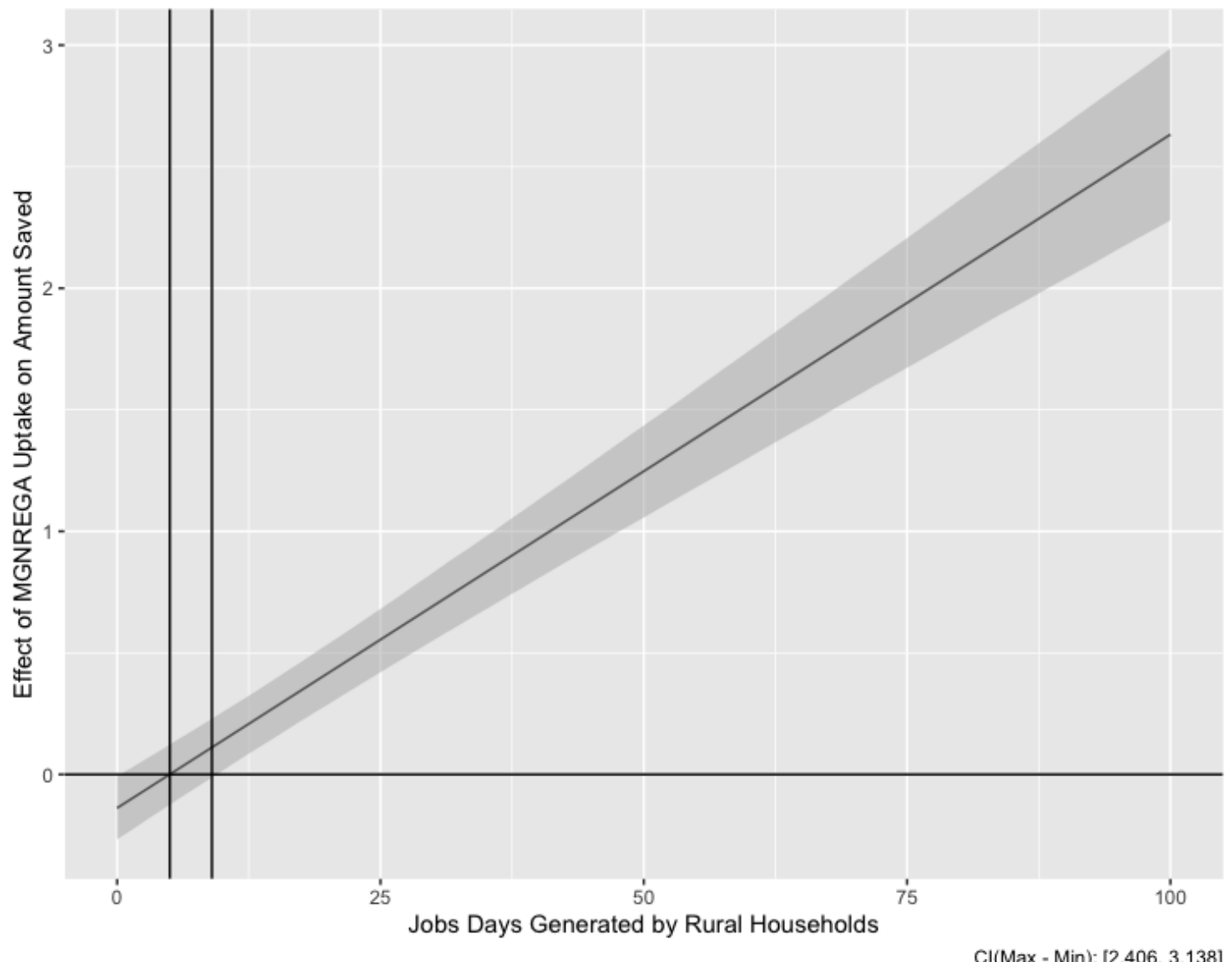

In the following section, I examine possible mechanisms through which I identify this increase in the demand for microfinance. Two mechanisms that I investigate consider this demand as indicative of either poverty alleviation or entrepreneurship.

\section{Mechanisms of Demand for Microfinance}

To this point, I have identified a strong, causal relationship between income opportunities and the growth in microfinance activities across districts. Now that a relationship exists, we want to know more about how and in what circumstances the relationship between income growth and microfinance operates. To explore this relationship, I analyze these results in light of the literature on microfinance, which discusses two mechanisms through which households demand microfinance, as entrepreneurship or to cope with negative income shocks. For this analysis, I need a context in which we can disentangle how microfinance is being used across districts. One such context is measuring the concentration of our main results given adverse rainfall shocks.

A majority of microfinance clients, both globally and in India, are farmers, with much of the microcredit targeting agricultural businesses (Parizat and Strubenhoff, 2018). By isolating the effect of MGNREGA on microfinance given annual rainfall per district, we can distinguish the mechanism of demand for microfinance. Households could demand microfinance to cope with the negative income shocks that come with adverse 
weather conditions (Shoji, 2010; Becchetti and Castriota, 2011). Demand could also increase during average to moderate rainfall conditions (Demont, 2016), indicating the mechanism of demand is entrepreneurship. Studies have shown that as one of the largest rice producers in the world, average to increased rainfall across districts in India positively correlates with increased agricultural production (Asada and Matsumoto, 2009). Increased demand during these rainfall conditions suggests that households are using the uptake of MGNREGA and microcredit to invest in future productive activities. Given these two mechanism, I further investigate the effect of MGNREGA uptake on microfinance given annual rainfall in a district.

\subsection{Microfinance As Poverty Alleviation}

Farmers and agricultural businesses remain the largest clients of microfinance around the world. As microfinance works to meet the needs of these clients, farmers remain vulnerable to unpredictable weather conditions. Rural farmers are the most vulnerable to these conditions. With high levels of subsistence farming and increasing demand for food in urban areas (Minten et al., 2009), agricultural output represents a major portion of rural household income and consumption.

Several studies identify microfinance institutions using insurance schemes (Giné et. al, 2010), microcredit (Goodspeed, 2016) and savings products (Aggarawal, Brailovskaya, and Robinson, 2018) to try to mitigate the effects of adverse weather on agrarian-based households, each instrument offering various levels of success. Studies have also been done to measure how microfinance institutions use other products like fertilizer investments (Duflo, Kremer and Robinson, 2011) and health savings accounts (Dupas and Robinson, 2013) to prevent potential shocks to household income. Microfinance in these contexts is used as a mechanism for poverty alleviation, as household demand for microfinance increases given adverse weather shocks.

\subsection{Microfinance as Entrepreneurship}

Alternatively, microenterprises have been the target of microfinance institutions from the outset of the microcredit movement with the Grameen Bank in Bangladesh. Unable to receive investment from large financial institutions, small-scale entrepreneurs seek out microfinance institutions to increase the capacity of their business or to start new business ventures entirely. This class of entrepreneurs and their ventures represent a significant segment of a growing labor force in development countries.

Microfinance in the context of entrepreneurship focuses on how best to meet demand for credit so that entrepreneurs can effectively boost the capacity of their businesses. Motivated by the fact that 600 million Job Days are needed over the next 15 years to keep employment rates at their current level, Grimm and Paffhausen (2015) review the literature on how investment in small and medium-sized firms increases employment in developing countries. While finding overall modest effects, it appears that business training or business development services relative to financial interventions have a stronger effect in boosting the self-employment or expanding employment of small-sized enterprises. Since entrepreneurship often requires elements of creativity and control, the effects of entrepreneurial training can spillover onto individual behavior and aspects of the household. Studies confirm positive spillover effects of business training and consulting on microenterprises like entrepreneurial motivation (Bruhn, Karlan, and Schoar, 2018) and women decisionmaking in the household (Huis, et al., 2019). Demand in this context is forward-thinking, as opposed to demand as poverty alleviation, which is reactive to income shocks. Being able to discern which type of demand we see in our main results can lend further insight into how household make decisions regarding whether or not to engage with financial markets. 


\subsection{Microfinance and Annual District Rainfall Analysis}

Exploiting the variation and exogeneity of adverse weather shocks across districts like Paxson (1992), I estimate the effect of uptake in MGNREGA on microfinance in a district given annual rainfall in a district to understand how the demand for microfinance increases with uptake in MGNREGA. This empirical strategy will provide insight into the circumstances in which households demand microfinance as household incomes increase. If I detect my main results in times of adverse weather, which we would identify in the tails of the distribution of annual rainfall across districts, which represent drought and flood conditions in a district then this would suggest that the character of demand is one of consumption smoothing. Yet, if my main results concentrate in times of average rainfall, then this the character of demand is more entrepreneurial, as households engage in microfinance in times of relative prosperity.

For this analysis, I collect both the long-term (50 year) average rainfall per district and monthly rainfall accumulations for districts across my sample. The Indian Meteorological Department ("IMD") classifies annual rainfall conditions with respect to the long term average of a given district. Thus with respect to its average, I calculate annual rainfall relative to the long term average and segment districts according to average, moderate, and severe rainfall conditions (Ministry of Water Resources, 2017). Much of India faces problems with lack of rainfall. IMD estimates that $68 \%$ of the country is "drought prone". The IMD defines droughts as any district that receives less than $1125 \mathrm{~mm}$ of rain per year (IMD, 2017).

IMD categorizes rainfall conditions into three categories: average, moderate, and severe. Severe conditions exist when rainfall accumulation is less (more) than $50 \%$ of the average district rainfall. IMD considers moderate drought and flood conditions to be less (more) than 26-50\% of average rainfall, and average conditions $25 \%$ less (more) than the average. By calculating and classifying each district's annual rainfall, I can create dummy variables for these different annual rainfall classifications. I then interact my main results on the effects of MGNRGEA on microfinance according to average, moderate, and severe annual rainfall conditions within a district. Das and Mocan (2016) identify a negative relationship between rainfall and MGNREGA across districts. This suggests households use MGNREGA as an insurance scheme, as demand decreases with the agricultural production that comes from increased rainfall. Given these results, I explore how rainfall conditions affect the relationship between MGNREGA uptake and microfinance.

Table 17 estimates the effect of rainfall on my main results for microcredit. Results appear to concentrate highest in times of moderate to increased rainfall conditions. Concentration of demand at these times suggests that demand for microfinance increases in times of stable to increased rainfall conditions, particularly during moderate droughts and severe floods. The intent to treat effect from my rainfall analysis, as seen in Table 17. shows that districts demand microcredit when experiencing severe flood conditions. When I interact the number of job days generated in a district with the various rainfall measures, we see that the demand for microcredit concentrates in times of stable to increased rainfall districts. As noted previously, both average to heavy rains have positive effects on agricultural production across India and over $65 \%$ of districts are classified as drought prone. Finding my main results given stable and heavy rains suggests that the mechanism of demand for microcredit is entrepreneurship, as stability or increases to income allow for investments in households or local enterprises. Analysis of my main results with a more coarse distribution of rainfall, like in Tables 20 and 21 of the Appendix, confirm the discussion of my results in Table 17, as my effects concentrate in districts with average to above average rainfall. 
Table 17: Effect of MGNREGA on Microcredit Given Annual District Rainfall

\begin{tabular}{|c|c|c|c|c|}
\hline \multirow[b]{2}{*}{ Intent-to-Treat } & \multicolumn{4}{|c|}{ Dependent variable: } \\
\hline & \multicolumn{2}{|c|}{ Credit Self-help Groups } & \multicolumn{2}{|c|}{ Credit Disbursed } \\
\hline MGNREGA $\times$ Severe Drought & $\begin{array}{c}0.001 \\
(0.105)\end{array}$ & & $\begin{array}{l}-0.042 \\
(0.086)\end{array}$ & \\
\hline MGNREGA $\times$ Moderate Drought & $\begin{array}{l}0.172^{*} \\
(0.089)\end{array}$ & & $\begin{array}{c}0.090 \\
(0.070)\end{array}$ & \\
\hline MGNREGA $\times$ Average Rain & $\begin{array}{c}0.068 \\
(0.084)\end{array}$ & & $\begin{array}{c}0.069 \\
(0.064)\end{array}$ & \\
\hline MGNREGA $\times$ Moderate Flood & $\begin{array}{c}0.026 \\
(0.096)\end{array}$ & & $\begin{array}{c}0.042 \\
(0.080)\end{array}$ & \\
\hline MGNREGA $\times$ Severe Flood & $\begin{array}{c}0.121 \\
(0.102)\end{array}$ & & $\begin{array}{l}0.146^{*} \\
(0.081)\end{array}$ & \\
\hline Treated-on-Treatment & & & & \\
\hline MGNREGA & & $\begin{array}{c}0.062 \\
(0.092)\end{array}$ & & $\begin{array}{l}-0.011 \\
(0.070)\end{array}$ \\
\hline MGNREGA $\times$ Job Days $\times$ Severe Drought & & $\begin{array}{c}0.002 \\
(0.003)\end{array}$ & & $\begin{array}{c}0.004 \\
(0.003)\end{array}$ \\
\hline MGNREGA $\times$ Job Days $\times$ Moderate Drought & & $\begin{array}{l}0.006^{* *} \\
(0.002)\end{array}$ & & $\begin{array}{c}0.008^{* * *} \\
(0.002)\end{array}$ \\
\hline MGNREGA $\times$ Job Days $\times$ Average Rainfall & & $\begin{array}{l}0.0002 \\
(0.003)\end{array}$ & & $\begin{array}{c}0.003 \\
(0.002)\end{array}$ \\
\hline MGNREGA $\times$ Job Days $\times$ Moderate Flood & & $\begin{array}{c}-0.0001 \\
(0.003)\end{array}$ & & $\begin{array}{l}0.005^{*} \\
(0.003)\end{array}$ \\
\hline MGNREGA $\times$ Job Days $\times$ Severe Flood & & $\begin{array}{c}0.006^{*} \\
(0.003)\end{array}$ & & $\begin{array}{c}0.013^{* * *} \\
(0.003) \\
\end{array}$ \\
\hline Controls & $\checkmark$ & $\checkmark$ & $\checkmark$ & $\checkmark$ \\
\hline District FE & $\checkmark$ & $\checkmark$ & $\checkmark$ & $\checkmark$ \\
\hline Year FE & $\checkmark$ & $\checkmark$ & $\checkmark$ & $\checkmark$ \\
\hline
\end{tabular}

Dependent variables are count variables for the number of credit groups and the amount of credit disbursed (in Lakh) to groups that I transform using inverse hyperbolic sine transformation; Intensity of MGNREGA is measured by the number of Job Days generated by rural households in a district; I control for access to water, literacy rates, population density, scheduled caste and tribe, incidence of domestic violence, and area of agricultural land; For rainfall variables, I use the create dummy variables for severe floods, moderate floods, average rainfall, moderate drought, and severe drought. The India Meteorological Department sets these standards as $25 \%$ or less is normal, $26-50 \%$ is moderate and more than $50 \%$ is severe; Annual rainfall data is not available for some districts, so I exclude these observations from my analysis; The number of observations per rainfall category are 400 for Severe Drought, 1100 for Moderate Drought conditions, 2600 for Average Rainfall, 441 for Moderate Floods, and 528 for Severe Floods; I include district and year fixed effects in all models; Robust standard errors are clustered at the district level (391 clusters) and given in parentheses; ${ }^{*} \mathrm{p}<0.1 ;{ }^{* *} \mathrm{p}<0.05 ;{ }^{* * *} \mathrm{p}<0.01$

Table 18 shows my main results regarding the demand for savings interacted with annual district rainfall conditions. Interestingly, savings mobilization increases in all rainfall conditions. These results indicate that 
regardless of weather conditions, the demand for savings increases given income growth from MGNREGA employment. As no effects exists regarding the intent to treat in Table 18, households appear to engage with savings actively after taking up employment through MGNREGA.

As many studies in development work to encourage savings behavior among low-income households, these results suggest that programs like conditional-cash transfers (Haushofer and Shapiro, 2016) and contestlinked savings accounts (McCannon, Rodriguez, and Sheremeta, 2020) could be useful mechanisms to encourage savings, as these programs offer shocks household income. These shocks to income, like the access to and uptake of MGNREGA, provide households with new cash flows to manage, which can provide the catalyst for them to engage with formal savings markets. 
Table 18: Effect of MGNREGA on Savings Given Annual District Rainfall

\begin{tabular}{lccc}
\hline \hline & \multicolumn{3}{c}{ Dependent variable: } \\
\cline { 2 - 4 } & Savings Self-help & Savings Group & Amount \\
Intent-to-Treat & Groups & Members & Saved \\
\hline MGNREGA $\times$ Severe Drought & -0.221 & 0.227 & -0.056 \\
& $(0.185)$ & $(0.298)$ & $(0.117)$ \\
MGNREGA $\times$ Moderate Drought & -0.166 & 0.378 & -0.056 \\
& $(0.183)$ & $(0.274)$ & $(0.112)$ \\
MGNREGA $\times$ Average Rain & -0.228 & 0.263 & -0.097 \\
MGNREGA $\times$ Moderate Flood & $(0.165)$ & $(0.268)$ & $(0.103)$ \\
MGNREGA $\times$ Severe Flood & -0.194 & 0.259 & -0.053 \\
& $(0.187)$ & $(0.284)$ & $(0.117)$ \\
\hline
\end{tabular}

Treated-on-Treatment

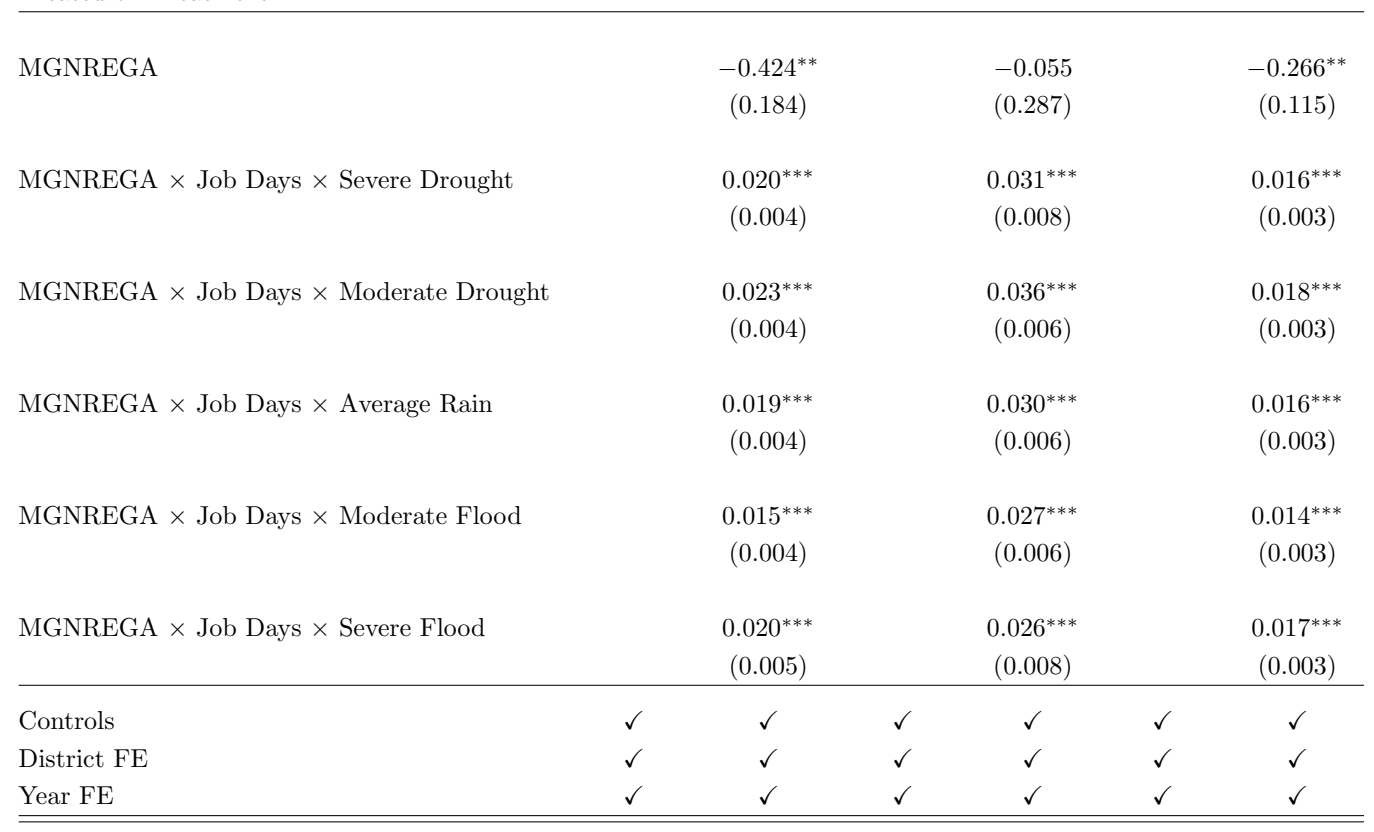

Dependent variables are count variables for the number of savings groups, members and amount (in Lakh) saved per group that are transformed using inverse hyperbolic sine transformation; Intensity of MGNREGA is measured by the number of Job Days generated per rural households in a district; I control for access to water, literacy rates, population density, scheduled caste and tribe, and area of agricultural land; For rainfall variables, I segment rainfall across districts like in Table 17. The number of observations per rainfall category are 400 for Severe Drought, 1100 for Moderate Drought conditions, 2600 for Average Rainfall, 441 for Moderate Floods, and 528 for Severe Floods; I include district and year fixed effects in all models; Robust standard errors are clustered at the district level (391 clusters) and given in parentheses; ${ }^{*} \mathrm{p}<0.1 ;{ }^{* *} \mathrm{p}<0.05 ;{ }^{* * *} \mathrm{p}<0.01$

Overall, analysis of the mechanism of demand indicates that as household incomes grow, individuals demand microfinance during times of adverse weather shocks. With rainfall either less than or exceeding expectations within districts, individuals engage in microfinance activities, which suggests that the mecha- 
nism of demand for microfinance, in the case of our main results, is of consumption smoothing, rather than entrepreneurship. The following section discusses these results and limitations to this analysis.

\section{Discussion}

My main results from Tables 15 and 16 indicate that the demand for microfinance increases given growth to household income. Identifying a complimentarity between income from employment and microfinance suggests that households cope with risk differently in the availability of guaranteed income. Morduch (1995) refers to stages of risk coping in low-income households, where households first income smooth by making conservative employment choices and diversifying their economic activity. After exhausting income-smoothing options, a household then moves to consumption smoothing, seeking financial services and depleting assets to cope with risk. My main results relate to this discussion of risk-coping, as the demand for microfinance increases, in almost all cases, depending on the uptake of MGNREGA employment. Households seem to engage in microfinance only have engaging in income-smoothing activity. This lends empirical support to the stages of risk-coping, and carries implications regarding how microfinance institutions operate and target potential clients.

If the demand for microfinance only occurs given growth to household incomes, then microfinance initiatives that target individuals living in extreme poverty may not be as effective, since these results suggest that individuals would not willing engage in microfinance activities without a change to household income. Policy implications of these results suggest alternative development initiatives to microfinance for those living in extreme poverty. Organizations like GiveDirectly find positive effects of unconditional cash transfers to households in extreme poverty (Haushofer and Shapiro, 2016), suggesting an alternative poverty reduction tool to microcredit that aligns with our current results.

By taking further steps to identify the mechanism of this demand, I find that demand occurs in times of relative prosperity across districts, as measured by annual rainfall conditions. I find that as incomes through MGNREGA employment, district demand for microfinance increases during times of average rainfall. I interpret this effect as households becoming more willing to take entrepreneurial risks given growth to household incomes and expected rainfall.

I do not see any increase in demand for credit or savings in times of severe droughts, which indicates households preference for alternative risk-coping mechanism to microfinance in times of little rainfall. Demand for microfinance does increases during flood conditions, with the magnitude of the effect decreasing as the severity of the drought increases. I interpret this effect as indication that households demand microfinance as incomes increase in times of relative prosperity, which suggests that entrepreneurship is the mechanism through which I identify my main results. However, an alternative interpretation is that in times of adverse weather shocks, households turn to informal credit markets, where access may be more convenient and transactions costs may be lower (Kochar, 1997) and prefer to work with formal credit given larger investments in their home or business (Karaivanov and Kessler, 2018). Further data on why and at what cost households choose to enter financial markets is necessary to better identify the mechanism for this demand. Collins et al. (2009) provides a way to do this by distributing, collecting, and analyzing household-level financial diaries from Bangladesh, India, and South Africa. Information on how cash flows within the household can more precisely differentiate the effects of income and adverse weather shocks on household consumption. 


\section{Conclusion}

This analysis provides a novel measurement of the demand for microfinance given increases to household income through the world's largest employment guarantee program in India, The Mahatma Gandhi National Rural Employment Program. Results identify a causal relationship between growth in household income from employment and the demand for microfinance across districts. As incomes grows across districts with MGNREGA uptake, demand for credit and savings increases. After identifying this demand for microfinance, I explore possible mechanism of this demand.

The literature on microfinance identifies two potential mechanism of demand, either as a mechanism of entrepreneurship or poverty alleviation. The main results of the analysis only describe increased demand, but not a possible mechanism. Using annual district rainfall data, I investigate the increased demand for microfinance given MGNREGA employment in light of adverse weather shocks in a district. Intuition suggests that increased demand during times of adverse weather indicates households use microfinance as a relief mechanism, and if demand increases during average and positive rainfall conditions, the demand could be considered entrepreneurial, as households are able to take more risks when income is less volatile. Analysis of adverse weather shocks indicates that the demand for microfinance increases given uptake of MGNREGA employment during times of average or increased rainfall. These results suggest that microfinance is used during times of relative prosperity and that households may rely less on microfinance as an insurance mechanism when income is more volatile.

Implications from these results indicate that low-income households may prefer alternative poverty alleviation programs to microfinance for coping with adverse income shocks to the household. My results suggest that we temper discussions regarding microfinance as a method for poverty alleviation mechanism

and consider the demand for microfinance as a mechanism for entrepreneurship and releasing the productive capacity of low-income households.

\section{References}

Acquah, Joseph Kofi and Roshani Dahal (2018), "ROSCAs as Lenders of Last Resort after Financial Crises: Lessons from Indonesia." Journal of International Development 30(7): 1223-1239.

Al-Azzam, Moh'd, R.Carter Hill, and Sudipta Sarangi, (2012) "Repayment performance in group lending: Evidence from Jordan." Journal of Development Economics 97(2): 404-414.

Aggarwal, Shilpa, Valentina Brailovskaya and Jonathan Robinson, Jonathan (2018), "Saving for Multiple Financial Needs: Evidence from Malawi." Working Paper. The Bureau for Research and Economic Analysis of Development. (Unpublished).

Anderson, Siwan and Jean-Marie Baland (2002) "The Economics of Roscas and Intrahousehold Resource Allocation." The Quarterly Journal of Economics 117(3), 963-995.

Aruna, M. and Rema Jyothirmayi (2011), "The role of microfinance in Women Empowerment: A study on the SHG Bank Linkage Program in Hyderabad." he Indian Journal of Commerce and Management Studies 2(4): 77-95

Asada, H., and Matsumoto, J. (2009), "Effects of rainfall variation on rice production in the GangesBrahmaputra Basin" Climate Research 38(3): 249-260. 
Ashraf, Nava, Dean Karlan, Wesley Yin (2006), "Tying Odysseus to the Mast: Evidence From a Commitment Savings Product in the Philippines." The Quarterly Journal of Economics 121(2): 635-672.

- (2008), "Female Empowerment: Impact of a Commitment Savings Product in the Philippines." World Development 38(3): 333-344.

Baker, Scott R. (2018), "Debt and the Response to Household Income Shocks: Validation and Application of Linked Financial Account Data." Journal of Political Economy 126(4): 1504-1557.

Banerjee, Abhijit, Esther Duflo, and Richard Hornbeck (2014), "Bundling Health Insurance and Microfinance in India: There Cannot be Adverse Selection If There Is No Demand." American Economic Review 104(5): 291-297.

Banerjee, Abhijit, Dean Karlan, and Jonathan Zinman (2015), "Six Randomized Evaluations of Microcredit: Introduction and Further Steps." American Economic Journal: Applied Economics 7(1): 1-21.

Barnett, Barry and Olivier Mahul (2007), "Weather Index Insurance for Agriculture and Rural Areas in Lower-Income Countries." American Journal of Agricultural Economics 89(5): 1241-1247.

Becchetti Leonardo and Stefano Castriota (2011), "Does microfinance work as a recovery tool after disasters? Evidence from the 2004 tsunami." World Development 39 (6), 898-912.

Berg, Erlend, Sambit Bhattacharyy, D. Rajasekhar, and R. Manjula (2018), "Can public works increase equilibrium wages? Evidence from India's National Rural Employment Guarantee." World Development 103: $239-254$.

Breza, Emily and Cynthis Kinnan (2018) "Measuring the Equilibrium Impacts of Credit: Evidence from the Indian Microfinance Crisis" NBER Working Paper No. 24329.

Chopra, Deepta (2015), "Political Commitment in India's Social Policy Implementation: Shaping the Performance of MGNREGA." ESID Working Paper No. 50.

Churchill, Craig (2002), "Trying to understand the demand for microinsurance." Journal of International Development 14(3): 381-387.

Collins, Daryl, Jonathan Morduch, Stuart Rutherford, and Orlanda Ruthven (2009), "Portfolios of the Poor: How the World's Poor Live on $\$ 2$ a Day" Princeton: Princeton University Press.

Cull, Robert, Asli Demirgüç-Kunt, and Jonathan Morduch (2009) "Microfinance Meets the Market." Journal of Economic Perspectives 23(1): 167-92.

- and Morduch, Jonathan (2017), "Microfinance and Economic Development." World Bank Policy Research Working Paper No. 8252.

Das, Satadru and Naci Mocan (2016), "Analyzing the Impact of the World's Largest Public Works Project on Crime." NBER Working Paper No. 22499.

Das, Upasak, Ashish Singh, and Nitay Mahanto (2012), "Awareness about Mahatma Gandhi National Rural Employment Guarantee Act: Some evidence from the northern parts of West Bengal, India." Economics Bulletin 32(1): 528-537 
Davis J, White G, Damodaron S, Thorsten R. (2008), "Improving access to water supply and sanitation in urban India: microfinance for water and sanitation infrastructure development." Water Science 83 Technology 58: 887-91.

Deininger, Klaus and Yanyan Liu (2013), "Economic and Social Impacts of an Innovative Self-Help Group Model in India." World Development 43: 149-163.

Demont, Timothée (2016), "Microfinance spillovers: A model of competition in informal credit markets with an application to Indian villages." European Economic Review 89: 21-41.

Desai, Raj M.; Joshi, Shareen (2013), "Collective action and community development : evidence from selfhelp groups in rural India." Policy Research working paper ; no. WPS 6547; Impact Evaluation series ; no. IE 101. Washington, DC: World Bank.

DiSanto, Jill (2018), “The Economic Impact of India's Self-help Group Movement” Penn Today, Posted on December 14, 2018.

Duflo, Esther (2012) "Women Empowerment and Economic Development." Journal of Economic Literature 50(4): 1051-79.

Duflo, Esther, Michael Kremer, and Jonathan Robinson (2011) "Nudging Farmers to Use Fertilizer: Theory and Experimental Evidence from Kenya." American Economic Review 101(6): 2350-90.

Dupas, Pascaline, Dean Karlan, Jonathan Robinson, and Diego Ubfal (2018) "Banking the Unbanked? Evidence from Three Countries." American Economic Journal: Applied Economics 10 (2): 257-97.

- and Jonathan Robinson (2013), "Why Don't the Poor Save More? Evidence from Health Savings Experiments." American Economic Review 103(4): 1138-1171.

Evenson, Robert E., and Douglas Gollin (2003), "Assessing the impact of the Green Revolution, 1960 to 2000." Science 300(5620): 758-762.

Field, Erica, Rohini Pande, John Papp, and Natalia Rigol (2013), "Does the Classic Microfinance Model Discourage Entrepreneurship among the Poor? Experimental Evidence from India." American Economic Review 103(6): 2196-2226.

Ganle,John Kuumuori, Kwadwo Afriyie, and Alexander Yao Segbefia (2015), "Microcredit: Empowerment and Disempowerment of Rural Women in Ghana." World Development 66: 335-345.

Gaurav, Sarthak (2015), "Are Rainfed Agricultural Households Insured? Evidence from Five Villages in Vidarbha, India" World Development 66: 719-736.

Gertler, Paul, David I. Levine, and Enrico Moretti (2008), "Do microfinance programs help families insure consumption against illness?" Health Economics 18(3): 257-273.

Giné, Xavier, Lev Menand, Robert Townsend and James Vickery (2010), "Microinsurance: a case study of the Indian rainfall index insurance market." In Handbook of the Indian Economy, edited by Chetan Ghate, 167-94. New York: Oxford University Press 
Grimm, Michael and Anna Luisa Paffhausen (2015), "Do interventions targeted at micro-entrepreneurs and small and medium-sized firms create jobs? A systematic review of the evidence for low and middle income countries." Labour Economics 32: 67-85.

Guangwen, He (2008), "An Analysis of Microfinance Demand in China" Proceedings of the World Microfinance Forum, February 2008.

Haggblade, Steven, Peter Hazell, and Thomas Reardon (2010), "The Rural Non-farm Economy: Prospects for Growth and Poverty Reduction". World Development 38(10): 1429-1441.

Haushofer, Johannes and Jeremy Shapiro (2016), "The Short-term Impact of Unconditional Cash Transfers to the Poor: Experimental Evidence from Kenya." The Quarterly Journal of Economics 131(4): 1973-2042.

Hermes, Niels, Robert Lensink and Aljar Meesters (2011), "Outreach and Efficiency of Microfinance Institutions" World Development 39(6): 938-948.

Holvoet, Nathalie (2005), "The Impact of Microfinance on Decision-Making Agency: Evidence from South India." Development and Change 36(1): 75-102.

Huis, Marloes, Robert Lensink, Nhung Vu, and Nina Hansen (2019), "Impacts of the Gender and Entrepreneurship Together Ahead (GET Ahead) training on empowerment of female microfinance borrowers in Northern Vietnam." World Development 120: 46-61.

Imai, Katsushi S., Arun, Thankom, and Annim, Samuel Kobina (2010), "Microfinance and Household Poverty Reduction: New Evidence from India" World Development 38(12): 1760-1774.

Imbert, Clément, and John Papp (2015), "Labor Market Effects of Social Programs: Evidence from India's Employment Guarantee." American Economic Journal: Applied Economics 7(2): 233-63.

- (2016), "Short-term Migration Rural Workfare Programs and Urban Labor Markets - Evidence from India." Economic Research Papers 269578, University of Warwick.

Kaleem, Ahmad and Saima Ahmed (2009), "The Quran and Poverty Alleviation: A Theoretical Model for Charity-Based Islamic Microfinance Institutions (MFIs)" Nonprofit and Voluntary Sector Quarterly 39(3): 409-428.

Karaivanov, Alexander and Anke Kessler (2018), "(Dis)advantages of informal loans - Theory and evidence." European Economic Review 102: 100-128.

Karlan, Dean and Jonathan Zinman (2005), "Elasticities of Demand for Consumer Credit," mimeo, Yale University.

- and Martín Valdivia (2011), "Teaching Entrepreneurship: Impact of Business Training on Microfinance Clients and Institutions." The Review of Economics and Statistics 93(2): 510-527.

- and Jonathan Zinman (2011), "Microcredit in Theory and Practice: Using Randomized Credit Scoring for Impact Evaluation" Science 332: 1278-1284.

- and Leigh L. Linden (2014) "Loose Knots: Strong versus Weak Commitments to Save for Education in Uganda." NBER Working Paper No. 19863. 
-, Bram Thuysbaert, and Bobbi Gray (2017), "Credit with Health Education in Benin: A Cluster Randomized Trial Examining Impacts on Knowledge and Behavior." The American Journal of Tropical Medicine and Hygiene 96(2): 501-510.

Karuppannan, Rajendran (2012), "Micro Finance through Self Help Groups - A Survey of Recent Literature in India" International Journal of Marketing, Financial Services \&3 Management Research 1(12): 1-16.

Khandker, Shahidur R. (2005), "Microfinance and Poverty: Evidence Using Panel Data from Bangladesh." The World Bank Economic Review 19 (2): 263-286

Kochar, Anjini (1997), "An empirical investigation of rationing constraints in rural credit markets in India." Journal of Development Economics 53(2): 339-371.

- (1999), "Smoothing Consumption by Smoothing Income: Hours-of-Work Responses to Idiosyncratic Agricultural Shocks in Rural India." The Review of Economics and Statistics 81(1): 50-61.

Laha, Arindam and Pravat Kumar Kuri (2015), "Measuring Access of Microfinance on Poverty in India: Towards a Comprehensive Index." International Journal of Financial Management 5(1): 11-17.

Maiorano, Diego, Upasak Das, and Silvia Masiero (2018), "Decentralisation, clientelism and social protection programmes: a study of India's MGNREGA." Oxford Development Studies 46(4): 536-549.

McIntosh, Craig, Gonzalo Villaran and Bruce Wydick (2011), "Microfinance and Home Improvement: Using Retrospective Panel Data to Measure Program Effects on Fundamental Events" World Development 39(6): 922-937.

Meyer, R. L. (2002), "The demand for flexible microfinance products: lessons from Bangladesh" Journal of International Development 14(3): 351-368.

Maldonado, Jorge and Claudio González-Vega, (2008) "Impact of Microfinance on Schooling: Evidence from Poor Rural Households in Bolivia." World Development 36(11): 2440-2455.

Ministry of Water Resources, River Development, Ganga Rejuvenation, (2017) "A Brief on Droughts." Published 16 Aug 2017, http://mowr.gov.in/brief-drought.

Minten, Bart, Reardon, Thomas Reardon, and Anneleen Vandeplas (2009), "Linking urban consumers and rural farmers in India: A comparison of traditional and modern food supply chains." IFPRI discussion papers 883, International Food Policy Research Institute (IFPRI).

Monne, Jérôme, Louche, Céline Louche, and Christophe Villa (2016), "Rational Herding toward the Poor: Evidence from Location Decisions of Microfinance Institutions within Pakistan." World Development 84: 266-281.

Montalvao, Joao, Nirmala Nair, Suchitra Rath, and Rajendra Mahapatra (2013), "Integration of Microfinance and Health Education: Evidence from a Cluster-Randomized Controlled Trial in Rural India." Working Paper.

Morduch, Jonathan (1995), "Income Smoothing and Consumption Smoothing." Journal of Economic Perspectives $9(3)$ : 103-114.

- 1999, "The Microfinance Promise." Journal of Economic Literature 37(4): 1569-1614 
Ngo, Thi Minh-Phuong and Wahhaj, Zaki (2012), "Microfinance and gender empowerment." Journal of Development Economics 99(1): 1-12

Padma, K. (2016), "MGNREGA and Rural Distress in India" International Journal of Humanities and Social Science Invention 4(8): 67-76.

Pantoja, Enrique (2002), "Microfinance and Disaster Risk Management: Experience and Lessons Learned" Washington, DC: Wold Bank Prevention Consortium.

Parizat, Roy and Heinz-Wilhelm Strubenhoff (2018), "Using big data to link poor farmers to finance". Brookings Institute Future Development Blog, Accessed January 1, 2020.

Patil, Sandeep and Kiran Kokate (2017), "Identifying factors governing attitude of rural women towards Self-Help Groups using principal component analysis." Journal of Rural Studies 55: 157-167.

Paxson, Christina H (1992). "Using Weather Variability to Estimate the Response of Savings to Transitory Income in Thailand." American Economic Review 82(1): 15-33.

Planning Commission (2003), "Identification of Districts for Wage and Self Employment Programmes" Report of the Task Force.

Rai, Ashok and Ravi, Shamika (2011), "Do Spouses Make Claims? Empowerment and Microfinance in India." World Development 39(6): 913-921

Raza, Wameq A., Ellen Van de Poel, Pradeep Panda, David Dror \& Arjun Bedi (2016), "Healthcare seeking behaviour among self-help group households in Rural Bihar and Uttar Pradesh, India" BMC Health Services Research 16(1).

Samphantharak, Krislert, and Robert M. Townsend (2010), "Household as Corporate Firms: An Analysis of Household Finance Using Integrated Household Surveys and Corporate Financial Accounting." New York: Cambridge University Press.

Shah, Mihir (2016), "Should India do away with the MGNREGA?" The Indian Journal of Labour Economics 59(1): 125-153.

Shoji, M. (2010) "Does contingent repayment in microfinance help the poor during natural disasters?" Journal of Development Studies 46(2) 191-210.

Sukhtankar, S. (2016), "India's National Rural Employment Guarantee Scheme: What Do We Really Know about the World's Largest Workfare Program?" India Policy Forum (Vol. 13, pp. 2009-10).

Swain, Ranjula Bali and Fan Yang Wallentin (2009), "Does microfinance empower women? Evidence from self-help groups in India." International Review of Applied Economics 23(5): 541-556.

Swamy, Vighneswara (2014), "Financial Inclusion, Gender Dimension, and Economic Impact on Poor Households." World Development 56: 1-15

Witte, Susan S., T. Aira, LC. Tsai, M. Riedel, R. Offringa, M. Chang, N. El-Bassel, F. Ssewamala (2015), "Efficacy of a savings-led microfinance intervention to reduce sexual risk for HIV among women engaged in sex work: a randomized clinical trial." American Journal of Public Health 105(3):e95-102. 
Yadav, Satendra Kumar and Dwivedi Ram Kumar (2019), "Role of Microfinance in Inclusive Growth of India" PRAGATI: Journal of Indian Economy 6(1): 52-68.

Yunus, Muhammad (1999), Banker to the Poor: Micro-lending and the Battle against World Poverty, New York: Worth Publishers.

\section{Appendix}

\subsection{Parallel Trends}

In order to carry out a difference-in-difference analysis, we need to satisfy the pre-trends assumption, which states that absence any treatment through the employment guarantee program, the microfinance activity across districts is trends similiarly. First, I use phase 1 districts as my omitted category for my analysis of pre-trends of microcredit activity across districts. I test this assumption using the following econometric specification:

$$
\begin{aligned}
& y=\beta_{0}+\beta_{1} \text { Phase } 2+\beta_{2} \text { Phase } 3+\beta_{3} \text { Post } 06+\beta_{4} \text { Post } 07 \times \text { Phase } 2+\beta_{5} \text { Post } 08 \times \text { Phase } 3 \\
& +\beta_{6} \text { Year }+\beta_{7} \text { Year } \times \text { Phase } 2+\beta_{8} \text { Year } \times \text { Phase } 3+\beta_{9} \text { Year } \times \text { Post } 06+\beta_{10} \text { Year } \times \text { Post } 07 \times \text { Phase } 2 \\
& +\beta_{11} \text { Year } \times \text { Post } 08 \times \text { Phase } 3
\end{aligned}
$$

My econometric test of parallel trends is concerned with $\beta_{6}, \beta_{7}, \beta_{8}$, as these give us information regarding the differences in the time trends before the roll out of MGNREGA across India. For my savings outcomes, as discussed previously, due to a lack of preperiod data for phase one, I exclude phase 1 from my analysis of savings. Therefore, I analyze differences between pre-trends for phase 2 vs. phase 3 . Table 32 presents the estimation results. Across my outcome variables, microfinance activity is rather flat in Phase 1 and the for the pre-period. The pre-preiod trends are slightly increasing for Phase 2 and 3, but these differences are statistically insignificant. 
Table 19: Parallel Trends Analysis of Microfinance

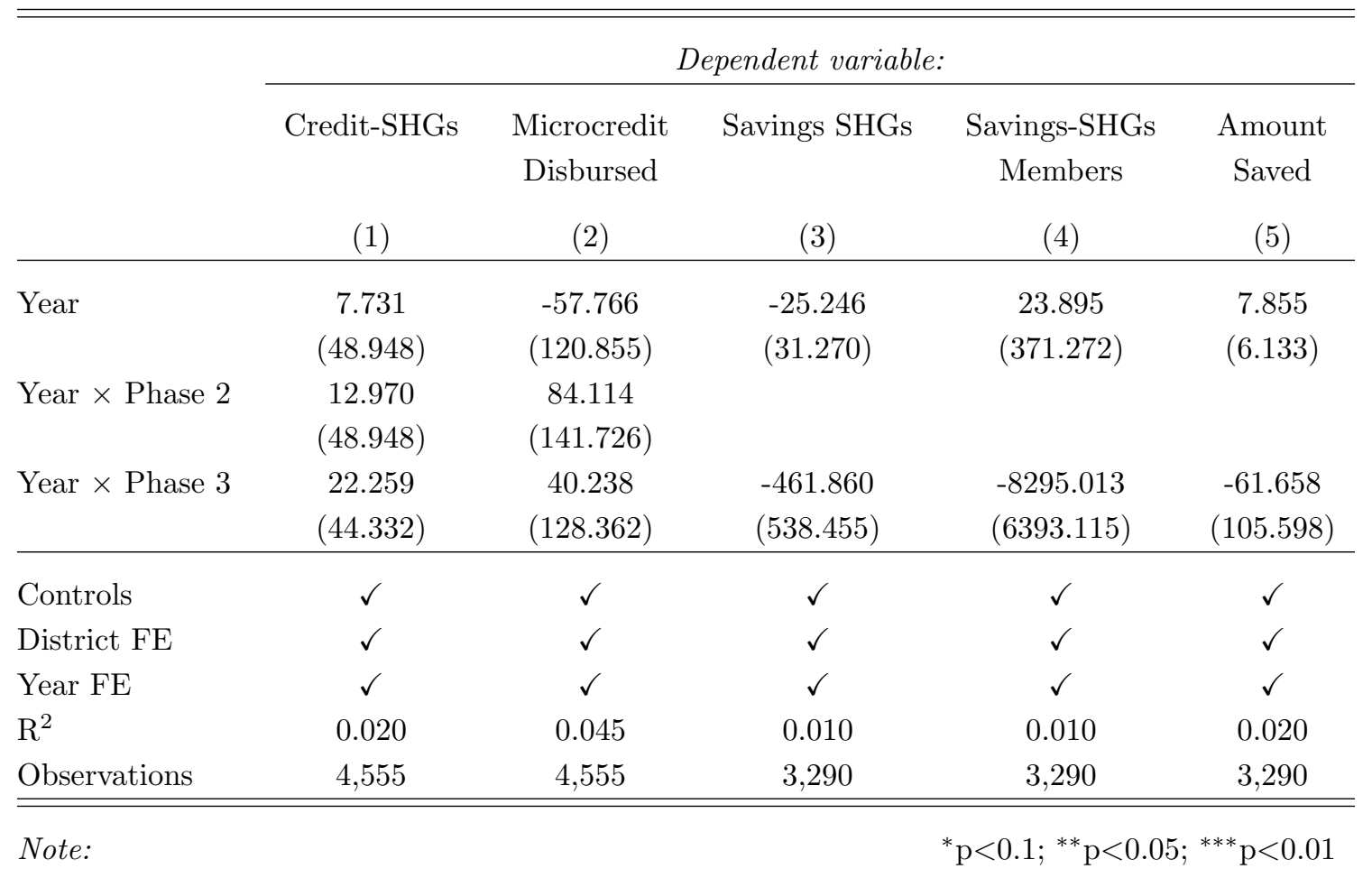


Figure 23: Early and Late District Trends - Credit-linked SHGs

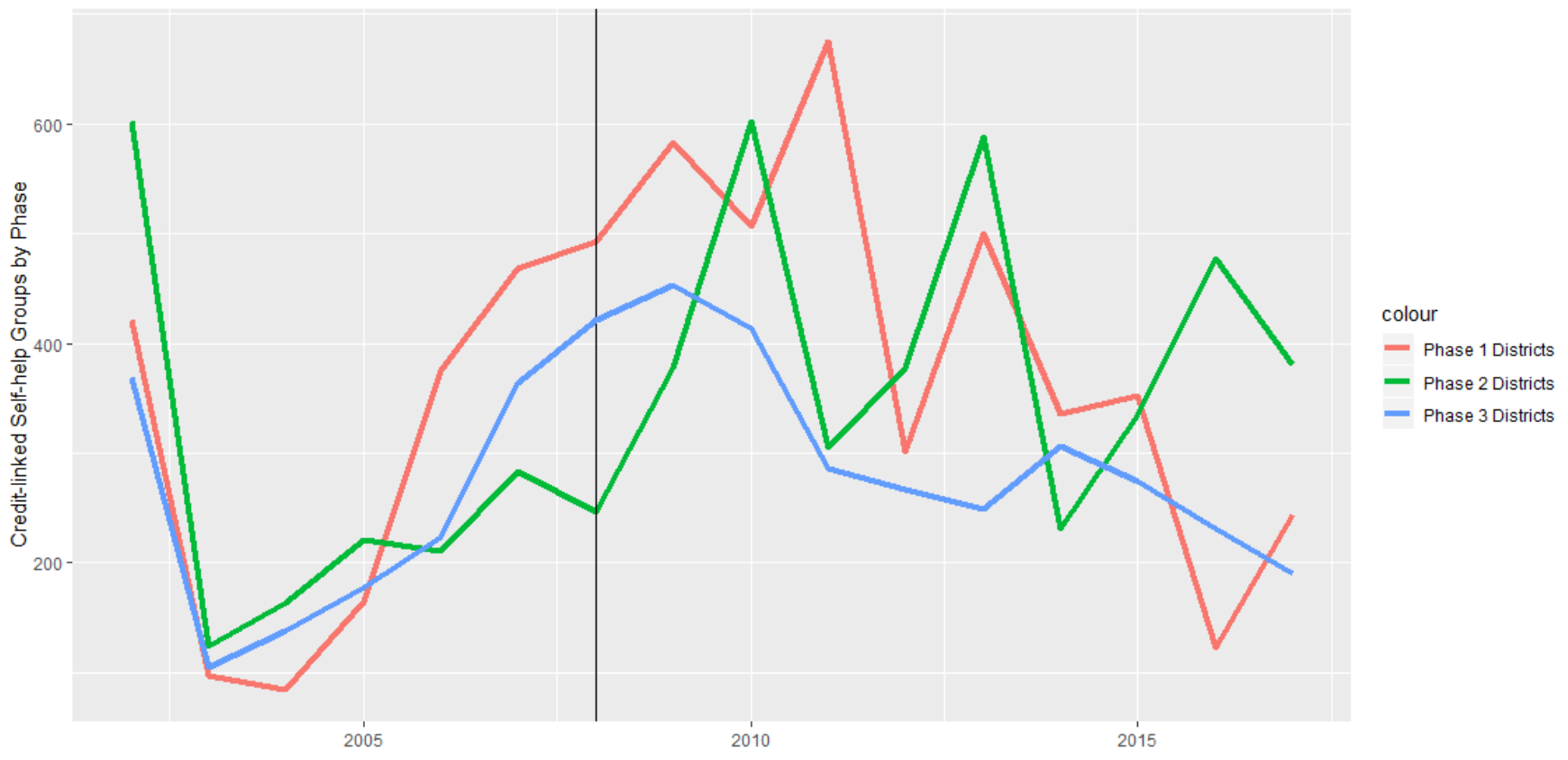

Figure 24: Early and Late District Trends - Savings-linked SHGs

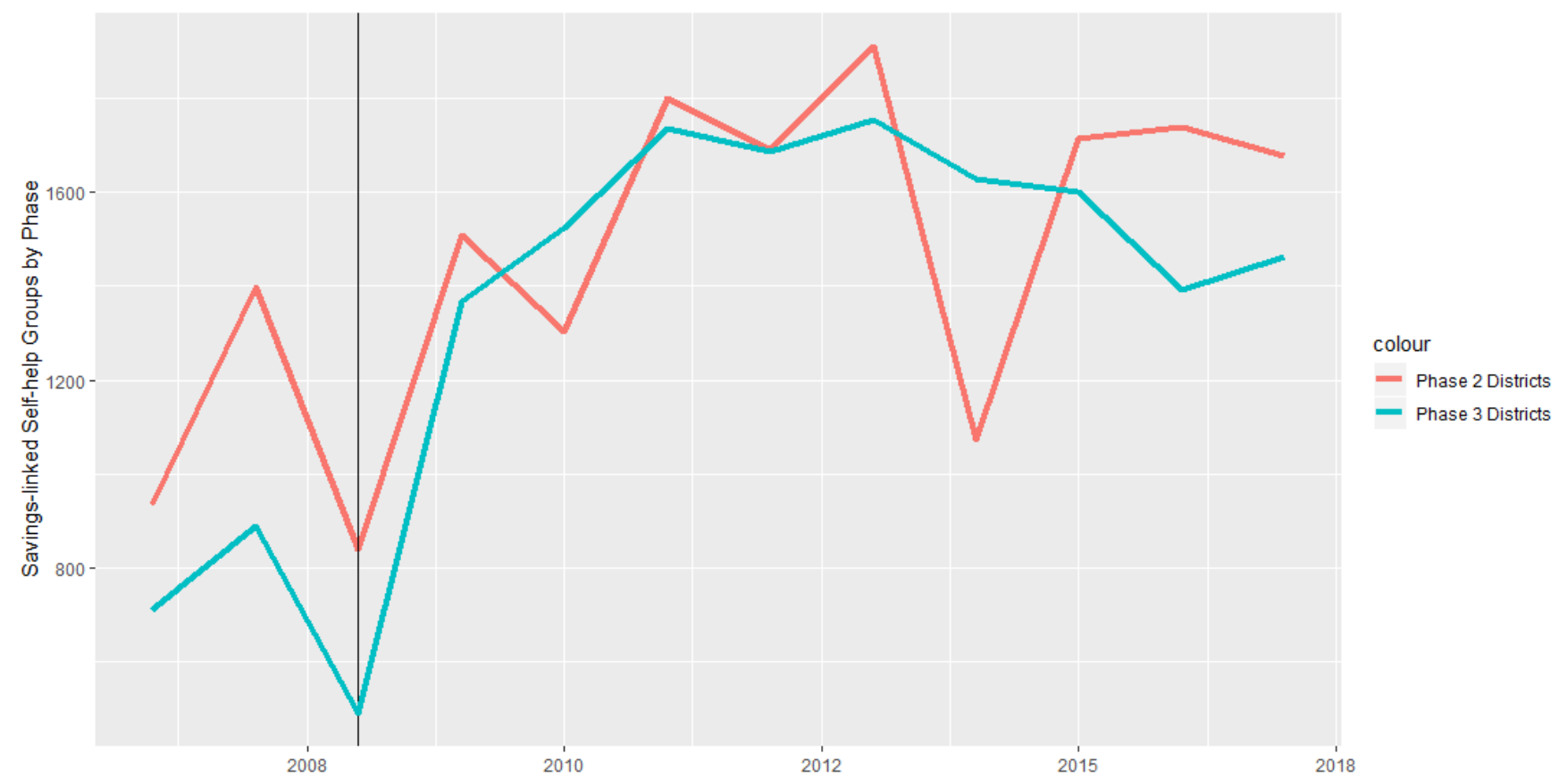


Figure 25: Early and Late District - Savings-linked SHG Membership

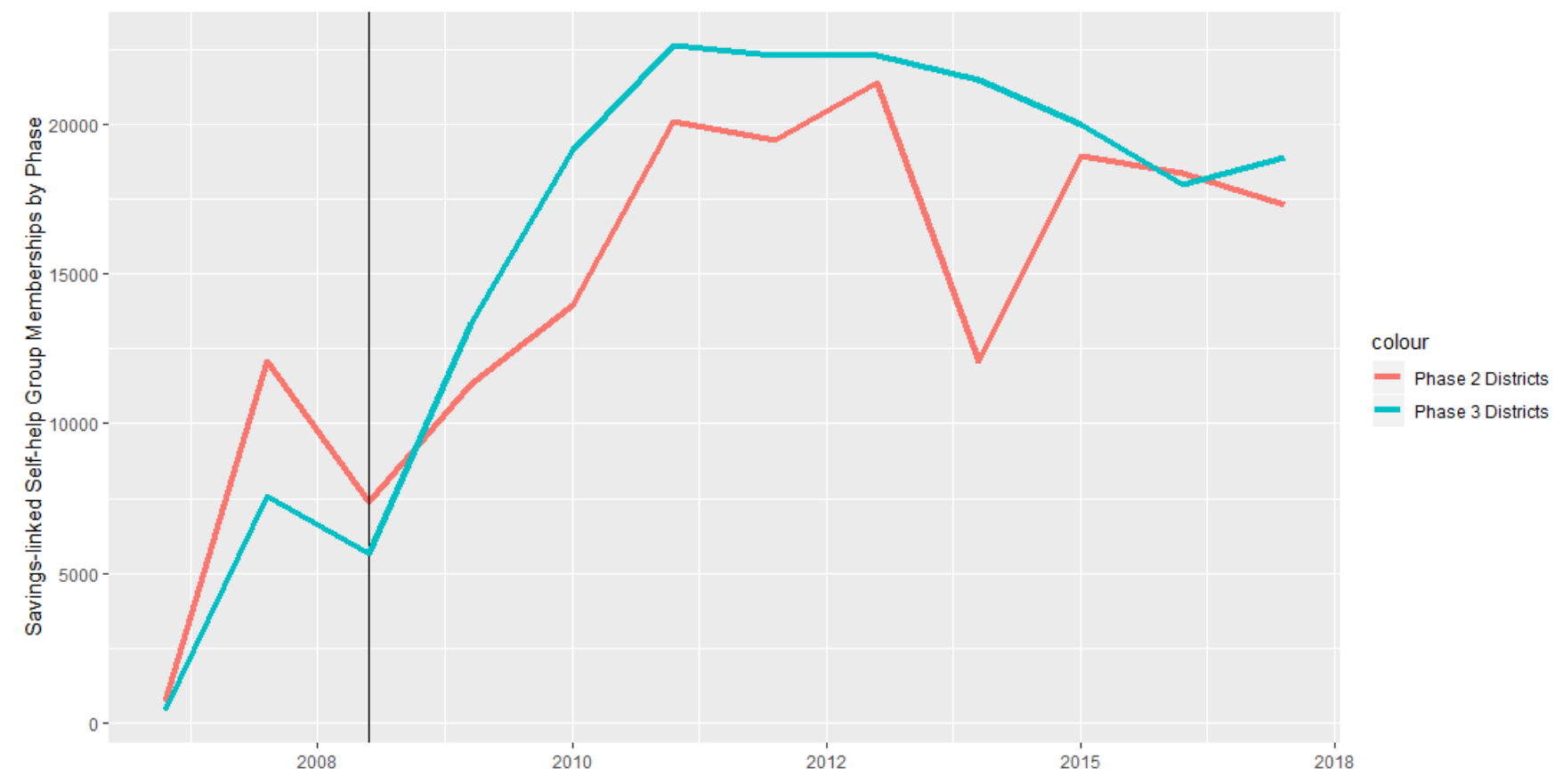

Figure 26: Early and Late District Trends - Microcredit Disbursed to SHGs

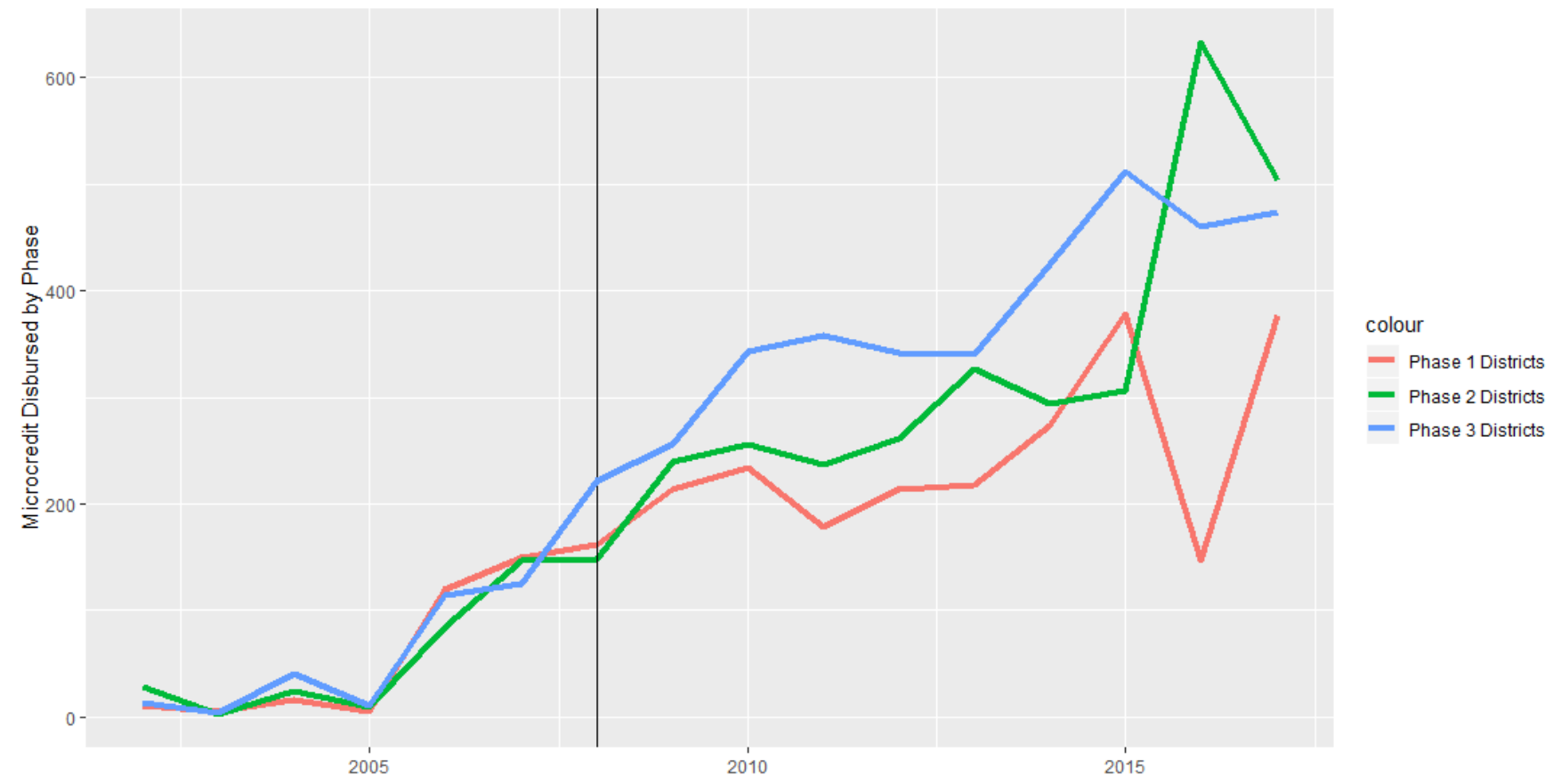


Figure 27: Early and Late District Trends - Deposited Amount by SHGs

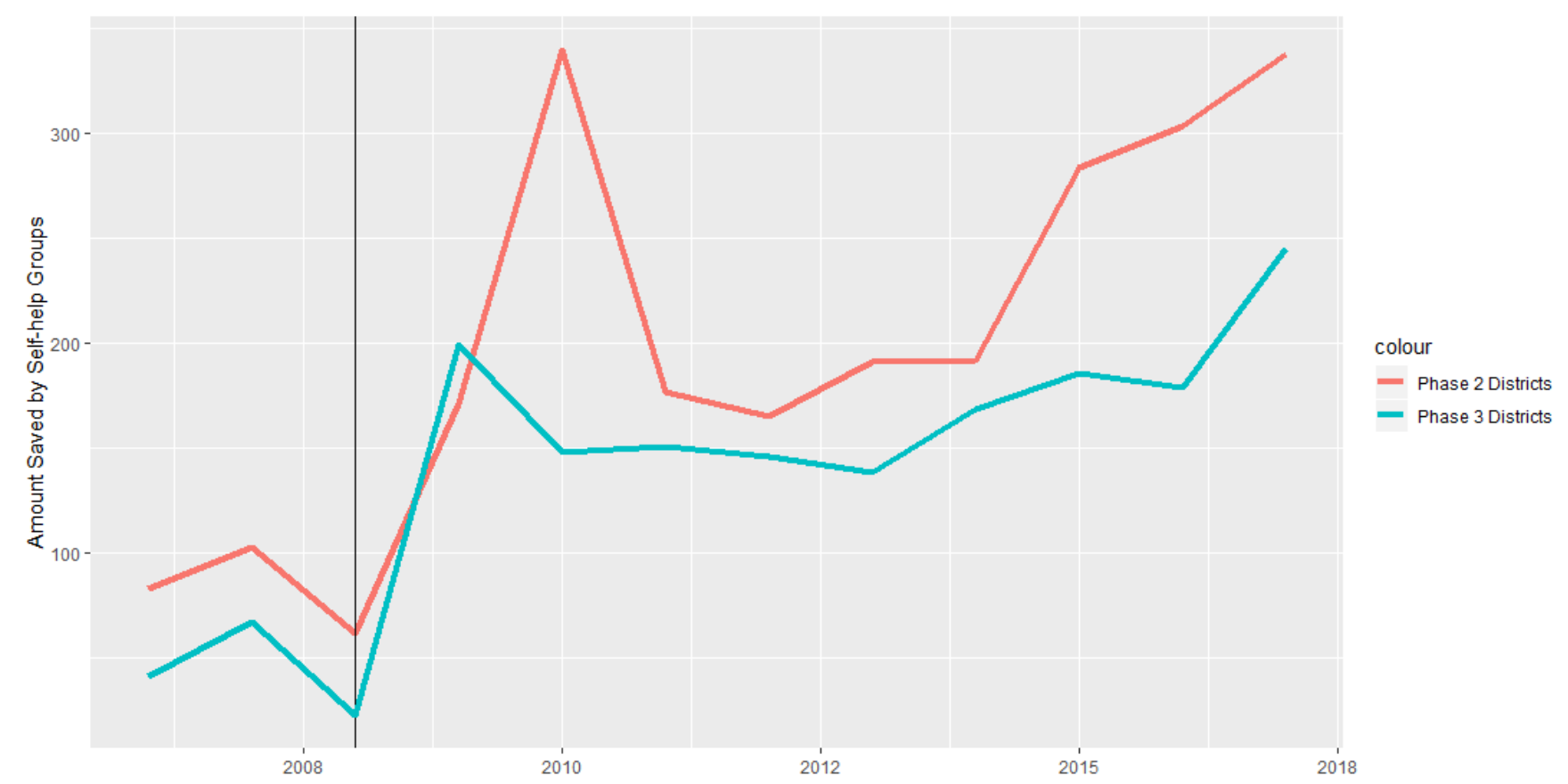




\subsection{Histograms of Microfinance Use}
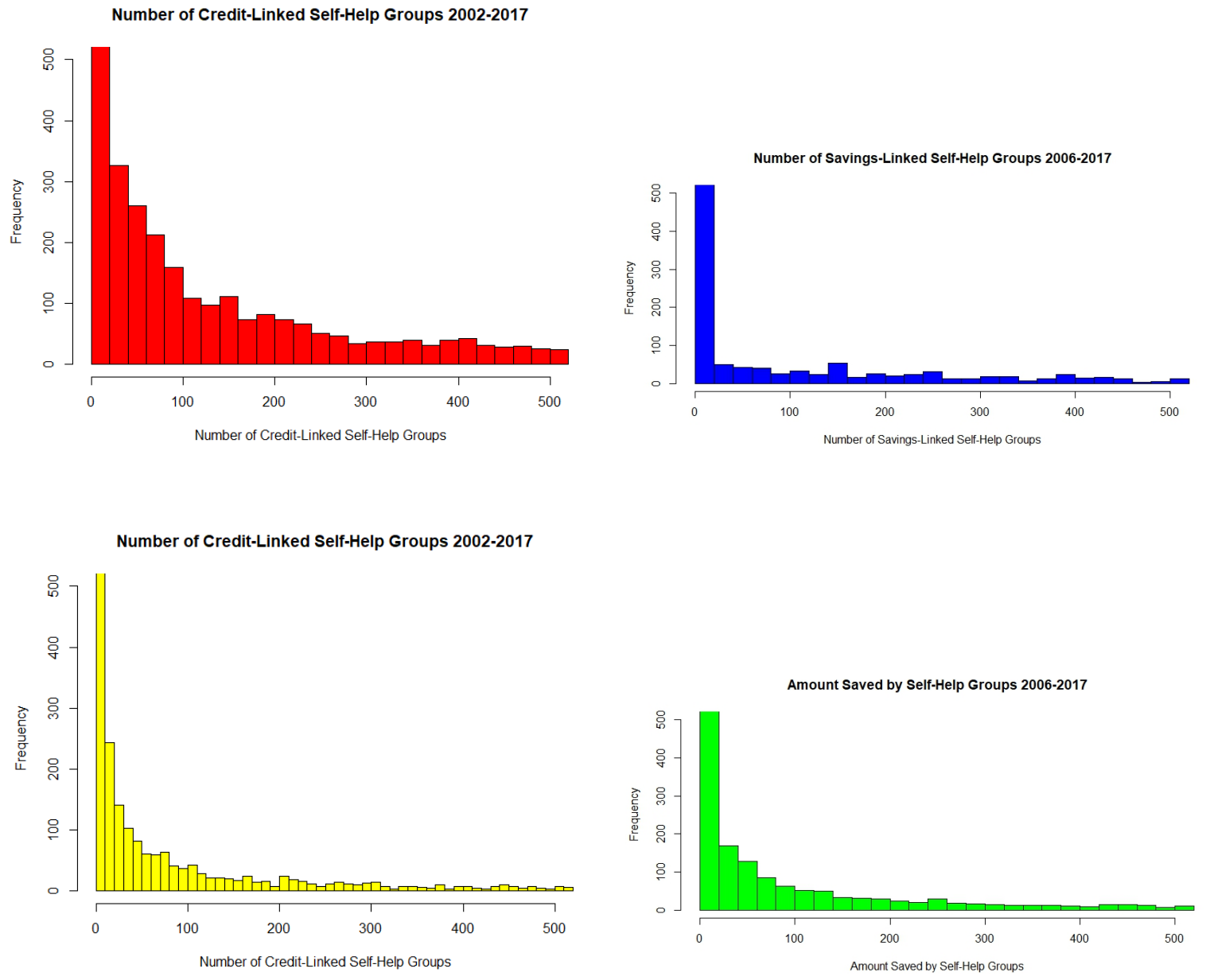


\subsection{Pre and Post Period Comparison of Microfinance Outcomes}

Figure 28: Pre and Post Comparison of Credit Disbursed to Self-help Groups across Phases

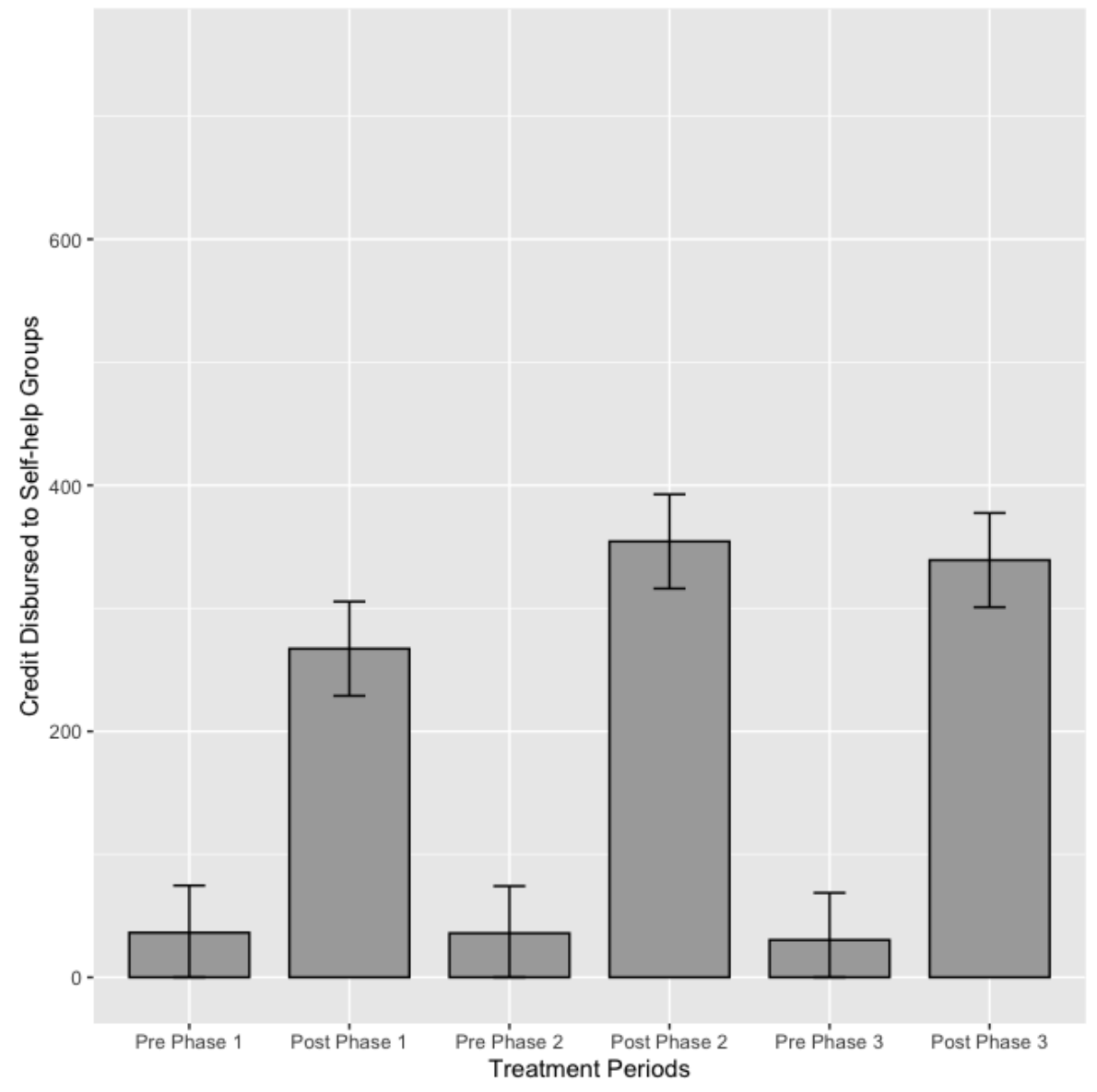


Figure 29: Pre and Post Comparison of Savings Self-help Group Membership across Phases

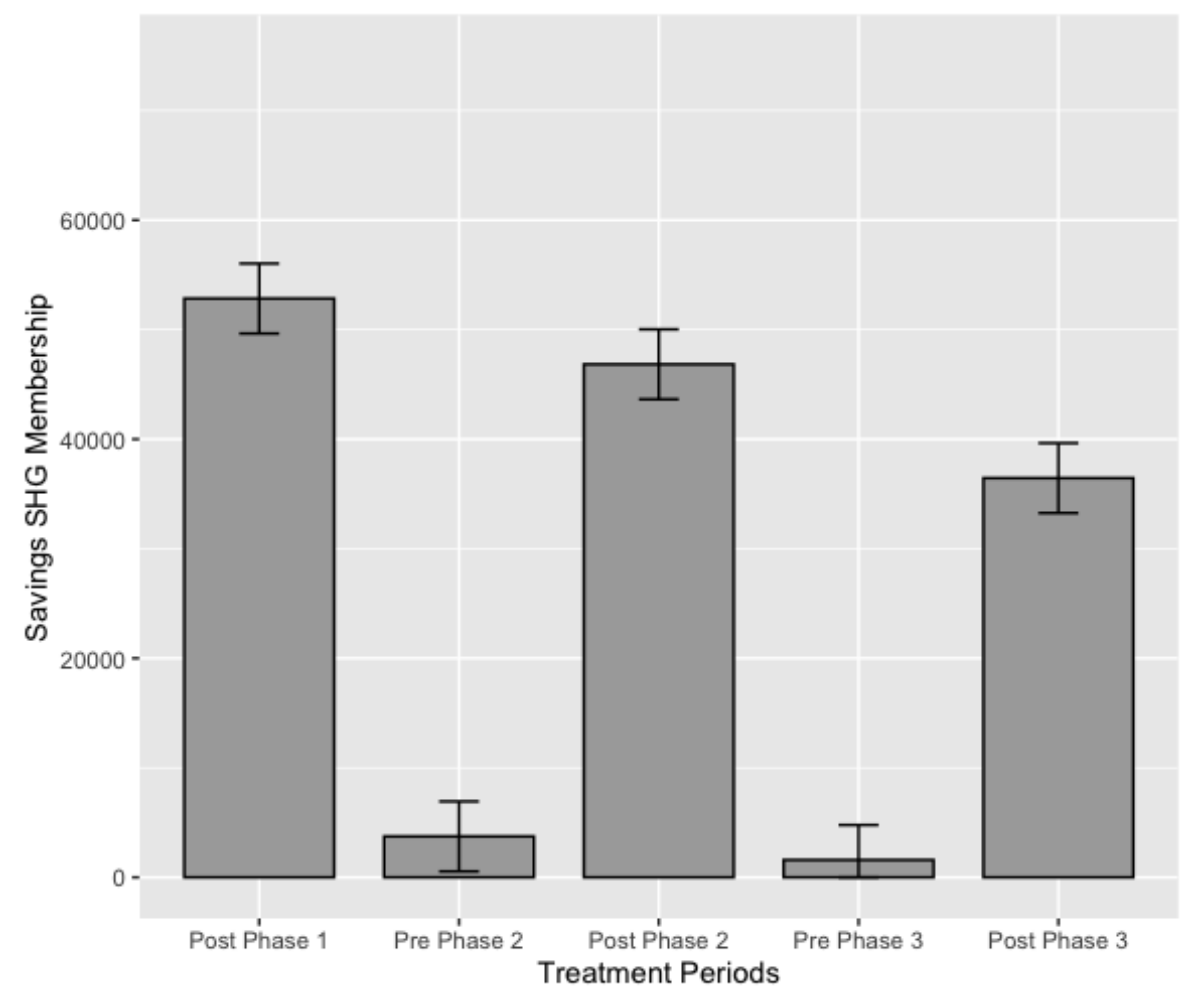

Figure 30: Pre and Post Comparison of Amount Saved by Self-help Groups across Phases

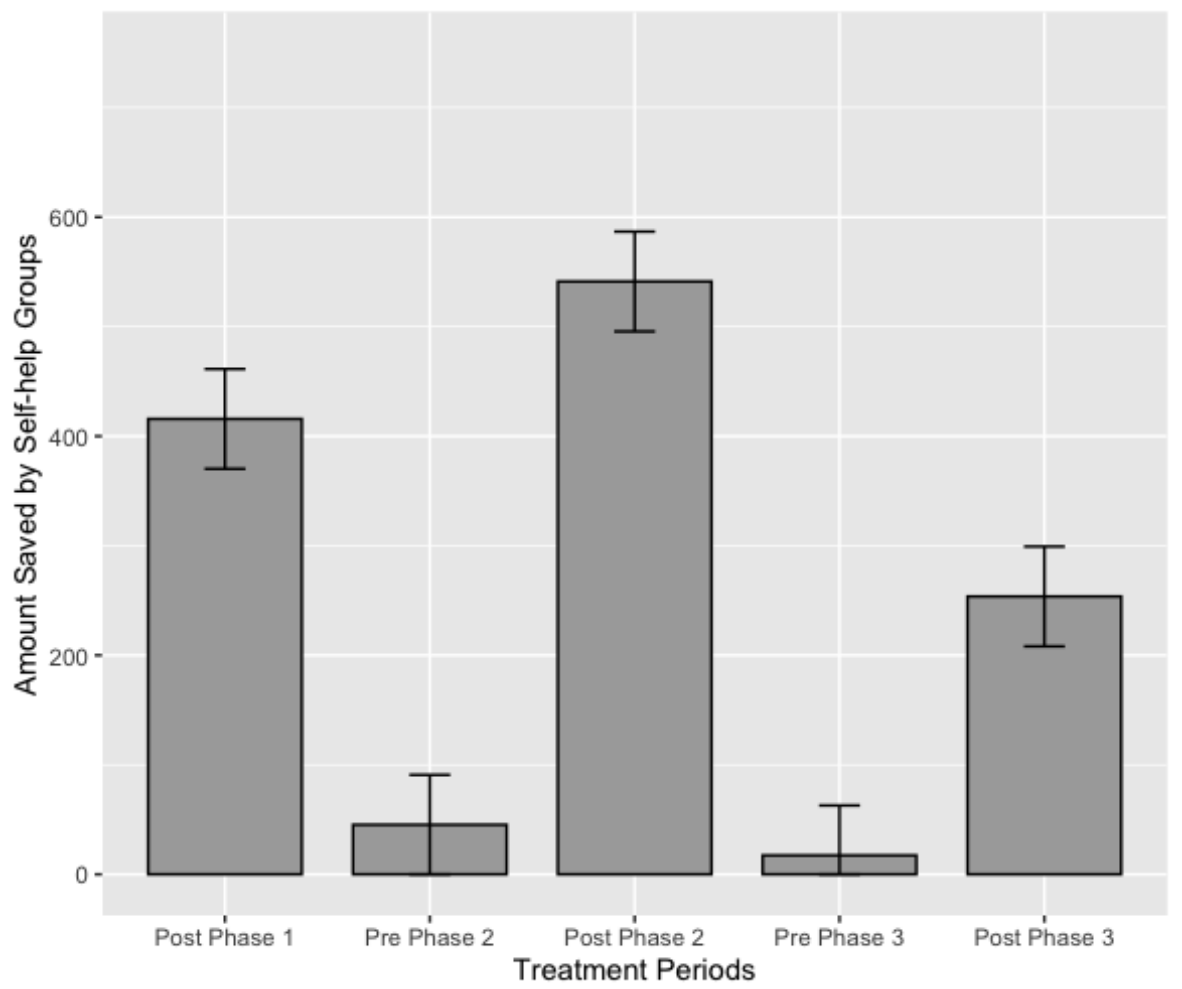




\subsection{Mechanism of Demand - Extended Treated-on-Treatment Rainfall Analy- sis}

Table 20: Effect of MGNREGA on Microcredit Given Annual District Rainfall

\begin{tabular}{lcc}
\hline \hline & \multicolumn{2}{c}{ Dependent variable: } \\
\cline { 2 - 3 } & Credit Self-help & Amount \\
& $(1)$ & $(2)$ \\
\hline MGNREGA & 0.043 & -0.025 \\
& $(0.092)$ & $(0.070)$ \\
Severe Drought $\times$ Job Days & 0.002 & 0.004 \\
& $(0.003)$ & $(0.003)$ \\
Average Rain $\times$ Job Days & 0.002 & $0.005^{* * *}$ \\
& $(0.002)$ & $(0.002)$ \\
Severe Flood $\times$ Job Days & $0.006^{*}$ & $0.014^{* * *}$ \\
& $(0.003)$ & $(0.003)$ \\
\hline District FE & & \\
Year FE & $\checkmark$ & $\checkmark$ \\
\hline \hline Note: & $\checkmark$ & $\checkmark$ \\
\hline
\end{tabular}

Dependent variables are count variables for the number of credit groups and the amount of credit disbursed (in Lakh) to groups that I transform using inverse hyperbolic sine transformation; Intensity of MGNREGA is measured by the number of Job Days generated by rural households in a district; I control for access to water, literacy rates, population density, scheduled caste and tribe, incidence of domestic violence, and area of agricultural land; For rainfall variables, I use the create dummy variables for droughts, average rainfall, and floods. The India Meteorological Department sets these standards as more or less than $50 \%$ of average annual rainfall; Annual rainfall data is not available for some districts, so I exclude these observations from my analysis; The number of observations per rainfall category are 1,045 for Drought, 4,141 for Average Rainfall, and 1,499 for Floods; I include district and year fixed effects in all models; Robust standard errors are clustered at the district level (391 clusters) and given in parentheses; ${ }^{*} \mathrm{p}<0.1 ;{ }^{* *} \mathrm{p}<0.05 ;{ }^{* * *} \mathrm{p}<0.01$ 
Table 21: Effect of MGNREGA on Savings Mobilization Given Annual District Rainfall

\begin{tabular}{lccc}
\hline \hline & \multicolumn{3}{c}{ Dependent variable: } \\
\cline { 2 - 4 } & Savings Self-help & SHG & Amount \\
& $(1)$ & $(2)$ & $(3)$ \\
\hline MGNREGA & $-0.453^{* *}$ & -0.079 & $-0.273^{* *}$ \\
& $(0.185)$ & $(0.284)$ & $(0.116)$ \\
Severe Drought $\times$ Job Days & $0.019^{* * *}$ & $0.030^{* * *}$ & $0.016^{* * *}$ \\
& $(0.004)$ & $(0.008)$ & $(0.003)$ \\
& & & \\
Average Rain $\times$ Job Days & $0.020^{* * *}$ & $0.032^{* * *}$ & $0.017^{* * *}$ \\
& $(0.003)$ & $(0.005)$ & $(0.003)$ \\
Severe Flood $\times$ Job Days & $0.020^{* * *}$ & $0.026^{* * *}$ & $0.017^{* * *}$ \\
& $(0.005)$ & $(0.008)$ & $(0.003)$ \\
& & & \\
\hline District FE & $\checkmark$ & $\checkmark$ & $\checkmark$ \\
Year FE & $\checkmark$ & $\checkmark$ & $\checkmark$ \\
\hline \hline Note: & & $* \mathrm{p}<0.1 ;{ }^{* *} \mathrm{p}<0.05 ;{ }^{* * *} \mathrm{p}<0.01$ \\
\hline
\end{tabular}

Dependent variables are count variables for the number of savings groups, members and amount (in Lakh) saved per group that are transformed using inverse hyperbolic sine transformation; Intensity of MGNREGA is measured by the number of Job Days generated per rural households in a district; I control for access to water, literacy rates, population density, scheduled caste and tribe, and area of agricultural land; For rainfall variables, I use the create dummy variables for droughts, average rainfall, and floods. The India Meteorological Department sets these standards as more or less than $50 \%$ of average annual rainfall; Annual rainfall data is not available for some districts, so I exclude these observations from my analysis; The number of observations per rainfall category are 1,045 for Drought, 4,141 for Average Rainfall, and 1,499 for Floods; I include district and year fixed effects in all models; Robust standard errors are clustered at the district level (391 clusters) and given in parentheses; ${ }^{*} \mathrm{p}<0.1{ }^{* *} \mathrm{p}<0.05 ;{ }^{* * *} \mathrm{p}<0.01$ 


\section{The Power of Employment: Effects of India's Employment Guarantee on Women Empowerment}

Decisions made in the household affect the economic status of a community, like choosing whether or not to open a bank account, to send your children to school, or start a small business. As these decisions can lead to important changes in the growth trajectory of a community, how decision-making occurs in the household is of serious interest. In many countries, women do not share the same decision-making power as the men around them, due to social norms that can dictate gender roles in a community (Bicchieri and McNally, 2018). This preexisting discrimination suggests an imbalance in decision-making power in the household, which makes empowering the role of women a necessity for the health and development of our communities.

Duflo (2012) explains how governments and international organizations work to address gender inequality, providing analysis of the channels used to transform the role of women in communities. Gender-based initiatives work as a direct channel to specifically empower women's individual rights and public participation, like increased access to women's healthcare (Bloom, Kuhn, and Prettner, 2015) and gender quotas in government positions (Besley et al., 2017). These initiatives ensure that policies which inform community development affect opportunities for men and women equally. Generally, economic growth operates as an indirect channel for women empowerment, as increased education and employment opportunities contributes to equality across men and women decision-makers. Given the impact that household decision-making has on a community, measuring the empowerment of women decision-makers is critical to understanding the economic, social, and health status of a community.

The empirical literature on women empowerment ranges widely between studies that focus on women gaining access to simple factors of production (i.e. credit or land inheritance) to studies on gender gaps in wages and barriers to promotions (Mammen and Paxson, 2000). These studies often differ in their contexts, as women empowerment in developing countries is largely concerned with the differences in social norms across communities, and how these norms affect the allocation of household resources. Duflo and Udry, 2004 measures differences in social norms that dictate gender roles regarding agricultural production in Côte d'Ivoire and finds that the effect of weather shocks changes resource allocation decisions across genders in households. Rainfall shocks that impact crops tended only by women shifts all purchases toward food consumption, while no effect exists for crops tend only by men. Rakib and Matz (2016) find similar results regarding the impact of asset holdings across households in Bangladesh. Adverse weather shocks appear to harm the household head's assets (i.e. land and agricultural production) more so than their wives' assets (jewelry), while wives' assets are used as a coping mechanism for illness or the death of family members. The use of wives' assets in this manner is linked to their low representation in the agricultural industry.

Results from these studies and others indicates that men and women differ in their allocation of household resources, and that the balance of decision-making power depends on the income earned by members of the household. Each of these results carries serious implications for the growth of households and communities at large, and especially so for those in developing countries. As a contribution to this literature, I exploit the staggered roll out of the Mahatmas Gandhi Rural Employment Guarantee Act of 2005 ("MGNREGA") to investigate the causal effects of increased income through employment on women empowerment across districts in India.

The MGNREGA program entitles any household in rural India up to 100 days of employment for members

who are willing to do unskilled, manual labor. The empirical strategy for this study is possible through the efforts of the MGNREGA Planning Commission to balance the spread of employment across states. By 
ranking districts along certain demographic and social characteristics, the Commission gradually provided access to MGNREGA employment across India in three distinct phases. Using this ranking, the 200 most "backward" districts could access employment in February 2006 (Phase 1), then it was extended to another 130 districts in April 2007 (Phase 2), and then to the rest of India in January 2008 (Phase 3). Like Clement Imbert and Papp (2015) I exploit this gradual implementation, first to the districts ranked as having lower agricultural wages, higher proportions of "backward castes", and lower agricultural output per-worker, and then to the rest of India.

The Ministry of Rural Development in India collects, and makes public, detailed information regarding MGNREGA number of job cards, workers expenditure details, work details, and worker account details. The worker detail most important for this study is their gender. By analyzing the intensity of MGRNEGA uptake across districts and genders, I can use a difference-in-differences panel fixed effect regression model to estimate the causal effects of increased income for women on outcome variables that represent key decisions made in the household related to women empowerment. The outcomes variables I analyze are the demand for microfinance, primary school enrollment and violence against women. Changes in these variables represent the effects of increased income through employment on what the literature identifies changes in women empowerment.

Results from this analysis indicate several changes to women empowerment within districts due to uptake of MGNREGA employment by women. As people take up employment through MGNREGA across districts, and differentiating employment uptake by gender, I find that the demand for both credit and savings increases for women, while remaining unchanged or decreasing for men. I also explore effects of employment Lower primary (Grades 1-4) and Upper Primary (Grades 5-8) enrollment. I find that as women employment within a district increases, government lower primary school enrollment increases. Results regarding school enrollment suggest that income earned from MGNREGA employment is sufficiently high to cover the costs of government-aided schooling. Finally, I document decreases to incidents of sexual harassment and interpersonal violence as women employment increases through MGNREGA. Take together, these results indicate positive increases to women empowerment across districts due to MGNREGA employment.

The paper begins by providing an overview of the literature pertaining to my outcome variables and women empowerment in Section 2. Sections 3 and 4 explain the data and empirical strategy, respectively, and Section 5 offers the results of the analysis. Section 6 discusses the interpretation of the results and discusses channels of further analysis, and Section 7 concludes.

\section{Literature Review}

Literature on development and women empowerment is widespread across topics and growing in the depths of its analysis. Upadhyay et al. (2014) and Pratley (2016) offer systematic reviews of both qualitative and quantitative studies on the role of women and their economic and health status in communities around the world. This literature continues to grow as more countries adopt gender-specific policies to promote gender equality in household decision-making and community leadership. A motivation for this analysis comes from recent studies on women empowerment initiatives that identify differences in how men and women make investments in their households given shocks to household income from conditional cash transfer programs (Almås et al., 2018).

Two key decision-making areas regarding the allocation of household resources that I will investigate in this study are the use of financial markets and investments in human capital through education. Shifts in 
the allocation of resources could indicate effects of these policies on the empowerment of women. Further, a large literature identifies shifts in household decision-making dynamics and the role of women in communities as affecting the incidence of physical and psychological conflict (Bhattacharyya, Bedi, and Chhachhi, 2011). The following sections explores the literature on each of these variables and their link to the empowerment of women in households and communities.

\subsection{Women Empowerment and Microfinance}

In 2018, 139.9 million clients benefited from microfinance worldwide, with large portions of those beneficiaries being women and rural households (Microfinance Barometer, 2019). A reason why women benefit so much from microfinance is that a major component of many microfinance initiatives is women empowerment through access to financial services. Use of credit and savings has been identified in the literature as an indication of increased female empowerment within the household (Ashraf, Karlan, and Yin, 2010 Ganle, Afriyie, and Segbefia, 2015). Differences in borrowing behavior between men and women show that men tend to spend borrowed money on themselves, while women are more likely to share money across the household (Kabeer, 2009). These borrowing characteristics, along with addressing gender discrimination, have caused microfinance initiatives all over the world to adopt strategies to target and empower women in communities.

In 1992, NABARD started the Self-Help Group - Bank Linkage Program to provide financial services to underserved households throughout India. The NABARD linkage program is considered one of the largest microfinance efforts in terms of clientele and outreach, in the world 28. The NABARD self help group linkage program functions by connecting commercial, regional, and cooperative banks and non-government organizations with rural, poor groups of about 10-15 individuals. These groups are encouraged to meet frequently and pool their savings, so that they can open a savings account, as many people do not have enough savings to open an account on their own (Bansal, 2003). NABARD had the explicit purpose of targeting women at the beginning of the self help group linkage program, but has since focused on both men and women. Overall benefits of self-help groups to men and women group members like increases by $17 \%$ in employment, $33 \%$ in net income per household, $72 \%$ in assets and $200 \%$ in savings per capita post-group formation (Garikipati, 2008).

A reason for looking into the relationship between employment and microfinance comes from evidence that while many women are interested in the benefits of self-help groups, a lingering fear of predatory lending in rural areas. In these areas, women would prefer secure employment to microcredit as a way of supporting their personal businesses (Desai and Joshi, 2014). Women using self help groups may also qualify for other poverty alleviation initiatives, which allows for interaction and substitution across program benefits. Research on the interaction between microcredit and other cash transfer programs in India shows that women can benefit from taking advantage of the positive interaction of these economic and social policies to realize their full potential in communities (Sharma, Dua, and Hatwal, 2012). Rodriguez2020microfinance analyzes the effects of India's employment guarantee program on the demand for microfinance in self help groups, finding demand increases given uptake of MGNREGA. As other studies identify how self-help groups foster women empowerment (Patil and Kokate, 2017), I contribute to this literature by analyzing the effect of employment by women on the demand for microfinance.

\footnotetext{
${ }^{28}$ MicoCredit Innovations Department, NABARD
} 


\subsection{Women Empowerment and Primary Education}

Labor force participation behavior is likely to be affected significantly by the costs associated with replacing maternal care with nonmaternal care (Kimmel, 1998). Evidence from studies on child care subsidies in Germany find policies that expand the coverage availability of child care availability longer significantly increases maternal employment (Müller and Wrohlich, 2020). Gender-focused policies like these increase access to employment and provide an opportunity for women to gain and maintain decision-making power in the household as income-earners.

Subsidies are not accessible or available in communities to lower the costs of child care for women. Public education and afterschool programs offer opportunities for both household investment and child care provision. Results from randomized controlled trials in Chile find that afterschool programs act as a substitution for at-home child care, which allows for increased maternal employment and labor participation (Martınez and Perticará, 2017). Early education programs have been found to have as similar effects as afterschool programs. Pre-primary school participation among children aged between 3 and 5 induced by the program appears to increases maternal employment in Argentina (Berlinski and Galiani, 2007. The added costs of free, compulsory education are often responsible for households keeping their younger children at home, while still providing a homeschooled education to children (Behrman et al., 1999).

Like other countries in the world, the Indian government provides free and compulsory elementary education (grades 1 through 8) to children across all districts in the country. Elementary education refers to lower primary level, grades 1-5, and upper primary level, grades 6-8. Households need to incur the costs of education if a child is going to attend school. Tilak (2002) discusses important distinctions between private and government-aided schools. While it is free to attend government schools, households still need to pay the costs of attending and boarding at theses schools.

Given costs to education, access to MGNREGA could trigger an increase in enrollment for government and private schools, as households earn enough income from maternal employment to send children to school. While Afridi, Mukhopadhyay, and Sahoo (2016) documents a positive effects of women participation in MGNREGA and school enrollment using child-level school enrollment in the state of Andhra Pradesh, Francavilla, Giannelli, and Grilli (2013) identifies an income threshold that households must cross in order to send their children to school. It appears that the income earned from self-employment does not sufficiently cover the costs of schooling, but wages generated by MGNREGA employment are sufficiently high to cause an increase in school enrollment.

\subsection{Women Empowerment and Violence Against Women}

Violence against women is a pervasive and constant problem, which is why the World Health Organization and other development entities work to implement initiatives that reduce interpersonal violence during the "normal times" (Kabeer, 2014). Women empowerment initiatives mainly target activities that affect the risk of intentional violence, which include instances where physical violence or emotional intimidation is used to maintain household roles and incentives. Tur-Prats (2019) offers evidence that households where childcare is handled by another family member, thus allowing the wife to work, experience less intimate partner violence than households where a wife raises children at home. The cost of violence is high for a wife working, as it will result in reduced household productivity.

Women who control resources for the household also face an increased risk of violence. Hsu (2017) provides evidence of this risk by analyzing the timing of welfare payments to female TANF recipients. Hsu 
finds increased incidence of assault and intimidation before payment dates, suggesting men use the threat of violence to gain control of household resources before payments get disbursed to women. Similar results were found using a randomized control trial where abuse against women increased with participation in entrepreneurship training programs. Bulte and Lensink (2019) conclude that association between increased income and the program is the likely mechanism for violence.

If women can maintain control of resources under the threat of violence, results indicate that transfers reduce controlling behaviors and physical and/or sexual violence by 6 to 7 percentage points in Ecuador (Hidrobo, Peterman, and Heise, 2016) with similar results found Bangladesh (Roy et al., 2019) and Spain (Alonso-Borrego and Carrasco, 2017). Other studies emphasize the availability of cash transfers programs for both men and women as the mechanism for reductions in intimate partner violence. Haushofer and Shapiro (2016) and Haushofer, Ringdal, et al. (2019) analyze evidence from a randomized control trial in Kenya where unconditional cash transfers reduce both physical and sexual violence as both men and women become eligible for the transfer. Haushofer, Ringdal, et al. (2019) develop a theory to explain these results. Defining violence as a way to extract resources, if men use physical violence, but find it distasteful, then we can expect physical violence to decrease as men receive cash transfers. While sexual violence is extractive and pleasurable for men, we would expect decreases in sexual violence as women receive transfers and gain decision-making power in the household.

\section{Data and Setting}

The setting for this study is at the district level in India. The analysis for this study is possible through several publicly available data sources that track changes in MGNREGA employment, microfinance, crime, and primary school enrollment in communities throughout India. The following sections describe the data collected for all variables used in my analysis.

\subsection{The Mahatma Gandhi National Rural Employment Guarantee Act 2005}

The Mahatma Gandhi National Rural Employment Guarantee Act ("MGNREGA") passed in September 2005. The act entitles any household in rural India up to 100 days of employment for members who are willing to do unskilled, manual labor (Clement Imbert and Papp, 2015). If workers demand employment and they are not granted work within 15 days, then they are entitled to unemployment allowance. Funding for MGNREGA comes from both the central and state governments. The central government provides $100 \%$ of the wages and $75 \%$ of the material costs for MGNREGA projects undertaken by Indian states (Padma, 2015 ). State governments provide $25 \%$ of the material costs, and $100 \%$ of unemployment allowances, which is approximately $50 \%$ of an insured worker's daily average earnings. Over 52 million rural households were provided with 2.6 billion person-days of employment in FY 2018-2019 (MGNREGA At a Glance, 2018). These statistics make MGNREGA the largest workforce program in the world.

To obtain employment, adult household members register with the gram panchayat (MGNREGA Operational Guidelines, 2013), which refers to the village council within a district. After submitting the necessary documents, the gram panchayat issues a job card to household members. Registered workers then submit applications for work to the gram panchayat. Employment is to be provided at a minimum of fourteen days of continuous work and within a radius of $5 \mathrm{~km}$ of the panchayat. Extra wages are given to employment that is beyond the $5 \mathrm{~km}$ radius. The Ministry of Rural Development collects detailed information regarding 
number of job cards, workers expenditure details, work details, and worker account details. We are able to analyze this information because the MRD makes all employment information publicly available.

Information regarding uptake of MGNREGA is tracked and made public by the Ministry of Rural Development. Uptake of MGNREGA is tracked in terms of the annual number of jobs per village, district, and state, in terms of worker-days generated, as the program works by offering 100 days of employment per rural household. Like (S. Das and Mocan, 2016), I calculate the intensity of the MGNREGA program by dividing the total number of worker days generated in each district by the number of rural households.

Given the intention of the program, I exclude some districts from my analysis. Urban districts were not included in the roll-out of MGNREGA and so I omit these district from my analysis. Following (S. Das and Mocan, 2016), I exclude Northeastern States except for Asaam, as these dates benefit from other funding from the central government as part of other programs. I also exclude the Union Territories, as the governance follows a different structure to other states and Maharashtra because it has its own rural employment guarantee scheme since 1977, which could bias my results. Finally, I drop divided or newly established districts between 2002-2017. Thus, of the 624 districts in India, my sample includes 144 Phase 1 districts, 85 Phase 2 districts, and 162 Phase 3 districts, for a total of 391 districts. The following table presents summary statistics regarding district uptake of MGNREGA employment generally and across genders.

Table 22: Summary Statistics - MGNREGA Job Days Generated by Phase

\begin{tabular}{lll} 
Variables & Average & Standard Deviation \\
\hline Job Days Per Rural Household & & \\
Phase 1 & $17.12^{* * *}$ & 15.53 \\
Phase 2 & $12.05^{* *}$ & 11.06 \\
Phase 3 & 11.13 & 12.55 \\
Men Job Days per Rural Household & & \\
Phase 1 & $9.17^{* * *}$ & 7.86 \\
Phase 2 & $6.32^{* * *}$ & 4.82 \\
Phase 3 & 4.46 & 4.40 \\
Women Job Days Per Rural Household & & \\
Phase 1 & $8.00^{* * *}$ & 9.39 \\
Phase 2 & $5.91^{* * *}$ & 7.62 \\
Phase 3 & 6.75 & 9.92 \\
\hline
\end{tabular}

I use a paired t-test to separate our sample into two comparable samples: Phase 1 districts vs. Phase 3 districts and Phase 2 districts vs. Phase 3 districts; ${ }^{* *} 1 \%,{ }^{* *} 5 \%,{ }^{*} 10 \%$ level of significance.

While state specific studies like Carswell and De Neve (2014) and Breitkreuz et al. (2017) identify other positive outcomes like increased rural wage levels, enhanced low-caste working bargaining power, and reduced dependence on high-caste employers. Yet, several criticism have been levied against MGNREGA with regards to untimely payments for work and lack of available employment. Chopra (2015) and U. Das, Singh, Mahanto, et al. (2012) analyze specific states, Rajasthan and West Bengal, respectively, and document how participation may be low in areas due to a lack of awareness in how MGNREGA operates. This lack of information contributes to administrative corruption, and ultimately, households not receiving MNGREGA 
benefits. Others studies, like Mihir Shah (2016), argue against broader consequences of MGNREGA and its effects on the agricultural industry, as farmers move away from their farms for the benefits of the employment guarantee, thus making agriculture less productive. With its criticisms, rural households continue to use MGNERGA, and therefore, its effects on rural households is both policy relevant and socially significant.

\subsection{NABARD and the Self-Help Group Model}

The NABARD linkage model represents a decentralised, cost effective microfinance initiative, successfully facilitating access to financial services for over 103 million households 29 NABARD tracks the success and growth of self-help groups through its Status of Microfinance report, which has been published since 2000. The self-help groups monitored by NABARD represent about $55 \%$ of total self-help groups in the country, the rest remaining unlinked to a third-party financial institution (A Handbook on SHG - Bank Linkage Program, 2017). In all of its activities, NABARD works with about 33 percent of all microfinance customers in Asia and the Pacific as of 2013 (Cull and Morduch, 2017). Others have used this data set to analyze access to microfinance (Laha and Kuri, 2014), as well as, financial inclusion and gender (Swamy, 2014).

In its early years, NABARD focused exclusively on microcredit, as early NABARD reports focus only on credit activities at the state and district level across India. In 2006, NABARD started tracking savingslinked self-help groups, which are separately tracked from credit-linked self-help groups. In their reports, NABARD tracks the number of self help groups established annually through its various partner agencies: commercial banks, regional rural banks, cooperative banks, and non-profit organizations. I will focus my analysis on self-help groups connected to both district cooperative banks and non-government organizations. Each of these entities work on a grassroots, district level to establish, develop, and connect self-help groups to microfinance institutions. Average annual income among self-help groups members has been estimated to be $\$ 337.00$ (25,689 Rs.), while unbanked members is estimated to be $\$ 219$ (16,779 Rs.) (dutta2017). These unbanked members are considered below the poverty line in India, which demonstrates what access to financial services can mean for communities as we analyze the growth in microfinance across districts.

NABARD records the amount disbursed as credit, as well as, the amount saved by self-help groups per institution. I include these as outcome variables in my analysis. Lastly, regarding savings activity, NABARD collects information regarding self-help groups membership, number of groups, and annual group deposits. NABARD does not collect information regarding credit-linked self-help group membership, which is a limitation to the analysis. My sample of 391 district compares 162 Phase 1 districts, 85 Phase 2 districts, and 162 Phase 3 districts who gain access to the program in 2006, 2007, and 2008 respectively. For my preperiod, I use information from 2002, 2003 and 2004 in my analysis of credit. I use 2006 and 2007 as my preperiod in my savings analysis, comparing Phase 2 to Phase 3 districts. Table 23 presents the average and standard deviation for each of my microfinance outcome variables across all phases. Both credit and savings activity appears different for districts in Phases 1 and 2, as compared groups in Phase 3 districts. Paired differences in average microfinance activity are statistically significant in Phase 1 and Phase 2, each relative to Phase 3. However, microcredit disbursed to self-help groups does not appear to be different. This suggests that mobilization with regards to microfinance is different across phases, while there are no differences in credit disbursements to self-help groups.

\footnotetext{
${ }^{29}$ 2017-18 Status of Mircofinance
} 
Table 23: Summary Statistics - Microfinance Use by Phase

\begin{tabular}{|c|c|c|}
\hline Variables & Average & Standard Deviation \\
\hline \multicolumn{3}{|c|}{ Credit Self help Groups } \\
\hline Phase 1 & $768^{* * *}$ & 2,287 \\
\hline Phase 2 & $853^{* * *}$ & 2,605 \\
\hline Phase 3 & 498 & 1,054 \\
\hline \multicolumn{3}{|c|}{ Credit Disbursed to SHGs (in Rs. Lakh) } \\
\hline Phase 1 & 303.49 & 106.44 \\
\hline Phase 2 & 390.21 & 128.65 \\
\hline Phase 3 & 369.49 & 127.39 \\
\hline \multicolumn{3}{|c|}{ Savings Self help Groups } \\
\hline Phase 1 & $4,122^{* * *}$ & 5,165 \\
\hline Phase 2 & $4,234^{* * *}$ & 6,443 \\
\hline Phase 3 & 2,589 & 3,597 \\
\hline \multicolumn{3}{|c|}{ Savings Group Membership } \\
\hline Phase 1 & $48,066.07^{* * *}$ & $74,065.28$ \\
\hline Phase 2 & $51,774.15^{* * *}$ & $69,106.89$ \\
\hline Phase 3 & $29,605.92$ & $47,991.48$ \\
\hline \multicolumn{3}{|c|}{ Amount Saved by SHGs (in Rs. Lakh) } \\
\hline Phase 1 & $452.66^{* * *}$ & 109.73 \\
\hline Phase 2 & $586.45^{* * *}$ & 148.25 \\
\hline Phase 3 & 270.99 & 693.18 \\
\hline
\end{tabular}

Several studies analyze the impact of self-help groups on the health, economic, and social status of communities, while focusing the scope of their analysis to particular states or districts within states in India. Karuppannan (2012) provides a literature review of 53 such studies conducted from 2000-2012. The review identifies positive trends in poverty alleviation and economic well-being across Indian states. Many of these focused studies find SHG membership has positive effects on female empowerment and community development (Swain and Wallentin, 2009), healthcare seeking behavior (Raza et al., 2015), and long-term consumption and asset accumulation (Deininger and Liu, 2013). I contribute to this literature by providing a comprehensive evaluation of credit and savings self-help group formation and activity across and within districts in India, given positive changes to household income.

\subsection{District Information System for Education}

The District Information System for Education is a government initiative to build and maintain an information system regarding the education in India. Started in 1995 and redesigned in 2001, the initiative coordinates information from districts and states on students, teachers, and school infrastructures for all levels of education in India (DISE Mission Statement, 2001). For this study, I collect data on primary school enrollment across schools in India. The education system breaks lower primary and upper primary education into eight standard levels. Lower primary refers to grades 1-5 (ages 6 to 10) and upper primary refers to grades 6-8 (ages 11 and 12). 
Table 24: Summary Statistics - Enrollment Across Grade Levels by Phase

\begin{tabular}{cll} 
Variables & Mean & Standard Deviation \\
\hline Lower Primary Enrollment & & \\
Phase 1 & $0.480^{* * *}$ & 1.209 \\
Phase 2 & $0.405^{* *}$ & 1.586 \\
Phase 3 & 0.263 & 0.705 \\
Upper Primary Enrollment & & \\
Phase 1 & $0.183^{* * *}$ & 0.451 \\
Phase 2 & $0.174^{*}$ & 0.834 \\
Phase 3 & 0.125 & 0.359 \\
\hline
\end{tabular}

Lower primary refers to grades 1-5 and upper primary refers grades 6-8 enrollment by district population; I use a paired t-test to separate our sample into two comparable samples: Phase 1 districts vs. Phase 3 districts and Phase 2 districts vs. Phase 3 districts; *** $1 \%,{ }^{* *} 5 \%,{ }^{*} 10 \%$ level of significance.

Another facet of the DISE is that it tracks primary school enrollment of both government and private schools. In this data, the DISE also distinguishes between rural and nonrural government and private schools. Since MGNREGA is a rural development program, studying its effects on rural schools provides insight into direct spillovers from increased income on human capital investment.

Table 25: Summary Statistics - School Enrollment by Phase

\begin{tabular}{lll} 
Variables & Mean & Standard Deviation \\
\hline Govt Schools & & \\
Phase 1 & $0.505^{* * *}$ & 1.318 \\
Phase 2 & $0.408^{* * *}$ & 1.295 \\
Phase 3 & 0.229 & 0.653 \\
Rural Govt Schools & & \\
Phase 1 & $0.472^{* * *}$ & 1.244 \\
Phase 2 & $0.376^{* * *}$ & 1.206 \\
Phase 3 & 0.197 & 0.582 \\
Private Schools & & \\
Phase 1 & 0.135 & 0.470 \\
Phase 2 & 0.130 & 0.400 \\
Phase 3 & 0.141 & 0.479 \\
Rural Private Schools & & \\
Phase 1 & 0.083 & 0.287 \\
Phase 2 & 0.076 & 0.244 \\
Phase 3 & 0.072 & 0.223 \\
\hline
\end{tabular}

Variables are enrollment across all goverment and private schools by district population; I use a paired t-test to separate our sample into two comparable samples: Phase 1 districts vs. Phase 3 districts and Phase 2 districts vs. Phase 3 districts; ${ }^{* * *} 1 \%,{ }^{* *} 5 \%, * 10 \%$ level of significance.

Other research has used the DISE data to explore the effects of compulsory education policies (Manisha 
Shah and B. Steinberg, 2019) and information technology (Oster and B. M. Steinberg, 2013). Using the DISE and the Annual Status of Education Report, a survey on educational achievement of children aged 3-16 in India, Manisha Shah and B. M. Steinberg (2019) finds the exposure to MGNREGA causes a 2 percentage point decrease in school enrollment for older children (ages 13 to 16) across districts. The effect appears to concentrate among boys rather than girls, which reveals an unintended spillover of guaranteed employment on human capital investment.

As a contribution to this literature, my analysis will focus on younger children and how MGNREGA uptake affects enrollment across government and private schools.

\subsection{National Crime Records Bureau}

The National Crime Records Bureau collects crime statistics for each district and publishes this information in the annual report, Crime in India. The report provides the total number of reported crimes in a given year according the various property and violent crimes. Given the our concern with women empowerment, I analyze crimes which the literature defines as instances where the victims of these crimes are most likely women, which include sexual harassment, sexual assault, and interpersonal violence. I collect statistics on these crimes from 2002 to 2017 . The following table provides summary statistics for each of my crime outcome variables.

Table 26: Summary Statistics - Violence Against Women by Phase

\begin{tabular}{lll} 
Variables & Average & Standard Deviation \\
\hline Incidents of Sexual Assault & & \\
$\quad$ Phase 1 & $2.90^{* * *}$ & 6.22 \\
$\quad$ Phase 2 & $3.58^{* * *}$ & 7.41 \\
$\quad$ Phase 3 & 14.26 & 30.57 \\
Incidents of Sexual Harassment & & \\
$\quad$ Phase 1 & $14.80^{* * *}$ & 34.88 \\
$\quad$ Phase 2 & $20.59^{* * *}$ & 49.16 \\
$\quad$ Phase 3 & 22.24 & 53.02 \\
Incidents of Interpersonal Violence & & \\
$\quad$ Phase 1 & $14.26^{* * *}$ & 30.57 \\
$\quad$ Phase 2 & $22.23^{* *}$ & 53.02 \\
Phase 3 & 26.38 & 43.79 \\
\hline
\end{tabular}

Crime rates are calculated per 100,000 residents, using district populations. Complete definitions of physical and sexual crimes (according to the Indian Penal Code) are given in the Appendix.

Several studies have documented high levels of violence against women across India. Jeyaseelan et al. (2007) finds that higher socioeconomic status and social support networks protect women against spousal physical violence.Babu and Kar (2009) also finds factors like urban residence, older age, lower education and lower family income are associated the prevalence of domestic violence. Given access to employment, we could expect crime and violence to change as household income grows. S. Das and Mocan (2016) offers an explicit analysis of the relationship between MGNREGA and crime throughout districts in India, finding an overall negative effect on both property and violent crime as MGNREGA employment in a district increases. 
As a contribution to this literature, I estimate the causal effects of employment across genders on violence against women.

\subsection{Controls}

The Ministry of Health and Family Welfare and the International Institute of Population Sciences conduct the district level household and facility survey to collect information regarding the health and well-being of all 611 districts in India. The survey has been carried out in four rounds, starting in 1998-99, 2002-04, 2007-08, and 2012-2013. I also connect these survey questions to those collected as part of the USAID demographic and health survey collected in 2015-2016. Questions regarding household living conditions, gender composition, tribe and caste composition, and literacy are comparable across surveys. As in Clement Imbert and Papp (2015) and S. Das and Mocan (2016), I interpolate data across surveys and survey rounds to construct controls for my empirical analysis so as to capture demographic and social changes in districts over time.

\section{Empirical Strategy}

The empirical strategy for this study is possible through the efforts of the MGNREGA Planning Commission to balance the spread of employment across states. Access to MGREGA was implemented and made available to districts over three distinct phases from April 2006 to January 2008. Sukhtankar (2016) provides a literature review of the various empirical strategies used by researchers to measure the effects of MGNREGA. A difference-in-differences framework is most commonly used for analysis of MGNREGA, as the approach measures level differences between phases of the roll-out. An important assumption of this approach requires that the outcomes being tested follow similar pre-trends before MGNREGA was accessible in a district, otherwise we cannot be sure that any effects found are due to the implementation of MGNREGA. I econometrically test trends in my women empowerment outcomes to confirm the parallel trend assumption. Using a simple regression, my outcome variables will show pre-trend differences across any MGRNEGA implementation phases. Results of parallel trends show no pre-trend differences across phases. These results can be found in the Appendix. Another threat to identification could be that households migrate across districts to take advantage of the program. Clément Imbert and Papp (2016) identifies reductions in short-term or seasonal labor migration to urban areas, thus addressing this concern.

MGNREGA and its effects on districts and households have been analyzed in terms of employment and wages (Clement Imbert and Papp, 2015), schooling and child labor (Manisha Shah and B. M. Steinberg, 2019), newborn survival (Chari et al., 2019) and crime (S. Das and Mocan, 2016) using this difference-indifferences framework. Each study exploits the roll-out of MGNEGRA to compare its effects on various outcomes across districts. Like these studies, I exploit the gradual implementation of the roll-out to estimate of the causal impact of MGNREGA on microfinance outcomes.

Figure 31 highlights the differences in timing of MGNREGA across districts. The roll out of MGNREGA across districts appears to be balanced across phases and states in Figure 31 . Since the intention of the Planning Commission was to affect more impoverished districts with access to guaranteed employment, comparing our microfinance outcomes and controls across districts can provide cursory evidence of how MGNREGA affected households. 
- Phase 1

- Phase 2

- Phase 3

II N/A

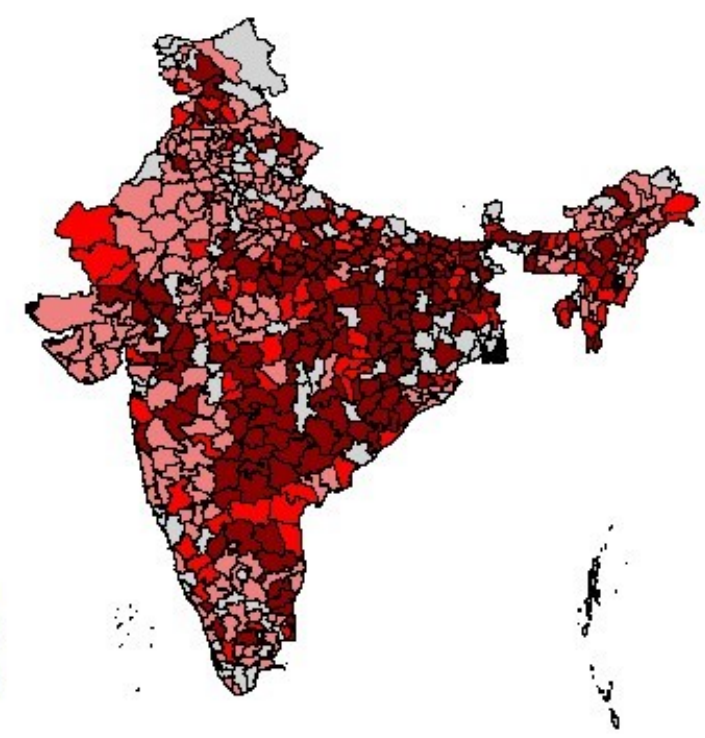

\subsection{Regression Framework}

Using data from both when MGNREGA becomes available in a district and the number of job days generated in a district, I use both an intent-to-treat and treated-on-treatment difference-in-differences test on my women empowerment outcomes variables. My treated-on-treatment analysis will be analyzed both at the aggregated level of total job days generated in a distrcit, and then disaggregated by gender. This level of analysis will provide insight into how both access and uptake of MGNREGA affects women empowerment. Estimates for the intent-to-treat effect on the demand for microfinance is based on the following equation:

$$
y_{d t}=\beta_{0}+\beta_{1} M G N R E G A_{d t}+\lambda X_{d t}+\sigma_{t}+\mu_{d}+\epsilon_{d t} .
$$

I estimate the intent-to-treat effect on my women empowerment outcome variable, $y_{i d t}$, using an indicator variable, MGNREGA $A_{d t}$, that indicates when a district gains access to the program. I include controls, $\lambda X_{i t}$, to capture differential changes across districts. These controls are caste composition, agricultural output per worker, levels of education, gender, and population density. I choose these controls based on what the MGNREGA Planning Commission preprogram measures (Clement Imbert and Papp, 2015. $\sigma_{t}$ and $\mu_{d}$ represents time and district fixed effects, respectively. The district fixed effects account for any time-invariant factors that may affect decision-making power in the household at the district level and the time fixed effects account economic flutuations over time. $\epsilon_{i d t}$ is my error term. Estimates for the treatment effect of MGNREGA on the demand of credit-linked self-help groups is based on the following equations:

$$
y_{d t}=\beta_{0}+\beta_{1} M G N R E G A_{d t}+\beta_{2} M G N R E G A_{d t} \times J o b s_{d t}+\lambda X_{d t}+\sigma_{t}+\mu_{d}+\epsilon_{d t} .
$$


Following S. Das and Mocan (2016), the main difference between the specification in Equation 1 and 2 is the addition of $J o b s_{d t}$, which interacts the number of jobs days generated in a district with the indicator variable, MGNREGA $A_{d t}$, to estimate the overall effect on MGNREGA employment has on my women empowerment outcome variables. Equation 2 contains the same controls variables and fixed effects. The interaction of the uptake of jobs in a district provides a treated-on-treatment estimate, which indicates the effect of increased income on the demand for microfinance in a district. My final specification in Equation 3 disaggregate the number of jobs days generated in a district, $J o b s_{d t}$, into jobs days generated by men MenJobsDays $_{d t}$ and women, WomenJobsDays $d t$. I include the same contorls and fixed effects as my other equations.

$$
\begin{aligned}
y_{d t}=\beta_{0}+\beta_{1} M G N R E G A_{d t}+ & \beta_{1} M G N R E G A_{d t} \times \text { MenJobsDays }_{d t} \\
& +\beta_{1} M G N R E G A_{d t} \times \text { WomenJobsDays }_{d t}+\lambda X_{d t}+\sigma_{t}+\mu_{d}+\epsilon_{d t} .
\end{aligned}
$$

Using this framework, I am able to estimate the causal impact of MGNREGA employment by women on women empowerment in district across India. The following section presents and explains the results from my difference-in-differences analysis and discusses possible interpretations of my results.

\section{Results}

This section presents and explains a series of results that investigate how increased employment by women in a districts affects the empowerment of women. In each section, I begin by explaining comparing changes in my empowerment variables before and after MGNREGA was accessible in a district. Next, I provide my difference-in-differences estimations for each of my empowerment variables to measure the effect of MGNREGA uptake by men and women over time.

\subsection{Women Empowerment and Microfinance}

Results in this section explore the effects of MGNREGA on the demand for microfinance across men and women. We know from the large literature on microfinance that the role of women in the household can transform when give access to factors of production like credit and savings. Figure 32 graphs the averages of the microcredit variables before and after MGRENGA is implemented. Both graphs indicate that the demand for both credit self-help groups and credit disbursed to groups increases after the MGNREGA program is implemented in a district. To investigate these results more deeply, we need to consider how the uptake of employment affects the demand for microfinance. It could be the case that the demand for microfinance is driven by the income generated from employment, not just its access. For this reason, I look at how many jobs are taken up by men and women in a district to see its effect on the demand for microfinance. 
Figure 32: Demand for Microcredit Post MGNREGA Access
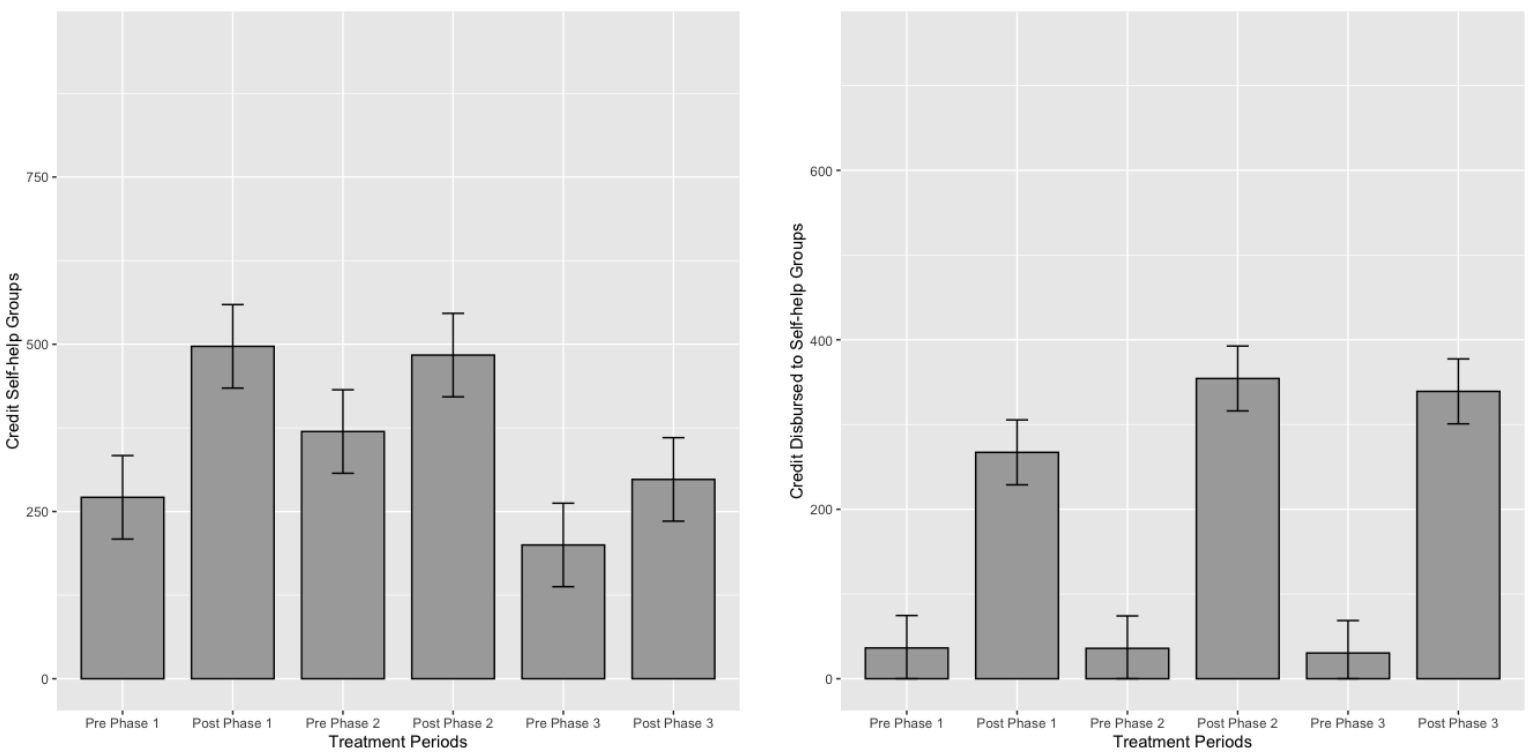

I use nonparametric alternatives to the two sample t-test estimate the difference between samples. Wilcoxon rank sum tests show no significant differences for credit self-help groups and microcredit across phases after MGNREGA is accessible. Kolmogorov-Smirnov tests show significant differences in microcredit, which indicates a change in the distribution of credit disbursed distrcits after MGRENGA is implemented.

The results presented in Table 27 estimate the effect of MGNREGA employment uptake on microcredit activity overall, and across genders in districts. Using district and year fixed effects, I control for any possible unobservable variation between districts. Columns 1 and 4 show the effect of MGNREGA at the extensive margin, while 2 and 5 estimate the effect of MGNREGA, given its uptake in a district, on the demand for microcredit. Demand increases for microcredit as employment increases in a district, which means that as income increases, people demand microcredit. Having established an increase in the demand for microcredit given employment uptake in a district, we can investigate this effect across men and women in Columns 3 and 6. Interestingly, the demand for microcredit concentrates in districts given the uptake of MGNREGA employment by women. This indicates that as women gain income through employment, their demand for microcredit increases. In line with the broader literature on women empowerment (Rahman, 2019), this increase in demand suggests a change in decision-making power in the household, as women earning their own income through MGNREGA employment. 
Table 27: Effect of MGNREGA on Microcredit

\begin{tabular}{|c|c|c|c|c|c|c|}
\hline & \multicolumn{6}{|c|}{ Dependent variable: } \\
\hline & \multicolumn{3}{|c|}{ Credit Self-help Groups } & \multicolumn{3}{|c|}{ Credit Disbursed } \\
\hline & $(1)$ & $(2)$ & $(3)$ & $(4)$ & $(5)$ & $(6)$ \\
\hline MGNREGA & $\begin{array}{c}0.131^{*} \\
(0.076)\end{array}$ & $\begin{array}{c}0.076 \\
(0.083)\end{array}$ & $\begin{array}{c}0.111 \\
(0.084)\end{array}$ & $\begin{array}{c}0.075 \\
(0.054)\end{array}$ & $\begin{array}{c}-0.042 \\
(0.060)\end{array}$ & $\begin{array}{c}0.043 \\
(0.060)\end{array}$ \\
\hline MGNREGA $\times$ Job Days & & $\begin{array}{l}0.004^{*} \\
(0.002)\end{array}$ & & & $\begin{array}{c}0.008^{* * *} \\
(0.002)\end{array}$ & \\
\hline MGNREGA $\times$ Men Job Days & & & $\begin{array}{l}-0.006 \\
(0.006)\end{array}$ & & & $\begin{array}{c}-0.015^{* * *} \\
(0.004)\end{array}$ \\
\hline MGNREGA $\times$ Women Job Days & & & $\begin{array}{c}0.010^{* *} \\
(0.004) \\
\end{array}$ & & & $\begin{array}{c}0.023^{* * *} \\
(0.004)\end{array}$ \\
\hline Controls & $\checkmark$ & $\checkmark$ & $\checkmark$ & $\checkmark$ & $\checkmark$ & $\checkmark$ \\
\hline District FE & $\checkmark$ & $\checkmark$ & $\checkmark$ & $\checkmark$ & $\checkmark$ & $\checkmark$ \\
\hline Year FE & $\checkmark$ & $\checkmark$ & $\checkmark$ & $\checkmark$ & $\checkmark$ & $\checkmark$ \\
\hline $\mathrm{R}^{2}$ & 0.616 & 0.617 & 0.617 & 0.646 & 0.643 & 0.650 \\
\hline
\end{tabular}

Dependent variables are transformed using inverse hyperbolic sine transformation ( $\mathrm{N}=5,613)$; Intensity of MGNREGA is measured by the number of Job Days generated by rural households in a district; Men and Women Job Days disaggregate uptake of MGNREGA per rural household by gender; I control for access to water, literacy rates, population density, scheduled caste and tribe; I include district and year fixed effects in all models; Robust standard errors are clustered at the district level and given in parentheses; ${ }^{*} \mathrm{p}<0.1 ;{ }^{* *} \mathrm{p}<0.05 ;{ }^{* * *} \mathrm{p}<0.01$

Next, I look at the effect of MGNREGA employment on the demand for savings. The variables of interest are the number of savings self-help groups, the number of members per savings self-help group, and the amount saved by self-help groups. Figure 33 compares averages across each savings variable before and after MGNREGA is accessible in a district. The differences before and after MGNREGA are significantly different for all savings variables. Since NABARD began collecting data on savings in 2006, Phase 1 does not have a preperiod comparison group, but savings increases dramatically after MGNREGA becomes accessible in Phase 2 and 3 districts. This suggests that as household income increases through employment, the demand for savings increases. 
Figure 33: Demand for Savings Mobilization Post MGNREGA Access

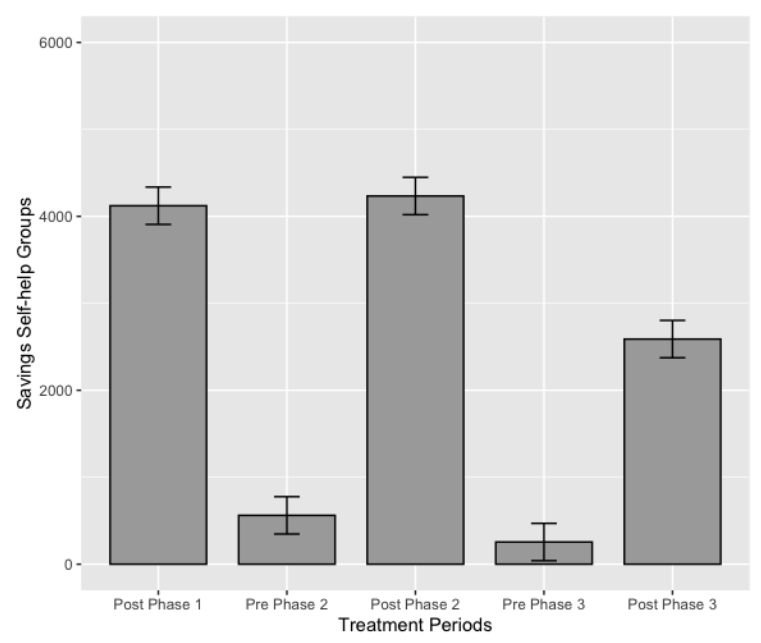

(a) Savings Self-help Groups

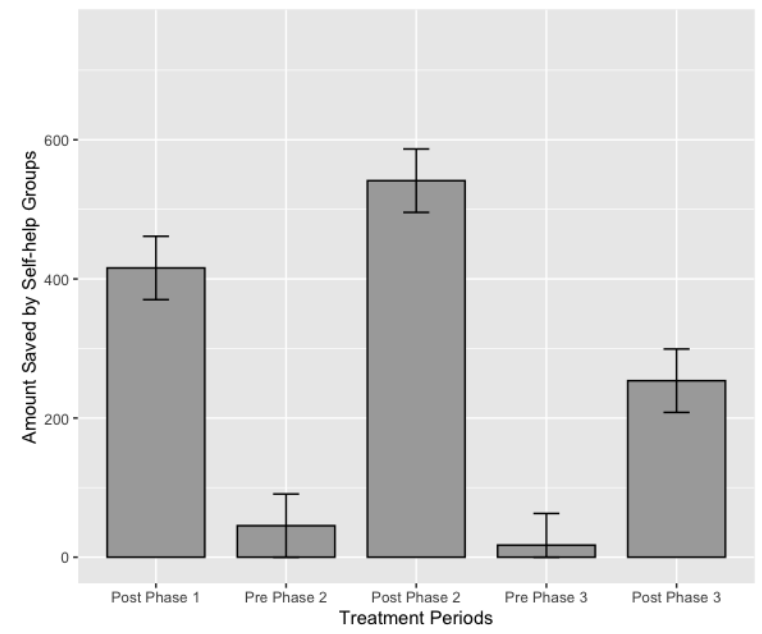

(b) Amount Saved by Groups

Like the previous analysis of microcredit, Table 28 analyzes the effect of MGNREGA uptake on savings mobilization. Demand for savings increases as employment uptake increases, and this effect concentrates among women. Like the results for microcredit, the demand for savings is driven by women taking up employment through MGRNEGA. These results are found in Columns 3, 6, and 9. The demand for savings is negative a significant for savings among men. We found the similar results when it came to credit disbursed in districts as men took up MGNREGA employment. The difference in credit and savings behavior across men and women suggests a difference in decision-making given earned income. Women appear to engage financial services as their income from employment increases, whereas men demand microfinance services less. 
Table 28: Effect of MGNREGA on Savings Activity

\begin{tabular}{|c|c|c|c|c|c|c|c|c|c|}
\hline & \multicolumn{9}{|c|}{ Dependent variable: } \\
\hline & \multicolumn{3}{|c|}{ Savings Self-help Groups } & \multicolumn{3}{|c|}{ SHG Membership } & \multicolumn{3}{|c|}{ Amount Saved } \\
\hline & $(1)$ & $(2)$ & (3) & $(4)$ & $(5)$ & (6) & $(7)$ & (8) & (9) \\
\hline MGNREGA & $\begin{array}{l}-0.058 \\
(0.123)\end{array}$ & $\begin{array}{c}-0.240^{*} \\
(0.130)\end{array}$ & $\begin{array}{c}-0.174 \\
(0.133)\end{array}$ & $\begin{array}{l}0.381^{* *} \\
(0.188)\end{array}$ & $\begin{array}{c}0.073 \\
(0.194)\end{array}$ & $\begin{array}{c}0.173 \\
(0.198)\end{array}$ & $\begin{array}{c}0.013 \\
(0.077)\end{array}$ & $\begin{array}{c}-0.141^{*} \\
(0.082)\end{array}$ & $\begin{array}{l}-0.086 \\
(0.084)\end{array}$ \\
\hline MGNREGA $\times$ Job Days & & $\begin{array}{c}0.019^{* * *} \\
(0.003)\end{array}$ & & & $\begin{array}{c}0.032^{* * *} \\
(0.005)\end{array}$ & & & $\begin{array}{c}0.016^{* * *} \\
(0.002)\end{array}$ & \\
\hline MGNREGA $\times$ Men Job Days & & & $\begin{array}{c}-0.013^{*} \\
(0.008)\end{array}$ & & & $\begin{array}{l}-0.018 \\
(0.011)\end{array}$ & & & $\begin{array}{c}-0.011^{* *} \\
(0.005)\end{array}$ \\
\hline MGNREGA $\times$ Women Job Days & & & $\begin{array}{c}0.035^{* * *} \\
(0.005)\end{array}$ & & & $\begin{array}{c}0.057^{* * *} \\
(0.009)\end{array}$ & & & $\begin{array}{c}0.029^{* * *} \\
(0.004)\end{array}$ \\
\hline Controls & $\checkmark$ & $\checkmark$ & $\checkmark$ & $\checkmark$ & $\checkmark$ & $\checkmark$ & $\checkmark$ & $\checkmark$ & $\checkmark$ \\
\hline District FE & $\checkmark$ & $\checkmark$ & $\checkmark$ & $\checkmark$ & $\checkmark$ & $\checkmark$ & $\checkmark$ & $\checkmark$ & $\checkmark$ \\
\hline Year FE & $\checkmark$ & $\checkmark$ & $\checkmark$ & $\checkmark$ & $\checkmark$ & $\checkmark$ & $\checkmark$ & $\checkmark$ & $\checkmark$ \\
\hline $\mathrm{R}^{2}$ & 0.696 & 0.702 & 0.704 & 0.621 & 0.632 & 0.636 & 0.697 & 0.706 & 0.710 \\
\hline
\end{tabular}

Dependent variables are transformed using inverse hyperbolic sine transformation $(\mathrm{N}=2,964)$; Intensity of MGNREGA is measured by the number of Job Days generated by rural households in a district; Men and Women Job Days disaggregate uptake of MGNREGA per rural household by gender; I control for access to water, literacy rates, population density, scheduled caste and tribe; I include district and year fixed effects in all models; Robust standard errors are clustered at the district level and given in parentheses; ${ }^{*} \mathrm{p}<0.1 ;{ }^{* *} \mathrm{p}<0.05 ;{ }^{* * *} \mathrm{p}<0.01$

Combining the results on credit and savings, I identify an increase in the demand for microfinance as income increases through employment among women. These results align with other literature on gender empowerment and microfinance (Ngo and Wahhaj, 2012) which argues that benefits to microfinance concentrate with women and balance of power in the household. One may ask about the mechanism of this demand and in what situations women demand microfinance. Rodriguez, 2020 analyzes the effect of MGNREGA employment on microfinance using rainfall to determine the character of the demand for microfinance. Demand concentrates in times of average rainfall, which means the mechanism is entrepreneurship, rather than consumption smoothing. In terms of women empowerment, if the character of this demand is entrepreneurial, than we can think of this increased demand by women as indicating a shift in decision-making power in the household as women earn and invest income from MGNREGA employment.

\subsection{Women Empowerment and Primary School Enrollment}

Results in this section begin by discussing the effects of MGNREGA employment across genders on primary school enrollment across districts. I then conduct an identical analysis, but my dependent variables are enrollment across government and private schools. Using these two levels of analysis, I identify an increase in free, government schools for younger children (ages 6-10) as women take up MGNREGA employment. 


\subsubsection{Primary School Enrollment}

Figure 42 shows the average lower and upper primary school enrollment before and after districts gained access to MGNREGA employment. For all grades, enrollment increases after districts gain access to MGNREGA employment. The increases in enrollment before and after MGNREGA are significantly different for all phases and appear largest for Phase 1 districts. This evidence suggests that primary enrollment is increasing, however, there could be many other policies or shocks that caused jump in enrollment.

Figure 34: Primary School Enrollment Post MGNREGA Access

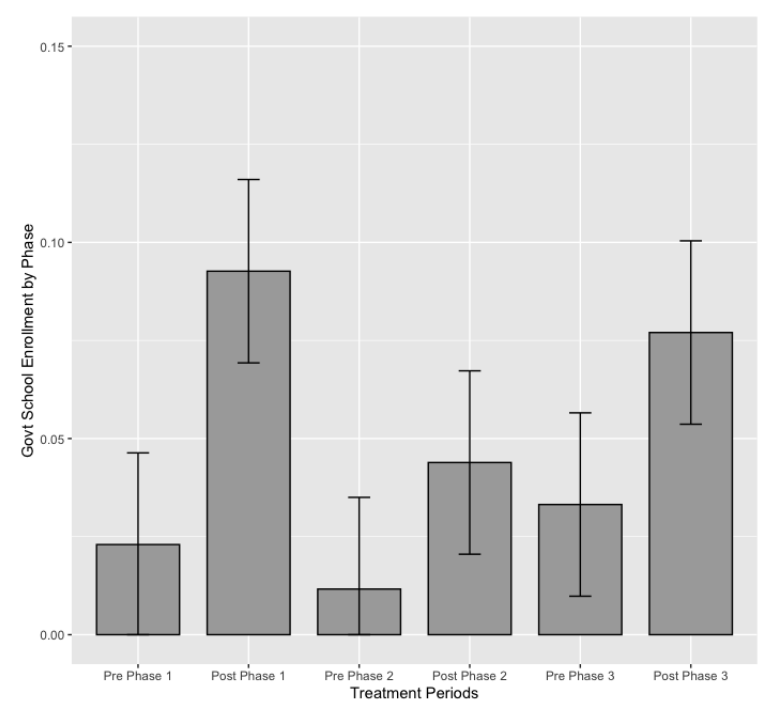

(a) Lower Primary School Enrollment

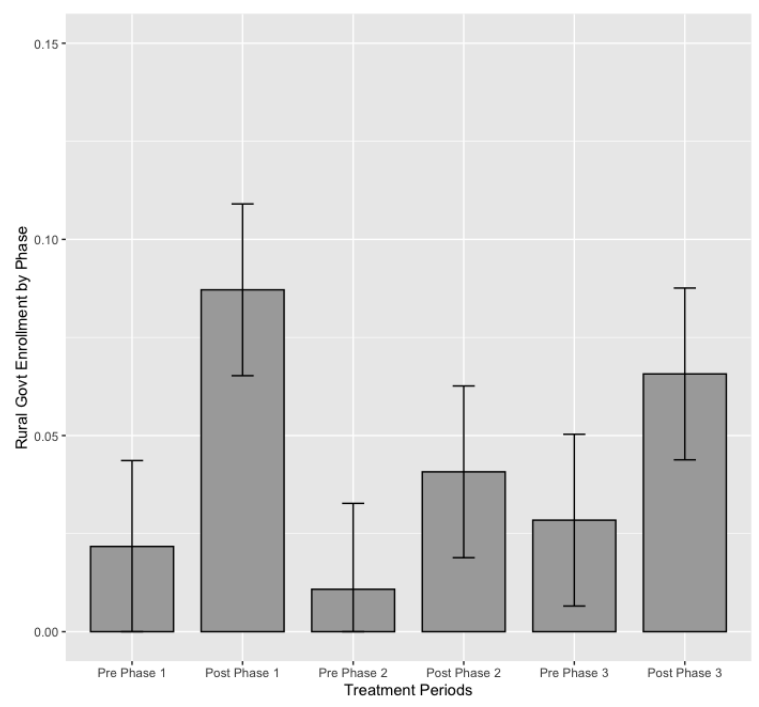

(b) Upper Primary School Enrollment

Table 29 provides my difference in differences estimation of MGNREGA employment uptake across genders on primary school enrollment. Columns 1-3 show how both the intent-to-treat and treatment effects of MGNREGA employment cause an increase in primary school enrollment. In Column 3, we can see that this effect is driven by women taking up MGNREGA employment across districts. Interpretation of this effect is that as women take up employment, lower primary enrollment increases or children ages 6-10. We do not see this effect in upper primary enrollment. Columns 4-6 show a weak, positive effect for MGNREGA uptake on upper primary enrollment, but no effects exists for enrollment when I disaggregate jobs days worked by gender. These results show us that enrollment for younger children increases as women take up MGNREGA employment. Even though district fixed effects should capture any variation between district, several studies have noted the role that state governments play in the administration of education across districts. Taking this into consideration, the results in Table 29 are robust to state by year fixed effects. Having established this increase in enrollment, I investigate government and private schools to see where this effect concentrates. 
Table 29: Effect of MGNREGA on School Enrollment By Grade

\begin{tabular}{|c|c|c|c|c|c|c|}
\hline & \multicolumn{6}{|c|}{ Dependent variable: } \\
\hline & \multicolumn{3}{|c|}{ Primary School Enrollment } & \multicolumn{3}{|c|}{ Upper Primary Enrollment } \\
\hline & $(1)$ & $(2)$ & $(3)$ & $(4)$ & $(5)$ & $(6)$ \\
\hline MGNREGA & $\begin{array}{c}0.100^{* *} \\
(0.043)\end{array}$ & $\begin{array}{c}0.033 \\
(0.042)\end{array}$ & $\begin{array}{c}0.043 \\
(0.043)\end{array}$ & $\begin{array}{c}0.015 \\
(0.015)\end{array}$ & $\begin{array}{l}-0.012 \\
(0.018)\end{array}$ & $\begin{array}{l}-0.009 \\
(0.018)\end{array}$ \\
\hline MGNREGA $\times$ Job Days & & $\begin{array}{c}0.003^{* *} \\
(0.002)\end{array}$ & & & $\begin{array}{l}0.001^{*} \\
(0.001)\end{array}$ & \\
\hline MGNREGA $\times$ Men Job Days & & & $\begin{array}{c}0.001 \\
(0.003)\end{array}$ & & & $\begin{array}{c}0.001 \\
(0.001)\end{array}$ \\
\hline MGNREGA $\times$ Women Job Days & & & $\begin{array}{c}0.005^{* *} \\
(0.002) \\
\end{array}$ & & & $\begin{array}{c}0.002 \\
(0.001) \\
\end{array}$ \\
\hline Controls & $\checkmark$ & $\checkmark$ & $\checkmark$ & $\checkmark$ & $\checkmark$ & $\checkmark$ \\
\hline District FE & $\checkmark$ & $\checkmark$ & $\checkmark$ & $\checkmark$ & $\checkmark$ & $\checkmark$ \\
\hline Year FE & $\checkmark$ & $\checkmark$ & $\checkmark$ & $\checkmark$ & $\checkmark$ & $\checkmark$ \\
\hline $\mathrm{R}^{2}$ & 0.661 & 0.655 & 0.655 & 0.651 & 0.633 & 0.633 \\
\hline
\end{tabular}

Dependent variables are primary school enrollment (grades 1-5) and upper primary enrollment (grades 6-8) per district population $(\mathrm{N}=3,582)$; Intensity of MGNREGA is measured by the number of Job Days generated by rural households in a district; Men and Women Job Days disaggregate uptake of MGNREGA per rural household by gender; I control for literacy rates, total population, scheduled caste and tribe; I include district and year fixed effects in all models; Robust standard errors are clustered at the district level and given in parentheses; ${ }^{*} \mathrm{p}<0.1 ;{ }^{* *} \mathrm{p}<0.05 ;{ }^{* * *} \mathrm{p}<0.01$;

\subsubsection{Government School Enrollment}

Analysis of enrollment across school type will provide insight into how the mechanism behind this increased enrollment, as the decision to send your children to government or private school indicates differences in household resources among those using MGNREGA. For each phase, we see an increase enrollment across government schools after districts gain access to MGNREGA. 
Figure 35: Government School Enrollment Post MGNREGA Access

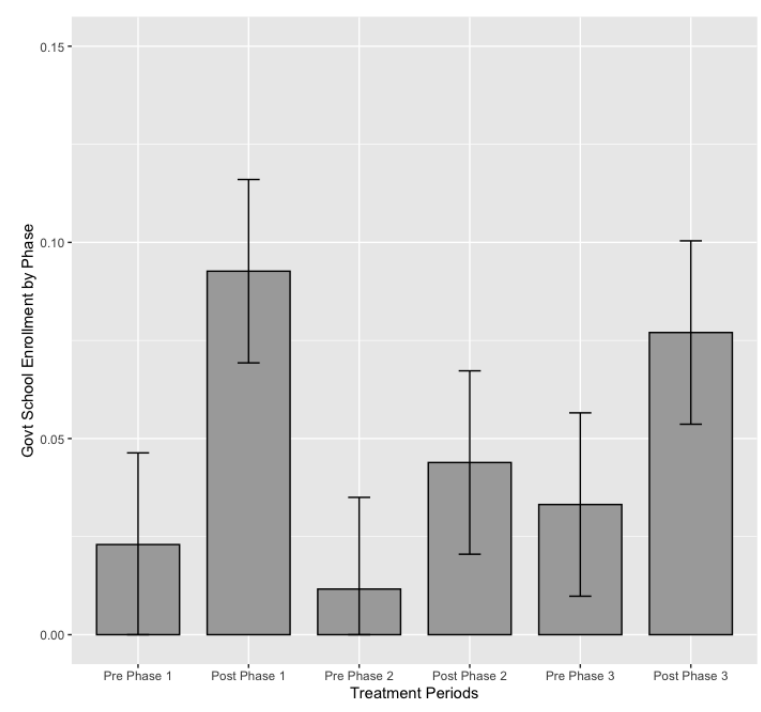

(a) Government School Enrollment

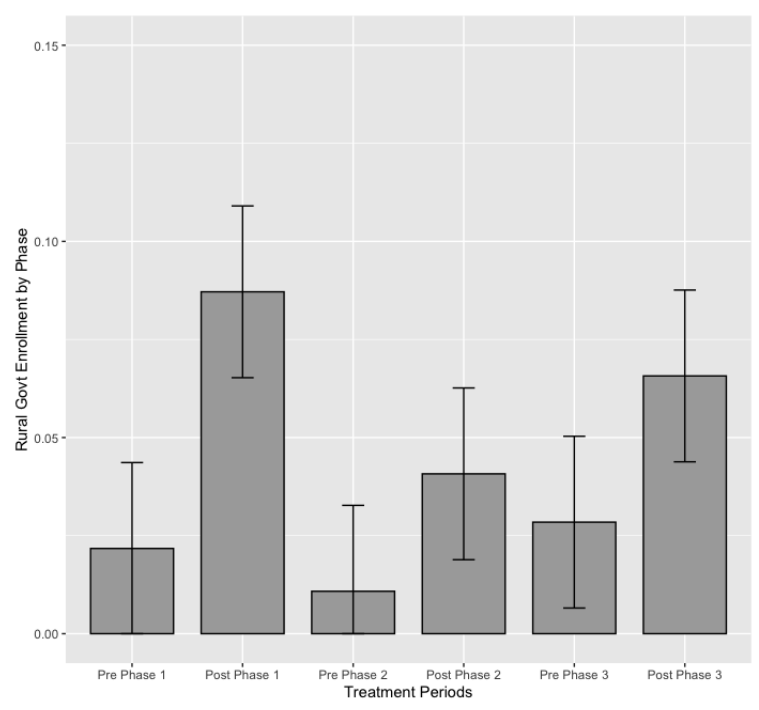

(b) Rural Government School Enrollment

Since there are many other factors that could be driving this enrollment, Table 30 gives the results from the difference in differences estimation of MGNREGA employment on primary enrollment in both rural and urban government schools. Results indicate that primary school enrollment across urban and rural government schools is increasing as women take up MGNREGA employment. Taken with the previous results in Table 29, it appears that the increased enrollment of lower primary students (ages 6-10) is increasing in government schools as more job days worked by women increases. In the Appendix, I include results for an identical analysis of private urban and rural schools across district. Figure 44 Table 35 indicate that there is no change in the enrollment of children across private schools when I disaggregate the job days generated in a district by gender. While not as large as the increase in government school enrollment, private school enrollment increases across all districts after MGNREGA made accessible. The largest increase occurs in Phase 3 districts. Given aims of the MGRENGA roll-out, Phase 3 districts may have higher incomes and access to private schools, thus giving validity to the increase concentrating in Phase 3 districts. Results from the regression analysis provides weak evidence that private primary school enrollment increases as MGNREGA uptake increases, but these effects do not appear to concentrate in districts across genders. 
Table 30: Effect of MGNREGA on Enrollment Across Government Schools

\begin{tabular}{|c|c|c|c|c|c|c|}
\hline & \multicolumn{6}{|c|}{ Dependent variable: } \\
\hline & \multicolumn{3}{|c|}{ Urban Govt Schools } & \multicolumn{3}{|c|}{ Rural Govt Schools } \\
\hline & (1) & $(2)$ & $(3)$ & $(4)$ & $(5)$ & $(6)$ \\
\hline MGNREGA & $\begin{array}{c}0.113^{* *} \\
(0.047)\end{array}$ & $\begin{array}{c}0.028 \\
(0.050)\end{array}$ & $\begin{array}{c}0.034 \\
(0.051)\end{array}$ & $\begin{array}{c}0.111^{* *} \\
(0.045)\end{array}$ & $\begin{array}{c}0.036 \\
(0.047)\end{array}$ & $\begin{array}{c}0.042 \\
(0.049)\end{array}$ \\
\hline MGNREGA $\times$ Job Days & & $\begin{array}{c}0.003 \\
(0.002)\end{array}$ & & & $\begin{array}{c}0.002 \\
(0.002)\end{array}$ & \\
\hline MGNREGA $\times$ Men Job Days & & & $\begin{array}{c}0.002 \\
(0.004)\end{array}$ & & & $\begin{array}{c}0.001 \\
(0.004)\end{array}$ \\
\hline MGNREGA $\times$ Women Job Days & & & $\begin{array}{c}0.003^{* *} \\
(0.002)\end{array}$ & & & $\begin{array}{c}0.003^{* *} \\
(0.002)\end{array}$ \\
\hline Controls & $\checkmark$ & $\checkmark$ & $\checkmark$ & $\checkmark$ & $\checkmark$ & $\checkmark$ \\
\hline District FE & $\checkmark$ & $\checkmark$ & $\checkmark$ & $\checkmark$ & $\checkmark$ & $\checkmark$ \\
\hline Year FE & $\checkmark$ & $\checkmark$ & $\checkmark$ & $\checkmark$ & $\checkmark$ & $\checkmark$ \\
\hline $\mathrm{R}^{2}$ & 0.639 & 0.704 & 0.704 & 0.645 & 0.744 & 0.744 \\
\hline
\end{tabular}

Dependent variables are total enrollment across all government schools per district population $(\mathrm{N}=3,582)$; Intensity of MGNREGA is measured by the number of Job Days generated by rural households in a district; Men and Women Job Days disaggregate uptake of MGNREGA per rural household by gender; I control for literacy rates, total population, scheduled caste and tribe; I include district and year fixed effects in all models; Robust standard errors are clustered at the district level and given in parentheses; ${ }^{*} \mathrm{p}<0.1 ;{ }^{* *} \mathrm{p}<0.05 ;{ }^{* * *} \mathrm{p}<0.01$

Taken as a whole, these results indicate that as women take up employment through MGNREGA, government school enrollment of young children (ages 6-10) increases. Carta and Rizzica (2018) and Clark et al. (2019) shows how randomized access to free, early childhood education leads to increased labor force participation among women. However, the costs of sending a child to school can be high, even when the education is free in government schools. Costs of boarding, uniforms, food, and school supplies remain an obstacle for many low-income households around the world. Increases in literacy among women and homeschooling among households in India has been shown to be an important factor for economic growth among populations who cannot afford the costs of schooling (Behrman et al., 1999). Francavilla, Giannelli, and Grilli (2013) use the National Family Health Survey to identify a negative relationship between women employment and school attendance among "compulsory age" students. The negative relationship suggests that women do not make enough income through the means of local, self-employment to send their child school. This effect does not exist across wealthier households. My main results suggest that income from MGNREGA is sufficiently high to enable households to send children to school.

A limitation to this analysis is that I do not observe the many other ways that households could be reallocating resources. In order to isolate the effect of increased income on school enrollment, we need to collect 
data on all other household incomes and expenses. Household financial diaries are a tool that household members can use to track their daily transactions, as well as document assets and capital accumulation over time. Examples of this use of financial diaries to understand the flow of resources within a household has been done in the United States (Schuh, 2018), Bangladesh, India, South Africa (Collins et al., 2009), and Thailand (Samphantharak and Townsend, 2010).

\subsection{Women Empowerment and Violence Against Women}

A negative spillover from implementing policies that affect gender inequality is that women recipients may be more at risk for violence in the household. Figure 36 describes this spillover, as we see both sexual harassment and interpersonal violence (violence by husbands against wives) increases after districts gain access to MGNREGA. In the Appendix, Figure 45 shows similar increases in sexual assaults across phases. The differences are all significantly different from each other, but I am not controlling for any other changes taking place in households over time. To address this, Table 31 estimates the overall effect of MGNREGA employment across genders on violence against women.

Figure 36: Crimes Against Women Post MGNREGA Access

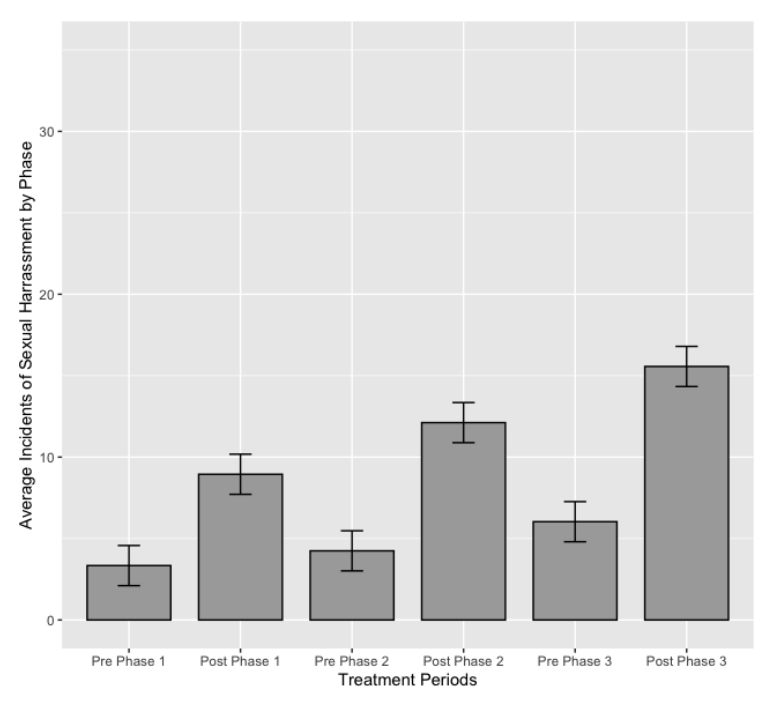

(a) Incidents of Sexual Harassment

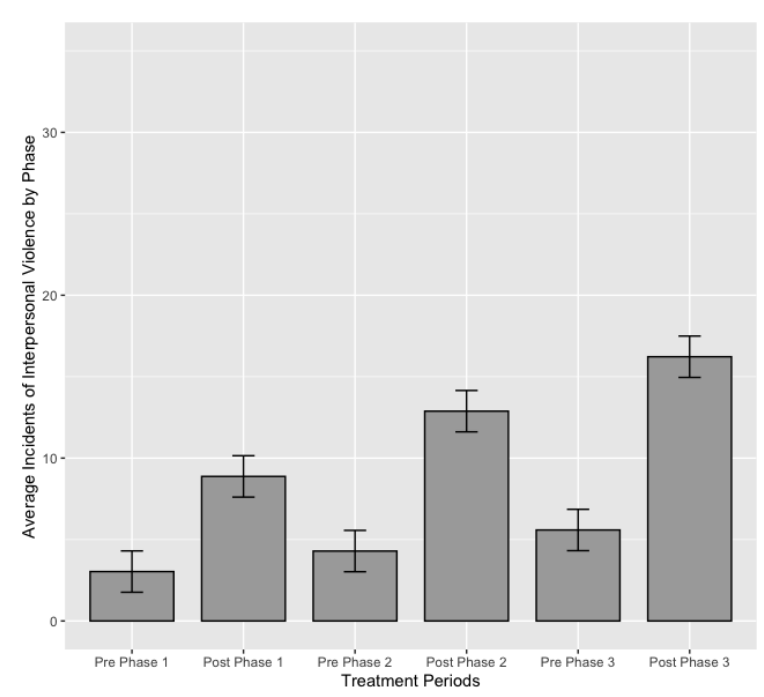

(b) Incidents of Interpersonal Violence

Like the intent-to-treat effects identified in Figure 45, Columns 1 and 4 in Table 30 show an increase in violence against women as MGNREGA is made accessible across districts. And while violence against women is significantly increasing after MGNREGA is implemented, I identify an the opposite effect as households take up MGNREGA employment in Columns 2 and 5. Violence against women decreases as household take advantage of the program. Further investigation reveals that this effect concentrates across districts as women take up MGNREGA employment, specifically. Table 36 in the Appendix shows an identical analysis for sexual assaults. No relationship appears to exist for between MGNREGA employment and sexual assaults. Literature on violence against women supports these results as sexual harassment and interpersonal violence represent violence associated with shifts in power in the household, more so than sexual assaults. We may expect these crimes to be affected due to income growth from MGNREGA employment. 
Table 31: Effect of MGNREGA on Crimes Against Women

\begin{tabular}{|c|c|c|c|c|c|c|}
\hline & \multicolumn{6}{|c|}{ Dependent variable: } \\
\hline & \multicolumn{3}{|c|}{ Sexual Harassment } & \multicolumn{3}{|c|}{ Interpersonal Violence } \\
\hline & $(1)$ & $(2)$ & $(3)$ & $(4)$ & $(5)$ & $(6)$ \\
\hline MGNREGA & $\begin{array}{c}1.520 \\
(1.300)\end{array}$ & $\begin{array}{c}3.063^{* *} \\
(1.410)\end{array}$ & $\begin{array}{c}2.295 \\
(1.461)\end{array}$ & $\begin{array}{c}1.236 \\
(1.228)\end{array}$ & $\begin{array}{l}3.019^{* *} \\
(1.346)\end{array}$ & $\begin{array}{l}2.301^{*} \\
(1.387)\end{array}$ \\
\hline MGRENGA $\times$ Job Days & & $\begin{array}{r}-0.105^{*} \\
(0.054)\end{array}$ & & & $\begin{array}{c}-0.121^{* *} \\
(0.048)\end{array}$ & \\
\hline MGRENGA $\times$ Men Job Days & & & $\begin{array}{c}0.112 \\
(0.113)\end{array}$ & & & $\begin{array}{c}0.081 \\
(0.099)\end{array}$ \\
\hline MGRENGA $\times$ Women Job Days & & & $\begin{array}{c}-0.253^{* *} \\
(0.115) \\
\end{array}$ & & & $\begin{array}{c}-0.258^{* *} \\
(0.114) \\
\end{array}$ \\
\hline Controls & $\checkmark$ & $\checkmark$ & $\checkmark$ & $\checkmark$ & $\checkmark$ & $\checkmark$ \\
\hline District FE & $\checkmark$ & $\checkmark$ & $\checkmark$ & $\checkmark$ & $\checkmark$ & $\checkmark$ \\
\hline Year FE & $\checkmark$ & $\checkmark$ & $\checkmark$ & $\checkmark$ & $\checkmark$ & $\checkmark$ \\
\hline $\mathrm{R}^{2}$ & 0.621 & 0.621 & 0.621 & 0.633 & 0.633 & 0.634 \\
\hline
\end{tabular}

The dependent variables in my regression are the number of crimes per 100,000 people in a district in a year; My number of observations for each regression is $(\mathrm{N}=5,689)$; Intensity of MGNREGA is measured by the number of Job Days generated by rural households in a district; Men and Women Job Days disaggregate uptake of MGNREGA per rural household by gender; I control for access to water, literacy rates, population density, scheduled caste and tribe; I include district and year fixed effects in all models; Robust standard errors are clustered at the district level and given in parentheses; $\mathrm{N}=5,689$ for all regression models; ${ }^{*} \mathrm{p}<0.1 ;{ }^{* *} \mathrm{p}<0.05 ;{ }^{* * *} \mathrm{p}<0.01$;

As discussed previously, household decision-making power can shift as incomes change across genders and these shifts in power can trigger violent outbursts between men and women as ways to regain and maintain control of household resources. As women maintain control of resources, these shifts in power can lead to decreased violence and empower women decision-making in the household. Another reason why we may observe a decrease in violence against women is that other studies conducted in India, like Shakya et al. (2017), find that the empowerment of women in communities leads to more reporting of crimes. It is possible that the higher likelihood of being reported increases the costs to violence for men. Overall, the results in this analysis suggest that women are becoming more empowered across districts, as violence against women decreases as women take up MGNREGA employment.

\section{Conclusion}

The balance of decision-making power in the household between men and women affects the health and well-being of household members. The Mahatmas Gandhi Rural Employment Guarantee program is an 
example of an initiative where access to guaranteed employment can have potential spillovers onto women empowerment. MGNREGA offers 100 days of guaranteed employment to rural households across districts in India. By differentiating employment by gender, I estimate the effect of income growth for men and women on a series of outcome variables that represent changes to women empowerment across districts. These outcomes include the demand for microfinance, primary school enrollment, and violence against women.

Results from my analysis document how MGNREGA employment by women has a positive effect on women empowerment through districts in India. First, MGNREGA employment by women leads to an increased demand for credit and savings. Income growth through this employment program appears to encourage women to engage in financial services, which has been noted in the literature as indicative of increased women decision-making power in the household. Next, I find that primary school enrollment for young children (ages 6-10) increases as women take up MGNREGA employment. Further, this increase in enrollment concentrates in government-aided, rather than private schools. These results suggest the income earned from MGNREGA is sufficiently high to cover the added costs of government school education. Other studies document similar income effects related to the costs of sending a child to school. Finally, as women take up MGNREGA employment, violence against women appears to decrease across districts. Both sexual harassment and interpersonal violence decreases as incomes grow across women, which is suggestive of changes in behavior in the workplace and in the household. Taken together, MGNREGA employment appears to positively affect the role of women in household across India.

Women empowerment remains an essential issue in the growth and development of communities. Initiatives like the 2000 Millennium Development Goals and UN Women, the United Nations Entity for Gender Equality and the Empowerment of Women recognize the global scale of this issue and work to implement programs that encourage and foster women's voices around the world. Programs like these require monitoring and evaluation to ensure that the role of women is transforming in communities. Survey instruments like the World Values Survey (Davis and Williamson, 2019) and the Women's Empowerment in Agriculture Index (Alkire et al., 2013) provide detailed insight into women decision-making in the household and women labor force representation within and across industries. As a contribution to this literature, my analysis evaluates the effects of MGNREGA employment on women empowerment, and I document three separate changes that represent an increase in the decision-making power of women in the household.

\section{References}

Afridi, Farzana, Abhiroop Mukhopadhyay, and Soham Sahoo (2016). "Female labor force participation and child education in India: evidence from the National Rural Employment Guarantee Scheme". In: IZA Journal of Labor 83 Development 5.1, p. 7.

Alkire, Sabina et al. (2013). "The women's empowerment in agriculture index". In: World Development 52, pp. $71-91$.

Almås, Ingvild et al. (2018). "Measuring and changing control: Women's empowerment and targeted transfers". In: The Economic Journal 128.612, F609-F639.

Alonso-Borrego, César and Raquel Carrasco (2017). "Employment and the risk of domestic violence: does the breadwinner's gender matter?" In: Applied Economics 49.50, pp. 5074-5091.

Ashraf, Nava, Dean Karlan, and Wesley Yin (2010). "Female empowerment: Impact of a commitment savings product in the Philippines". In: World development 38.3, pp. 333-344. 
Babu, Bontha V and Shantanu K Kar (2009). "Domestic violence against women in eastern India: a population-based study on prevalence and related issues". In: BMC public health 9.1, p. 129.

Bansal, Hema (2003). "SGH-bank linkage program in India: An overview". In: Journal of Microfinance/ESR Review 5.1, p. 3.

Behrman, Jere R et al. (1999). "Women's schooling, home teaching, and economic growth". In: Journal of political Economy 107.4, pp. 682-714.

Berlinski, Samuel and Sebastian Galiani (2007). "The effect of a large expansion of pre-primary school facilities on preschool attendance and maternal employment". In: Labour Economics 14.3, pp. 665-680.

Besley, Timothy et al. (2017). "Gender quotas and the crisis of the mediocre man: Theory and evidence from Sweden". In: American economic review 107.8, pp. 2204-42.

Bhattacharyya, Manasi, Arjun S Bedi, and Amrita Chhachhi (2011). "Marital violence and women's employment and property status: Evidence from north Indian villages". In: World Development 39.9, pp. 16761689.

Bicchieri, Cristina and Peter McNally (2018). "Shrieking Sirens: Schemata, Scripts, and Social Norms. How Change Occurs". In: Social Philosophy and Policy 35.1, pp. 23-53.

Bloom, David E, Michael Kuhn, and Klaus Prettner (2015). The contribution of female health to economic development. Tech. rep. National Bureau of Economic Research.

Breitkreuz, Rhonda et al. (2017). "The Mahatma Gandhi National Rural Employment Guarantee Scheme: A Policy Solution to Rural Poverty in India?" In: Development Policy Review 35.3, pp. 397-417.

Bulte, Erwin and Robert Lensink (2019). "Women's empowerment and domestic abuse: Experimental evidence from Vietnam". In: European economic review 115, pp. 172-191.

Carswell, Grace and Geert De Neve (2014). "MGNREGA in Tamil Nadu: A story of success and transformation?" In: Journal of Agrarian Change 14.4, pp. 564-585.

Carta, Francesca and Lucia Rizzica (2018). "Early kindergarten, maternal labor supply and children's outcomes: evidence from Italy". In: Journal of Public Economics 158, pp. 79-102.

Chari, Amalavoyal V et al. (2019). "Workfare and infant health: Evidence from India's public works program". In: Journal of Development Economics 138, pp. 116-134.

Chopra, Deepta (2015). "Political commitment in India's social policy implementation: Shaping the performance of MGNREGA". In:

Clark, Shelley et al. (2019). "The Impact of Childcare on Poor Urban Women's Economic Empowerment in Africa". In: Demography 56.4, pp. 1247-1272.

Collins, Daryl et al. (2009). Portfolios of the poor: how the world's poor live on \$2 a day. Princeton University Press.

Cull, Robert and Jonathan Morduch (2017). Microfinance and economic development.

Das, Satadru and Naci Mocan (2016). Analyzing the Impact of the World's Largest Public Works Project on Crime. Tech. rep. National Bureau of Economic Research.

Das, Upasak, Ashish Singh, Nitay Mahanto, et al. (2012). "Awareness about Mahatma Gandhi National Rural Employment Guarantee Act: Some evidence from the northern parts of West Bengal, India". In: Economics Bulletin 32.1, pp. 528-537.

Davis, Lewis S and Claudia R Williamson (2019). "Does individualism promote gender equality?" In: World Development 123, p. 104627.

Deininger, Klaus and Yanyan Liu (2013). "Evaluating program impacts on mature self-help groups in India". In: The World Bank Economic Review 27.2, pp. 272-296. 
Desai, Raj M and Shareen Joshi (2014). "Collective action and community development: Evidence from self-help groups in rural India". In: The World Bank Economic Review 28.3, pp. 492-524.

Duflo, Esther (2012). "Women empowerment and economic development". In: Journal of Economic literature 50.4, pp. 1051-79.

Duflo, Esther and Christopher Udry (2004). Intrahousehold resource allocation in Cote d'Ivoire: Social norms, separate accounts and consumption choices. Tech. rep. National Bureau of Economic Research.

Francavilla, Francesca, Gianna Claudia Giannelli, and Leonardo Grilli (2013). "Mothers' employment and their children's schooling: A joint multilevel analysis for India". In: World Development 41, pp. 183-195.

Ganle, John Kuumuori, Kwadwo Afriyie, and Alexander Yao Segbefia (2015). "Microcredit: Empowerment and disempowerment of rural women in Ghana". In: World Development 66, pp. 335-345.

Garikipati, Supriya (2008). "The impact of lending to women on household vulnerability and women's empowerment: evidence from India". In: World development 36.12, pp. 2620-2642.

Haushofer, Johannes, Charlotte Ringdal, et al. (2019). Income changes and intimate partner violence: Evidence from unconditional cash transfers in kenya. Tech. rep. National Bureau of Economic Research.

Haushofer, Johannes and Jeremy Shapiro (2016). "The short-term impact of unconditional cash transfers to the poor: experimental evidence from Kenya". In: The Quarterly Journal of Economics 131.4, pp. 19732042.

Hidrobo, Melissa, Amber Peterman, and Lori Heise (2016). "The effect of cash, vouchers, and food transfers on intimate partner violence: evidence from a randomized experiment in Northern Ecuador". In: American Economic Journal: Applied Economics 8.3, pp. 284-303.

Hsu, Lin-Chi (2017). "The timing of welfare payments and intimate partner violence". In: Economic inquiry 55.2 , pp. 1017-1031.

Imbert, Clement and John Papp (2015). "Labor market effects of social programs: Evidence from india's employment guarantee". In: American Economic Journal: Applied Economics 7.2, pp. 233-63.

Imbert, Clément and John Papp (2016). Short-term migration rural workfare programs and urban labor markets-Evidence from India. Tech. rep.

Jeyaseelan, Lakshman et al. (2007). "Physical spousal violence against women in India: some risk factors". In: Journal of biosocial science 39.5, pp. 657-670.

Kabeer, Naila (2009). "Conflicts over credit: re-evaluating the empowerment potential of loans to women in rural Bangladesh". In: Microfinance. Routledge, pp. 128-162.

- (2014). "Violence against women as 'relational'vulnerability: engendering the sustainable human development agenda". In: Occasional Paper for UNDP Human Development Report Office. Available online also at: http://hdr. undp. org/sites/default/files/kabeer_hdr14. pdf [accessed in Bandung, West Java, Indonesia: April 1, 2018].

Karuppannan, Rajendran (2012). "Micro Finance through Self Help Groups-A Survey of Recent Literature in India". In: International Journal of Marketing, Financial Services \& Management Research 1.12.

Kimmel, Jean (1998). "Child care costs as a barrier to employment for single and married mothers". In: Review of Economics and Statistics 80.2, pp. 287-299.

Laha, Arindam and Pravat Kumar Kuri (2014). "Measuring the impact of microfinance on women empowerment: A cross country analysis with special reference to India". In: International Journal of Public Administration 37.7, pp. 397-408.

Mammen, Kristin and Christina Paxson (2000). "Women's work and economic development". In: Journal of economic perspectives 14.4, pp. 141-164. 
Martınez, Claudia and Marcela Perticará (2017). "Childcare effects on maternal employment: Evidence from Chile". In: Journal of Development Economics 126, pp. 127-137.

Müller, Kai-Uwe and Katharina Wrohlich (2020). "Does subsidized care for toddlers increase maternal labor supply? Evidence from a large-scale expansion of early childcare". In: Labour Economics 62, p. 101776.

Ngo, Thi Minh-Phuong and Zaki Wahhaj (2012). "Microfinance and gender empowerment". In: Journal of Development Economics 99.1, pp. 1-12.

Oster, Emily and Bryce Millett Steinberg (2013). "Do IT service centers promote school enrollment? Evidence from India". In: Journal of Development Economics 104, pp. 123-135.

Padma, K (2015). "MGNREGA and rural distress in India". In: International Journal of Humanities and Social Science Invention 4.8, pp. 67-76.

Patil, Sandeep and Kiran Kokate (2017). "Identifying factors governing attitude of rural women towards Self-Help Groups using principal component analysis". In: Journal of rural studies 55, pp. 157-167.

Pratley, Pierre (2016). "Associations between quantitative measures of women's empowerment and access to care and health status for mothers and their children: a systematic review of evidence from the developing world". In: Social Science \& Medicine 169, pp. 119-131.

Rahman, Aminur (2019). Women and microcredit in rural Bangladesh: An anthropological study of Grameen Bank lending. Routledge.

Rakib, Muntaha and Julia Anna Matz (2016). "The impact of shocks on gender-differentiated asset dynamics in Bangladesh". In: The Journal of Development Studies 52.3, pp. 377-395.

Raza, Wameq A et al. (2015). "Healthcare seeking behaviour among self-help group households in Rural Bihar and Uttar Pradesh, India". In: BMC health services research 16.1, p. 1.

Rodriguez, Zachary (2020). "The Demand for Microfinance: The Effect of India's Employment Guarantee on Microfinance". In: Working Paper.

Roy, Shalini et al. (2019). "Transfers, behavior change communication, and intimate partner violence: Postprogram evidence from rural Bangladesh". In: Review of Economics and Statistics 101.5, pp. 865-877.

Samphantharak, Krislert and Robert M Townsend (2010). Households as corporate firms: an analysis of household finance using integrated household surveys and corporate financial accounting. 46. Cambridge University Press.

Schuh, Scott (2018). "Measuring consumer expenditures with payment diaries". In: Economic Inquiry 56.1, pp. 13-49.

Shah, Manisha and Bryce Steinberg (2019). "The right to education act: Trends in enrollment, test scores, and school quality". In: AEA Papers and Proceedings. Vol. 109, pp. 232-38.

Shah, Manisha and Bryce Millett Steinberg (2019). "Workfare and human capital investment: Evidence from India". In: Journal of Human Resources, 1117-9201R2.

Shah, Mihir (2016). "Should India do away with the MGNREGA?" In: The Indian Journal of Labour Economics 59.1, pp. 125-153.

Shakya, Holly B et al. (2017). "Longitudinal associations of intimate partner violence attitudes and perpetration: Dyadic couples data from a randomized controlled trial in rural India". In: Social science $\mathcal{E}^{2}$ medicine 179, pp. 97-105.

Sharma, Ajay, Sapna Dua, and Vinod Hatwal (2012). "Micro enterprise development and rural women entrepreneurship: way for economic empowerment". In: Arth Prabhand: A Journal of Economics and Management 1.6, pp. 114-127. 
Sukhtankar, Sandip (2016). "India's National Rural Employment Guarantee Scheme: What Do We Really Know about the World's Largest Workfare Program?" In:

Swain, Ranjula Bali and Fan Yang Wallentin (2009). "Does microfinance empower women? Evidence from self-help groups in India". In: International review of applied economics 23.5, pp. 541-556.

Swamy, Vighneswara (2014). "Financial inclusion, gender dimension, and economic impact on poor households". In: World development 56, pp. 1-15.

Tilak, Jandhyala BG (2002). Determinants of household expenditure on education in rural India. 88. Citeseer.

Tur-Prats, Ana (2019). "Family Types and Intimate Partner Violence: A Historical Perspective". In: Review of Economics and Statistics 101.5, pp. 878-891.

Upadhyay, Ushma D et al. (2014). "Women's empowerment and fertility: a review of the literature". In: Social Science 83 Medicine 115, pp. 111-120.

\section{Appendix}

\subsection{Parallel Trend Analysis}

Table 32: Parallel Trends Analysis of Microfinance

\begin{tabular}{lccccc}
\hline \hline & \multicolumn{5}{c}{ Dependent variable: } \\
\cline { 2 - 6 } & Credit-SHGs & $\begin{array}{c}\text { Microcredit } \\
\text { Disbursed }\end{array}$ & Savings SHGs & $\begin{array}{c}\text { Savings-SHGs } \\
\text { Members }\end{array}$ & $\begin{array}{c}\text { Amount } \\
\text { Saved }\end{array}$ \\
& $(1)$ & $(2)$ & $(3)$ & $(4)$ & $(5)$ \\
\hline Year & 7.731 & -57.766 & -25.246 & 23.895 & 7.855 \\
& $(48.948)$ & $(120.855)$ & $(31.270)$ & $(371.272)$ & $(6.133)$ \\
Year $\times$ Phase 2 & 12.970 & 84.114 & & & \\
Year $\times$ Phase 3 & $(48.948)$ & $(141.726)$ & & -8295.013 & -61.658 \\
& 22.259 & 40.238 & -461.860 & $(6393.115)$ & $(105.598)$ \\
\hline Controls & $(44.332)$ & $(128.362)$ & $(538.455)$ & $\checkmark$ & $\checkmark$ \\
$\mathrm{R}^{2}$ & $\checkmark$ & $\checkmark$ & $\checkmark$ & 0.010 & 0.020 \\
\hline \hline Note: & 0.020 & 0.045 & 0.010 & & ${ }^{*} \mathrm{p}<0.1 ;{ }^{* *} \mathrm{p}<0.05 ;{ }^{* * *} \mathrm{p}<0.01$
\end{tabular}


Figure 37: Demand for Microcredit By Phase Parallel Trends

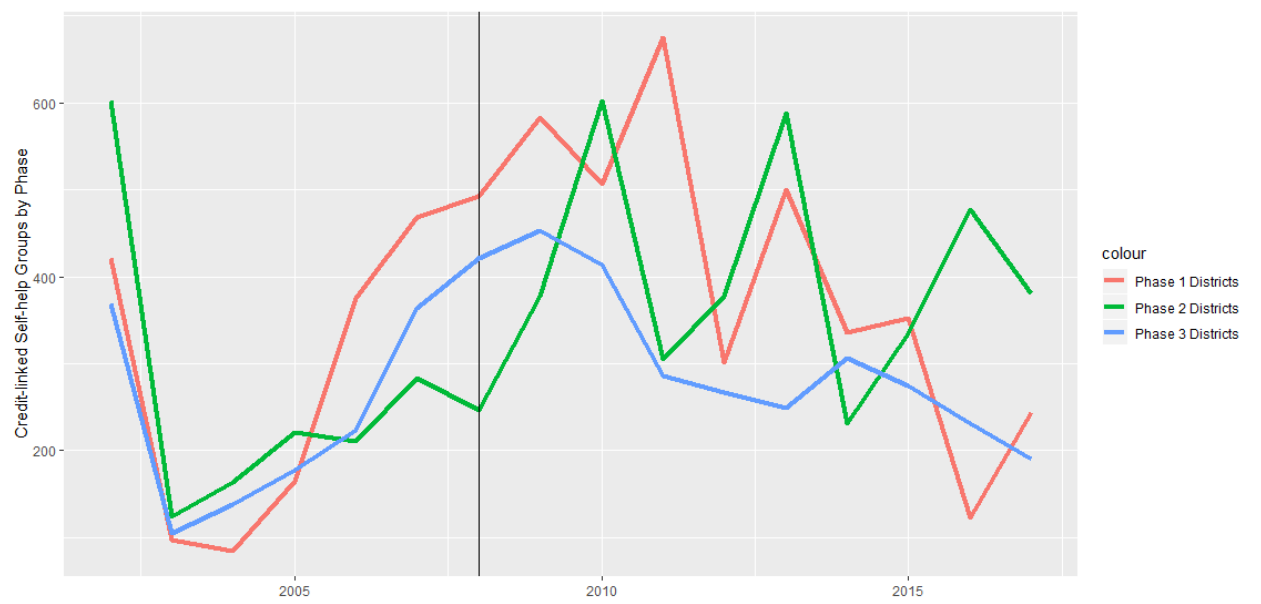

(a) Credit Self-help Groups

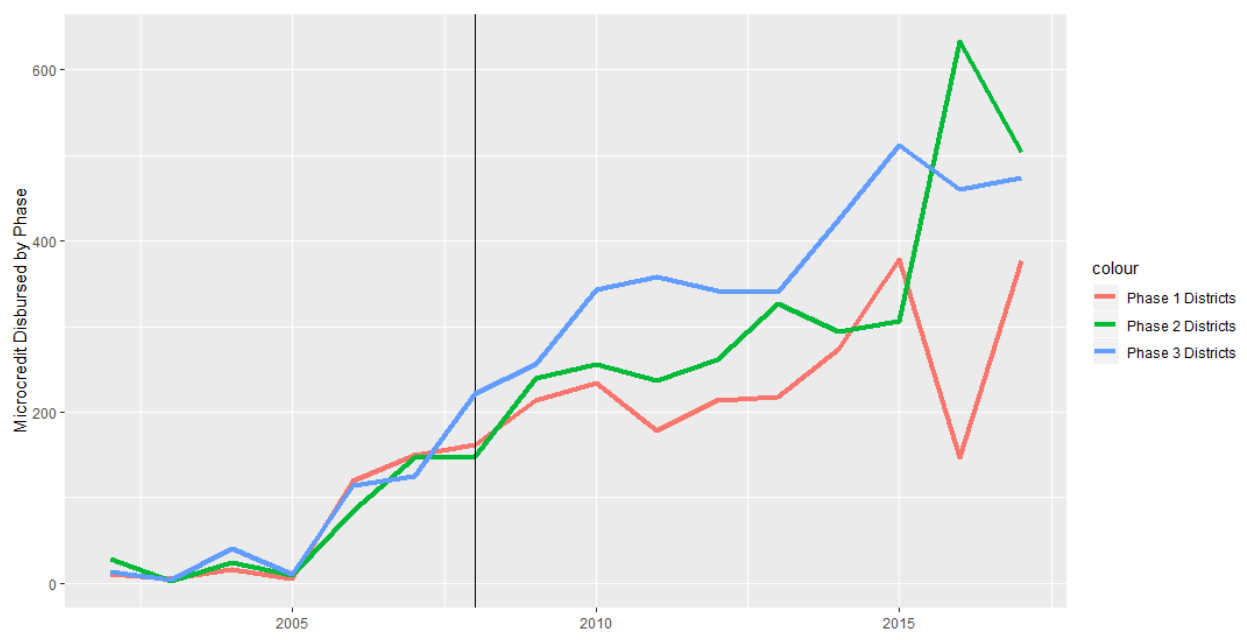

(b) Credit Disbursed 
Figure 38: Savings Mobilization By Phase Parallel Trends

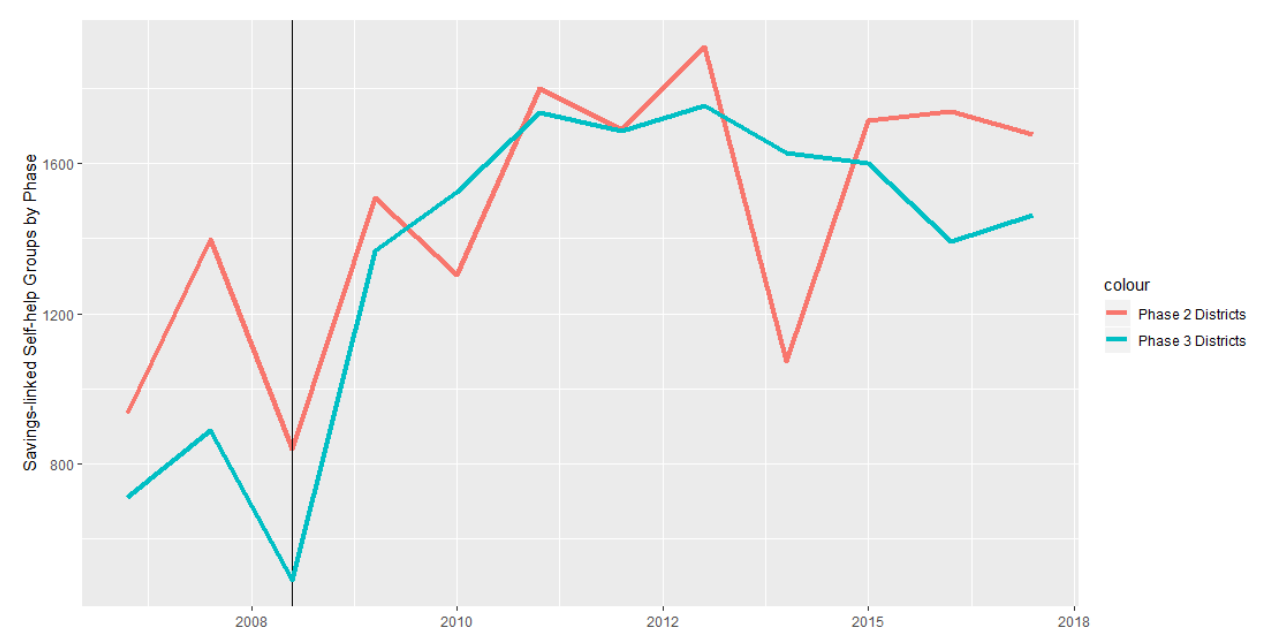

(a) Savings Self-help Groups

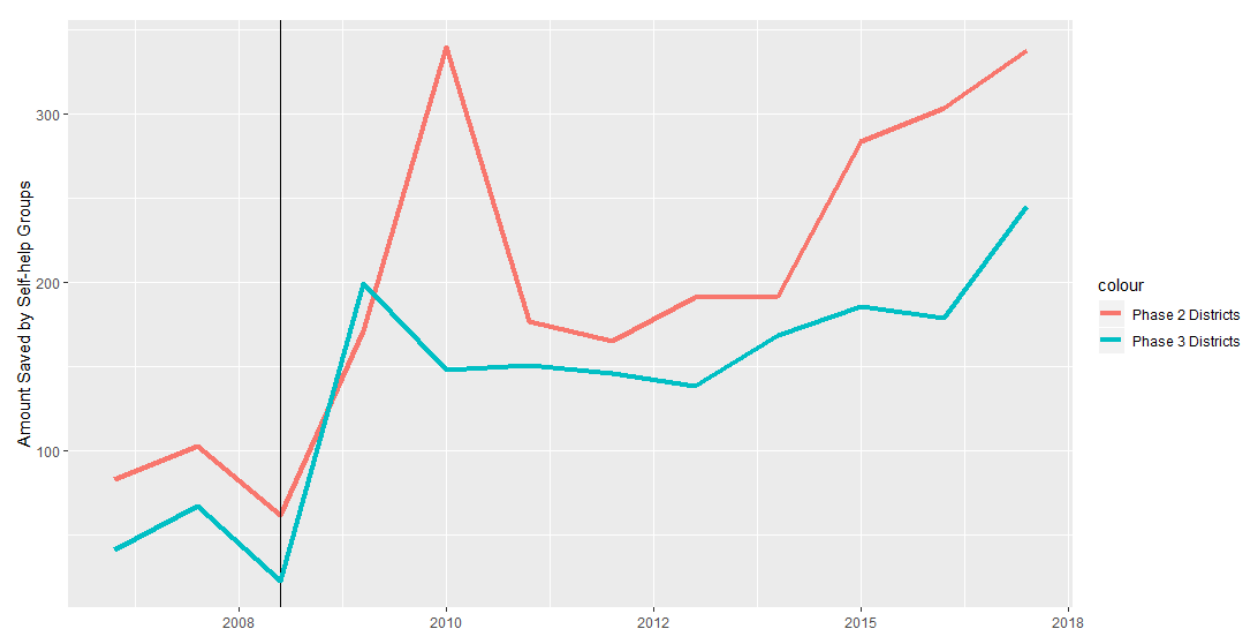

(b) Amount Saved 
Figure 39: Savings Moblization by Phase Parallel Trends

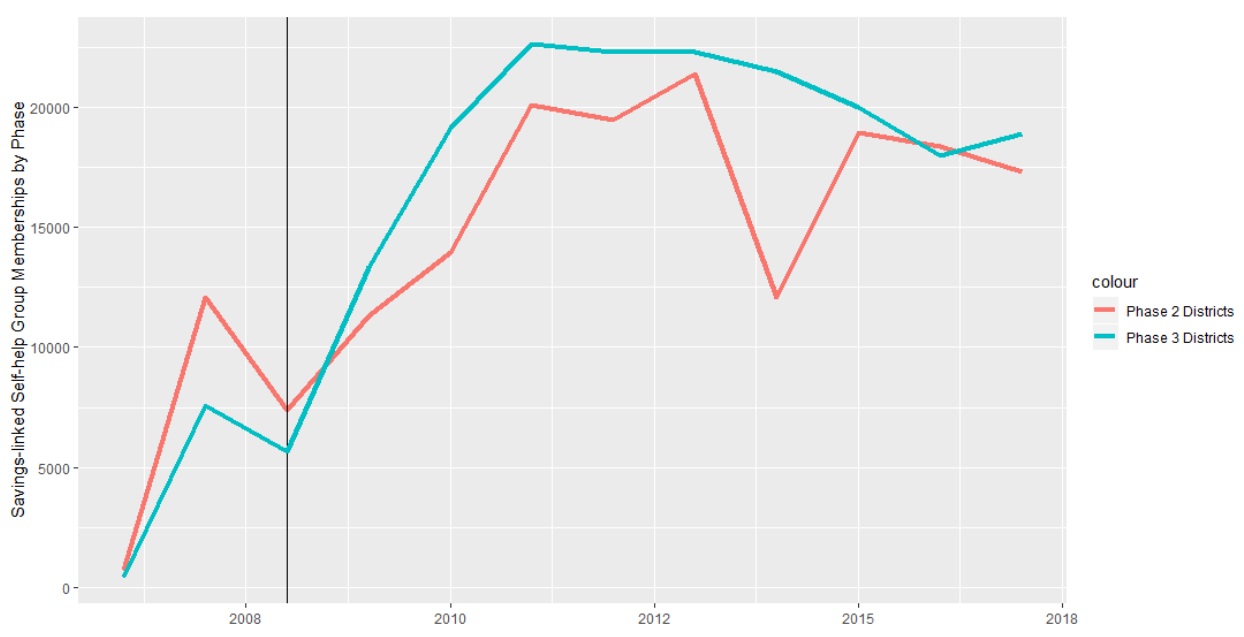

(a) Savings SHG Membership

Table 33: Parallel Trends Analysis for Primary School Enrollment

\begin{tabular}{|c|c|c|c|c|c|c|}
\hline & \multicolumn{6}{|c|}{ Dependent variable: } \\
\hline & $\begin{array}{c}\text { Lower Primary } \\
\text { Enrollment } \\
(1) \\
\end{array}$ & $\begin{array}{c}\text { Upper Primary } \\
\text { Enrollment } \\
(2) \\
\end{array}$ & $\begin{array}{c}\text { Govt } \\
\text { Schools } \\
(3)\end{array}$ & $\begin{array}{c}\text { Rural Govt } \\
\text { Schools } \\
(4)\end{array}$ & $\begin{array}{c}\text { Prvt } \\
\text { Schools } \\
(5) \\
\end{array}$ & $\begin{array}{c}\text { Rural Prvt } \\
\text { Schools } \\
(6)\end{array}$ \\
\hline Year & $\begin{array}{c}0.067 \\
(0.111)\end{array}$ & $\begin{array}{c}0.011 \\
(0.015)\end{array}$ & $\begin{array}{c}0.081 \\
(0.117)\end{array}$ & $\begin{array}{c}0.083 \\
(0.111)\end{array}$ & $\begin{array}{c}0.011 \\
(0.012)\end{array}$ & $\begin{array}{c}0.009 \\
(0.009)\end{array}$ \\
\hline Year $\times$ Phase 2 & $\begin{array}{c}-0.014 \\
(0.118)\end{array}$ & $\begin{array}{c}0.013 \\
(0.021)\end{array}$ & $\begin{array}{l}-0.027 \\
(0.123)\end{array}$ & $\begin{array}{l}-0.031 \\
(0.117)\end{array}$ & $\begin{array}{c}0.012 \\
(0.018)\end{array}$ & $\begin{array}{c}0.004 \\
(0.011)\end{array}$ \\
\hline Year $\times$ Phase 3 & $\begin{array}{l}-0.058 \\
(0.112) \\
\end{array}$ & $\begin{array}{l}-0.002 \\
(0.016) \\
\end{array}$ & $\begin{array}{l}-0.085 \\
(0.117) \\
\end{array}$ & $\begin{array}{l}-0.088 \\
(0.111) \\
\end{array}$ & $\begin{array}{c}0.003 \\
(0.013) \\
\end{array}$ & $\begin{array}{l}-0.002 \\
(0.009) \\
\end{array}$ \\
\hline Controls & $\checkmark$ & $\checkmark$ & $\checkmark$ & $\checkmark$ & $\checkmark$ & $\checkmark$ \\
\hline
\end{tabular}


Figure 40: Primary School Enrollment By Phase Parallel Trends

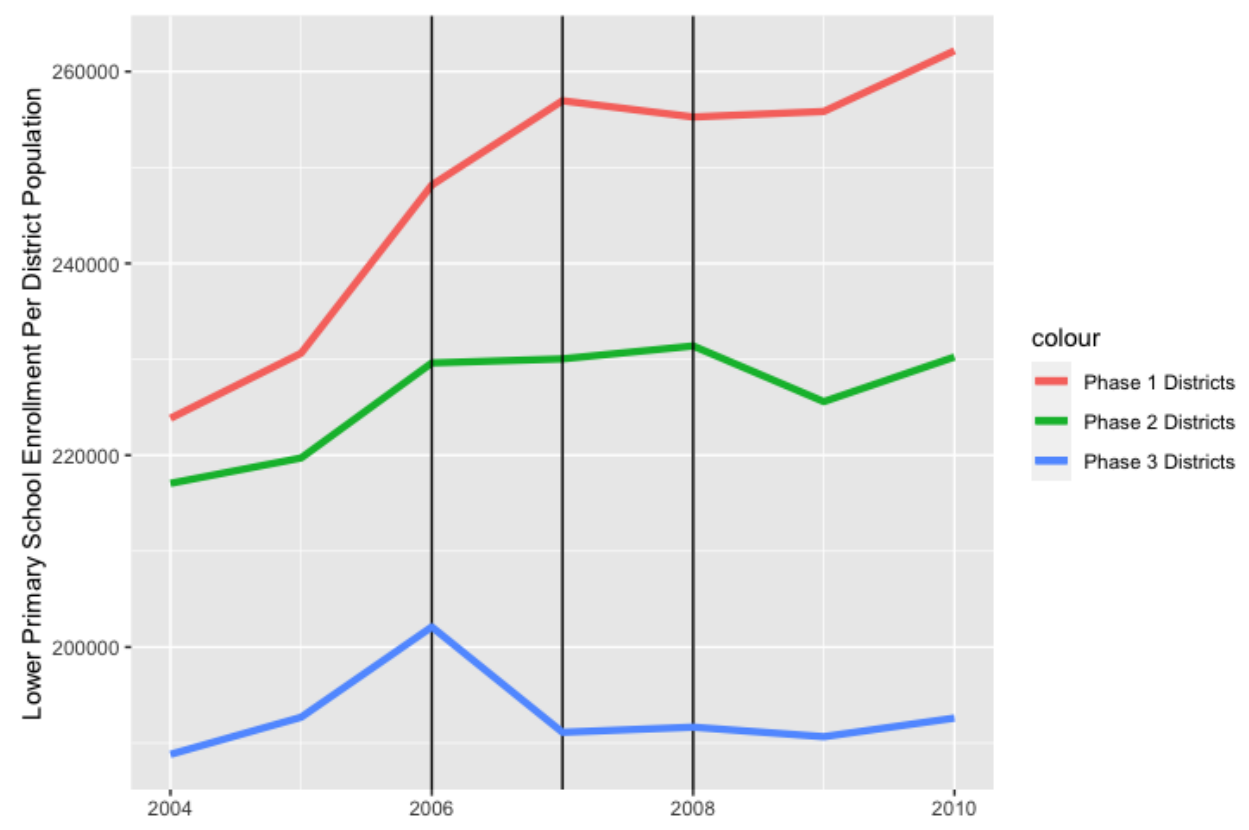

(a) Lower Primary School Enrollment

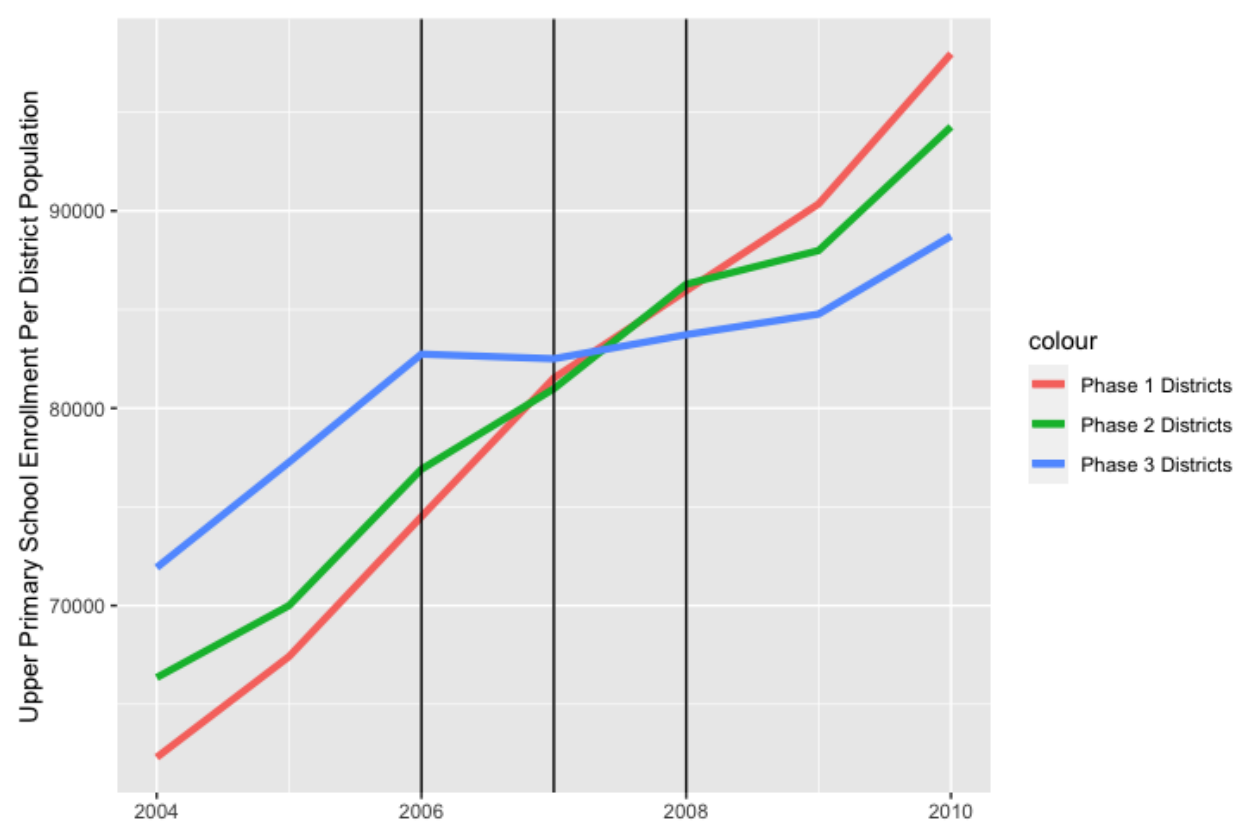

(b) Upper Primary School Enrollment 
Figure 41: Government School Enrollment By Phase Parallel Trends

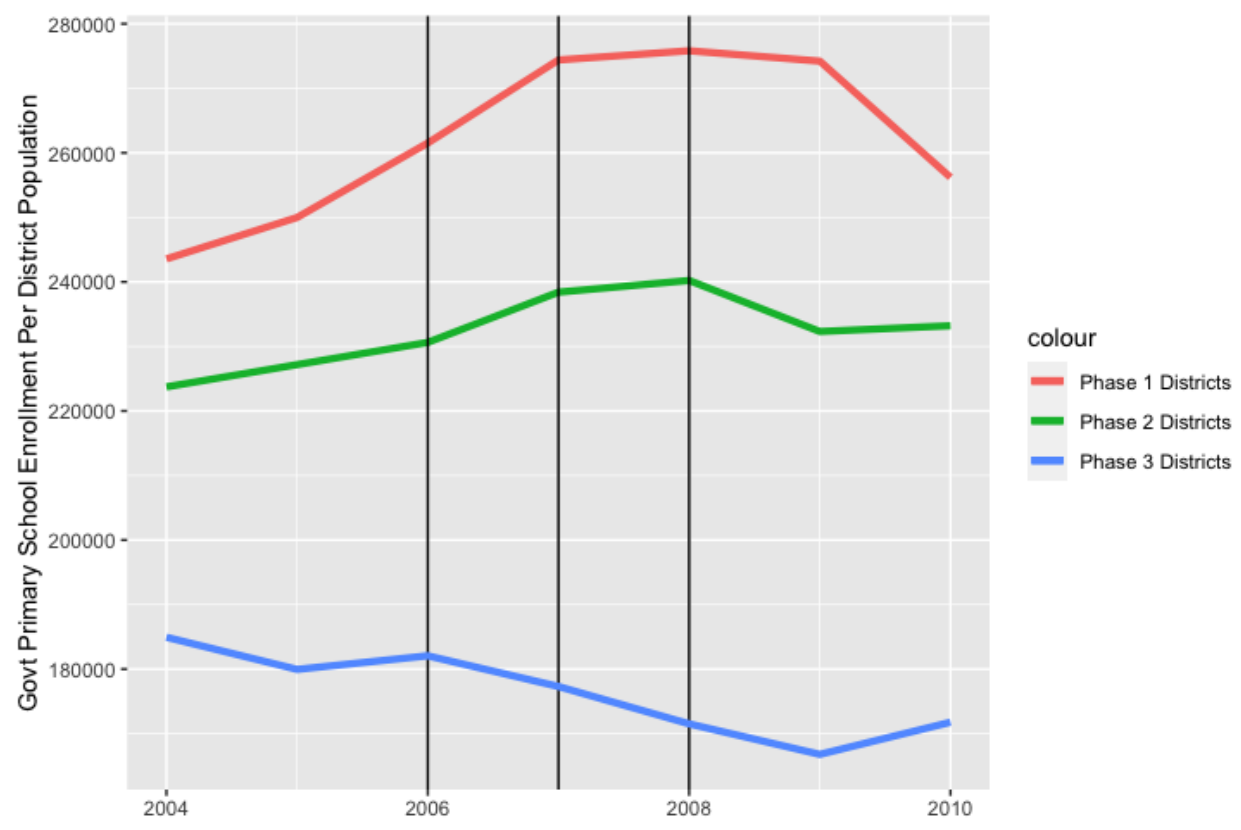

(a) Govt School Enrollment

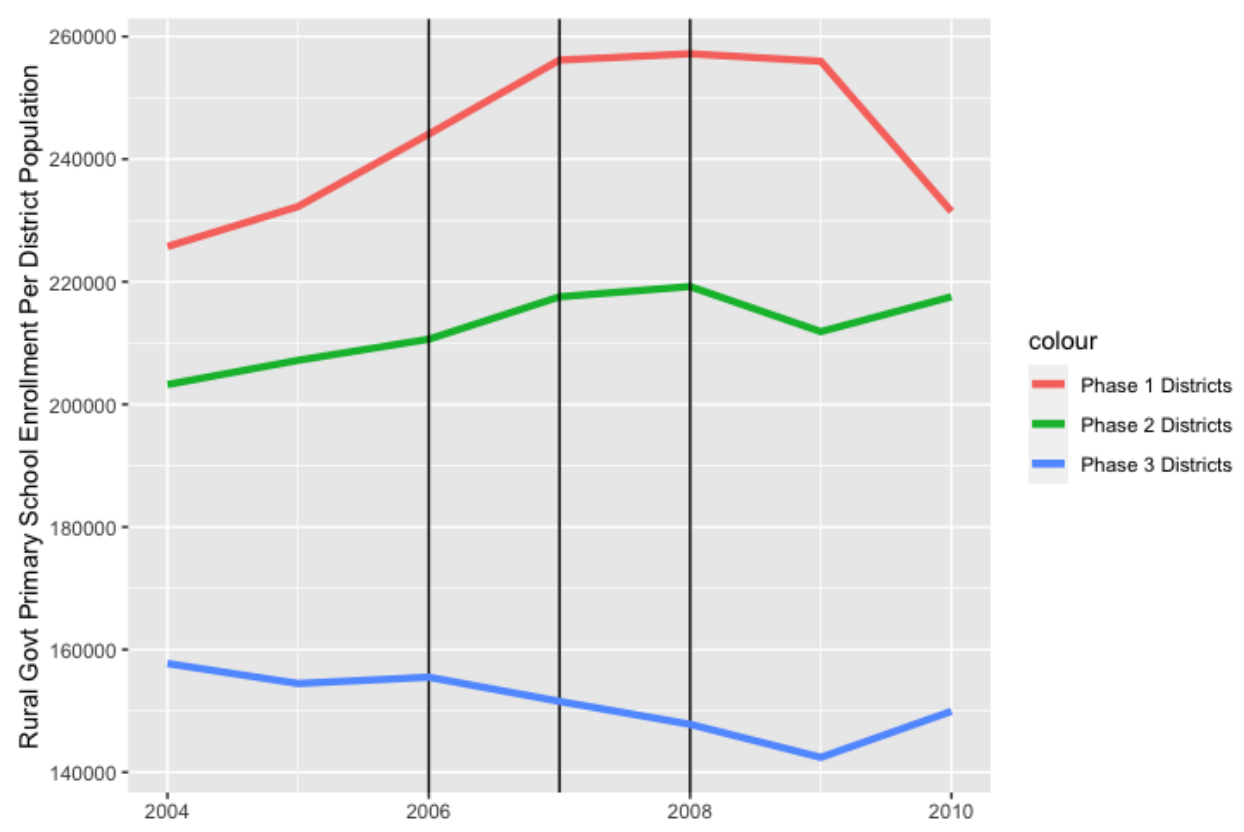

(b) Rural Govt School Enrollment 
Figure 42: Private School Enrollment By Phase Parallel Trends

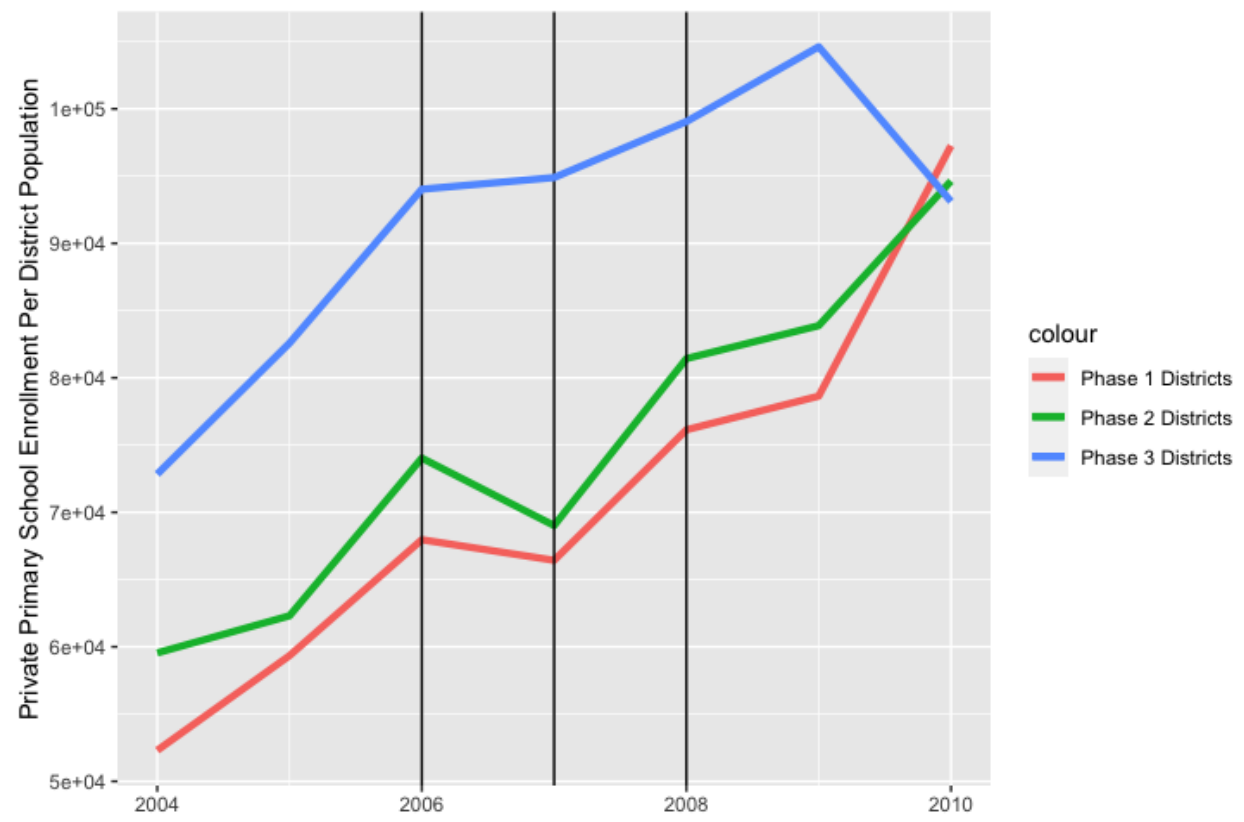

(a) Private School Enrollment

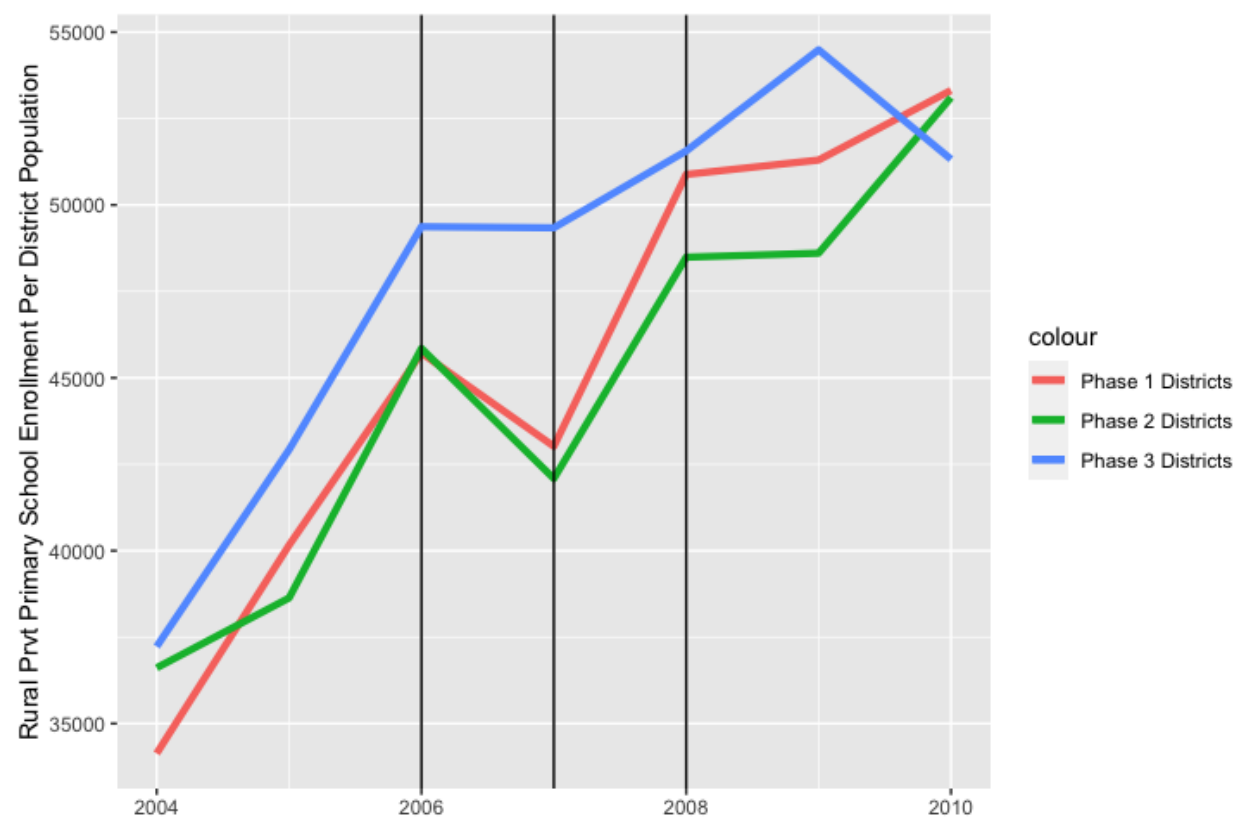

(b) Rural Private School Enrollment 
Table 34: Parallel Trends Analysis for Violence Against Women Outcomes

\begin{tabular}{lccc}
\hline \hline & \multicolumn{3}{c}{ Dependent variable: } \\
\cline { 2 - 4 } & $\begin{array}{c}\text { Sexual } \\
\text { Assault }\end{array}$ & $\begin{array}{c}\text { Sexual } \\
\text { Harassment }\end{array}$ & $\begin{array}{c}\text { Interpersonal } \\
\text { Violence }\end{array}$ \\
& $(1)$ & $(2)$ & $(3)$ \\
\hline Year & -0.304 & -1.413 & -0.534 \\
& $(0.280)$ & $(1.331)$ & $(1.105)$ \\
Year $\times$ Phase 2 & 0.282 & 2.101 & 1.155 \\
& $(0.260)$ & $(1.678)$ & $(1.439)$ \\
Year $\times$ Phase 3 & 0.064 & 0.835 & 0.676 \\
& $(0.342)$ & $(1.278)$ & $(1.097)$ \\
\hline Controls & $\checkmark$ & $\checkmark$ & $\checkmark$ \\
\hline \hline \multirow{2}{*}{ Note: } & & ${ }^{*} \mathrm{p}<0.1 ;{ }^{* *} \mathrm{p}<0.05 ;{ }^{* * *} \mathrm{p}<0.01$
\end{tabular}

Figure 43: Violence Against Women By Phase Parallel Trends

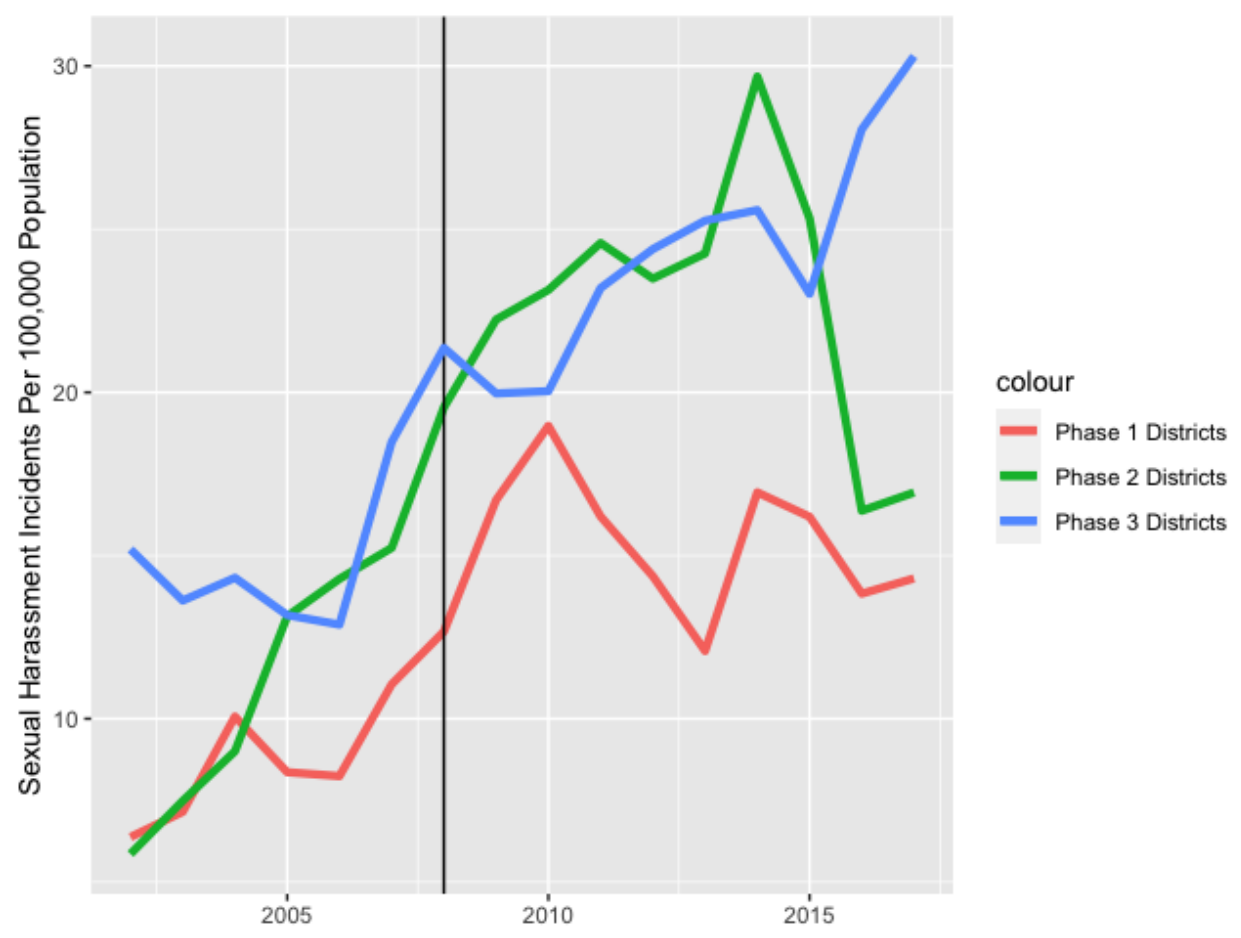

(a) Sexual Harassment Incidents Per 100,000 Population 


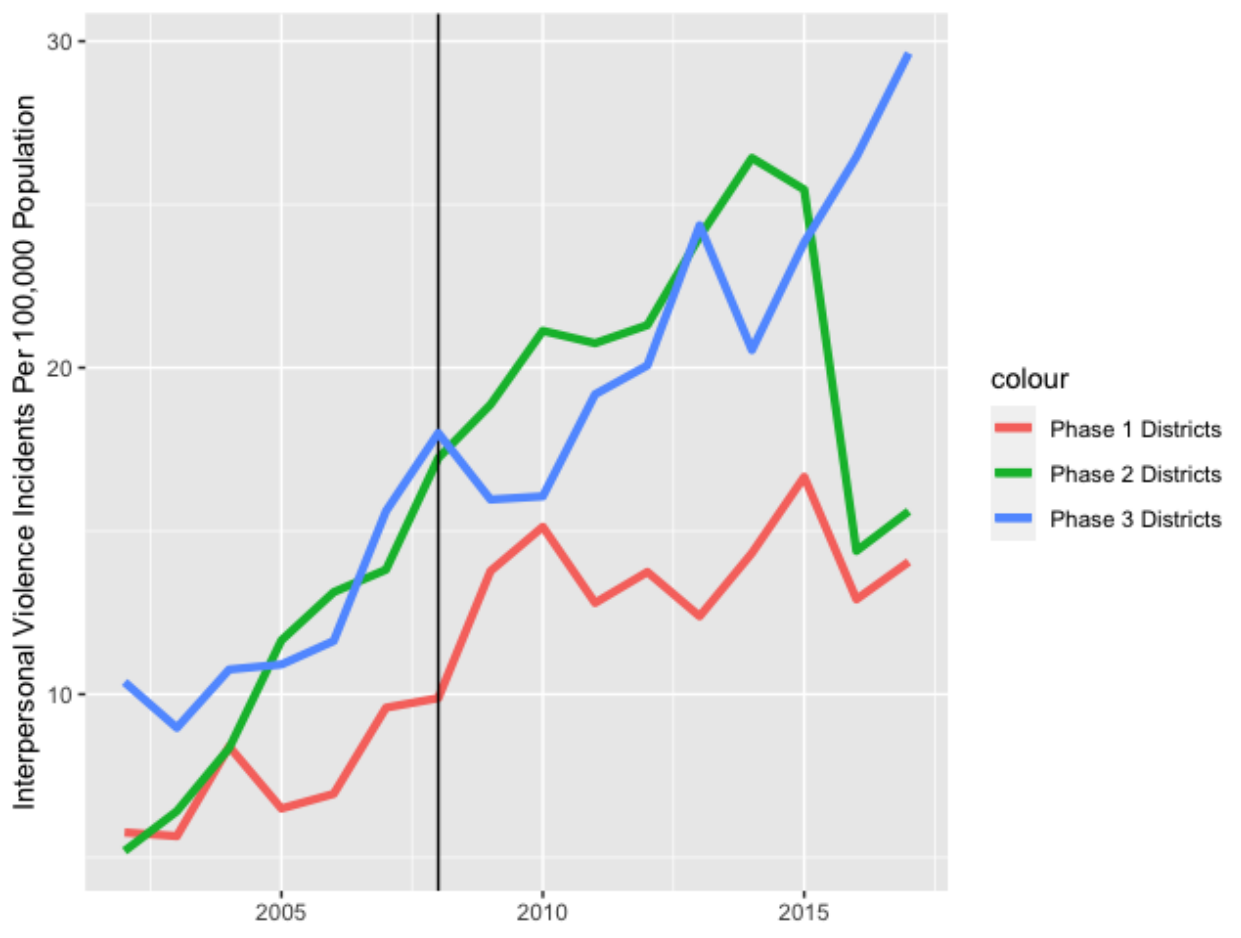

(b) Interpersonal Violence

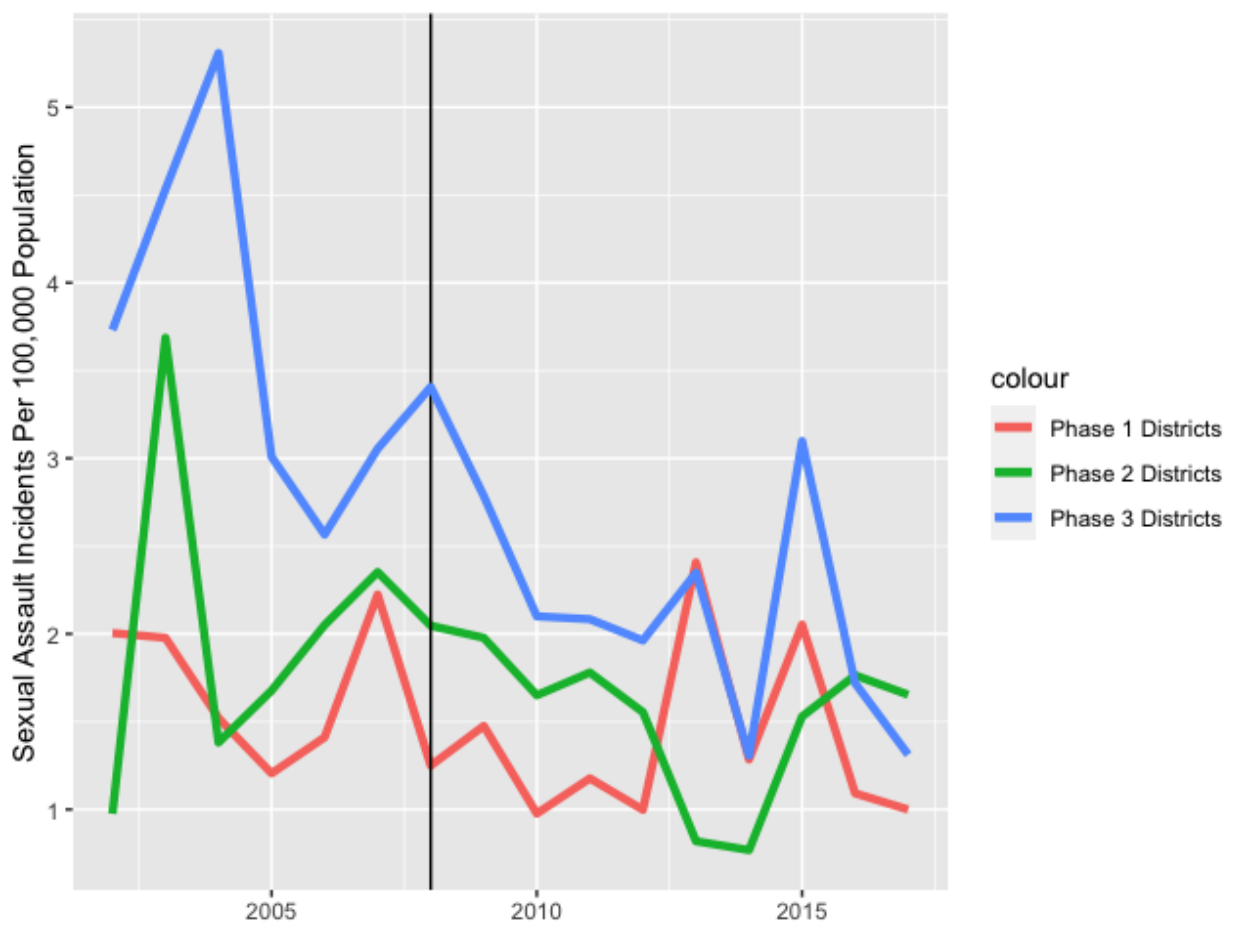

(c) Sexual Assault Incidents Per 100,000 Population 
27.2 Women Empowerment and Microfinance - Self-help Groups Membership

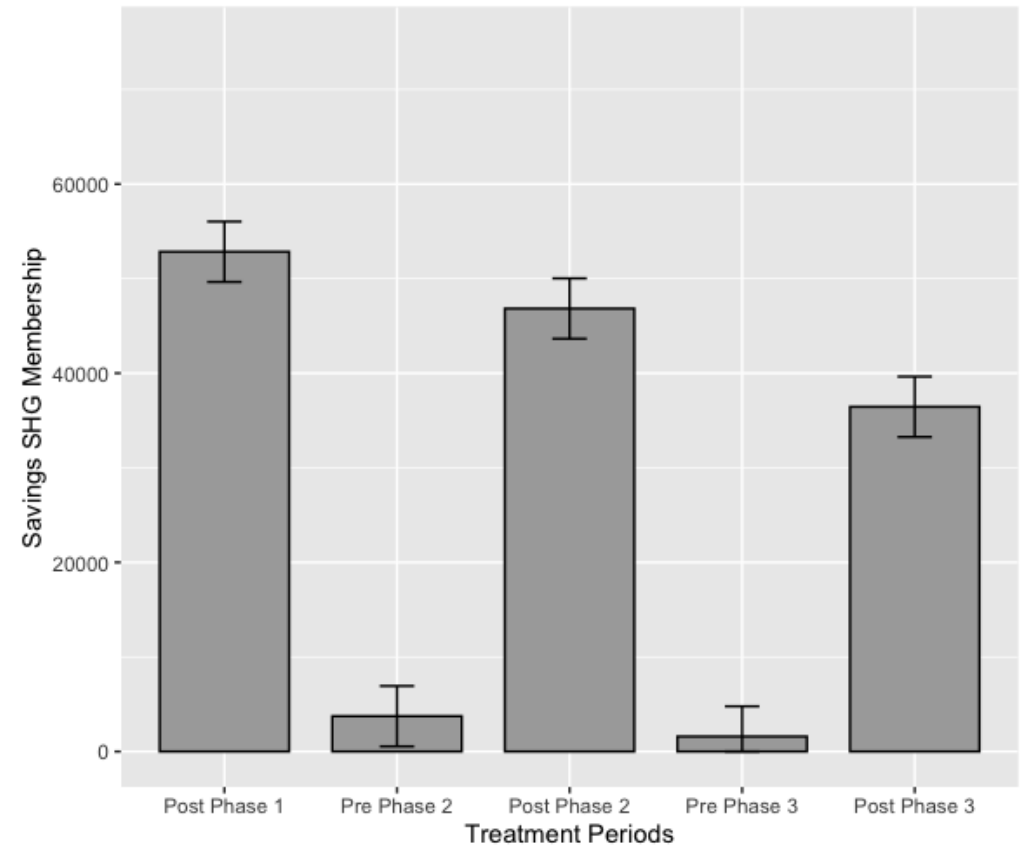

27.3 Private School Enrollment

Figure 44: Private School Enrollment Post MGNREGA Access

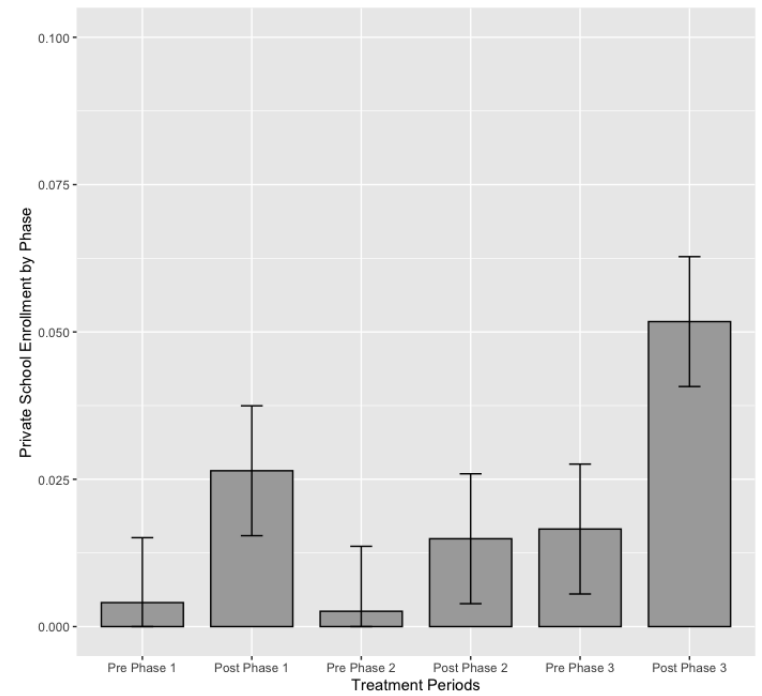

(a) Private School Enrollment

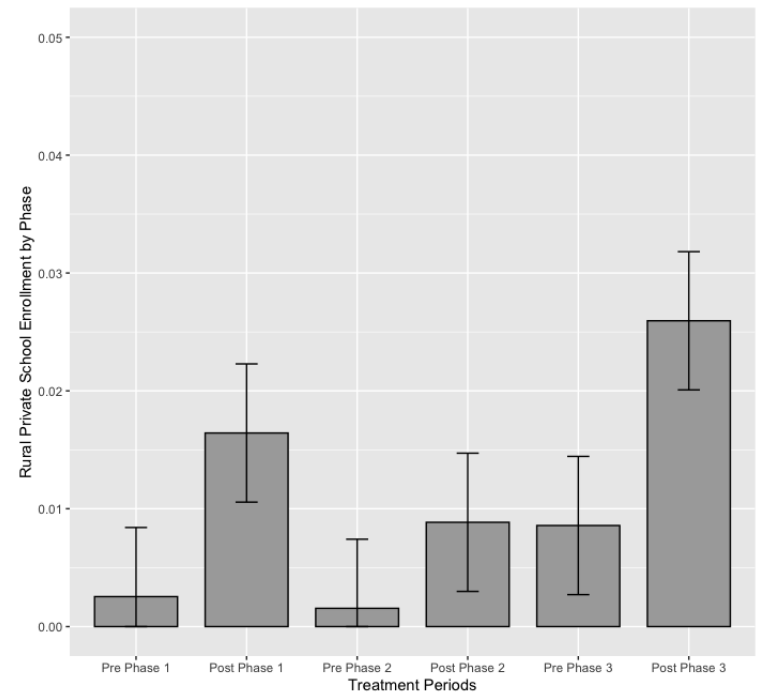

(b) Rural Private School Enrollment 
Table 35: Effect of MGNREGA Uptake on Enrollment Across Private Schools

\begin{tabular}{|c|c|c|c|c|c|c|}
\hline & \multicolumn{6}{|c|}{ Dependent variable: } \\
\hline & \multicolumn{3}{|c|}{ Urban Prvt Schools } & \multicolumn{3}{|c|}{ Rural Prvt Schools } \\
\hline & $(1)$ & $(2)$ & $(3)$ & $(4)$ & $(5)$ & $(6)$ \\
\hline MGNREGA & $\begin{array}{c}0.013 \\
(0.018)\end{array}$ & $\begin{array}{c}0.008 \\
(0.022)\end{array}$ & $\begin{array}{c}0.009 \\
(0.022)\end{array}$ & $\begin{array}{c}0.005 \\
(0.009)\end{array}$ & $\begin{array}{c}0.003 \\
(0.012)\end{array}$ & $\begin{array}{c}0.004 \\
(0.011)\end{array}$ \\
\hline MGNREGA $\times$ Job Days & & $\begin{array}{l}0.001^{*} \\
(0.001)\end{array}$ & & & $\begin{array}{c}0.001^{*} \\
(0.0003)\end{array}$ & \\
\hline MGNREGA $\times$ Men Job Days & & & $\begin{array}{c}0.001 \\
(0.002)\end{array}$ & & & $\begin{array}{c}0.001 \\
(0.001)\end{array}$ \\
\hline MGNREGA $\times$ Women Job Days & & & $\begin{array}{c}0.001 \\
(0.001) \\
\end{array}$ & & & $\begin{array}{c}0.001 \\
(0.001) \\
\end{array}$ \\
\hline Controls & $\checkmark$ & $\checkmark$ & $\checkmark$ & $\checkmark$ & $\checkmark$ & $\checkmark$ \\
\hline District FE & $\checkmark$ & $\checkmark$ & $\checkmark$ & $\checkmark$ & $\checkmark$ & $\checkmark$ \\
\hline Year FE & $\checkmark$ & $\checkmark$ & $\checkmark$ & $\checkmark$ & $\checkmark$ & $\checkmark$ \\
\hline $\mathrm{R}^{2}$ & 0.598 & 0.672 & 0.672 & 0.593 & 0.710 & 0.711 \\
\hline
\end{tabular}

Dependent variables are total enrollment across private schools per district population $(\mathrm{N}=3,582)$; Intensity of MGNREGA is measured by the number of Job Days generated by rural households in a district; Men and Women Job Days disaggregate uptake of MGNREGA per rural household by gender; I control for literacy rates, total population, scheduled caste and tribe; I include district and state by year fixed effects in all models; Robust standard errors are clustered at the district level and given in parentheses; ${ }^{*} \mathrm{p}<0.1 ;{ }^{* *} \mathrm{p}<0.05 ;{ }^{* * *} \mathrm{p}<0.01$ 
27.4 Violence Against Women - Sexual Assault

Figure 45: Reported Sexual Assault Post MGNREGA Access

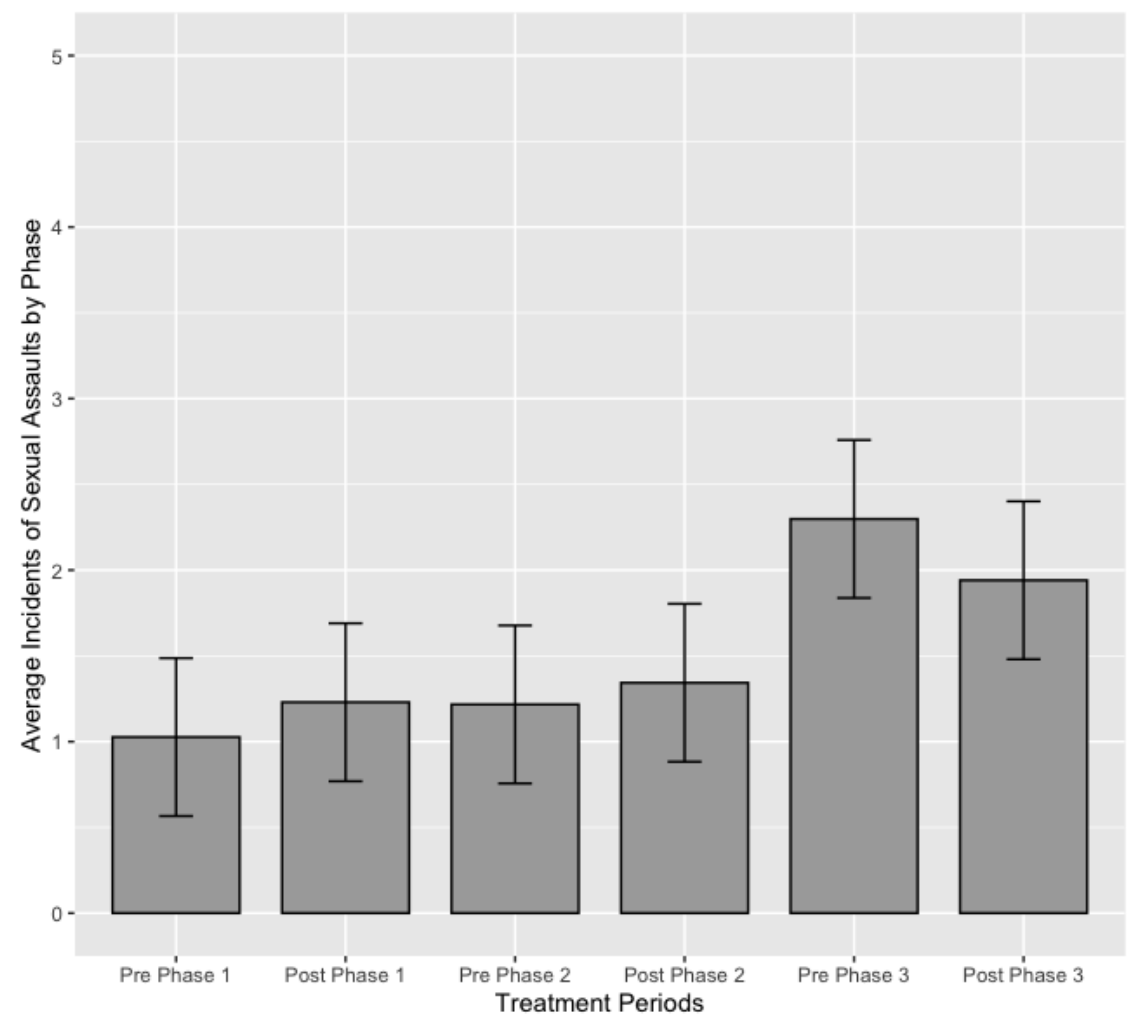


Table 36: Effect of MGNREGA on Crimes Against Women

\begin{tabular}{|c|c|c|c|}
\hline & \multicolumn{3}{|c|}{ Dependent variable: } \\
\hline & \multicolumn{3}{|c|}{ Sexual Assault } \\
\hline & $(1)$ & $(2)$ & $(3)$ \\
\hline MGNREGA & $\begin{array}{c}0.008 \\
(0.389)\end{array}$ & $\begin{array}{c}-0.291 \\
(0.429)\end{array}$ & $\begin{array}{l}-0.257 \\
(0.407)\end{array}$ \\
\hline MGNREGA $\times$ Job Days & & $\begin{array}{c}0.020 \\
(0.019)\end{array}$ & \\
\hline MGNREGA $\times$ Men Job Days & & & $\begin{array}{c}0.011 \\
(0.033)\end{array}$ \\
\hline MGNREGA $\times$ Women Job Days & & & $\begin{array}{c}0.027 \\
(0.028) \\
\end{array}$ \\
\hline Controls & $\checkmark$ & $\checkmark$ & $\checkmark$ \\
\hline District FE & $\checkmark$ & $\checkmark$ & $\checkmark$ \\
\hline Year FE & $\checkmark$ & $\checkmark$ & $\checkmark$ \\
\hline
\end{tabular}

The dependent variables in my regression are the number of reported sexual assaults per 100,000 people in a district in a year; My number of observations for each regression is $(\mathrm{N}=5,689)$; Intensity of MGNREGA is measured by the number of Job Days generated by rural households in a district; Men and Women Job Days disaggregate uptake of MGNREGA per rural household by gender; I control for access to water, literacy rates, population density, scheduled caste and tribe; I include district and year fixed effects in all models; Robust standard errors are clustered at the district level and given in parentheses; $N=5,689$ for all regression models; ${ }^{*} \mathrm{p}<0.1 ;{ }^{* *} \mathrm{p}<0.05 ;{ }^{* * *} \mathrm{p}<0.01$; 